\title{
Repräsentationen von Geschichte in südchilenischer Lyrik nach 1973
}

Dissertation zur Erlangung des Doktorgrades der Philosophischen Fakultät der Georg-August-Universität zu Göttingen

vorgelegt von Annette Karl aus Kassel 


\section{Inhaltsverzeichnis}

1. A MODO DE PROEMIO - WIE EIN VORWORT ...........................................1

2. REPRÄSENTATIONEN VON GESCHICHTE .......................................... 7

2.1 Der Begriff der Repräsentation...................................................................................

2.1.1 Die sprachliche Repräsentation ...........................................................................

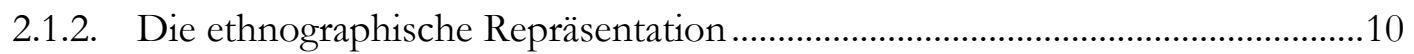

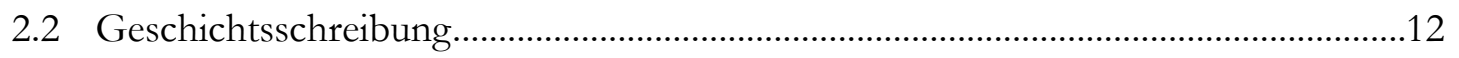

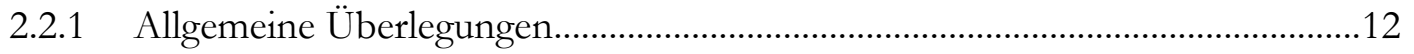

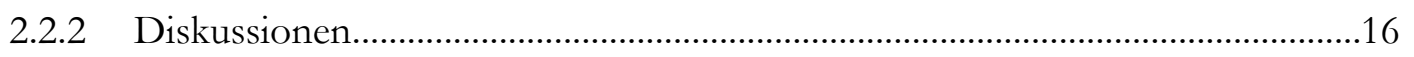

2.2.2.1 Historistischer Objektivismus vs. subjektiver Blickwinkel..............................16

2.2.2.2 Die Narration als Wesenszug der Historiographie? .........................................19

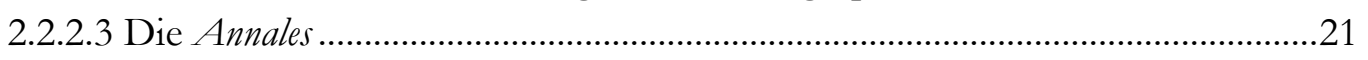

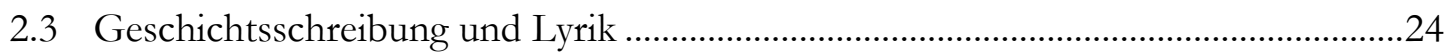

\section{DICHTUNG IN CHILENISCHER GESCHICHTE UND GESCHICHTE} IN CHILENISCHER DICHTUNG ...................................................... 27

3.1 Der literarische Text und die Geschichtsschreibung ....................................................27

3.2 Gedichtete Geschichtsbücher: Canto general und El estrecho dudoso ..............................29

3.3 1973: Der Militärputsch und die Folgen für die Dichtung ............................................36

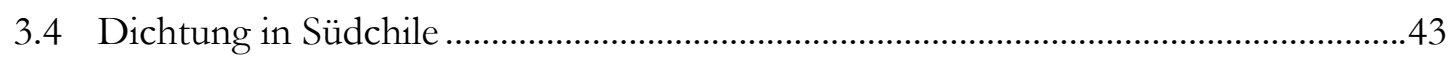

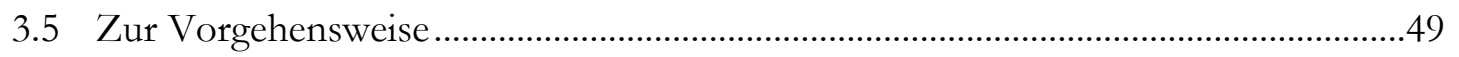

4. JUAN PABLO RIVEROS: DE LA TIERRA SIN FUEGOS .............................51

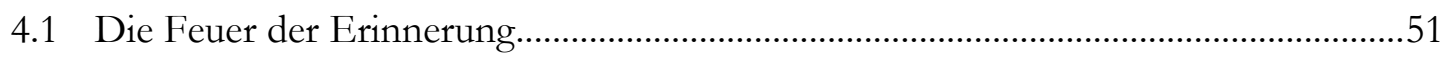

4.2 Der Kunstgriff des Cautiverio feliz: Ein Augenzeugenbericht........................................55

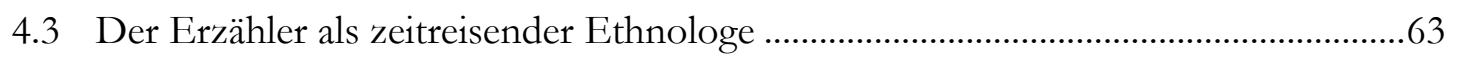

4.4 Momentaufnahmen der Vergangenheit in Wort und Bild ..........................................67

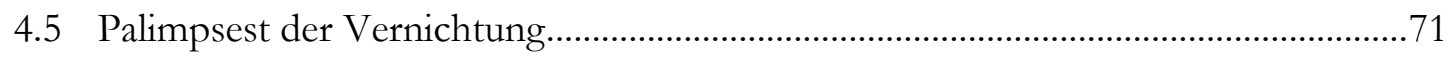

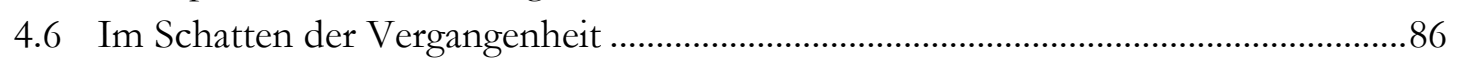

5. ROSABETTY MUÑ OZ: BAILE DE SEÑ ORITAS....................................... 88

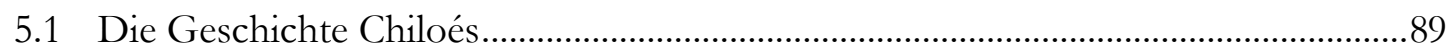

5.2 Invasiones: Männer kommen übers Meer .................................................................92

5.3 Schuld des sehenden Auges, Schuld des blinden Auges ........................................... 101

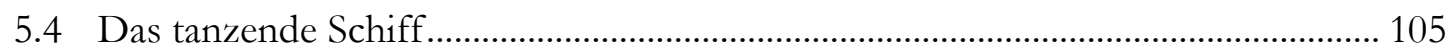

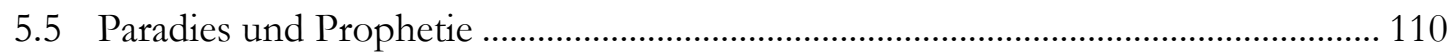

5.6 Hybridität und Identität .......................................................................................... 112 
6. CLEMENTE RIEDEMANN : KARRA MAW'N .......................................... 115

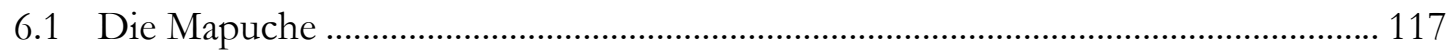

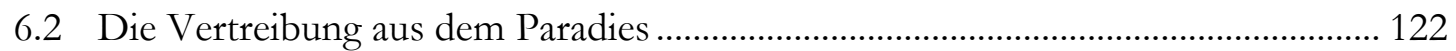

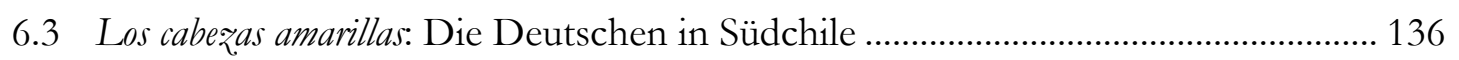

6.4 Erschütterungen: Das Erdbeben und der Golpe de Estado........................................... 144

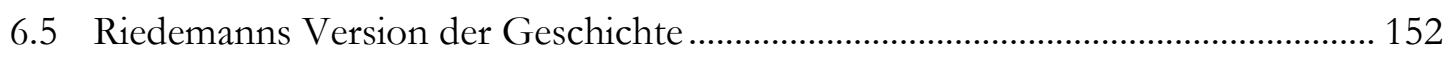

7. ELICURA CHIHUAILAF: EN EL PAÍS DE LA MEMORIA ....................... 157

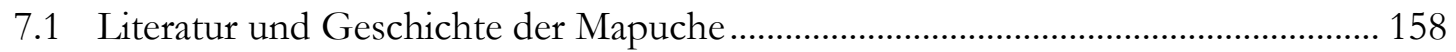

7.2 Schreie aus der Vergangenheit und Träume von der Zukunft................................ 164

7.3 Temuco: Die Stadt und ihre Straßen.......................................................................... 168

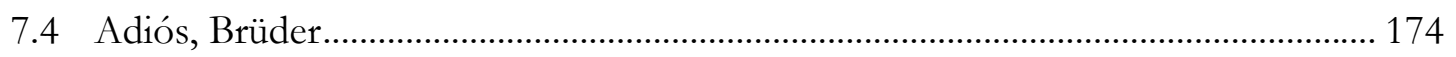

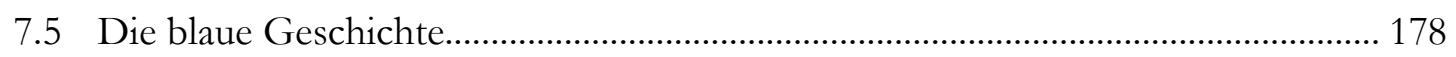

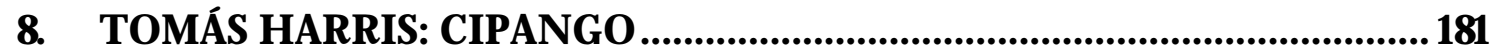

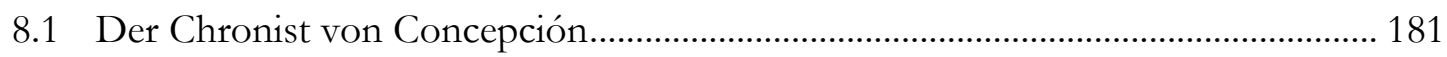

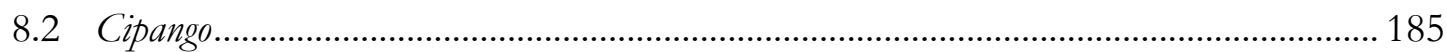

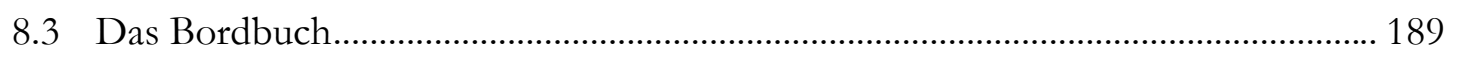

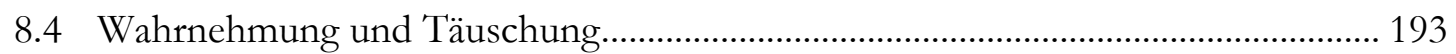

8.5 Inszenierung der Geschichte: Flucht in die Fiktion................................................. 200

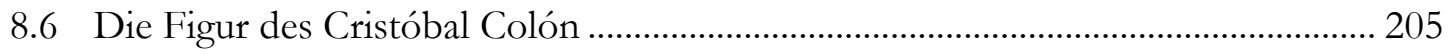

8.7 Verflechtungen der Geschichte ............................................................................... 215

9. TRUJILLO ÜBER MAN SILLA ÜBER TRUJILLO:

GEGENWARTSGESCHICHTE ..........................................................2217

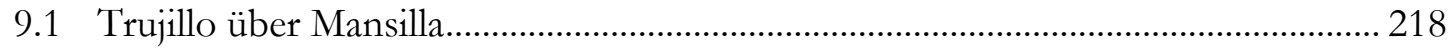

9.2 Mansilla über Trujillo: „Carlos Trujillo: El sueño de otra historia“ “................................ 225

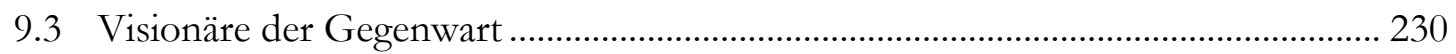

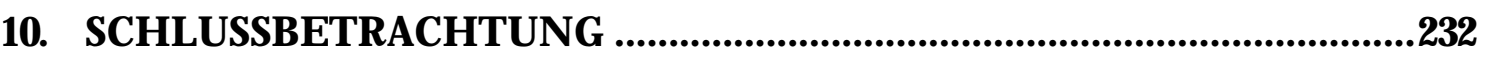

LITERATURVERZEICHN IS...................................................................2242 


\section{A MOdO DE PROEMIO - WIE EIN VORWORT}

\section{Mario Contreras Vega: A MODO DE PROEMIO${ }^{1}$}

„Soy me digo no la cuarta carabela de Colón que no la tuvo sólo la quinta."

Cuando llegó Ercilla la tierra estaba descubierta.

Cuando llegó Ruiz de Gamboa ya era tarde.

Hacía tiempo que estos pueblos escribían su historia.

Todos sus hijos hacían esa historia.

5 „En ligeras piraguas volaban, dice Rosales, mercando en sus caserios sus cholguas o sus ovejas".

Pero ahora

por lo que toca a sus costumbres

casi nada sabemos a no ser por los periódicos

10 que sólo hablan de crímenes o ebriedad todo el tiempo.

Eso digo.

Que nada más dice el blanco de los indios

aunque

no más de un par he visto bien vestidos / alimentados...

$15 y$ después, en un palo de la plaza,

(sigo leyendo)

después de haber sido degollados

como carneros en la plaza de San Pedro / digo de Accla

la cabera de Balboa

20 el magnánimo, el magnífico, el yerno de Pedrarias

(... mientras las naves deste mismo

entre ellas las islas australes descubiertas

iban quedando a la deriva

en los mares del sur y yo no invento la historia 
Y entonces entramos a la historia.

Con letras de sangre se puede decir que entramos.

Porque así es como se hace toda historia.

Los que nada poseen en sus mares pobrísimos

30

en sus tierras pobrísimas de oro

se nos llevan lo nuestro

en libertad sin duda

bajo el imperio de las santas leyes patrias.

Así es como se hace -me repito-

y Pizarros furiosos

y todos tras lo mismo

tras los mismos placeres que hoy se llevan los Morgan

la Bethlehem o el Fondo...)

Zentrales Thema des Gedichtes von Mario Contreras Vega ist die Geschichte Lateinamerikas. Der Begriff ,Geschichte` selbst findet sich fünfmal in dem Text. Der Historiograph Diego de Rosales wird zitiert („En ligeras piraguas volaban, dice Rosales, / mercando en sus caserios sus cholguas o sus ojevas" $).{ }^{2}$ Historische Persönlichkeiten, die alle für bestimmte historische Momente innerhalb der Conquista Amerikas stehen, werden genannt: „la cuarta carabela de Colón“; „Cuando llegó Ercilla“; „Cuando llegó Ruiz, de Gamboa“; „la cabeza de Balboa“; „el yerno de Pedrarias“; „que Pedrarias, Cortés, que Colones, que Ojeas / y Pizarros furiosos“" (meine Hervorhebungen).

Obwohl der Gegenstand des Textes also auf den ersten Blick einfach und eindeutig zu bestimmen ist, entsteht gleichzeitig der Eindruck von Vielschichtigkeit. Es verdichten sich unterschiedliche Aspekte von Geschichte, indem verschiedene Stimmen von ihrem Standpunkt aus mit der ihnen eigenen Intention über dasselbe Thema sprechen und die Geschichte dabei aus unterschiedlichen Winkeln beleuchten. Es geht um Geschichte, die gemacht wird („Todos sus hijos hacían esa historia“; „,[a]sí es como se hace toda historia“),

${ }^{2}$ Der Jesuit Diego de Rosales lebte im 17. Jahrhundert im heutigen Argentinien. Er schrieb die Historia General de el Reyno de Chile, in der er detailliert über die Fertigung und den Gebrauch der piraguas auf Chiloé spricht. (Rosales 1877:175) 
Geschichte, die geschrieben wird („estos pueblos escribían su historia“), Geschichte, die (nicht) erfunden wird (,yo no invento la historia“) und Geschichte, die gedichtet wird (die Zeilen 15 und 17-19 sind zum Teil wörtliche Zitate aus Ernesto Cardenals El estrecho dudoso). Schließlich geht es darum darum, in die Geschichte einzutreten („,Y entonces entramos a la historia“): Erlebte, gelesene, erinnerte, gedichtete und erfundene Geschichte verbinden sich in diesem Text.

Contreras Vega stellt die Einmaligkeit konkreter Ereignisse aus der chilenischen oder lateinamerikanischen Vergangenheit neben die Vorstellung der ständigen Wiederholung als einen Mechanismus, der scheinbar aller Geschichte innewohnt: „Porque así es como se hace toda historia“, „qué curiosa manera de reiterar el pasado“, „y todos tras lo mismo“. Die Gegenwart bekommt als Teil und vorläufiges Ergebnis der vergangenen Ereignisse ihren Platz innerhalb einer sich wiederholenden Geschichte zugewiesen.

Diese verschiedenen Ansichten auf und Vorstellungen von Geschichte sind innerhalb des Textes unterschiedlichen Personen zugeordnet. Sie sind mehr oder weniger deutlich jeweils anderen Sprechern in den Mund gelegt.

Bei dem Motto und den Zitaten ist schon formal klar zu erkennen gegeben, dass es sich um die übernommenen Worte konkreter Personen handelt - oder zumindest handeln soll. Verborgene Sprecher erahnt man beim Lesen im wechselnden Tonfall, der eher auf Sprechertypen statt auf Individuen hinweist. Auf dichterische Sprache folgt eine umgangssprachliche Passage, dann ein Geschichtsbuchtext, abstrakte Betrachtungen in metaphorischer Sprache und schließlich eine Aufzählung von authentischen, historischen Namen. Es gibt beteiligte und nüchterne Stimmen sowie eine (oder mehrere) Ich- und Wir-Stimmen. Im zweiten Teil wirft ein philosophierend-reflektierendes Ich die Frage auf, ob Vergangenheit und Gegenwart - statt in einem linearen Verhältnis zueinander zu stehen, in dem die Gegenwart aus der Vergangenheit hervorgeht - nicht eher ständige Wiederholungen derselben Geschichte, also einer begrenzten Anzahl von Situationen und Ereignissen darstellen.

So wird das Thema ,Geschichte` im Text auf vielfältige Weise aufgegriffen und dargestellt. Dadurch wird weniger die Geschichte selbst als vielmehr unsere Vorstellung von Geschichte und unser Umgang mit ihr thematisiert und hinterfragt.

A modo de proemio ist kein Einzelfall. Geschichte ist in auffällig vielen Texten der neuesten chilenischen Lyrik mehr als nur allgegenwärtiges Beiwerk oder Kulisse. Vielmehr wird sie 
in den Vordergrund gestellt und problematisiert. Auch die Vorgehensweise von Contreras Vega ist nicht ungewöhnlich. Viele Dichterinnen und Dichter erreichen durch derartige Collagen verschiedener Sprecher, Sichtweisen und unterschiedlicher Perspektiven auf historisches Geschehen eine lebendig und eigenwillig schillernde Darstellung von Geschichte.

Weiterhin begegnen in der Dichtung häufig einzelne Episoden mit historischem Hintergrund, die ihre Aussagekraft nicht so sehr durch die Art ihrer Darstellung, als vielmehr durch ihre Auswahl erhalten. In einem relativ kurzen Text - wie ein Gedicht es ist bekommt die Tatsache, dass ein bestimmtes und kein anderes Ereignis ausgewählt wird (wie bei Contreras Vega der Tod von Balboa), eine besondere Bedeutung.

Schließlich sind Überlegungen über den allgemeinen Gang der Geschichte, die Rückbindung an die Gegenwart sowie die Vision einer Zukunft immer wiederkehrende Motive innerhalb lyrischer Texte.

Aus dieser Heterogenität der Darstellung ergab sich für mich das Vorhaben, die verschiedenen Erscheinungsformen von Geschichtsdarstellung in zeitgenössischer chilenischer Lyrik zu untersuchen. Dabei beschränke ich mich auf Dichterinnen und Dichter aus dem Süden des Landes. ${ }^{3}$ Chile ist ein dichterisch sehr produktives Land, so dass bei fehlender Fokussierung des Textkorpus' die Gefahr der Oberflächlichkeit besteht. Die ,geografía loca“ Chiles, ${ }^{4}$ die sich zum einen aus der Nord-Süd-Erstreckung des Landes, zum anderen aus der landschaftlichen, klimatischen, wirtschaftlichen und kulturhistorischen Binnendifferenzierung ergibt, legt es nahe, Unterschiede auch im künstlerischen Ausdruck zu vermuten. Schließlich hat gerade die Lyrik des Südens sehr eigene Charakteristika aufzuweisen und tritt der Lyrik des restlichen Landes - vor allem der Zentralregion um Santiago - ausgesprochen emanzipiert gegenüber. ${ }^{5}$

Eine weitere Eingrenzung betrifft den Zeitraum. Es finden nur Texte Berücksichtigung, die nach 1973 geschrieben wurden, also nach Beginn der Militärdiktatur unter Pinochet. Dabei handelt es sich sowohl um Texte, die während der Diktatur, also zwischen 1973 und 1989 entstanden sind, als auch um spätere entstandene Dichtung. Grundannahme bei der Aus-

\footnotetext{
${ }^{3}$ Was mit dieser - hier noch vagen - Einschränkung konkret geographisch gemeint ist, ist in Kapitel 3.4 nachzulesen.

${ }^{4}$ Vgl. hierzu den Titel einer Sammlung von Essays Chile o una Loca Geografia von Benjamín Subercaseaux. Der Schriftsteller und Anthropologe stellt in diesem 1940 erschienenen Buch verschiedene Regionen des Landes aus anthropologisch-historischer Perspektive vor.

${ }^{5}$ Diese Aussage wird in Kapitel 2.3 ausgeführt.
} 
wahl ist, dass der Putsch von 1973 und die Diktatur direkten Einfluss sowohl auf die Dichtung, als auch auf die Beschäftigung mit Geschichte genommen haben. Weiterhin wird davon ausgegangen, dass die geschichtlichen Ereignisse nicht nur bis zum Ende der 80er Jahre, sondern auch noch lange nach 1989 Wirkung gezeigt haben, mehr noch, dass das formale Ende der Diktatur Voraussetzung für deren Aufarbeitung sein und die häufige Erwähnung von regionaler, nationaler und kontinentaler Geschichte im Zusammenhang mit der chilenischen Militärregierung stehen könnte.

Das führt zu der Ausgangshypothese, dass derart einschneidende Ereignisse wie ein gewaltsamer Regierungssturz und das anschließende Leben unter den Bedrohungen einer Diktatur eine Art Sollbruchstelle im Kontinuum der menschlichen Geschichtswahrnehmung darstellen. An einem solch neuralgischen Punkt kann sich die Einstellung zur Geschichte grundlegend ändern. Es ist davon auszugehen, dass Menschen in einer Ausnahme-Situation, wie die Repression in der Diktatur sie darstellt, aufgrund der Erfahrungen in ganz besonderem Maße Überlegungen bezüglich ihrer Geschichte anstellen. In diesem Zusammenhang stellt sich die Frage, welche Funktionen historische Betrachtungen und historiographische Bemühungen haben können - für einzelne Menschen wie auch für ein Kollektiv.

Der Aufbau der Arbeit trägt diesem sehr allgemeinen Aspekt des Umgangs mit Geschichte ebenso Rechnung wie der Tatsache, dass die Auswahl des Gegenstandes und die Perspektivierung seiner Behandlung in einem eigenen historisch-sozialen Kontext stehen. Im ersten Kapitel werden Begriff und Bedeutung von Geschichtsschreibung anhand eines Überblicks über die wichtigsten Tendenzen der modernen Historiographie erörtert sowie Überlegungen zum Verhältnis von Geschichtsschreibung und Literatur angestellt.

Im anschließenden Kapitel werden die literar- und und realhistorischen Kontexte dargestellt, in die die spezifische Problemstellung der Arbeit eingebettet ist. Im Laufe des Abschnittes verengt sich der Blick. Den Einstieg bildet ein Portrait zweier lateinamerikanischer Dichter dieses Jahrhunderts, die als Vorbilder für Poesie mit historischem Inhalt betrachtet werden können. Es folgt ein Abschnitt mit Informationen zur politischen, gesellschaftlichen und kulturellen Situation Chiles während der Diktatur und insbesondere über die Lage der Schriftstellerinnen und Schriftsteller. Abschließend werden die besonderen Bedingungen der Dichtung im Süden des Landes vorgestellt.

Der Hauptteil der Untersuchung besteht in den anschließenden sechs Kapiteln mit Textanalysen. In ihnen sollen die thematischen und formalen Besonderheiten der ausgesuchten 
Texte herausgearbeitet werden. Aufgrund des Themas ,Geschichte' werden dabei sowohl text- als auch kontextorientierte Analyseverfahren Anwendung finden, um Semantik, Syntaktik und Pragmatik der Gedichte zu erfassen.

Weiterhin soll danach gefragt werden, was die Gattung, Lyrik` für die Geschichtsschreibung leisten kann, bzw. welche Konsequenzen die Thematisierung von Geschichte für die lyrische Form mit sich bringt, um nach Möglichkeit verallgemeinerungsfähige Aussagen über die Darstellungen von Geschichte in lyrischen Texten formulieren zu können. 


\title{
2. REPRÄSENTATIONEN VON GESCHICHTE
}

\subsection{Der Begriff der Repräsentation}

\subsubsection{Die sprachliche Repräsentation}

\author{
Una hoja cae; algo pasa volando; \\ Cuanto miren los ojos creado sea, \\ Y el alma del oyente quede temblando. \\ Inventa mundos nuevos y cuida tu palabra;
}

Vicente Huidobro

Eine der wichtigsten und zugleich umstrittensten Funktionen von Sprache, und somit auch von Literatur, ist die Repräsentation. In den Diskussionen der Ästhetik und der Semiotik geht die Bedeutung, die der Repräsentation beigemessen wird, über das reine Darstellen oder Abbilden von Welt weit hinaus: Etwas sprachlich zu repräsentieren heißt keineswegs, eine vollständige Entsprechung zwischen Welt und Sprache herzustellen. Vielmehr impliziert der Begriff Ambiguität und Subjektivität in der Darstellung und schließt Missverständnisse nicht aus. (Nünning 1998:458)

Eben deshalb ist der Umgang mit Repräsentationen nicht unproblematisch. Die meisten Kulturen zensieren und verbieten bestimmte Repräsentationen. Ein solcher Fall ist etwa das religiöse Verbot „Du sollst dir kein Bildnis machen“, das verhindern soll, dass Bildnisse von Gott, also Götzen, an Stelle von Gott selbst angebetet werden. Im Islam wie auch im Judentum sind daher entweder Darstellungen generell, unbedingt aber Darstellungen von Menschen als nach Gottes Ebenbild geformte Wesen untersagt.

Auch die heute in vielen Ländern bestehende Kontrolle und Zensur von Bild- und Filmmaterial mit pornographischem oder gewaltverherrlichendem Inhalt stellt keine Sanktionierung von Handlungen, sondern von Repräsentationen dar.

Der Repräsentation wird also Macht beigemessen. Bestimmte Bilder lenken von der im religiösen oder ideologischen Sinne einzig zu beachtenden und zu feiernden Wirklichkeit ab, andere können als Anregung für unerwünschtes Verhalten dienen. Schon Plato hat den Einfluss der Repräsentationen auf die Menschen als Gefährdung angesehen. Er fürchtete, die Darstellung von Gewalt und unrealistischen Zuständen könnte unsoziales Verhalten hervorrufen und duldete in seinem idealen Staat nur streng überwachte und zensierte literarische Repräsentationen. 
Repräsentationen spiegeln also nicht nur die Wirklichkeit, sondern es wird ihnen zumindest die Macht zugeschrieben, Menschen zu manipulieren, zu gefährden und bestehende Verhältnisse in Frage zu stellen.

Zur Illustration der Funktionsweise einer Repräsentation entwirft Mitchell folgende Grafik (Mitchell 1995:12):

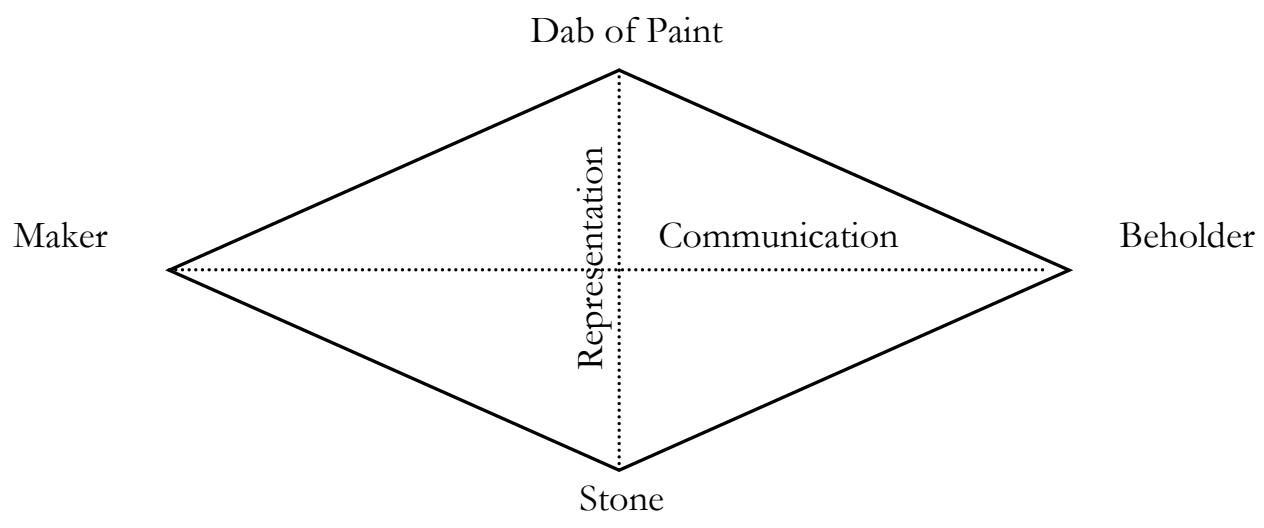

Die Achse der Repräsentation verbindet innerhalb eines gemalten Bildes einen Farbklecks mit einem Stein. Sie zeigt, dass der Klecks für einen Stein steht. Die Achse der Kommunikation verbindet die Personen, die die Beziehung zwischen Farbe und Stein verstehen. Sie stellt das Verhältnis zwischen demjenigen dar, der das Bild gemalt hat und demjenigen, der es betrachtet und in der Farbe einen Stein erkennt.

Mitchell drei unterscheidet Formen der Repräsentation: Die iconic representation basiert auf dem Prinzip der Ähnlichkeit. Wenn ein Wort, ein Bild oder ein Gegenstand in diesem Sinne für etwas anderes stehen soll, muss es zwischen beiden eine Art von Ähnlichkeit geben. So kann ein Stein einen Menschen etwa repräsentieren, weil seine Form einem Menschen ähnelt oder weil der Mensch, den er darstellen soll, hartherzig ist.

Symbolic representations hingegen benötigen keinerlei Übereinstimmung oder Vergleichbarkeit des repräsentierenden Elements mit dem repräsentierten. Sie beruhen auf willkürlicher Festlegung. Hiernach funktioniert Sprache mit der Arbitrarität ihrer Zeichen auf der Grundlage symbolischer Repräsentation. ${ }^{6}$

Schließlich nennt Mitchell eine Repäsentation indexical, wenn das Repräsentierende ein Indiz für das Repräsentierte darstellt. Eine Fußspur oder ein verlorenes Schmuckstück sind Indizien für einen Menschen, der sich an jenem Ort aufgehalten hat. Diese Form der Repräsentation basiert auf Ursache und Wirkung. 
Die sprachliche Repräsentation - als wesentliches Merkmal sprachlicher Prozesse - wird mit Hilfe von semiotischen Modellen erklärt. C. K. Ogden und I. A. Richards erweiterten 1923 das bilaterale Zeichenmodell von Saussure (signifié und signifiant) zum triadischen, indem sie das Bezugsobjekt (referent) miteinbezogen. (Ogden/Richards 81953:11)

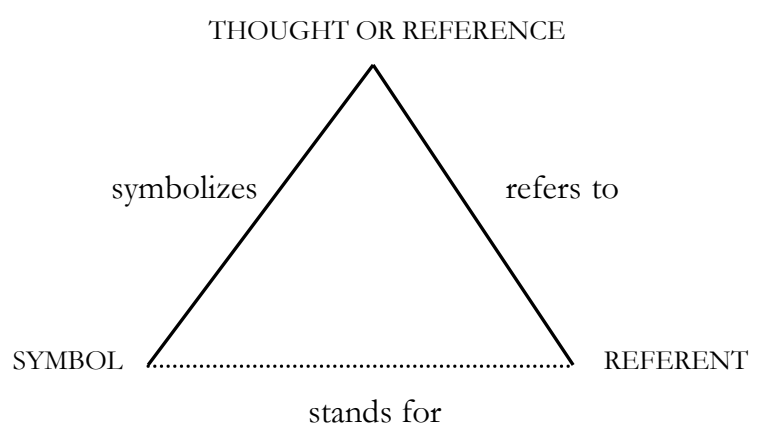

Um vom realen Objekt (referent) zum repräsentierenden sprachlichen Symbol (symbol) zu kommen, muss der Sprecher den Umweg über den Gedanken oder die Vorstellung vom Gegenstand (thought or reference) nehmen. Die Vorstellung, die er sich von dem Gegenstand macht, ist zwar sozial und kulturell geprägt, aber letztlich ein individueller und subjektiver Gedanke; ebenso wie die Auswahl des Symbols, das die Vorstellung des Sprechers seiner Meinung nach am besten wiedergibt. Demnach impliziert die Rede von der sprachlichen Repräsentation von Etwas immer auch die subjektive Sicht des Sprechers auf dieses Etwas. Während ein einzelnes Wort sich nach Mitchell auf symbolische Weise, also auf willkürlicher Festlegung und Konvention beruhend, auf sein Bezugsobjekt bezieht, funktionieren Sätze oder ganze Texte wieder anders: „Representation is an extremely elastic notion which extends all the way from a stone representing a man to a novel representing a day in the life of several Dubliners.“ (Mitchell 1995:13)

Ein Text kann auf verschiedene Weise repräsentieren. Die jeweilige Art der Repräsentation definiert sich nach Preminger/Brogan gemäß ihrem Referenzobjekt (dem Repräsentierten), da die Referenz die wichtigste Komponente der Repräsentation sei. Daher seien vier Formen der Repräsentation zu unterscheiden: Worte oder Texte können Bezug auf die externe Welt nehmen (extratextual representation), auf andere Worte oder Texte (intertextual representation), auf sich selbst (intratextual representation) oder auf den Prozess der Bezugnahme (metatextual representation). (Preminger/Brogan 1993:1037-8)

${ }^{6}$ Zur Arbitrarität des sprachlichen Zeichens vgl. Saussure ${ }^{31965: 100 f f . ~}$ 
Unter keinen Umständen sei es Sprache und Text möglich, die Repräsentation zu vermeiden. Auch der poesie pure und ihren Nachfolgern könne dies nicht gelingen, jede Kleinigkeit ziele auf eine Bedeutung ab, und Form ohne Repräsentation sei nicht denkbar. (Preminger/Brogan 1993:1038)

Gerade in der Lyrik gab es immer wieder Versuche, der extratextual representation, also der Bedeutung der Worte auf eine Wirklichkeit ausserhalb des Textes zu entfliehen.

In der vorliegenden Arbeit werden lyrische Texte betrachtet, deren wesentlicher Bestandteil es gerade ist, dass sie sich auf die historische Wirklichkeit (extratextual representation) und auf historiographische Texte (intertextual representation) beziehen.

\subsubsection{Die ethnographische Repräsentation}

Der Begriff der Repräsentation wurde in den 80er Jahren des 20. Jahrhunderts von der Ethnologie und Kulturanthropologie kritisch hinterfragt und für ihre eigenen Belange definiert (Berg/Fuchs 1995:7). Dabei wird sie als die „-- textliche - Objektivierung der Anderen“ zum Dreh- und Angelpunkt insbesondere der Ethnographie, deren Aufgabe die „Darstellung des Fremden“ ist. (Berg/Fuchs 1995:7)

Berg/Fuchs übersetzen den aus der englischsprachigen Diskussion übernommenen Begriff der ,Repräsentation“ (representation) mit Darstellung, Vorstellung, Vergegenwärtigung und Vergegenständlichung. Die Aufgabe des Ethnographen sei es, eine ihm fremde Kultur kennenzulernen und sie dann möglichst detailliert darzustellen, so dass sie sich im Text vergegenwärtige. Da dies immer nur aus der kulturellen Distanz möglich sei, könne man kein ethnographisches Zeugnis über seine eigene Kultur anfertigen. Das sei notwendige Voraussetzung und gleichzeitig die Gefahr jeder ethnographischen Betrachtung. Nur durch die kulturelle Differenz, die zwischen dem Schreibenden und dem Beschriebenen besteht, werde eine Aufzeichnung zu einer ethnographischen. Es gelte gerade das zu beschreiben, was die jeweilige Kultur von der eigenen unterscheidet. Andererseits bringe die Differenz eine Perspektivierung mit sich, die notwendigerweise subjektiv sei:

Über andere zu reden, heißt, über sich selbst zu reden. Die Konstruktion der Anderen ist zugleich die Konstruktion des Selbst. Wie eng Fremdbild und Selbstbild, die Darstellung, die man vom Fremden gibt, mit der Vorstellung, die man von der eigenen Welt hat, verknüpft ist, ist in jüngster Zeit eindringlich vor Augen geführt worden. (Berg/Fuchs 1995:11)

Das subjektive Moment der Ethnographie liegt also zum einen darin, dass die eigene Kultur in der Beschreibung präsent ist und als Folie für die fremde dient. Genauso wichtig ist nach Geertz zum anderen eine individuell-subjektive Komponente: 
The ability of anthropologists to get us to take what they say seriously has less to do with either a factual look or an air of conceptual elegance than it has with their capacity to convince us that what they say is a result of their having acually penetrated (or, if you prefer, been penetrated by) another form of life, of having, one way or another, truly ,been there'." (Geertz 1988:4f.)

Dieses „dort gewesen sein“ ist ein zentrales Anliegen von Geertz; er fordert, dass der Ethnograph als Subjekt, das sich mit anderen Kultur auseinandersetzt, greifbar ist, glaubwürdig wirkt und eine gewisse emotionale Beteiligung seinerseits beim Lesen spürbar ist.

Schärfer formuliert er an einer anderen Stelle: „Ethnologische Schriften selbst sind Interpretationen und obendrein solche zweiter und dritter Ordnung. Sie sind Fiktionen, und zwar in dem Sinn, dass sie etwas ,Gemachtes' sind, ,etwas Hergestelltes،“" (Geertz 51997:23)

Die Forderung nach der Aufweichung der starken Subjekt-Position, bzw. der scharfen Trennung von Subjekt und Objekt in ethnograpischen Schriften, der Geertz hier Ausdruck verleiht, ist als Reaktion auf eine philosophische Debatte aus den 80er Jahren zu verstehen. In diesem Zusammenhang wurde Kritik laut, die ,sich vor allem auf die Annahme der Existenz einer beschreibungsunabhängigen Wirklichkeit und die Idee der Repräsentation als innerer Spiegelung und Visualisierung eines äußeren Objekts“ richtete. (Berg/Fuchs 1995:72) Um diese starre Ethnographie, in der nicht nur ausschließlich über, sondern auch für die Anderen gesprochen wurde, zu beleben, wurde von vielen Ethnographen eine dialogische Form nicht nur der untersuchenden Interaktion, sondern auch der beschreibenden Repräsentation gewählt. Der Dialog sollte die Distanz ersetzen, die Forschung auf einer „kommunikativen Beziehung“ basieren und auch die Beschreibung sollte die ,gemeinsame Verstehensbasis“ spiegeln. Berg/Fuchs nennen diese Entwicklung „dialogische Wendung“, doch fehle der neuen Tendenz noch eine angemessene Repräsentationsform. (Berg/Fuchs 1995:80)

Wir haben gesagt, dass für eine ethnographische Beschreibung kulturelle Differenz vorhanden sein muss. Analog dazu ist für eine historiographische Beschreibung eine zeitliche Distanz zwischen dem Schreibenden und dem Objekt seiner Beschreibung notwendig. Insofern stellen sich bezüglich der historiographischen Repräsentation dieselben Frage nach der Perspektive und der Subjektivität. Die Dichotomie des Selbst und des Anderen liegt nicht notwendigerweise in derselben Schärfe vor, da etwa bei der Rekonstruktion der Geschichte des eigenen Landes oder der eigenen Region trotz der zeitlichen Differenz eine 
gewisse Identifikation zu erwarten ist. Aber auch - und gerade - dann bleibt das prinzipielle Problem der Perspektive bestehen, die Frage nach der Subjektivität und inwieweit sie transparent gemacht wird.

\subsection{Geschichtsschreibung}

Nach den vorangegangenen Erläuterungen zum Begriff der Repräsentation kann ,Repräsentation von Geschichte' also nicht als die Geschichte und nicht einmal die Repräsentation von Geschichte verstanden werden, sondern ist immer nur eine mögliche Darstellung unter vielen. Die Frage nach der Repräsentation ist demnach die Frage nach der jeweiligen Art der Darstellung und der Perspektive. Der gleiche historische Ausschnitt kann sich in einem anderen Zusammenhang anders präsentieren, jede Repräsentation ist daher eine Interpretation, eine Subjektivierung, eine Version.

Dieses Kapitel beschäftigt sich zunächst mit der Frage, inwieweit es gerechtfertigt ist, von Repräsentationen, also von Versionen der Geschichte zu sprechen und wie die Geschichtstheorie damit umgeht. Im Weiteren werden die für die Geschichtsphilosophie des letzten Jahrhunderts entscheidenden Repräsentationsformen von Geschichte vorgestellt. Im Mittelpunkt stehen dabei europäische und angloamerikanische Debatten, die im Zusammenhang dieser Arbeit aufschlussreich sind. Der Blick auf die Geschichtsschreibung und -theorie soll verdeutlichen, welche Probleme und Implikationen der Versuch, ein Stück Geschichte niederzuschreiben, mit sich bringt und welche unterschiedlichen Methoden hierfür gewählt werden können.

\subsubsection{Allgemeine Überlegungen}

Der Begriff ,Geschichte w wird auf zwei Arten verwendet, die nur auf den ersten Blick voneinander zu unterscheiden, letztlich aber untrennbar miteinander verbunden sind. Zum einen bezeichnet man als ,Geschichte' das Geschehene, die Gesamtheit vergangener Ereignisse und Entwicklungen. Zum anderen meint der Begriff die schriftlich oder mündlich überlieferte Geschichte, die bereits selektierte, interpretierte und diskutierte Vergangenheit, wie sie zum Beispiel im Geschichtsunterricht oder in historiographischen Werken vermittelt wird.7 In beiden Fällen kann Geschichte spezifiziert werden, indem man die Ereignisse

${ }^{7}$ „Geschicbte vereinigt in unserer Sprache die objektive sowohl als die subjektive Seite und bedeutet ebensogut die historiam rerum gestarum als die res gestas selbst; sie ist das Geschehene nicht minder wie die Geschichtserzäblung". (Hegel 1986:83) Vgl. hierzu auch die Dreiteilung in res gestae, die Erzählung davon, und die Historiographie. (Schulze 21991:225) 
und Entwicklungen, die man meint, auf ein geographisch und politisch festgelegtes Gebiet und auf einen bestimmten Zeitraum beschränkt („europäische“ oder „chilenische“ Geschichte, „deutsche Geschichte nach 1945“).

Der Versuch einer Unterscheidung in wirklich Geschehenes einerseits und die Überlieferung der Ereignisse andererseits, die im Grunde von einer Antwort auf die Frage abhängt, ob Wirklichkeit adäquat darstellbar ist, bleibt - außer für geschichtsphilosophische oder erkenntnistheoretische Gedankenexperimente - jedoch irrelevant. Wir werden niemals die vollständige Einsicht in den tatsächlichen Hergang einer Begebenheit haben. Niemals werden wir ein wirkliches Geschehen in all seinen Aspekten und aus allen möglichen Perspektiven erfassen können. Nicht zeitgleich, weil wir immer nur eine einzige Perspektive einnehmen können, und viel weniger zu einem späteren Zeitpunkt. Bereits kurze Zeit nach einem Geschehen - oft schon zeitgleich damit, wenn es sich außerhalb unserer Möglichkeiten der Inblicknahme befindet (große räumliche Distanz, nicht öffentlich zugängliche Informationen) - sind wir auf Dokumentationen angewiesen.

Die „wirklich geschehene Geschichte“ wäre demnach nur wahrzunehmen von und nachzulesen bei einem Idealen Chronisten, wie ihn Arthur Danto in seiner Analytischen Philosophie der Geschichte entwickelt:

Was immer geschieht, er weiß es stets im selben Moment, in dem es geschieht, er weiß sogar, was in anderen Köpfen vorgeht. Er besäße zudem die Gabe der instantanen Transkription: all das, was längs dem vorgeschobenen Saum der Vergangenheit geschieht, würde von ihm - sobald es geschieht, in der Weise, in der es geschieht - unmittelbar niedergelegt. (Danto 1980:241)

Abgesehen davon, dass es schlechterdings nicht möglich ist, alles aufzuschreiben, was geschieht, und weiterhin dass, selbst wenn es möglich wäre (etwa mit Hilfe einer Maschine, wie Danto vorschlägt), dann niemand auch nur auf ein Teilgebiet der Geschichte bezogen jemals alles lesen könnte, was dazu in der Idealen Chronik stehen müsste, entwickelt Danto im weiteren, dass eine solche Ideale Chronik keineswegs die erstrebenswerte Frucht der Arbeit eines Historiker sei. Auf der einen Seite überstiege sie die Möglichkeiten des Historikers um ein Vielfaches, aber auf der anderen könne sie nicht leisten, was die Historiographie ausmache:

Denn es gibt eine Klasse von Beschreibungen eines beliebigen Ereignisses, in deren Rahmen das Ereignis nicht bezeugt werden kann, und diese Beschreibungen sind notwendig und systematisch von der I. C. [Idealen Chronik] ausgeschlossen. Die ganze Wahrheit über ein Ereignis kann erst im Nachhinein, und gelegentlich nur lange nachdem ein Ereignis stattgefunden hat, gewußt werden, und diesen Teil der Geschichte zu erzählen, obliegt einzig den Historikern. [...] 
Ohne Beziehung auf die Zukunft, ohne dem vorzugreifen, was über das aktuelle Geschehen hinausgehend ausgesagt werden kann, sobald es geschieht, in der Weise, in der es geschieht, hätte er [der Ideale Chronist] im Jahre 1618 nicht einmal schreiben können: Jetzt beginnt der Dreißigjährige Krieg - wenn dieser Krieg den Namen seiner Dauer verdankt. (Danto:1980:245f.)

Danto folgend können wir also nicht nur ausschließen, dass es sich bei Geschichtsschreibung um eine exakte Abbildung, also um eine Rekonstruktion der Vergangenheit handelt, sondern ebenso, dass dies auch nur erstrebenswert wäre. Dabei würde ein - Danto zufolge - konstitutives Merkmal für Geschichtsschreibung verlorengehen. ${ }^{8}$

$\mathrm{Zu}$ einem ähnlichen Ergebnis kommt Ferdinand Fellmann, der sich in seinem Text Das Ende des Laplaceschen Dämons mit der Theorie Dantos auseinandersetzt. (Fellmann 1973) An den Beginn seiner Überlegungen stellt Fellmann folgende Minimaldefinition Dantos der Geschichtsschreibung: „The very least that historians do is to try to make true statements, or to give true descriptions, of events in their past.“. Fellmann vermisst in dieser Definition den Begriff der Erklärung, relativiert das Fehlen aber sofort mit der Bemerkung, dass seit Danto im Konzept der Geschichtsschreibung die Erklärung der Geschehnisse immer bereits mitgedacht werden müsse. Ein Auswahlprinzip, das die geschilderten Ereignisse als zu einer einheitlichen Geschichte gehörige erkennen lässt, macht sie so zu historischen Ereignissen und die Geschichte, die erzählt wird, zu einer Erklärung oder Interpretation. Die Darstellung von Geschichte und ihre Interpretation sind laut Danto untrennbar miteinander verbunden. (Fellmann 1973:115) „Eine Erzählung beschreibt und erklärt ineins.“ (Danto 1980:230)

Im weiteren Verlauf seiner Zusammenfassung Dantos unterstreicht Fellmann den Begriff der Perspektive. Danach ist „das Problem der historischen Erkenntnis primär kein quantitatives, sondern das der Gewinnung einer geeigneten Perspektive“. (Fellmann 1973:120f.) Erst diese Perspektive ermöglicht erzählende Sätze, die nötig sind, um Ereignisse als historische zu erfassen. Hiernach ist also ohne die Perspektive keine Erzählung und ohne die Erzählung keine historische Wahrnehmung denkbar. Geschichtsschreibung ist somit sowohl Erzählung als auch Erklärung, wobei beides unmittelbar zusammenhängt und erst aus der Perspektive des Historiographen entstehen kann.

\footnotetext{
${ }^{8}$ Dieses Merkmal, das mit der Perspektive des Historiographen zu tun hat, gilt es im Weiteren noch zu betrachten und seine Funktion innerhalb der Geschichtsschreibung zu konkretisieren (siehe Kapitel 2.2.2.1)
} 
Der Begriff der Erklärung ist in der Geschichtsphilosophie und in der Geschichte der Historiographie zentral. ${ }^{9}$ Im Streit um den Standort der Geschichtswissenschaft gegenüber den anderen Wissenschaften, insbesondere den Naturwissenschaften, sollte die Art der Erklärung, die Historiker verwenden, Aufschluss über ihre Zugehörigkeit innerhalb der verschiedenen Wissenschaften geben. ${ }^{10}$

Fellmann zieht zur Diskussion des Verhältnisses von Erzählung zu Erklärung die literaturwissenschaftliche Unterscheidung in story und plot heran. Die Chronik, also die reine chronologische Aufzählung und Aneinanderreihung von Ereignissen, entspreche der story, während die Historiographie mit dem - bereits interpretierenden - plot gleichzusetzen sei. ${ }^{11}$ Jedoch stellt er im direkten Anschluss daran die Trennung in story und plot als voneinander trennbare Elemente der Erzählung in Frage. Genauso wenig wie in Wahrheit der plot auf eine reine story reduziert werden könne, die an keiner Stelle vorgreift oder von einem gesetzten Anfang und Ende ausgeht, könne in Analogie dazu die Chronik, also die reine Erzählung geschichtlicher Ereignisse von einer interpretierenden, erklärenden Geschichtsschreibung abgespalten werden (Fellmann 1973:130). Vielmehr müsse sich der Historiker der Tatsache bewusst werden, dass er es gar nicht vermeiden könne, einen Standpunkt einzunehmen und sich - und seiner Leserschaft - über den jeweiligen Standpunkt Rechenschaft ablegen: „Historische Objektivität konstruiert sich erst durch die Reflexion auf den Standort.“ (Fellmann 1973:133f.)

Ein Geschichtsbuch zeichnet sich nach Fellmann daher durch den Versuch einer Antwort auf die Frage nach eben jener Art der Erklärung, also dem Wie oder der Art der Repräsentation, aus. Das bedeutet, auch die Umstände in Betracht zu ziehen, unter denen es überhaupt erst zu bestimmten Begebenheiten kommen konnte.

Abschließend fasst Fellmann seinen Standpunkt wie folgt zusammen:

Es soll aber heißen, daß in Dichtung und Geschichte eine identische Einstellung des Subjekts vorliegt, die in der Differenz von Geschichte und Geschehen, in das der Mensch verstrickt ist, ihren Ausdruck findet. Insofern bildet die Historie als nie zu Ende kommende Pluralität von immer neu zu erzählenden Geschichten gleichsam ein Reich zwischen Dichtung und Wirklichkeit. (Fellmann 1973:138)

Um die grundsätzliche Problematik der Affinität und Differenz von „Dichtung“ und „Geschichte“ (im Sinne Fellmanns) genauer zu erfassen, sollen im Folgenden die Formen

\footnotetext{
${ }^{9}$ Bereits im Historismus sprach man von der Dichotomie von Erklären einerseits und Verstehen andererseits. (vgl. Rossi 1987:7)

${ }^{10}$ Siehe hierzu Kapitel 1.2.2
} 
und Möglichkeiten, die für die Darstellung von Geschichte zur Verfügung stehen, anhand grundsätzlicher Überlegungen zur Historiographie zusammengefasst werden. Dabei gehe ich von Grundsatzdebatten der letzten Jahrzehnte aus, die die Motivation, den Anspruch, die Möglichkeiten und Zwänge desjenigen beleuchten, der Geschichte schreibt - das gilt für Dichter oft ebenso wie für Historiographen.

\subsubsection{Diskussionen}

Die folgenden Abschnitte beziehen sich auf einige der gängigsten Thesen und Streitpunkte in der Historiographie des zwanzigsten Jahrhunderts. Ich werde die jeweiligen Standpunkte deutlich machen, indem ich die Debatten skizziere, in denen sich die Vertreter der einzelnen Theorien besonders deutlich voneinander abgrenzen. Die einzelnen Diskussionen werden in stark verkürzter Form wiedergegeben, mit Gewicht auf eben jene Punkte, die im weiteren Verlauf für die hier zu behandelnden Texte von Bedeutung sind.

\subsubsection{Historistischer O bjektivismus vs. subjektiver Blickwinkel}

Der größte Teil der Geschichtsschreibung des 19. Jahrhunderts stand im Zeichen des Historismus. Historiographen wie Leopold von Ranke oder Jules Michelet wollten sich sowohl der Geschichtlichkeit der Ereignisse, die sie aufschrieben, als auch ihrer eigenen Geschichtlichkeit in jedem Moment bewusst werden, subjektive Betrachtungen als verfälschend entlarven und ihren eigenen individuellen Blickwinkel ausblenden. Ihr Kennzeichen waren ein hoher Grad an theoretischer Selbstreflexion und die Überzeugung, die Geschichte in einer Art und Weise wiedergeben zu können, die die Ereignisse gewissermaßen vorgeben, solange man sich nur darum bemüht, sie nicht zu verfälschen. (Fellmann 1973:23)

Die Geschichtsschreibung des Historismus war schnörkellos und nüchtern, der Historiker durfte keinen Gebrauch von seiner Phantasie machen, durfte seinen eigenen Standpunkt nicht deutlich werden lassen und musste sich jeden Urteils enthalten. Gertrude Koch spricht davon, dass im 19. Jahrhundert das stoische Ideal des Geschichtsschreibers, wie Lukian ihn beschreibt, wiederbelebt wird: Er darf keine Gefühle und Anteilnahme zeigen und muss ein Beispiel moralischer Vollkommenheit geben. (Koch 1983:30)

Trotz der geforderten Neutralität sollte der Geschichtsschreiber seinem Werk keineswegs unbeteiligt gegenüberstehen und nicht nur Fakten aneinanderreihen wie ein Chronist.

11 Die Begriffe ,plot und ,story', sowie im selben Bedeutungszusammenhang ,Fabel ${ }^{\star}$ und ,Geschichte ${ }^{6}$ werden in der Literaturwissenschaft keineswegs einheitlich gebraucht. Die von 
Vielmehr sollte er vor der Vergangenheit und der Tradition Ehrfurcht zeigen, indem er die Geschehnisse in sich stimmig darstellt. (Greenblatt 1991:12f.)

Schließlich kann der einzelne Mensch, so wie ihn der Historismus zeigt, nichts an den historischen Prozessen ändern, er wird kollektiviert, sein Handeln abstrahiert; das Individuum findet nur Erwähnung, wenn es sich dabei um einen Herrscher oder eine berühmte und einflussreiche Persönlichkeit handelt. (Greenblatt 1991:10f.)

Im Zusammenhang mit dieser Arbeit erscheinen zwei Gegenreaktionen auf den Historismus erwähnenswert. Zum einen ist es die ironische Haltung, die Hayden White für die Krise des Historismus verantwortlich macht. Als Beispiel für diesen Standpunkt führt White das Werk Burckhardts an, ,which is manifestly aestheticist in spirit, sceptical in point of view, cynical in tone, and pessimistic of any effort to know the ,real' truth of things“. (White ${ }^{81993: 41)}$

Der Geschichtsschreiber der diese Haltung vertritt, zweifelt nicht nur daran, dass eine andere oder auch seine eigene Beschreibung von einem Hergang die angemessene sei; vielmehr stellt er grundsätzlich jedes Bemühen „,to capture adequately the truth of things in language“ in Frage. (White 81993:37)

Die andere Reaktion ist die Ablösung der erstrebten Objektivität durch das bewusste Einführen von Perspektiven. In der Oral History zB, in der Alltagsgeschichte oder in der Mikrogeschichte werden Ausschnitte betrachtet, die weder repräsentativ sind, noch in direktem Zusammenhang stehen müssen mit größeren politischen Ereignissen innerhalb einer Nationalgeschichte. In diesen Strömungen der Geschichtsschreibung, die sich in der ersten Hälfte des 20. Jahrhunderts in Frankreich herausbildeten, werden Perspektiven verengt, vertieft, verschoben, und vor allem werden die Blickwinkel verschiedener, für die traditionelle Geschichte unbedeutender Menschen berücksichtigt. ${ }^{12,13}$

Damit vergleichbar ist das Bestreben des New Historicism, der in den 80er und 90er Jahren des 20. Jahrhunderts in den USA Bedeutung erlangte. In seinen Schriften ${ }^{14}$, die als Manifeste des New Historicism gelten können, fordert Stephen Greenblatt, dass jeder, der über Geschichte schreibt, sich bewusst sein müsse, dass auch Neutralität eine Haltung sei und in

Fellmann verwendete Terminologie entspricht der von Edward Forster. (Forster 1947)

${ }^{12}$ Letztere wird auch als, Geschichte von unten' bezeichnet. Die lateinamerikanische Version dieser Perspektivierung, die visión de los vencidos, wird in Kapitel 3.2 dargestellt.

${ }^{13}$ Die hier erwähnten Entwicklungen der Historiographie gingen von der Schule der Annales aus, die in Abschitt 2.2.3 noch behandelt wird. 
den meisten Fällen eine Wertung bedeute. Stellung zu beziehen sei unumgänglich, müsse aber für die Leserinnen und Leser transparent gemacht werden. Weiterhin müsse man sich die eigene Verstricktheit in die vergangenen Geschehnisse bewusst machen: „Die Kultur der Renaissance zu erforschen, bedeutet also, mich gleichzeitig meiner Wurzeln zu versichern und meiner Werte zu entfremden.“ (Greenblatt 1991:12)

Lützeler sieht die Abgrenzung zum Historismus des 19. Jahrhunderts innerhalb des New Historicism insbesondere in der Skepsis gegenüber einheitlich in sich geschlossenen Geisteshaltungen und in der ablehnenden Haltung gegenüber fixen Standpunkten. Dagegen setze der New Historicism nicht nur seine interpretative Vorgehensweise (im Gegensatz zum projektiven Vorgehen des Historismus), sondern auch seinen Pluralismus, sowie seine empirischen und pragmatischen Methoden, die im Zusammenspiel die Einheitsperspektive ersetzen sollen. (Lützeler 1990:170)

Bei Danto manifestiert sich die Perspektive in den sogenannten erzäblenden Sätžen, die ihm zufolge den Geschichtsschreiber ausmachen. Es handelt sich um die schon erwähnten Aussagen, die nur von der Zukunft aus gemacht werden können, aus der Sicht desjenigen, der weiß, wie eine Geschichte ausgegangen ist und welche Folgen sie nach sich gezogen hat. Zum Beispiel wird ein Historiograph über ein Ereignis graduell anders berichten, wenn es sich um ein bis dato einmaliges handelt, als wenn sich das Geschehen nach seinem Wissen noch in gleicher oder ähnlicher Weise wiederholen wird; und anders über eine vorläufige Niederlage, wenn er weiß, dass sich das Kriegsglück bald wenden wird, als über eine endgültige.

In gewisser Weise sind dies zwei Pole, zwischen denen die Geschichtsschreibung sich immer bewegt: Streben nach Objektivität einerseits, Brechung derselben, Selbstreflexion und Perspektivierung andererseits. Im ersten Fall sind Historiographie und Geschichtsphilosophie streng voneinander getrennt, während im letzteren beide ineinander übergehen. Jede Darstellung beinhaltet bereits ein Misstrauen gegen sich selbst, hinterfragt weiterhin die Perspektive des Geschichtsschreibers sowie die Möglichkeit von objektiver Geschichtsdarstellung überhaupt.

${ }_{14}$ ZB Marvelous Possessions: The Wonder of the New World; Shakespearean Negotiations:The Circulation of Social Energy in Renaissance England; Renaissance Self-Fashioning: From More to Shakespeare. 


\subsubsection{Die Narration als Wesenszug der Historiographie?}

Bereits unter 1.1 war die Rede von den geschichtstheoretischen Überlegungen Dantos und davon, dass er die Narration als die eigentlich angemessene, wenn nicht sogar einzig mögliche Form ansieht, mit Geschichte umzugehen. Wenn sich in der Diskussion die narrative und die dissertative (auch reflektive) Darstellungsform gegenüberstehen, dann gründen diese sich meist auf unterschiedliche Vorstellungen vom eigentlichen Wesen der Geschichte bzw. der Geschichtsschreibung. Croce formuliert die Notwendigkeit von Erzählstrukturen für das Zustandekommen von Geschichte so: „,[..] außerhalb der Erzählung [...] gibt es keine Geschichte“. (White 1987:60) Das hieße, dass die einfach nur geschehene und noch nicht in Erzählstrukturen gefasste Geschichte gar nicht existierte zumindest nicht in unserem Bewusstsein, nicht innerhalb unserer Denkstrukturen.

In dieser Vorstellung wird die Diskursform gleichzeitig zum Inhalt, „weil davon ausgegangen wurde, daß historische Ereignisse sich in der Realität als Elemente und Aspekte von Geschichten manifestieren.“. (White 1987:60)

Auch Danto versteht die Erzählung als notwendige Darstellungsform der Geschichte, sie bedeutet für ihn aber nicht nur Darstellung, sondern ist darüber hinaus Interpretation und Erklärung:

Diese Wissenschaftler [die anglo-amerikanischen Philosophen der analytischen Schule, unter ihnen auch Danto] versuchen, den epistemologischen Status von Narrativität als eine für die Erklärung historischer Ereignisse und Prozesse - im Gegensatz zu natürlichen Ereignissen - besonders geeignete Form der Explanation zu etablieren. ${ }^{15}$ (White 1987:62)

Hayden White gehört ebenfalls zu den Narrativisten unter den Historikern. Allerdings geht er noch einen Schritt weiter, indem er die narrativen Strukturen nicht nur als eine gemeinsame und notwendige Voraussetzung und Grundlage sowohl der Geschichtsschreibung als auch der Fiktion behandelt, sondern die Grenzen zwischen beiden praktisch auflöst. Er geht von einer weitreichenden Relativierung der Dichotomie von Fakten und Fiktion aus.

Im Historismus wurde die Darstellung ,nicht nur als überflüssiges Beiwerk, sondern als Verstellung der Wahrheit betrachtet. Der Gehalt eines Werkes wurde völlig unabhängig vom Stil betrachtet, Trennung in Eigentliches und Uneigentliches“. (Fohrmann 1993:162) White hingegen versucht, die Unterscheidung in Eigentliches und Uneigentliches aufzu-

\footnotetext{
${ }^{15}$ Die Rede vom Gegensatz zu den „,natürlichen Ereignissen“ spielt wiederum auf die Naturwissenschaften an und auf die klare Trennung zwischen Geschichtswissenschaft und Naturwissenschaften, die „diese Wissenschaftler“ propagieren und durch eigene Methoden und Begrifflichkeiten zu festigen versuchen.
} 
heben. Dabei unterstellt er, dass die Art und Weise des Darstellens einerseits und der eigentliche Inhalt andererseits ineinander übergehen.

Das bedeutet, dass White nicht davon ausgeht, dass ein Text ausserhalb seiner selbst eine rekonstruierbare Bedeutung habe, die auf Fakten basiert. Vielmehr geht er davon aus, dass die historische Erzählung autonom sei, und jede Geschichte auf viele verschiedene Weisen erzählt werden könne, das heißt, dass die im Text vom Autor gewählte Repräsentation der Geschichte nicht von der Wirklichkeit vorgegeben sei. Stattdessen wähle der Historiker eine Form für seine Darstellung, die seiner Interpretation entspricht. Damit lehnt White die Vorstellung ab, dass in der Natur jedes Ereignisses bereits festgelegt sei, in welcher Art es in der Erzählung wiedergegeben werden müsse. Diese Vorstellung, die er der traditionellen Historiographie zuschreibt, wird zu einem Konzept, das Reinhart Kosellek „die Fiktion der faktischen Repräsentation“ nennt. (Kosellek 1986)

Für White basiert die Geschichtsschreibung auf der Poesie; dementsprechend zerlegt er die historische Erzählung mit dem Instrumentarium poetischer Kategorien. Der Geschichtsschreiber kann und muss - analog zum Dichter - sein Material narrativ aufbereiten. Es liegt bei ihm, ob er ein Ereignis auf romantische, tragische, komische oder satirische Weise darstellt und ob seine Erzählung - oder auch nur Elemente derselben - als Metapher, Metonymie, Synekdoche oder Ironie funktionieren. ${ }^{16}$ (Damit erschöpfen sich nach White jedoch auch schon die Möglichkeiten des Historiographen - wie auch des Dichters -, seine Erzählung zu strukturieren.)

Aus dem radikalen Relativismus, den White vertritt, ergeben sich einige problematische Konsequenzen. Zunächst führt er zu einem geschichtstheoretischen Relativismus, der die Zufälligkeit und die Willkür jeder historiographischen Rekonstruktion von Wirklichkeit proklamiert. Damit lehnt White die für die Beschäftigung mit Geschichte konstitutive Voraussetzung ab, dass der Historiker mit Hilfe spezifischer Methoden und Untersuchungen Erkenntnis über Fakten und Strukturen der Vergangenheit erlangen kann.

Weiterhin zieht White den Erkenntnis- und Authentizitätsanspruch, den die Geschichtsschreibung im Allgemeinen erhebt, prinzipiell in Zweifel. Er hält eine wissenschaftstheoretische Rechtfertigung der Geschichtsschreibung nicht für möglich: „Die Lektüre von fiktionalen Texten [...] zieht die Abwesenheit von sozialen Sanktionen und Verifikationszwängen nach sich.“ (Lützeler 1997:13)

\footnotetext{
${ }^{16}$ Die jeweilige Art der Erzählstruktur ist innerhalb von Whites Theorie eng verbunden mit einer Art der Argumentation und einer Art der ideologischen Implikation. Damit will White an der gewählten
} 
Wenn White schließlich die Unterscheidung zwischen Geschichtsschreibung und Fiktion auflöst, ${ }^{17}$ so bedeutet das, dass er der historischen Erzählung die Wirklichkeitsadäquatheit abspricht. Das heißt, die Frage danach, ob die Erzählung wahr ist oder nicht, kann nicht mehr sinnvollerweise gestellt werden. Da nach White der narrative Diskurs per definitionem nicht auf die Wirklichkeit verweisen kann, sie nicht rekonstruiert, sondern stattdessen eine Geschichte konstruiert, wird die Frage nach ihrer Wirklichkeitsreferenz aufgehoben.

Whites Kritiker haben vor allem darauf hingewiesen, „daß es einen grundsätzlichen Unterschied zwischen Geschichtsschreibung und Fiktion gibt, daß White der Spannung, die zwischen dem Diskurs des Historikers und der Geschichte als res gestae besteht, nicht gerecht wird“. (Lützeler 1997:13)

\subsubsection{Die Annales}

White zufolge ist für die Befürworter einer ,sogenannten wissenschaftlichen' Historiographie „der fortgesetzte Gebrauch narrativer Darstellungsweisen bei den Historikern ein Indiz für gleichermaßen methodisches wie theoretisches Versagen”. (White 1987:57) Mit solchen und ähnlichen Aussagen wendet er sich insbesondere gegen die Schule der Annales $^{18}$, deren sozialwissenschaftlich orientierte Geschichtswissenschaftler die narrative Historiographie nicht nur für unwissenschaftlich, sondern für eine ,ideologierepräsentierende Strategie“ hielten. (White 1987:57)

Ihr Verdikt [das Verdikt der Annales] über die Geschichtserzählung (als einer „romanhaften“ Überbewertung zufälliger Einzelaktionen gegenüber der wahrhaft „wissenschaftlichen" Analyse langfristiger Strukturentwicklungen) will White treffen, wenn er nachweist, daß sich Sprache nie zu einem bloßen Transportmittel für ,wahre“ statistische Daten reduzieren läßt, sondern selbst noch in dieser kargen Form ein integraler, eigendynamischer Bestandteil historischen Denkens bleibt. (Walther 1992:26)

Es sind zwei Dinge, die Historiker wie Marc Bloch, Lucien Febvre oder François Furet von der Schule der Annales an der traditionellen Geschichtsschreibung kritisieren. In ihrer formalen Argumentation werfen sie der traditionellen Historiographie vor, mit der narra-

Erzählstruktur bzw. Argumentation eines Textes die vom Autor vertretene Ideologie erkennen. Nähere Ausführung dieses Schemas sowie Kritik daran siehe Fohrmann 1993.

${ }^{17}$ „Die spätestens seit dem 18. Jahrhundert verbreitete Kontrastierung von Historie und Fiktion als Gegensatz von scheinbar auf Wirklichkeit bzw. - so der Vorwurf gegenüber der Fiktion - nur auf irreal-imaginäre Konstrukte verweisenden Darstellungsformen erscheint ihm hinfällig, weil die Geschichtsschreibung selbst als bloßes literarisches Artefakt und ihr Authentizitätsanspruch lediglich als Resultat einer erfolgreichen Illusionsbildung erkennbar werden." (Renner 1995:178)

${ }_{18}^{18}$ Die Zeitschrift Annales d'histoire économique et sociale wurde 1929 von Lucien Febvre und Marc Bloch gegründet und erschien seit 1947 unter dem Titel Annales. Economies, Sociétés, Civilisations. Aus ihr ist die École des Annales hervorgegangen, die es sich zur Aufgabe gemacht hat, die positivistische Geschichtsschreibung insbesondere für die Sozialwissenschaften, aber zB auch für Geographie und Wirtschaftswissenschaften zu öffnen und eine größere Interdisziplinarität zu erreichen. 
tiven Darstellungsform zwangsläufig ,ihren Gegenstand zu ,dramatisieren“ oder ,romanhaft' zu gestalten“. (White 1987:65) In der Erzählung erhielten die Ereignisse ihren Platz innerhalb der Abfolge von Geschehen, es gebe einen Beginn und ein Ende, alles werde der Chronologie unterworfen, und diese überlagere die Bedeutung der Ereignisse selbst. (Furet 1987:162) „Tatsächlich folgt die traditionelle historische Interpretation der Logik der Erzählung: das Vorher erklärt das Nachher.“ (Furet 1987:157)

Die inhaltliche Kritik richtet sich gegen die Reduzierung der Geschichte auf vorwiegend politische Ereignisse, mit der die etablierte Historiographie den Gegenstand der Geschichte einseitig und beschränkt behandele. Stattdessen gaben die Historiker der Annales der Aufzeichnung zB sozialer, wirtschaftlicher oder demografischer Prozesse den Vorrang, wobei sie den Schwerpunkt auf eine quantitative Erfassung möglichst vieler Entwicklungen legten. (Clark 1999:239)

Hinter der Missbilligung der inhaltlichen Eindimensionalität, nämlich der Einschränkung auf die Politik, verbirgt sich zum einen die Meinung, Geschichte sei weniger die Ereignisgeschichte meist politischer Begebenheiten, als die sie bis dahin fast ausschließlich behandelt worden war, sondern vielmehr Struktur- oder Prozessgeschichte: „Zum Beispiel hat man jahrhundertelangen Stillstand für nichthistorisch gehalten. Nur der Wandel war historisch.“ (Furet 1987:156) Zum anderen folgen die Annales dem Beispiel der Sozialwissenschaften, indem sie die Politik als „Lieblingsthema“ der traditionellen Geschichtsschreibung hinterfragen und durch andere Fragestellungen ersetzen:

Sie [die Geschichtsschreibung] zieht die Analyse verborgener Tendenzen der Analyse oberflächlicher Veränderungen vor, das Studium des kollektiven Verhaltens dem der individuellen Willensäußerung, die Untersuchung der ökonomischen und sozialen Determination der der Institutionen und Regierungsbeschlüsse. So bearbeiten Demographie, Ökonomie und Soziolologie ein Gebiet, das immer mehr von all denen verlassen wird, die es solange bevölkert haben - die Könige, die Großen, die Nationen und das Schauspiel der Macht, um die sie alle ständig kreisten. (Furet 1987:159f.)

Aus den Forderungen der Annales ergaben sich verschiedene Strömungen. Allen gemeinsam ist das „Bestreben, bisher allzusehr vernachlässigte Aspekte der conditio bumana aufzudecken, indem sie Bezüge materieller, sozialer und kultureller Art, Mentalität, Sitten und derartige Faktoren mehr berücksichtigen“. (Salvatori 1987:275)

Insbesondere möchte ich vier der im Zuge der nouvelle histoire entstandenen Strömungen skizzieren.

Die Geschichte der langen Dauer (bistoire de longue durée) meint eine Geschichtswissenschaft, die es sich zur Aufgabe gemacht hat, „die ,Zeichen“ der Gesellschaft - deren Entwicklung vor allem über längere Zeiträume hinweg analysiert wird - zu entschlüsseln“. (Salvatori 
1987:277) Dabei gilt das Augenmerk der langfristigen Entwicklung und Veränderung gesellschaftlicher Strukturen (zB in demographischen Untersuchungen) „zur Entdeckung der geschichtlichen ,Tiefe‘ anstelle des Zufälligen und rein Oberflächlichen“. (Salvatori 1987:275) Dieselbe Vorgehensweise verfolgt die Schule der Annales mit der „Forderung nach einer Aufwertung des ,Sozialen“ gegenüber dem ,Politischen“ “. Der narrativen Geschichtsschreibung, gegen die die Annales polemisiert, wird die eigene entgegengesetzt, „die sich mit einer Analyse ,langfristiger ‘ Trends in Demographie, Ökonomie und Ethnologie, d.h. mit unpersönlichen Prozessen befaßt“". (White 1987:64)

Der Untersuchungsgegenstand der Mikrogeschichte ist ein kleiner Ausschnitt der traditionellen Geschichtschreibung. Sie beschäftigt sich beispielsweise mit der Biographie eines einzelnen Menschen, der sich weder in der Politik- noch in der Kulturgeschichte einen Namen gemacht hat und somit stellvertretend verstanden werden kann für die Untersuchung der allgemeinen Lebensbedingungen einer bestimmten Schicht. Mikrogeschichte kann sich auch auf eine bestimmte Gruppe von Menschen beziehen oder auf das Leben in einem einzelnen kleinen Dorf, wie im berühmt gewordenen Beispiel Montaillou. ${ }^{19}$

Ein ähnliches Konzept verfolgt die Alltagsgeschichte, die statt von Staatsereignissen zu berichten, alltägliche Details des Lebens festhält. Dabei stehen Menschen im Mittelpunkt, die nicht als Individuen hervorstechen, sondern durch die Tatsache interessant werden, dass ihre Alltag der vieler anderer Menschen ähnelt. Der Fokus ist jedoch nicht so reduziert wie bei der Mikrogeschichte, stattdessen kann sich die Untersuchung zB auf eine gesamte Klasse beziehen. ${ }^{20}$

Die Mentalitätsgeschichte schließlich (l’histoire des mentalités), die „das Studium von ,Mentalitäten“ innerhalb einer Gesellschaft oder einer bestimmten Gruppe“ (Furet 1987:168) beinhaltet, arbeitet eng zusammen mit der Ethnologie und der Anthropologie und „beruht auf der Dialektik der erfahrenen Fremdartigkeit und der wiedergefundenen Vertrautheit“. (Furet 1987:167)

Als später Ableger der Annales kann der New Historicism gelten. Der New Historicism ist gewissermaßen Geschichtsschreibung für Grenzgänger, da er programmatisch andere Disziplinen (Literatur, Literaturgeschichte, Ethnologie, Anthropologie) berücksichtigt. Die

\footnotetext{
${ }^{19}$ Die Werke Montaillou, village occitan de 1294 à 1324 (Emmanuel Le Roy Ladurie, 1975) und La Méditerranée et le monde méditerranéen à l'époque de Philippe II (Fernand Braudel, 1949) waren gewissermaßen die Publikumserfolge der Annales-Bibliothek.

${ }^{20}$ So gehört beispielsweise die Untersuchung von Heiko Haumann: Arbeiteralltag in Stadt und Land. Neue Wege der Geschichtsschreibung zur Alltagsgeschichte, aber nicht zur Mikrogeschichte, da sie ihren Gegenstandbereich nicht eng geographisch eingeschränkt.
} 
Anhänger dieser Strömung haben ein Interesse an ungelösten Konflikten und Widersprüchen, befassen sich mit der Peripherie, den Randerscheinungen, die Greenblatt die „Fransen des Teppichs“ nennt. Allerdings betont Greenblatt, dass die Neuhistoristen ihr Augenmerk auch auf vermeintlich Unwichtiges, Befremdliches und Bizarres legen: Darstellungen von Träumen, Festen und Sexualität rücken in den Blick, Geburts- und Sterberegister, Abhandlungen über Kleidung oder den Wahnsinn. Das bisher ausgeklammerte Gefühl der Differenz und Distanz solle wiederbelebt werden. (Greenblatt 1991:13f.)

\subsection{Geschichtsschreibung und Lyrik}

Ich möchte hier weder diskutieren, ob oder wo genau zwischen Fiktion und Wirklichkeit der wahre Standort der Geschichtsschreibung anzusiedeln wäre, noch inwieweit es Sinn macht, die Geschichtswissenschaft, ihre Methoden und ihren Erkenntnisanspruch mit dem der Naturwissenschaften zu vergleichen.

In dieser Arbeit geht es nicht eigentlich um Geschichtsschreibung, sondern um Lyrik, die aufgrund ihrer Thematik, ihrer Methodik oder ihres Anspruchs Aspekte aufweist, die einen Vergleich mit der Geschichtsschreibung nahelegen. Es sei unbestritten, dass es im Wesen von Geschichtsschreibung und Dichtung grundsätzliche Unterschiede gibt, jedoch soll die gegenseitige Abgrenzung beider hier nicht thematisiert werden. Diese Arbeit beschäftigt sich nicht damit, Grenzen zu ziehen und Gattungen zu definieren. Vielmehr sind es die Schnittmengen und die partiellen Grenzüberschreitungen, die in den Blick genommen werden. Dabei frage ich nach der Rolle, die die Geschichte für die Menschen spielt und welche Funktionen sie übernehmen kann (sowohl in Gestalt der Historiographie als auch in der Dichtung).

In den vorausgegangenen Abschnitten hat sich die Frage nach Subjektivität und Objektivität in der Geschichtsdarstellung als zentral erwiesen. Gerade vor diesem Hintergrund gewinnt die Verbindung von Geschichtsschreibung und Lyrik an Bedeutung, da es sich bei der Lyrik um eine Gattung handelt, deren Protagonist - zumindest in der Tradition des 20. Jahrhunderts - das lyrische Ich und somit ein eo ipso subjektiver Sprecher ist.

In Bezug auf die zu untersuchenden lyrischen Texte wird daher insbesondere nach Strategien persönlicher Perspektivierung zu fragen sein. Wo und wie werden individuelle Blickwinkel eingesetzt? Wo und wie subjektive Bewertungen ausgesprochen? Auch auf die erzählende Funktion von vor- und rückwärts gerichteten Bezügen innerhalb historischer Darstellungen wird zu achten sein und auf die damit verbundene Historisierung von Subjekten. Wir werden in der Textanalyse zB sehen, wie manche Darstellung früherer 
Ereignisse direkt darauf angelegt ist, späteres Geschehen (meist während der Diktatur) zu konnotieren, vorzubereiten, zu relativieren oder augenfälliger zu machen, manchmal auch in synekdochischer, symbolischer oder analoger Weise darauf hinzudeuten.

Ein wesentlicher Streitpunkt in der Geschichtsschreibung war, wie oben ausgeführt, der narrative Charakter. Mit der Aussage, die Historiographie habe narrativ zu sein, wird eine unmittelbare Nähe zur Literatur hergestellt, jedoch eher zur Prosa denn zur Lyrik. Die Lyrik bedient sich traditionellerweise nur sehr eingeschränkt erzählerischer Mittel. Darüber hinaus gilt sie nicht in der Art als Fiktion wie erzählende Prosa. In gewisser Weise steht sie zwischen Fiktion und Wirklichkeit. ${ }^{21}$ Daraus ergibt sich erstens die Frage, ob die Geschichtsdarstellung in der Lyrik ohne erzählerische Elemente auskommt und wenn nicht, in welcher Weise sie sich ihrer bedient; und zweitens, welchen Stellenwert Fiktionalitäts- bzw. Authentizitätsmerkmale in den Texten einnehmen. ${ }^{22}$ Eine typisch lyrische Sprache mit Ambiguitäten, Stilmitteln, und einer stark verkürzten, elliptischen Darstellung scheint auf den ersten Blick nicht geeignet zu sein, Geschichte angemessen wiederzugeben. Es wird $\mathrm{zu}$ untersuchen sein, inwieweit die typisch lyrische Darstellungsweise modifiziert oder durch untypische Elemente ergänzt wird (zB durch Zitate oder Glossare). Dort, wo die Form weitgehend bewahrt wird, bleibt zu ermitteln, wie sich diese eigenwillige Form auf den historiographischen Inhalt auswirkt.

Aber auch die der narrativen Geschichtsschreibung entgegengesetzte Darstellungsform der Annales findet sich in den lyrischen Texten. Insbesondere einige Charakteristika der skizzierten Varianten der Historiographie der Annales finden sich in den lyrischen Texten wieder. Inhalte der Mikro- sowie der Alltagsgeschichte werden häufig in Gedichten thematisiert. Ebenso die aus traditioneller Sicht zunächst bizarren und abwegigen Betrachtungen, die der New Historicism favorisiert. Die anthropologisch eingefärbte Mentalitätsgeschichte kann gerade in einem kulturellen Schmelztiegel wie Südchile eine wichtige Rolle spielen.

${ }^{21},[\ldots .$.$] das Faktum [...], daß erzählende und dramatische Dichtung uns das Erlebnis der Fiktion$ oder der Nicht-Wirklichkeit vermitteln, während dies bei der lyrischen Dichtung nicht der Fall ist. (Hamburger 21968:12).

22 Als Fiktionalitätsmerkmale, die als solche dem traditionell historiographischen Charakter widersprechen, verstehe ich eine bewusst subjektive Erzählperspektive, offene Ambiguitäten und Widersprüche, poetische Stilmittel, Unklarheit über den jeweiligen Sprecher, markierte Fiktionalität; demgegenüber zähle ich zu den Authentizitätsmerkmalen Zitate, Glossare, Zeittafeln, das Beziehen einer eindeutigen Gegenposition zur gängigen Geschichtsdarstellung, das Anknüpfen an Alltagsgeschichte, an die „Geschichte von unten“ oder die Mikrogeschichte. 
Neben der Frage nach der Darstellung der Geschichte steht die Frage nach der Funktion, die die Auseinandersetzung mit Geschichte (als res gestae) gerade im Medium der Lyrik haben könnte. Warum wird gerade in der „subjektivsten“ der literarischen Gattungen versucht, die Geschichtsschreibung zu ergänzen oder gar zu betreiben? Aus Sicht der Literaturwissenschaft geht es darum, eben nach dem Verhältnis von Geschichtserfahrung und Geschichtsverarbeitung bzw. -bewältigung in einer Textsorte zu fragen, die zumindest unter dem Gattungsaspekt den Gegenpol zu einer objektiven Darstellung von Wirklichkeit bilden will. 


\section{Dichtung in Chilenischer Geschichte UND GeSChichte IN CHILENISCHER DiChTUNG}

\subsection{Der literarische Text und die Geschichtsschreibung}

Por eso siempre he desconfiado de lo ,histórico', de ese dato ,minucioso y preciso'. Porque, ¿qué cosa es en fin la Historia? ¿Una fila de cartapacios ordenados más o menos cronológicamente?

Reinaldo Arenas ${ }^{23}$

Ich komme noch einmal auf das Textbeispiel aus der Einleitung zurück. Die stilistische Heterogenität im Text von Contreras Vega rührt insbesondere daher, dass er poetische Sprache, narrative Elemente der Geschichtsschreibung, Intertextualität und geschichtsphilosophische Reflexion in einem Gedicht verbindet. Die ersten sechs Verse sind strophisch gegliedert ${ }^{24}$ und enthalten poetische Stilmittel25; sie sind somit als dichterische Sprache gekennzeichnet. Zeile 5 und 6 dagegen bestehen aus einem Satz, der als Zitat aus einem Geschichtswerk von Diego de Rosales zu erkennen gegeben, also der nicht-literarischen Prosa zuzuordnen ist. So ist bereits die formale Einheit der ersten zwei Strophen stilistisch in poetische und prosaische Sprache geschieden. Ebensogut könnte man sagen, dass durch die formale Eingebundenheit der ersten sechs Zeilen in zwei Strophen die unterschiedlichen Stile oder Stimmen zusammengehalten werden.

Die thematische und formale Einheit überwindet in diesen sechs Zeilen die stilistische Uneinheitlichkeit, und das kann als programmatisch für den gesamten Text verstanden werden. Parallel zu den ersten Versen wird nämlich in der Form des Gedichtes die Konvention stilistischer Einheit überwunden, so dass das Thema auf sprachlich unterschiedlichste Weise angegangen werden kann.

Es sind traditionell zwei grundsätzlich voneinander verschiedene Fälle der Geschichtsdarstellung, die Contreras Vega in seinem Text nebeneinanderstellt: die konventionelle Geschichtsschreibung einerseits und die literarische Verarbeitung von historischen Themen

${ }^{23}$ (Arenas 1997:19) Ich zitiere Arenas an dieser Stelle unter anderem deshalb, weil er in Cuba ebenfalls unter einer staatlich organisierten Repression gelitten hat.

${ }^{24}$ Man kann an Terzinen denken, wenn auch das Reimschema fehlt.

${ }^{25}$ In den ersten vier Versen finden sich zwei Parallelismen: eine Anapher und eine Epipher. 
andererseits. Beide trennt eine traditionelle Grenze, deren Notwendigkeit wahrscheinlich ebenso häufig gefordert wurde wie ihre Aufhebung. ${ }^{26}$

Eine andere Grenze, nämlich die zwischen ethnologischen Texten und Dichtung, ist in Südchile schon länger als durchlässig erkannt worden. In den letzten Jahren wurde viel über die ethnokulturelle Komponente in der chilenischen Lyrik geschrieben, z. B. von Iván Carrasco Muñoz:

El gran aporte al discurso literario chileno de fines de siglo es la poesía etnocultural, es decir, un discurso poético fundado en la problemática propia de las sociedades y culturas en contacto, híbridas, superpuestas [...] Los elementos interculturales surgidos de la confluencia de las etnias y culturas hispánica, mapuche, aymara, rapa nui, colonias europeas, etc., en el tejido global de la cultura chilena, dibujan rasgos de sociedad, en forma análoga a lo que ocurre en otros países de Hispanoamérica. (Carrasco 1996a:1)

Die Liste von Texten zu diesem Thema ist lang, sowohl die Primär- als auch die Sekundärliteratur betreffend. ${ }^{27}$ Die Auseinandersetzung mit der kulturellen Heterogenität in der Region hat die Funktion, Identität zu problematisieren zu konstituieren und wird im Rahmen dieser Arbeit noch genauer untersucht werden.

Die kulturelle Begegnung zwischen zB den Spaniern und den Mapuche kann nicht thematisiert werden, ohne gleichzeitig entsprechende geschichtliche Ereignisse darzustellen und zu interpretieren. Bisher lag der Schwerpunkt von Untersuchungen der südchilenischen Lyrik jedoch eindeutig auf den ethnokulturellen Fragestellungen. In Analogie zu solchen Analysen, in denen lyrische Texte auf ihre ethnographischen Qualitäten und Momente betrachtet wurden, stelle ich die Nähe oder Ferne zur Historiographie in den Mittelpunkt der vorliegenden Arbeit. Dabei frage ich nicht nach theoretischen und grundsätzlichen Stellungnahmen zum Verhältnis von Dichtung und Geschichtsschreibung, sondern vielmehr nach dem tatsächlichen Umgang mit geschichtlichen Daten und Ereignissen in den Texten; nicht danach, ob eine Grenze zu wahren sei und ob Vermischung theoretisch möglich ist, sondern danach, ob und wie letztere vollzogen wird. Konkrete Textbeispiele zeigen nicht die möglichen Funktionen von Geschichtsdarstellung und lyrischer Produktion, sondern die tatsächlich realisierten und gestatten so eine Annäherung an das Verständnis, das der Autor vom eigenen konkreten Text und von der Geschichte hat.

Die zu untersuchenden Texte verbindet ihre Intention, Geschichte darzustellen, festzuhalten, sie zu reflektieren oder zu interpretieren. Trotzdem handelt es sich um lyrische

\footnotetext{
${ }_{26}$ Zur Gegenüberstellung von Lyrik und Geschichtsschreibung vgl. Kapitel 2.3 und Koch 1983, S14-19 und S22-34.

${ }^{27}$ Einschlägige Forschungsliteratur sind zB Carrasco 1992; Carrasco 1995a; González Cangas 1995.
} 
Texte. Die Gedichte verwandeln sich dadurch nicht in Geschichtsschreibung, sondern öffnen sich ihren Themen und mit ihnen auch oft For1melementen, die für Lyrik untypisch sind. Prosazitate im laufenden Text, Fußnoten oder Glossare sind keine Seltenheit und lassen einen Authentizitäts-Anspruch erkennen, der traditionellerweise in der Lyrik keine Rolle spielt. Das Thema bringt also in vielen Fällen einen spezifischen Stil hervor, der dem Anliegen gerecht werden soll und zum Teil eine didaktische Funktion hat, der aber nichts daran ändert, dass es sich um Lyrik handelt.

Im folgenden Kapitel soll die Situation der untersuchten chilenischen Dichter im Hinblick auf literarische Einflüsse, im Hinblick auf ihre historische Situation und schließlich im Hinblick auf ihre regionale Lage fokussiert werden. In einem ersten Abschnitt werden zwei Texte aus Chile und Nicaragua vorgestellt, deren wirkungsmächtige Geschichtslyrik einigen der Autoren, die im Textanalyseteil untersucht werden sollen, als Vorbild gedient hat: Canto general (1950) von Pablo Neruda und El estrecho dudoso (1966) von Ernesto Cardenal. ${ }^{28}$ Es folgen eine Situationsbeschreibung der Dichtung in Chile während der Militärdiktatur und Überlegungen zum dichterischen Umgang mit der unmittelbar erlebten Geschichte. Der letzte Abschnitt erklärt schließlich, was die Einschränkung auf den Süden Chiles impliziert, wobei die Region geographisch abgegrenzt und skizzenhaft vorgestellt wird.

\subsection{Gedichtete Geschichtsbücher: Canto general und El estrecho dudoso}

Die zeitgenössische lyrische Verarbeitung von geschichtlichen Ereignissen in Chile, die im Mittelpunkt der vorliegenden Arbeit steht, ist keinesfalls beispiellos. Im Gegenteil muss die Bedeutung einiger konkrete Werke als Vorbilder oder doch wenigstens als Anstöße zur Kenntnis genommen werden. Zwei einflussreiche Werke der lateinamerikanischen Literatur des 20. Jahrhunderts, die für andere Dichterinnen und Dichter als Inspiration gewirkt haben, werden in diesem Kapitel vorgestellt.

Insbesondere im chilenischen Kontext ist das Canto general (1950) von Pablo Neruda zu nennen. Neruda stammt nicht nur aus dem Süden Chiles, sondern zeigt sich darüber hinaus immer sehr verbunden mit seiner Heimatregion. Dies macht ihn in Bezug auf die neuere südchilenische Dichtung zu einem umso bedeutenderen Bezugspunkt. Er verbindet in

\footnotetext{
${ }^{28}$ Cardenal war bereits im Eingangsgedicht $A$ modo de proemio präsent (vgl. Kapitel 1, S2), und wird explizit bei Riedemann, Tomas Harris und bei Mansilla/Trujillo wiederbegegnen. Neruda wird von Juan Pablo Riveros und Elicura Chihuailaf in ihren Werken zitiert, wobei ich hiermit nur jeweils zwei der expliziten Bezugnahmen nenne.
} 
seinem Werk die Bemühungen um die regionale Geschichte und Tradition mit (hymnischen) Gesängen auf die subkontinentale oder sogar panamerikanische Einheit und Solidarität.

Im Canto general, der auf den Spuren Ercillas eine Art „Reimchronik” der amerikanischen Geschichte bieten will, wird er [Neruda] zum großen episch-lyrischen Sänger des Kontinents, der zu den indigenen Ursprüngen ebenso zurückgeht wie zu der unberührten Natur. (Rössner 1995: 367)

María Magdalena Solá erkennt bei Neruda die Absicht, mit seinem Gesang „poner en justa perspectiva la historia americana y elevar la autoestima del latinoamericanismo“. (Solá 1980:82) Zwei Vorhaben verfolgt demnach Neruda. Zum einen soll der sogenannten offiziellen Geschichte Amerikas ein anderer Blickwinkel entgegengestellt werden - mit den Worten Solás: la justa, der richtige, aber auch der gerechte. Das impliziert den Vorwurf der Ungerechtigkeit gegenüber den Historiographen. Zum anderen will er, dass dieses neue Geschichtsbild, das als eigenes begriffen werden soll, das die Selbstachtung und das Selbstbewusstsein der Menschen des Subkontinents wachsen lässt. Beide verfolgten Ziele wurzeln in Nerudas Selbstverständnis als Kommunist.

Der Dichter knüpft für sein Unterfangen ganz offensichtlich an die historiographischen Traditionen der crónicas und historias generale ${ }^{29}$ an. Chroniken datieren von der Spätantike bis ins 17. Jahrhundert. Sie unterscheiden sich von den Annalen dadurch, dass sie über die Aneinanderreihung von Ereignissen hinaus diese als Interpretation im Rahmen der von ihnen favorisierten Weltanschauung darstellen. Der Begriff der Chronik impliziert also ein System, dem die berichtete Geschichte gehorcht. Ob Welt-Chronik, Kaiserchronik, Stadtchronik, Klosterchronik, meist geht der Chronist von einem Anfang und einem Ende aus, von einer dem Gegenstand innewohnenden Ordnung, beispielsweise der Heilsgeschichte, die einen Bogen spannt von der Entstehung, einem Punkt Null bis zum Kulminationspunkt, also zur Erlösung, zum Ziel, zur Erfüllung oder zur Utopie.

Diese Bewegung wird bei Neruda deutlich nachgezeichnet. Sein marxistisch-materialistisch geprägtes Geschichtsbild lässt eine Chronik entstehen, deren treibende Kräfte Antagonisten im dialektischen Sinn sind. Der Kampf für das Volk und der Verrat am Volk stehen einander gegenüber und machen in ihrem Wechselspiel den Lauf der Geschichte aus. Alles läuft auf die Utopie eines befreiten und sich selbst sowie seiner Geschichte bewussten Volkes hinaus.

\footnotetext{
${ }^{29}$ Schon im Titel klingt der umfassende Anspruch dieser Geschichtswerke an (zB Historia general del mundo, Historia General de las Cosas de la Nueva España).
} 
Für die dialektisch-antagonistische Struktur gibt Neruda an einigen Stellen die chronologische Ordnung auf. Das Anknüpfen an die Gattung der Chronik impliziert ein bewusstes Aufgreifen und Problematisieren nicht nur der Geschichte, sondern auch der Geschichtsschreibung.

Ein zweites Charakteristikum des Canto general ist der Umgang mit dem historischen Helden: „Neruda destaca el papel de los grupos humanos en el acontecer histórico, en contraposición implícita al papel preponderante que la historiografía tradicional asigna a los héroes o caudillos individuales. “ (Solá 1980:83f.)

Entsprechend seinen marxistischen Überzeugungen lenkt er das Augenmerk eher auf das Kollektiv, aus dessen Handeln sich Entwicklungen und Ereignisse ergeben, als auf die Einzelnen, die schließlich im Rampenlicht stehen, weil sie die scheinbar entscheidende Unterschrift leisten oder das kämpfende Heer anführen. Dabei wird der Einzelne keineswegs unwichtig, vielmehr findet sich bei Neruda die Vorstellung eines durchaus starken Subjekts, das sich allerdings vom „Helden“ der traditionellen Geschichtsschreibung dadurch unterscheidet, dass es keine politisch oder gesellschaftlich ausgezeichnete Position einnimmt, sondern etwa Fischer ist, Minenarbeiter oder auf einer Bananenplantage arbeitet. ${ }^{30}$

Zum dritten ist das Canto in verschiedener Hinsicht mythisch organisiert. Juan Villegas weist in seiner Untersuchung Estructuras miticas y arquetipos en el CANTO GENERAL de Neruda auf die Bedeutung der Mythologie auf mehreren Ebenen in Nerudas Geschichtsdarstellung hin. Danach tragen sowohl die handelnden Figuren als auch das lyrische Ich selbst mythische Züge. ${ }^{31}$ Weiterhin arbeitet Villegas die mythologischen Dimensionen von Zeit und Raum heraus. ${ }^{32}$

\footnotetext{
${ }^{30}$ Vgl. hierzu Abschnitt XVII La tierra se llama Juan des Canto general. Schon der Name Juan (einer der häufigsten männlichen Eigennamen in Lateinamerika) deutet auf die Beispielhaftigkeit der besungenen Personen hin, auf ihre Austauschbarkeit durch andere Arbeiter.

31 Vgl. Villegas 1976, zB: „La interpretación del héroe araucano [Caupolicán] en Neruda corresponde, creemos, a la nota que proporciona la visión mítico-heroica del árbol [...].“ (S124) „Lautaro es el personaje histórico que Neruda más aproxima al héroe mítico [...].“ (S129) „[San Martín] pierde su realidad histórica, inmediata, concreta y asume rasgos maravillosos, sobre la base de ciertas imágenes continuas y recurrentes.“ (S137f.) Derselbe zum lyrischen Ich: „La mítificación del „yo poético“ (S77-115).

32 Obwohl das Thema im Rahmen dieser Arbeit nicht einmal annähernd befriedigend behandelt werden kann, soll doch zumindest auf die Problematik und Vielschichtigkeit der Diskussion hingewiesen werden. Die Kernfrage ist die nach dem Verhältnis, in dem Mythos und Geschichte, bzw. Mythologie und Geschichtsschreibung zueinander stehen. Unter Mythen versteht man im Allgemeinen Geschichten oder Erzählungen, die den Menschen Erklärungsansätze geben: Sie sollen Fragen nach dem Ursprung der Welt und ihrem Ende beantworten, nach der Herkunft der Götter und der Menschen. Sie sollen Naturphänomene erklären, die Entstehung von Ländern und Landschaften oder Gebräuchen. Nach Sigmund Freud kann der Mythos individuelle verdrängte Wünsche verkörpern und nach C. G. Jung fungiert er als „seelische Erfahrung überindividueller
} 
Schließlich durchzieht das Canto eine starke Präsenz des Ich. Autobiographische Anekdoten sowie offen subjektive Bewertungen lassen die Leserin und den Leser die Person des Dichters hinter dem Stoff nicht vergessen.

Unter den aufgezeigten Merkmalen finden sich Aspekte, die bereits in Kapitel 2.2 angesprochen wurden. So sind die Geschichte des kleinen Mannes sowie die Präsenz des Ich und seiner Subjektivität oben erwähnte Charakteristika und Instrumente einzelner Strömungen der Geschichtsschreibung. Innerhalb seines kulturellen Kontextes vertritt Neruda damit einen bestimmten Aspekt der ,Geschichte von unten', der seit dem 16. Jahrhundert in der Literatur und in der Geschichtsschreibung Lateinamerikas kursiert: die visión de los vencidos, die Geschichte aus der Sicht der Besiegten. In der US-amerikanischen Geschichtstheorie meint der Begriff der counter-history in etwa dasselbe. ${ }^{33}$

Das älteste Werk, das in diesem Zusammenhang zu nennen ist, ist die Historia general de las cosas de Nueva España von Fray Bernhardino de Sahagún. Der Franziskanermönch hat in zwölf Büchern die Geschichte, Kultur, Gesellschaft und Religion der Azteken dargestellt. Dabei ist er, selbst aus heutiger Sicht, erstaunlich unvoreingenommen vorgegangen und hat versucht, mit Hilfe von Befragungen unter der Bevölkerung ein möglichst objektives Bild zu erstellen. Er hat das aus christlicher Sicht ketzerische Brauchtum der Azteken so detailliert und distanziert geschildert, dass seine Schriften um 1579 von den Behörden beschlagnahmt wurden. Dabei ist unklar, inwieweit die Missionierung ihm als Vorwand gedient haben mag, um einem ethnologischen Interesse an der fremden Kultur nachzugehen.

Wahrheiten“. Besonders die Deutung Jungs war folgenreich für die Dichtung des 20. Jahrhunderts: „Mythos und Literatur können in dieser Auffassung in gleicher Weise als Objektivierungen von im kollektiven Unterbewußtsein verankerten Archetypen verstanden werden." (Schweikle 1990:316). Ich werde die hier angenommene Tragweite von Mythen im Denken der Menschen voraussetzen und mit Jan Assmann Mythen, wie im Falle Nerudas, als Form erinnerter Vergangenheit verstehen und sie somit als eine besondere Art der Darstellung von Geschichte betrachten (Assmann 1992:75f.)

${ }^{33}$ „[Counter-history's] function is polemical. [Its] method consists of the systematic exploitation of the adversary's most trusted sources against their grain-,,die Geschichte gegen den Strich kämmen." [Its] aim is the distortion of the adversary's self-image, of his identity, through the deconstruction of his memory." (Funkenstein 1993:36, zitiert nach Biale 1999)

Karen Slawner betont die Bedeutung der counter-bistory für den Fall Argentinien: „The importance of studying counter-history is dramatically highlighted by the case of Argentina. During the ,Dirty War' (1976-1983) the police and especially the military tortured and killed many thousands of unarmed civilians in the name of national security. [...] Survivor testimony must be seen as an act of political resistance to the dominant historical narrative perpetuated by the military and the government" (Slawner: Introduction). Besonders im Vergleich mit Argentinien fällt es leicht, den Begriff auf Chile zu übertragen, ihn als eine moderne Variante der, visión de los vencidos ${ }^{`}$ zu begreifen. 
Das zwölfte und letzte Buch der Historia enthält eine Beschreibung der Eroberung Mexikos aus der Sicht der Azteken. Sahagún hat ein linguistisches Interesse als Beweggrund für diese Aufzeichnungen vorgeschoben; Tatsache ist jedoch, dass dieses brisante Buch den ersten bekannten Versuch in der Geschichte der Eroberung darstellt, die Sicht des Anderen einzunehmen. Er geht somit über das Werk Las Casas' hinaus, der die Vorgehensweise der Spanier zwar verurteilte, aber aus den Positionen der Kirche argumentierte und in seiner vorgeschriebenen Rolle als missionierender Mönch verharrte. ${ }^{34}$

Bis heute herrscht ein erhebliches Ungleichgewicht zwischen der offiziellen Geschichtsschreibung einerseits, die aus der Sicht der Sieger, der Reichen und Mächtigen berichtet und den größten Raum einnimmt, und andererseits der Geschichte aus der Sicht der anderen Seite. W. B. Berg charakterisiert die ursprüngliche Funktion der offiziellen Geschichtsschreibung folgendermaßen: „Die Geschichtsschreibung ist konstitutiver Bestandteil der geistigen und kulturellen Eroberung des neuentdeckten Kontinents; sie läuft zur materiellen parallel“ (Berg 1995:29) und zieht die Konsequenzen für heute:

„Problematisch“ ist die Geschichte Lateinamerikas aufgrund ihres bislang durch und durch „eurozentrischen“ Zuschnitts. Die Wahrnehmung dieses - erst in den letzten Jahrzehnten entdeckten - „Defizits“ der gewissermaßen „offiziellen“ Geschichtsschreibung ist jedoch keineswegs identisch mit einer Antwort auf die Frage, wie der Forderung nach einer Geschichtsschreibung Lateinamerikas, die der sog. „visión de los vencidos“ gemäß ist, in der Praxis entsprochen werden kann. (Berg 1995:30)

Versuche, die unterdrückten Stimmen laut werden zu lassen und ihre Geschichte zu erzählen, die gewissermaßen in der Tradition Sahagúns stehen, hat es besonders in den letzten Jahrzehnten vermehrt gegeben. Da aber die „offizielle“ Historiographie traditionellerweise eine bestimmte Sicht wiedergibt, ist sie sicherlich für viele vencidos gar nicht das anzustrebendes Medium für eine counter-history. Vielmehr scheint es folgerichtig, dass sich die visiones de los vencidos andere Ausdrucksformen suchen, so zB die Musik oder die Poesie. Nerudas Canto ist nur ein Beispiel dafür und gleichzeitig Vorbild für andere Dichterinnen und Dichter, die sich mit dem Stoff der Geschichte beschäftigen.

Sehr vereinfacht kann man zwei große Ziele der Darstellung von Geschichte bei Neruda konstatieren. Zum einen bildet das Canto general eine Gegenversion zur offziellen Geschichte. Seine Helden sind die Antagonisten der spanischen Geschichtsschreibung (die ja lange Zeit die wichtigste Quelle war für die Geschichte Lateinamerikas). Zum anderen ist sein „Geschichtsunterricht“ identitätsbildend: Selbstverständnis und Solidarität auf konti-

\footnotetext{
${ }^{34}$ Vgl. Todorov 1982: „Las Casas aime les Indiens. Et il est chrétien. Pour lui, ces deux traits sont
} solidaires: il les aime précisement parce qu'il est chrétien, et son amour illustre sa foi““ (S173) und 
nentaler Ebene werden gestärkt. Nicht zuletzt deshalb ist Neruda als Dichter bis heute ein Vorbild, zumindest in Chile. Sowohl seine Wortgewalt wie auch die stringente politische Programmatik seiner Dichtung machen ihn zum Helden und Übervater für die chilenischen Dichterinnen und Dichter, zum poeta-vate par excellence.

Neben Nerudas Canto general ist die Geschichtsdichtung im Werk Ernesto Cardenals zu nennen. Dietrich Briesemeister sagt über die beiden Gedichtzyklen El estrecho dudoso (1960) und Homenaje a los indios americanos (1970):

Geschichtliche Rückbesinnung und visionärer Gegenentwurf für die Zukunft stehen immer unmittelbar in bezug zur Gegenwart [...] Cardenal beschwört Geschichte nicht in nostalgischer Erinnerung noch rekonstruiert er sie aus rein archäologischer Neugier, sondern mißt sie in ihrer Bedeutung für die Gegenwart aus und versteht sie als Kraft, die Zukunft mitgestaltet. (Briesemeister 1989:291)

Der starke Gegenwartsbezug in den Texten Cardenals mit historischem Inhalt entspringt dem sozialen und politischen Engagement, das Cardenal auszeichnet. Sein Schreiben ist immer Stellungnahme, Kritik, Solidarität, und selbst seine religiösen Texte wie Gethsemani Ky (1960) oder Salmos (1964) beinhalten eine politische Position. ${ }^{35}$ Stilistisch ist die collageartige Technik hervorzuheben, die Cardenal insbesondere in den Texten anwendet, die eine historische Dimension haben. Er stellt geschichtliche Quellentexte, Zeitzeugenberichte, literarische Zitate und eigene Kommentare in einem Text nebeneinander. Es entstehen vielstimmige Texte, bunte Mosaiken, die ein heterogenes Bild zeichnen und so einen lebensnahen Eindruck vermitteln. Einige von Cardenals Texten erinnern an murales, die Wandbilder, die ebenfalls engagierte Collagen zu einem bestimmten Thema zeigen. Coronel Urtecho nennt diese Methode „rápida técnica alucinante de una película documental“. (Coronel Urtecho 1980:31)

Beide Merkmale der Dichtung Cardenals lassen sich auf das Programm des von ihm selbst so benannten exteriorismo, zurückführen. Der Begriff soll die Bedeutung der äußeren Welt, der geschichtlichen, politischen und sozialen Realitäten für seine Dichtung verdeutlichen. Zum einen schließt das jede Form von l'art pour l'art aus. Stattdessen ist seine Dichtung erklärtermaßen engagiert. Zum andern erlaubt der exteriorismo die Miteinbeziehung nichtliterarischer Quellen. Vor allem fordert er aber die Verwendung einer möglichst einfachen

„Une chose est sûre: Las Casas ne veut pas faire cesser l'annexion des Indiens, il veut simplement que ce soit fait par des religieux plutôt que par des soldats“ (S175).

${ }^{35}$ José Miguel Oviedo meint hierzu: „Aber der göttliche Ruf war für ihn nur eine mystische Art, sich den Menschen und den Problemen Lateinamerikas näher zu fühlen. [...] Diese radikal den Menschen zugewandte Prägung seiner religiösen Erfahrung, dieser engagierte Mystizismus hat seine Wurzeln zum großen Teil in dem Einfluss Thomas Mertons und der Art seines Lebens, das er in 
Sprache, die sich deutlich der Prosa nähert. Es soll von äußeren und konkreten Dingen die Rede sein, die ohne Metaphern oder andere dichterische Stilmittel für alle leicht verständlich dargestellt werden. Dadurch erreicht Cardenal ein sehr viel breiteres Publikum, und insbesondere die nicht akademisch Gebildeten werden angesprochen.

Ich beschränke mich in der schlaglichtartigen Vorstellung auf den Text El estrecho dudoso. Der Titel bezieht sich auf die Meerenge, die den Atlantik mit dem Pazifik verbinden sollte und die die Europäer in Nicaragua zu finden hofften. Als sie vom Río San Juan in den Lago Nicaragua segelten, glaubten sie, die ersehnte Verbindung gefunden zu haben.

Die 25 lyrischen Texte erzählen die erste Durchquerung Nicaraguas von Osten nach Westen mit „fragmentos de documentos históricos, de cartas antiguas y de relatos de viaje, expresados en una sintaxis y ortografía ya arcaicas“. (Elias 1991:924) Der inhaltliche Schwerpunkt ist also die Suche nach der Meerenge auf den Spuren verschiedener spanischer Eroberer und Expeditionen; aber auch - und davon nicht zu trennen - die gewaltsame Eroberung Nicaraguas sowie die aktuelle politische und soziale Situation, die Cardenal erlebt. Tamara Williams nennt diese beiden Schienen, auf denen der Text sich bewegt „double-voiced discourse“. (Williams 1994:47) Die Stimme, die aus der Vergangenheit spricht, setzt sich aus intertextuellen Bezügen zusammen:

[...] the repetition of fragments of historical discourse invites the reader to explore the nature of the inter-textual dialogue thus created. [...] By acknowledging El estrecho's intertextual features it becomes clear that the work articulates the construction of a counterhegemonic reading of the first one hundred years of post-Columbian Central American history. (Williams 1994:48)

Aus der Einbindung vieler verschiedener Quellentexte entsteht in Cardenals Gedicht counter-history. Williams führt dies auf den häufigen Gebrauch der Stilmittel Ironie, Satire und Parodie durch Cardenal zurück. Dafür ist es nicht nötig, dass er selbst die Quellen entsprechend kommentiert, vielmehr entsteht die umwertende Ironie allein durch die Distanz zwischen dem Autor des ursprünglichen Textes und der Leserschaft des Textes von Cardenal. Seine Leserinnen und Leser verstehen die historischen Aussagen - oder die Ausführungen Cardenals in Anlehnung an diese - vor dem Hintergrund einer seitdem vollständig verschobenen und veränderten Perspektive und mit dem Wissen um den Fortgang der Geschichte.

The reader, therefore, overhears a dialogue or monologue in which the character, or the historian portraying the character, inadvertently reveals more weakness and vices than he intends. [...] The irony stems from the observable tension or contradiction between what

Gethsemani einführte.“ (Oviedo 1986:9) Thomas Merton (1915-1968), Mönch, Dichter und Philosoph, leitete das Trappistenkloster Gethsemani, dem Cardenal 1957 beitrat. 
the character $(\mathrm{X})$ intends by or understands about his acts and what the poet $(\mathrm{Y})$ shows them to mean. (Williams 1994:48)

Cardenals Umgang mit der Geschichte ist für die Dichtung in ganz Lateinamerika beispielhaft geworden. Briesemeister weist auf die Übertragbarkeit von Cardenals Stil hin: „Sie referiert nicht einfachhin Wirklichkeit, sondern macht diese durch zeichenhafte Ausdeutung von exemplarischen Gestalten und Ereignissen übersichtlich, verständlich.“ (Briesemeister 1989:292) Damit drückt Briesemeister aus, dass - trotz der Gebundenheit an das Konkrete und ,Äußere‘ durch den exteriorismo - in seiner Dichtung ein hohes Maß an Transzendenz erreiche.

Ein weiterer Grund für die Faszination, die von Cardenals Dichtung ausgeht, liegt in der Tatsache, dass sein Geschichtsbild ein sehr reales und greifbares Utopia beinhaltet, „das sich zwischen der Zeit der Eingeborenenmythen und der apokalyptischen Zeit des Abendlandes vollzieht, zwischen den Anfängen und der Katastrophe: diese Welten, die wir als tot und lang vergangen ansehen, sind hier, und die Geschichte kann von neuem beginnen“. (Oviedo 1986:12) Seine Texte schöpfen ihre Kraft aus der Vergangenheit, wollen jedoch Mut machen, in der Gegenwart die eigene Zukunft zu finden.

Man kann feststellen, dass die Geschichtsdarstellung in der lateinamerikanischen Dichtung des letzten Jahrhunderts eine Tradition aufweist, die versucht, der visión de los vencidos gerecht zu werden. So wirkungsmächtige Dichter wie Neruda und Cardenal haben Geschichtsepen geschrieben und dabei zum einen eine kritische Perspektive im Sinne der counter-history eingenommen. Zum anderen fällt auf, dass sie um den ständigen Bezug zur eigenen Gegenwart bemüht sind. Auf diese Merkmale sowie auf die angesprochenen stilistischen Techniken (Collage, Funktion des lyrischen Ich etc.) wird in den Textanalysen zurückzukommen sein.

\subsection{3: Der Militärputsch und die Folgen für die Dichtung}

Der Militärputsch 1973 war der gewaltsame Schlusspunkt einer langen und langsamen Spaltung innerhalb des chilenischen Volkes. Über insgesamt 40 Jahre hinweg, aber insbesondere in den Jahren 1970-1973, der Regierungszeit der sozialistischen Unidad Popular, hatte sich ein tiefer Graben zwischen den rechts-konservativen und den linken Kräften im Land gebildet. Weder die Reformen der Unidad Popular noch die Außenpolitik Salvador Allendes hatten in drei Jahren die erhofften Erfolge für die Wirtschaft Chiles gezeitigt. Die Stimmung in der Bevölkerung war angespannt und ließ viele mit einem bevorstehenden Bürgerkrieg rechnen. 
Mit dem Staatsstreich am 11. September, dem Sturz der Unidad Popular und dem gewaltsamen Tod des Präsidenten Allende wurde der Bürgerkrieg durch einen allgemeinen Ausnahmezustand verhindert. Es begann eine Zeit, die von Willkürakten des Militärregimes unter Pinochet geprägt war. Es gab demonstrative Gewaltakte wie die Internierung von über 3000 Zivilisten im Estadio Nacional, die man in den ersten Tagen der Diktatur dort zusammengetrieben hatte oder die Festnahme, Folter und Tötung von Personen, die unter der gestürzten Regierung politisch aktiv waren. (Siegler 1973:18185) Es gab zermürbende Kontrollmechanismen wie die nächtliche Ausgangssperre oder willkürlich und rücksichtslos durchgeführte Hausdurchsuchungen. Es gab die Politik der Desinformation, die Menschen im Unklaren zu lassen, falsch oder gar nicht zu informieren. Dazu gehörten die Zensur und das Stillschweigen über das Schicksal vieler politischer Häftlinge, so dass die Angehörigen nicht wussten, ob die desaparecidos-,,Verschwundene“ sich wirklich in der Hand der Putschisten befanden und falls ja, ob sie noch am Leben waren.

Die Folge war ein Leben in ständiger Unsicherheit, was längst nicht nur für aktive Regimegegner galt. Angst und Misstrauen beherrschten die Menschen, die nirgends vor Spitzeln der Diktatur sicher sein konnten. In jeder Familie gab es Personen, die ins Exil oder in den Untergrund gingen. Persönliche Bindungen wurden zerrissen, die Angst vor dem Zugriff der Militärs auf das eigene Leben war bei den meisten Menschen ständig gegenwärtig und fraß sich in den Alltag hinein. Die Spaltung der Bevölkerung spitzte sich weiter zu, da nun gegenseitige Schuldzuweisungen an der politischen Situation sowie Schuldgefühle auf beiden Seiten hinzukamen.

Im Moment des Militärputsches waren viele chilenische Dichterinnen und Dichter in Schreib-Werkstätten (talleres) und Gruppen tätig. Einige der wichtigsten waren Trilce (Valdivia), Tebaida (Arica), Arúspice (Concepción), TribuNo (Santiago) und Murciélago (Valdivia). In diesen Gruppen wurden Talente entdeckt und gefördert, sie veranstalteten nationale und internationale Dichtertreffen, ${ }^{36}$ und an ihre Mitglieder gingen die meisten der nationalen Auszeichnungen für Lyrik. Die sechziger und beginnenden 70er Jahre waren für Chile - wie oben erwähnt - eine Phase der politischen, ökonomischen und kulturellen Umwälzungen. Gleichzeitig erlebte die gesamte westliche Welt eine politisch bewegte und engagierte Zeit, an der auch die Chilenen teilnahmen: „guerra de Viet-Nam, la revolución

\footnotetext{
361965 fand in der Universidad Austral von Valdivia das sogenannte Primer Encuentro de la Joven Poesía Chilena statt; weitere Treffen dieser Art wurden 1967, 1971 und 1972 von der literarischen Gruppe Trilce - ebenfalls mit Unterstützung der Universität - organisiert. (Yamal 1988:19)
} 
cubana, mayo de 68”. (González Cangas 1994:159f.) Viele der Schriftsteller waren in einer der linken politischen Gruppierungen engagiert: „La vía Chilena al Socialismo despierta en todos la necesidad de tomar partido, desde distintos referentes: Ojeda desde el MAPU, Riedemann desde el MIR y Torres desde el PS.” (González Cangas 1994:160)

Mit dem Militärputsch wurden die politisch-oppositionellen Gruppen zerschlagen oder gingen in den Untergrund. Viele der Schriftsteller wurden aufgrund ihrer tatsächlichen oder vermeintlichen politischen Aktivitäten inhaftiert, und die literarischen Zirkel verschwanden ausnahmslos. ${ }^{37}$ „Todos nos retrotraíamos [sic] y prácticamente nos metimos en la caparazón del caracol para protegernos. Nadie debía tener contacto con nadie, el miedo fue una cosa terrible.“ (González Cangas 1994:160) Viele der Schriftsteller gingen - freiwillig oder unfreiwillig - ins Exil.

Mit diesem Datum änderte sich die Wirklichkeit der Chilenen massiv durch die allgegenwärtige Gewalt, durch Foltern, Morde und die Beschneidung der individuellen Freiheiten (Ausgangssperre, Zensur, Ausweisung). Aber auch die Wahrnehmung von Wirklichkeit wurde manipuliert. Die Zensur hindert die Menschen nicht nur daran, die Wirklichkeit so wiederzugeben, wie sie sie erleben oder einfach zu sagen, was sie sagen wollen, sondern sie vermittelt auch nach außen hin ein falsches Bild von dem, was die Menschen denken. In dem Maße, in dem also bewusst falsche Darstellungen der Wirklichkeit veröffentlicht oder korrekte unterdrückt werden, wird die Wahrnehmung der Wirklichkeit manipuliert. ${ }^{38}$

Ein Beispiel für diese manipulierte Wahrnehmung ist der Umgang mit den Informationen über Festgenommene. Die fehlende Gewissheit über ihren Aufenthaltsort und ihr Befinden verhinderte, dass von Häftlingen oder Opfern gesprochen werden konnte. Daher sprach man von desaparecidos, Verschwundenen. Der Begriff drückte dieselbe Anklage gegen das Regime aus, die in ,Ermordete' gesteckt hätte, aber da man sich nicht vollkommen sicher sein konnte, konnte man der desaparecidos nicht als Toter gedenken. Ohne Beweise für ihren Tod konnte es kein Grab geben, und es musste eine winzige Hoffnung bleiben. Die Wahr-

\footnotetext{
37 „Producido el golpe, los militares allanaron la Universidad, sacaron a todos los profesores de la Facultad de Letras con las manos en alto. A un profesor de fonética lo detuvieron acusado de tener una radio clandestina (en realidad se trataba de instrumentos acústicos para hacer experimentos de fonética); a otro profesor lo detuvieron a la salida del campus, fue encarcelado y liberado más tarde al no haber cargos en su contra; pero se le prohibió caminar por los terrenos del campus. Se le canceló la matrícula a la totalidad de los estudiantes, los que fueron luego rematriculados; pero en este proceso se dejó sistemáticamente al margen a todos los estudiantes que habían sido partidarios del gobierno de Allende.“ (Mansilla 1996:Kap.1, Fußnote 3)
} 
heit über den Verbleib von Angehörigen nicht zu kennen, war zermürbend, und das Stillschweigen oder gar Leugnen der Geschehnisse von Seiten der Militärs ein kalkuliertes, menschenverachtendes Spiel mit der Verzweiflung und Hoffnung Vieler.

Die Skizze der Situation macht deutlich, wie tief das Erleben der Diktatur sich in das Bewusstsein der Chilenen gegraben haben muss. Die Eindrücke und Erfahrungen dieser Zeit haben die Menschen traumatisiert. Jedes Nachdenken oder Schreiben über die Vergangenheit impliziert und erzwingt es, die Vergangenheit in eine Beziehung zur Gegenwart zu setzen. Dabei können Vergangenheit sowie die daran anschließende Gegenwart unterschiedlich zueinander ins Verhältnis gesetzt werden und verschiedene Erscheinungsformen annehmen. Eine Möglichkeit, die häufig begegnet, ist die Darstellung der Vergangenheit als der zeitlosen, idyllischen Kulisse einer noch unschuldigen Welt (vor 1973). Aus einer anderen Sichtweise wird das historisch verbrämte Szenario eines Sündenfalls geschildert, der es verdiente, derart drastisch bestraft zu werden (Diktatur als verdiente Strafe/ Strafe des Schicksals/ Strafe Gottes). Diesen beiden plakativ umrissenen Sichtweisen auf die Vergangenheit liegen zwei sehr unterschiedliche Weltanschauungen und unterschiedliche Vorstellungen von dem Lauf der Geschichte zugrunde, die an konkreten Fällen zu entwickeln sein werden.

Sergio Mansilla erkennt in der chilenischen Lyrik zwischen 1975 und 1995 eine

[...] aguda y al la vez refractaria conexión con la historia pasada, presente y futura, así como su rigurosa, y a menudo atormentada, autoconciencia escritural, que da paso a un tipo de discurso poético que se piensa radicalmente poderoso y precario al mismo tiempo [...]. (Mansilla 1996a:57)

Mansilla nennt die Dichterinnen und Dichter dieser Zeit mit Edurardo Llanos Melussas Worten generación del contragolpe. Im Gegensatz zur neutraleren Bezeichnung generación del postgolpe schreibt Llanos` Begriffsbildung den Bezeichneten eine Haltung zu. Das impliziert, dass sich nicht nur ihre innere Einstellung gegen die Diktatur richtet, sondern sich dies auch in ihren Texten niederschlägt. Als eines der wichtigsten Merkmale der Dichtung der generación del contragolpe nennt Mansilla das in ihr zum Ausdruck gebrachte Misstrauen gegenüber der Sprache und ihrer Fähigkeit, die Wirklichkeit zu repräsentieren:

Representar, entonces, la precariedad de la representación es representar el hecho real de la precariedad y, a la vez, la imposibilidad de representar las vastas dimensiones de una historia signada por la violencia, la represión, la inseguridad constantes. (Mansilla 1996a:59)

${ }^{38}$ Vgl. hierzu Zurita 1988 und Cánovas 1986. 
Mansilla bezieht sich hiermit insbesondere auf metapoetische und autoreflexive Texte, die ihre eigene Unfähigkeit formulieren, definitive Aussagen zu treffen. ${ }^{39}$ Die „precariedad de la representación“ zeigt sich aber auch in der Fiktionalisierung von vermeintlicher Wirklichkeit und in der Zerbrechlichkeit und Unsicherheit des Subjekts: „,no hay la confianza y seguridad desafiante de la pluralización nerudiana, sino una amargura sarcástica“..40 Und: „El yo se ha vuelto ahora plural, fragmentario, contradictorio, lejano de ese majestuoso y monológico yo colectivo nerudiano.“ (Mansilla 1996a:59) Fiktionalisierung findet auch statt, wenn man Wirklichkeit und Fiktion des Textes nicht mehr auseinanderhalten kann: „[...] la nueva realidad que no puede constituirse sino a través de la ficción; la nueva ficción, que no puede leerse-vivirse sino como historia real““. (Mansilla 1996a:59) Jaime Giordano drückt es so aus: „Las realidades que funda esta escritura se ficcionalizan.“ (Giordano 1987:333)

Das Vertrauen in eine Wirklichkeit, die durch Sprache ausgedrückt und eindeutig von der Lüge oder der Fiktion unterschieden werden könnte, schwindet in dem Maße, in dem die Militärregierung unter Pinochet die Sprache benutzt, um ihre eigene Wirklichkeit zu verkünden:

El estatuo mismo de la realidad se vuelve ambiguo, pues los discursos, verdaderos ${ }^{6}$ de la información oficial se vuelven objeto de sospecha o simplemente se los percibe como ficciones políticamente calculadas; situación que da pie para que los textos informativos se lean como „literatura“. (Mansilla 1997:71)

Aber auch andere Grenzen innerhalb der Literatur beginnen, mehr und mehr in einander überzugehen. Mansilla spricht davon, dass die generación del contragolpe dazu tendiert, jede Art von Text und jede Art von Stil in ihre eigene Dichtung zu integrieren. Literarische und nicht-literarische Texte, „gran literatura” und „textos desechables”, die Ikonen der chilenischen Literatur sowie die Umgangssprache. (Mansilla 1997:71)

Das grundlegende Misstrauen in die Möglichkeiten der Sprache, der Wirklichkeit gerecht zu werden, führt bei vielen Dichtern zum Verstummen. Andere hören auf zu schreiben, um nicht dieselben Wörter benutzen zu müssen, die die Putschisten gebrauchen, um ihre Macht zu konsolidieren oder ihr Vorgehen zu rechtfertigen. ${ }^{41}$

\footnotetext{
39 Als metapoetisch werden Texte bezeichnet, in denen Dichtung über Dichtung spricht, also die Poesie selbst, ihre Form und ihre Funktion thematisiert werden (vgl. Karl 1995).

${ }^{40}$ Die „pluralización nerudiana“ ist die Vielstimmigkeit, die im Canto general vorliegt. Vgl. Giordano 1987:327.
} 
Oscar Galindo erkennt dieselben Tendenzen der chilenischen Lyrik nach 1973, aber er betont im Gegensatz zu Mansilla die Möglichkeit, mit der Situation dichterisch umzugehen:

$\mathrm{Si}$ es cierto que la palabra no sólo dice al mundo sino que también lo funda, es posible también que esta afirmación sirva como una de las claves que expliquen la persistente preocupación por las relaciones entre el lenguaje y la realidad que caracterizan una zona significativa de la producción poética chilena contemporánea. Las fronteras de la realidad y del lenguaje como problema están en el centro de una literatura que como más de una vez se ha advertido se vio obligada a replantearse la búsqueda de un imaginario poético en contradicción con la obvia ficcionalización de la realidad. (Galindo 1992:205)

Galindo bezeichnet hier die das Nachdenken über die Beziehungen von Sprache und Wirklichkeit als charakteristisch für einen Teil der chilenischen Dichtung. Er begründet das mit der Fähigkeit zur Einflussnahme auf die Welt, die der Sprache - und somit der Dichtung - innewohnt. Im Folgenden erwähnt Galindo explizit die Darstellung von Geschichte in der Dichtung und ihre Notwendigkeit:

De esta manera, parece visible que la poesía se vio en la necesidad de contrarrestar un discurso público que interpretaba la historia y el presente a través del lugar común, el kish [sic] y la censura; pero, por otro lado, se vio también en la necesidad de recordar que la misma realidad era posible de ser sometida a las operaciones del lenguaje, fundando nuevas maneras de imaginar el mundo. Así, develación y enmascaramiento son claves permanentes de una escritura todavía en tránsito y búsqueda. (Galindo 1992:205)

Die beiden kontradiktorisch erscheinenden Schlüssel-Elemente, die er als konstitutiv für das Verhältnis von Poesie und Wirklichkeit beschreibt, sind einerseits das Bestreben, die Wirklichkeit von der verschleiernden Sprache, von Allgemeinplätzen, Kitsch oder Zensur zu befreien. Andererseits nennt er den Willen, die Wirklichkeit kraft Sprache und Imagination zu verändern.

Eine wichtige Strömung, die eine andere Reaktion, aber ebenfalls eine direkte Antwort auf die politische Situation in Chile darstellt, ist die poesía testimonial.

[La] poesía, por tanto, se sitúa como un elemento más de una lucha de liberación del país, por lo cual construye su texto a partir de un repertorio limitado de posibilidades de textualización poética: la función de denuncia y testimonio de una realidad cruel, la frecuente incorporación del no-texto histórico mediante la alusión referencial, la alegoría, la ironía o la mención directa, tanto de personas, como espacios, ideas, discursos, documentos, el uso de una estructuración simple del texto, de un lenguaje fundado en la experiencia del ciudadano medio. (Carrasco 1989b:39)

Literarische Testimonios wollen Zeugnis ablegen von der jeweiligen gesellschaftlichen oder politischen Situation oder von einem Ereignis, indem sie Erlebnisse und Geschehen möglichst unmittelbar schildern. Sie sind vorwiegend an politisch aussagekräftigen Darstellungen interessiert, die häufig in umgangssprachlicher Form vorgebracht werden. Es

${ }^{41}$ „Esta desconfianza hacia el lenguaje, la mala conciencia del hablante, es sí un hecho nuevo.“ (Zurita 1988:16) 
sind eben jene Texte, die politische und soziale Missstände anklagen und als „engagierte“ Texte eine wichtige Grundlage für die zu schreibende counter-history bilden.

Ich möchte folgende Punkte festhalten: Erstens unterstreicht Galindo die Allgegenwart des Spannungsverhältnisses zwischen Sprache und Wirklichkeit. Zweitens schreibt er der Sprache eine große Wirkungsmacht für die Wirklichkeit, also auch für die Geschichte zu. Drittens hat er eine Vermutung, warum dieses Thema in Chile von so großem Interesse ist. Er führt die Beschäftigung mit Geschichte und Gegenwart auf das Bedürfnis zurück, der offiziellen und öffentlichen, der vereinfachenden und euphemistischen Darstellung entgegenzutreten.

Zum anderen spricht er davon, dass die Einsicht in die Wirkung der Sprache auf die Wirklichkeit - zumindest aber auf die Wahrnehmung der Wirklichkeit - es Autorinnen und Autoren ermöglicht und sie dazu ermutigt, ihre eigene Wirklichkeit zu (er)finden.

Galindo sieht in der chilenischen Dichtung nach 1973 also zum einen das Bestreben, die Wahrheit ans Licht zu bringen - entgegen allem öffentlichen Lügen, Verleumden und Verschweigen. Zum anderen erkennt er den Versuch, mit denselben Mitteln der Sprache eine Gegenwelt zu erschaffen, die ebenso wenig mit einer objektiven Wirklichkeit zu tun hat. ,Aufdeckung' und ,Maskierung' nennt er diese Tendenzen, denen einerseits die poesía testimonial und andererseits die Fiktionalisierung der Wirklichkeit entsprechen.

Da der Umgang mit der Geschichte nichts anderes ist als der Umgang mit vergangener Wirklichkeit, ist er ein Spezialfall des Umganges mit Wirklichkeit, wie Galindo ihn beschreibt. Als solcher ist er immer gleichermaßen zum einen eng verbunden mit der jeweils konkreten Situation, in der sich jemand befindet, und zum anderen mit dessen individueller Wahrnehmung und Bewertung der Wirklichkeit.

Von den unmittelbaren literarischen Reaktionen auf den Staatsstreich über die Möglichkeit, eine Gegen-Wirklichkeit zu erschaffen, gelangt man in einem nächsten Schritt zu der identitätskonstituierenden Funktion der Dichtung.

Un gesto de la necesidad de tener historia para auto-contenernos, para auto-reconocernos, para auto-rastrearnos, algo de donde nos asimos para levantar sumatorias de identidades, que sostienen nuestras especificidades y que levantan nuestro discurso, nuestra diferencia. (González Cangas 1994:157)

Auch wenn sich Yanko González-Cangas hier in erster Linie auf die Literaturgeschichtsschreibung bezieht, lässt sich diese Aussage leicht auf die Schreibung von Realgeschichte übertragen, insbesondere, da er von der spezifischen Situation der Menschen in Chile nach 
1973 ausgeht. Er nennt die (Literatur-)Geschichtsschreibung als Instrument zur Selbstvergewisserung und Selbsterkenntnis: Man wird sich schreibend (und lesend) über ein bestimmtes Stück gemeinsamer Vergangenheit bewusst. Dabei kann es sich um nationale Geschichte handeln, die nationale Identität zu bilden hilft. Da für Chile jedoch die Nation als identifikatorischer Bezugsrahmen aufgrund der Diktatur problematisch ist, hat die Region, wie zB Südchile, als Größe an Bedeutung gewonnen.

\subsection{Dichtung in Südchile}

La palabra Sur es un poema, un aikú, donde todas las presencias huelen a vegetación y agua, un cuerpo húmedo tendido sobre la geografía. Pero el poema no es el mapa, sino el territorio mismo, fundado y reconocido en el continente del cuerpo.

Bruno Serrano

Spätestens seit den 60er Jahren nimmt die Dichtung im Süden des Landes eine Sonderstellung ein:

[...] desde inicios de los años 60, con la creación del grupo „Trilce”, las provincias del sur han venido desarrollando una dinámica literaria que tiende a la autonomía y la autosuficiencia, a riesgo de una práctica de lectura y de crítica excesivamente endógena, casi incestuosa. El sur, en este sentido, se vuelve un ámbito estético que otorga determinadas marcas diferenciales a los textos, por lo menos a nivel de imagen y representación de realidad. (Mansilla 1996:Kap.2)

Was ist gemeint mit "südchilenischer Dichtung"? Nach welchen Kriterien werden die Texte einer Dichterin oder eines Dichters unter diese wenig präzise Bezeichnung gefasst?

Zunächst ist das Kriterium offensichtlich ein geographisches und soll als solches kurz erläutert werden. Die chilenenische Staatsgebiet wird - angefangen im äußersten Norden an der Grenze zu Peru bis hinab in den antarktischen Süden - in zwölf durchnummerierte Regionen unterteilt. Santiago ist zB die fünfte Region. Unter Chiles Süden fasse ich im Folgenden die Regionen VIII bis XII zusammen. Den nördlichsten Rand des betreffenden Gebietes bildet die Region des Flusses Bío-Bío (VIII) mit der Hauptstadt Concepción. Die anschließende neunte Region wird auch die Araucanía genannt. Ihre Hauptstadt ist Temuco mit heute ca. 300.000 Einwohnern. Die Region der Seen (X) umfasst neben der Hauptstadt Valdivia die Städte Osorno und Puerto Montt sowie die Insel Chiloé. In den beiden südlichsten Regionen, der Region von Aysén (XI) mit der Hauptstadt Coihaique und schließlich der Region um Punta Arenas (XII) zerfällt Chile in zahllose kleine Inseln.

Aus dem Süden Chiles stammt nicht nur ein unverhältnismäßig großer Anteil der gesamtchilenischen Lyrik der letzten vierzig Jahre, sondern es handelt sich auch um qualitativ herausragende, innovative Werke. In der neunten und zehnten Region hat sich seit 
den 60er Jahren eine Infrastruktur für die Produktion und die Publikation von Dichtung entwickelt, der auf nationaler Ebene Aufmerksamkeit geschenkt wird: „Las agencias culturales y educacionales del Estado han ido reconociendo la relevancia (no siempre literaria, eso sî) de lo que suele llamarse a veces ,literatura regional'،“"(Mansilla 1997:75)

Auf längere Sicht konnte der Militärputsch von 1973 der Entwicklung nichts anhaben. 1975 ist in Valdivia der erste Gedichtband in Chile nach dem Staatsstreich und dem unmittelbar darauf folgenden literarischen Schweigen erschienen: Recurso de amparo von Jorge Torres. Das mag auf den ersten Blick ein unbedeutendes Faktum sein, das zwar symbolischen Wert besitzt, aber auf Zufall beruhen könnte. Tatsächlich jedoch hat sich dieser mutige Schritt des Südchilenen bis auf den heutigen Tag als symptomatisch und wegweisend in der chilenischen Lyrik erwiesen: „,...] desde 1975 a la fecha, el sur ha producido una decena de individualidades cuya obra, por calidad y cuantidad, es un real aporte a la poesía chilena del siglo XX“. (Mansilla 1997:75)

In seinem Abriss über die Entwicklung der Lyrik in Südchile seit 1975 unterteilt Mansilla den Zeitraum in drei Abschnitte. In der ersten Phase, etwa bis 1981, stehen diejenigen, die in Chile kulturell tätig sein wollen, vor einem vollständigen Neuanfang. Sämtliche Verbindungen zu Vergangenheit und Tradition sind gekappt worden, die Kontakte ins Ausland sowie in vielen Fällen auch die Kontakte innerhalb des Landes sind abgebrochen. Schriftstellerinnen und Schriftsteller befinden sich auf einer tierra devastada und müssen Aufbauarbeit leisten. Da die Meinungsfreiheit stark eingeschränkt ist und der Raum der Kulturschaffenden seine institutionell-rechtlichen Grenzen und Rahmen verloren hat, ist die Arbeit nur im Kollektiv denkbar. Es bilden sich talleres und literarische Gruppen, die zwar an die Tradition vor dem Staatsstreich anknüpfen, deren Aufgaben aber nun andere geworden sind. Eine neue kulturelle Infrastruktur muss entstehen, doch dazu ist es zunächst notwendig, dass Dichterinnen und Dichter sich der Funktion der Dichtung und ihrer eigenen Rolle in der speziellen politischen und gesellschaftlichen Situation bewusst werden. Meistens finden die Schriftstellerinnen und Schriftsteller unter dem Dach der Universitäten einen relativ geschützten Raum:

estos talleres y grupos se convirtieron, de hecho, en genuinos espacios de diálogo democrático y en verdaderos laboratorios de recomposición de la memoria histórica colectiva y de la utopía a través de los ejercicios de escritura y lectura. (Mansilla 1997:72)

Erst diese Arbeit am eigenen Bewusstsein ermöglicht eine erfolgreiche Weiterführung literarischer Arbeit und das Neuknüpfen der Verbindungen mit der eigenen Tradition sowie mit der ausländischen Dichtung und schließlich die Kontaktaufnahme mit den exilierten und autoexilierten chilenischen Autorinnen und Autoren. 
Eine zweite Phase sieht Mansilla in der Zeit zwischen 1981 und dem Ende der 80er Jahre. In dieser Zeit verlagern sich die Gruppen von den Universitäten an die Schulen, während die universitären Gruppierungen zunehmend politische Ziele verfolgen. Die häufigen Dichtertreffen in Puerto Montt und Osorno erzeugen seiner Meinung nach „el espacio de continuidad cultural propio de autores que vienen de la década anterior“". (Mansilla 1996:Kap.1) Neues ereignet sich hiernach erst wieder in der dritten Phase. Am Ende der Diktatur melden sich Dichterinnen und Dichter zu Wort, die von der Diktatur nicht in dem Maße betroffen sind wie ihre Vorgänger, ,autores que ya no viven la situación de urgencia de la cotidianidad represiva“. (Mansilla 1997:73) Sie schreiben nicht, um ihre Erfahrungen unter der Militärregierung zu verarbeiten und „dejan la sensación de estar bastante cansados del historicismo de los poetas anteriores“. (Mansilla 1997:73)

In meiner Untersuchung wird es um Texte aus den ersten beiden Phasen gehen. Das Kriterium hierfür ist nicht das Entstehungsjahr des Textes, sondern die Frage, ob er in irgendeiner Weise den problematischen Umgang mit der eigenen oder - möglicherweise stellvertretend - den mit einer anderen Geschichte thematisiert. Entscheidend ist also, ob die Autorin oder der Autor dazu beitragen will oder kann, die Scherben des gewaltsam zerbrochenen kollektiven Geschichtsgedächtnisses neu zusammenzufügen.

Es lassen sich einige Merkmale aufzählen, die als charakteristisch für diese Dichtung angenommen werden können. Besonders augenfällig ist das eigene Wesen der Provinzpoesie, wenn sich der umgebende Lebensraum in ihr spiegelt (und das geschieht fast immer auf direkte oder indirekte Weise). Klischeehaft gesprochen, schlägt sich die Metropole Santiago in einem Szenario aus Lärm, Verkehr, Hektik und schlechter Luft nieder, in Bildern von Armenvierteln, in der Darstellung von Konsumverhalten, Anonymität und Menschenmassen oder in mehr oder weniger symbolischen Neonlichtern und Mauern, während in den südchilenischen Texten Landschaft, Natur, Regen, Meer, Vulkane, Vögel und dörfliches Leben präsent sind. ${ }^{42}$

Eine weitere inhaltliche Eigenart eines großen Teils der südchilenischen Dichtung ist die Bedeutung ethnokultureller Elemente. Zum einen schlägt sich die Berührung und Beschäf-

${ }^{42}$ Ich will hier keineswegs die deterministischen Vorstellung vertreten, dass die Umgebung des Dichters für seine Dichtung verantwortlich ist. Meiner Meinung können sich aber Autorinnen und 
tigung mit marginalisierten Kulturen - oder wenigstens mit deren Spuren - in auffällig vielen südchilenischen Texten der $80 \mathrm{er}$ und 90er Jahre nieder. Zum anderen wächst das allgemeine Interesse an Texten von ethnischen Minderheiten, die sich wiederum mit dem interkulturellen Kontakt aus ihrer eigenen Perspektive beschäftigen. Beide Tendenzen fasst man unter der Bezeichnung Ethnokulturelle Poesie oder Ethnopoesie. In der neunten Region handelt es sich dabei um die Ethnie der Mapuche, einer zu prähispanischer Zeit hier bereits angesiedelten Volksgruppe. Zur ethnokulturellen Poesie gehören aber auch Texte aus dem tieferen Süden des Landes, die sich mit der Geschichte und der Kultur der Insel Chiloé befassen ${ }^{43}$ oder mit den bereits ausgelöschten Völkern Feuerlands. ${ }^{44}$

Die Santiaguiner Dichtung ist zwar weltoffen und bezieht Menschen und Literatur verschiedenster Kulturen mit ein ${ }^{45}$, aber die Auseinandersetzung mit den Kulturen Chiles bleibt im Wesentlichen den Provinzen vorbehalten (wo tatsächlich noch Spuren dieser Ethnien zu finden sind, wie in der Atacama-Wüste im Norden oder eben im Süden des Landes).

$\mathrm{Zu}$ den typischen Elementen der südchilenischen Dichtung muss auch der Larismo, die Larendichtung, gezählt werden. Diese Poesie, deren Bilder und Sprache tief in der provinziellen Dörflichkeit verwurzelt sind, hat innerhalb Chiles insbesondere Jorge Teillier vertreten, der sich mit Begriff und Konzept auf Rainer Maria Rilke bezieht. ${ }^{46}$ Teillier ist in Lautaro aufgewachsen und hat mit seinen nostalgischen Liebeserklärungen an einen heimatlichen Süden eine Tradition begründet. Teillier ist als Larendichter bis heute Vorbild für viele ihrer Heimat verhafteten Schriftstellerinnen und Schriftsteller, und der Larismo ist Ausdruck dieser Tradition geworden.

Autoren der Inspiration durch ihre Umwelt nur schwer entziehen. Selbst so universelle Dichter wie Pablo Neruda oder Gonzalo Rojas geben ihre Herkunft aus dem Süden immer wieder zu erkennen. ${ }^{43}$ Vgl. hierzu Carrasco 1995d.

${ }^{44}$ Verschiedene Ausformungen der ethnokulturellen Dichtung werden in den Kapiteln 4, 5, 6 und 7 anhand der jeweiligen Texte vorgestellt.

${ }^{45}$ Vgl. hierzu Bergenthal 2000.

${ }^{46}$ Für Rilke war eine der Aufgaben des Dichters, die ursprünglichen und ureigenen Charakteristika seiner jeweiligen Heimat im Gedicht festzuhalten: „Noch für unsere Großeltern war ein ,Haus‘, ein „Brunnen', ein ihnen vertrauter Turm, ja ihr eigenes Kleid, ihr Mantel: unendlich mehr, unendlich vertrauter; fast jedes Ding ein Gefäß, in dem sie Menschliches vorfanden und Menschliches hinzusparten. [...] Wir sind vielleicht die noch solche Dinge gekannt haben. Auf uns ruht die Verantwortung, nicht allein ibr Andenken zu erhalten (das wäre wenig und unzuverlässig), sondern ihren humanen und larischen Wert. (Larisch', im Sinne der Haus-Gottheiten).“ (Rilke 1991:376f.; Hervorhebungen von Rilke) Der Begriff der ,Laren` geht ursprünglich auf Horaz' Lob des Landlebens zurück. Dort spricht er vom „,heiligen Herd“ als Herzstück des Hauses. Der Herd ist heilig, weil er nicht nur mit seiner lebensspendenden Wärme ein Zentrum des Familienlebens darstellt, sondern er ist darüber hinaus ein Altar für die Hausgötter, die Laren genannt werden. 
Eine weitere Gemeinsamkeit ist nicht inhaltlicher Natur, sondern bezieht sich auf die Haltung und Selbsteinschätzung der Dichterinnen und Dichter. Für die Dichtung des gesamten Südens (allerdings auch für die Provinzen im Norden des Landes) gilt, dass offen oder verdeckt, bewusst oder unbewusst, immer ein Kampf in der Dichtung gegen die Metropole Santiago ausgefochten wird.

Hay bastante discriminación y siempre están mirando peyorativamente el trabajo de nosotros. [...] ¡Poder! Así de simple, tienen poder. Manejan los medios de comunicación., manejan los pocos espacios que hay para la cultura, manejan cierta cancha que nosotros no tenemos. Cuando vamos a los encuentros solemos ser rebasados fácilmente por ellos porque suelen forman cofradías, grupos que se manejan muy bien en sus ambientes. (Trujillo 1993b:Kap.5)

Die Provinz fühlt sich durch die zentralistischen Strukturen in nahezu allen Bereichen benachteiligt. Politik und Wirtschaft werden von Santigago aus gesteuert, und auch die Kultur der Hauptstadt hat durch eine entsprechende Infrastruktur, Unterstützungen und eine funktionierende Distribution zunächst einmal die besseren Möglichkeiten. ${ }^{47}$ Dies lässt den Wunsch entstehen, trotz der ungleichen Ausgangsbedingungen durch Talent, Inspiration und Ehrgeiz wenigstens auf dem Gebiet der Dichtung der Provinz zu einem Platz vor der Hauptstadt zu verhelfen.

Dennoch ist die südchilenische Dichtung keineswegs literarischer Audruck einer einheitlichen Denk- und Lebensweise. Vielmehr existieren in ihr sehr verschiedene Ausprägungen und Strömungen. Der nördlichste Teil des Gebietes, das ich zum Süden Chiles zähle, ist die Stadt Concepción in der VIII. Región. Um die Stadt herum hat sich eine ganz eigene Kultur gebildet. Über die neuere Dichtung, die daraus hervorgegangen ist, legt die Anthologie Las plumas del colibrí. Quince años de poesía en Concepción (1973-1988) Zeugnis ab. Dem eigentlichen Textteil, in dem 28 Dichterinnen und Dichter mit ihren Gedichten vorgestellt werden, gehen die beiden Aufsätze La Diáspora und El Regreso voran. Aus der Innenperspektive werden hier die Entwicklung, die Bedingungen und die Eigenarten der jüngsten Lyrik Concepcións nachgezeichnet und mit Textbeispielen illustriert. Concepción ist heute - zusammen mit der Nachbarstadt Talcahuana, mit der sie inzwischen zusammengewachsen ist - mit etwas mehr als einer Million Einwohnern nach Santiago die zweitgrößte Stadt in Chile. Die Dichtung, die in der Hauptstadt der Region VIII entsteht, ist zum großen Teil Großstadtlyrik, wie sie auch in Santiago geschrieben wird:

${ }^{47}$, ,...las representaciones tradicionalmente dominantes sobre la provincia chilena que la visualizan como ámbito residual, habitado por un desecho humano incapaz de romper la dependencia perversa que lo liga al centro del poder político, económico y cultural [...], siempre detentado, en las mismas representaciones, por la capital.“ (Alonso et al. 1989:13) 
Lugar del desecho, lugar de los discursos antiutópicos, lugar en que el amor sólo puede expresarse bajo la forma del odio, Concepción es el espacio húmedo y macabro en que la vida es una peregrinación del prostíbulo al Cementerio. (Alonso et al. 1989:16)

Andererseits ist in vielen Texten die Frustration zu spüren, die daherrührt, dass im Vergleich zu Santiago auch Concepción als Provinz gehandelt wird. Bianchi drückt es prägnant aus: „Santiago y su centralismo ahogan“. (Bianchi 1990a:153)

La situación marginal de la poesía (pre)destinada a habitar el espacio residual arquetípico [...], explica que la agresividad y violencia, "el veneno de Mandrágora" que exhala esta escritura, sea la respuesta más adecuada el intento de los poderes oraculares de "prostituir" a la poesía. (Alonso et al. 1989:14)

Die angrenzende Region der Araucanía ist - wie bereits angesprochen - Ursprung vieler ethnokultureller Texte. Insbesondere in Texten aus der Umgegend von Temuco spielt die ethnische Minderheit, zu der die Urbevölkerung der Region, die Mapuche48, gemacht wurde, eine nicht unerhebliche Rolle. Unter der Bezeichnung Poesía etnocultural werden Texte zusammengefasst, in denen sich Geschichte und Leben der Mapuche, aber auch das Zusammenleben von Chilenen und Mapuche widerspiegeln, sowie Texte, die von Mapuche geschrieben wurden. Letztere liegen meist zweisprachig vor und bedeuten einen wichtigen Schritt in der Verschriftlichung des Mapudungun und dessen Akzeptanz in der Bevölkerung. ${ }^{49}$ Ein weiteres kulturelles Merkmal der Region, das auch in der Dichtung seinen Ausdruck findet, ist die deutsche Besiedelung ab 1844, die bis heute Spuren in der Sprache, der Architektur, den Gebräuchen und in der sozialen Struktur der Region hinterlassen hat. ${ }^{50}$

Die Insel Chiloé (Region X) weist trotz ihrer Nähe zum Festland sehr eigenständige und autonome kulturelle Merkmale auf. Der Inselcharakter, die ständige Präsenz von Meer, Nebel und Booten sowie eine isolierte geschichtliche Entwicklung ${ }^{51}$ haben ein großes Repertoire an eigener Folklore und mythologischen Erzählungen sowie eine eigenwillige Fantasie- und Bilderwelt entstehen lassen.

\footnotetext{
${ }^{48}$ Mapu-che, dt.: die Leute der Erde. Ein Volk, das schon dem Eindringen der Inka Mitte des 15. Jahrhunderts unserer Zeitrechnung erfolgreich Widerstand leistete und schließlich auch von den Spaniern nicht endgültig bezwungen werden konnten. Stattdessen wurde 1641 eine Grenze in OstWest-Richtung durch das schmale Land gezogen, die, ähnlich dem Hadrianswall, das eroberte, "befriedete" Gebiet vom Territorium der Barbaren trennte. Zur Geschichte der Mapuche siehe Kapitel 6.1.

49 Mittlerweile werden im weiteren Sinne auch Texte als etnopoesía bezeichnet, die vom interethnischen Kontakt zwischen Chiloten und Spaniern oder zwischen Einwanderern und verschiedenen Indigenas handeln.

${ }^{50}$ Näheres siehe Kapitel 6.3.

${ }^{51}$ Darauf werde ich in Kapitel 5.1 näher eingehen.
} 
Das weitgehend menschenleere Feuerland (Region XII) ist insbesondere ethnokulturell interessant. Bis Ende des 19. Jahrhunderts lebten sowohl auf dem Festland als auch auf unzähligen der vorgelagerten Inseln vier Volksstämme, die mittlerweile faktisch ausgelöscht wurden. ${ }^{22}$ Einige Texte wollen dafür sorgen, dass weder diese verlorenen Kulturen noch die Tatsache ihrer Zerstörung in Vergessenheit geraten.

In diesem Überblick lasse ich jene Poesie unberücksichtigt, die auf regionale und zeitspezifische direkte Bezüge zu verzichten scheint, wie es viele ausgeprägt surrealistische Texte sind oder reine Liebeslyrik.

Zwei starke Kräfte in der südchilenischen Kultur und Dichtung sind deutlich geworden. Es handelt sich um einen geographisch und kulturell heterogenen Raum mit verschiedenen Tendenzen. Stärker als diese trennenden Faktoren ist allerdings der Zusammenhalt, den die Dichterinnen und Dichter aus dem Süden in ihrer Erd- und Heimatverbundenheit und in ihrem Kampf gegen den zentralistisch orientierten Großteil des Landes finden.

Uno de los elementos fundamentales de una zona de la poesía escrita en el sur de Chile es su persistente preocupación por las problemáticas históricas, sociales y antropológicas de este espacio geográfico y cultural. Pareciera que sus motivaciones nacen de la necesidad de releer, y refundar poéticamente dicho espacio, para, a su vez, reinterpretar el propio presente. De esta forma, estos textos que se relacionan fundamentalmente con el pasado, buscan provocar una lectura de gesto actual. [...] Es posible que sus antecedentes se encuentren en la lectura de los textos de Ernesto Cardenal y, parcialmente, de Pablo Neruda o Gabriela Mistral, pero sus razones profundas se vinculan a la construcción de una metáfora del presente. (Galindo 1992:224)

Sehr deutlich formuliert Galindo zum einen die Funktion der Dichtung, den eigenen Lebensraum und das Selbstverständnis mitzugestalten und mitzubegründen. Zum anderen betont er die Rolle, die das Bild der eigenen Vergangenheit bei der Identitätsbildung spielt. Der eigene Lebensraum und die Gegenwart werden poetisch neu erschaffen.

Inwieweit ein solches Ziel erreicht wird, ist nicht objektiv feststellbar, aber die Textanalysen sollen Aufschluss über die Mittel und Methoden geben, mit denen Dichterinnen und Dichter es verfolgt haben.

\subsection{Zur Vorgehensweise}

Aus der Darstellung der geographischen, literaturgeschichtlichen, politisch-gesellschaftlichen und regionalen Rahmenbedingungen ergeben sich einige konkrete Untersuchungskomplexe.

${ }^{52}$ Die Geschichte der Selk'nam, der Alacalufe, der Yámanas und der Quawashquar sowie deren 
Als eines der Ziele von einflussreichen Texten der Dichter Neruda und Cardenal habe ich den Entwurf einer counter-history aufgezeigt. Es muss geprüft werden, ob diese Art der Gegen-Geschichtsschreibung als Modell für die zu untersuchenden Texte gedient haben könnte oder ob zumindest die verfolgte Absicht unter diesen Begriff gefasst werden kann. Weiterhin werden die beschriebenen politischen Umstände in Chile miteinbezogen; es wird zu zeigen sein, wie sich im Kontext Südchiles verschiedene Arten des literarischen Umgangs mit der Erfahrung der Diktatur herausgebildet haben.

Die Textauswahl ist verhältnismäßig leicht gefallen. Alle sieben Dichter (acht mit Mario Contreras Vega, von dem das Eingangsgedicht stammt) haben sich bereits mit mehreren Veröffentlichungen innerhalb der 90er Jahre in der Literaturszene Chiles etabliert. ${ }^{53}$ Die konkrete Auswahl ergab sich aufgrund inhaltlicher Kriterien. ,Geschichte' sollte als ein zentrales Thema in mehr als nur vereinzelten Texten des jeweiligen Autors erkennbar sein. Bei fünf Autoren stieß ich auf ganze Gedichtzyklen, die sich mit historischen Szenarien befassen, was mir für eine Untersuchung besonders geeignet scheint (Juan Pablo Riveros, Rosabetty Muñoz, Clemente Riedemann, Elicura Chihuailaf, Tomás Harris, Kapitel 4-8). Auf zwei weitere wurde ich aufgrund ihrer theoretischen Reflexion über die Geschichte aufmerksam (Sergio Mansilla und Carlos Alberto Trujillo, Kapitel 9).

Darstellung ist Thema des vierten Kapitels.

53 Alle sind mit ihren Texten in der Anthologie Poetas actuales del sur de Chile vertreten. (Galindo 1992) 


\title{
4. Juan Pablo Riveros: De la tierra sin fuegos
}

\author{
Existen situaciones irreversibles, hechos definitivos, \\ imposibles de enmendar. Pero por irreparable que sea un \\ crimen, por terrible e inexorable que sea un destino, nada \\ más cruel que el silencio, la mordaza. \\ José María Borrero, La patagonia trágica
}

Juan Pablo Riveros ist 1945 in Punta Arenas geboren, in der südlichsten Stadt Chiles. Einen Teil seiner Kindheit verbrachte er auf der Insel Picton im Beagle-Kanal südlich von Feuerland, wo seine Eltern ähnlich wie die indigenen Völker der Region als nomadisierende Jäger lebten. Später ging er nach Concepción, wo er Wirtschaft studierte und promovierte. Daneben widmete er sich auf verschiedene Weise der Literatur: Er besaß einen Buchladen in Concepción, war unter anderem maßgeblich beteiligt an den LiteraturZeitschriften Cuadernos Sur, Lar de Poesía und Extremos und schrieb selbst Lyrik, bzw. Prosagedichte: Im Jahre 1980 veröffentlichte er Nimia, Poemas en prosa und in 1986 De la tierra sin fuegos.

\subsection{Die Feuer der E rinnenung}

De la tierra sin fuegos - vom Land ohne Feuer - ist ein Gesang an die ursprüngliche Bevölkerung Feuerlands; an drei Stämme, deren letzte Angehörige im Laufe des zwanzigsten Jahrhunderts gestorben sind; an Völker, die heute nicht mehr existieren.

Auf über 200 Seiten verbindet Juan Pablo Riveros Naturbetrachtungen, poetische Umsetzungen ethnologischer Beobachtungen, Zitate aus verschiedenen Quellen, ein Glossar mit kulturell wichtigen Begriffen und 18 fotografische Dokumente zu einer vielstimmigen Elegie an die ehemaligen Bewohner Südchiles. Dem eigentlichen Text vorangestellt findet sich eine Karte von Feuerland, das hier nicht nur als Name für die eigentliche Isla Grande de Tierra del Fuego verstanden wird, sondern für den gesamten Feuerland-Archipel, wozu zahlreiche kleine Inseln bis hin zum Kap Horn gerechnet werden, die der Isla Grande südlich vorgelagert sind.

Der Name ,Tierra del Fuego' geht auf den Seefahrer Magellan, bzw. seinen Logbuchschreiber Antonio de Pigafetta zurück. Auf der ersten Reise um die Erde brachen sie nach einem längeren Aufenthalt Ende August des Jahres 1520 von Puerto San Julián in Richtung Süden auf. Auf dieser Reise, auf der sie die den Atlantik und den Pazifik verbindende Meeresstraße entdeckten, die nach Magellan benannt werden sollte, fielen 
ihnen die unzähligen Lagerfeuer entlang den Küsten auf. Pigafetta vermerkte das im Logbuch und nannte das Land ,Feuerland‘. ${ }^{54}$

An ihren Lagerstätten entzünden die einzelnen Stammesgruppen der hier beheimateten Nomadenvölker große Feuer. Da die friedlichen Stämme nicht fürchteten, entdeckt zu werden, sah man nachts den Lichtschein und tagsüber den Rauch, mit dessen Hilfe sie über größere Entfernungen miteinander kommunizierten. ${ }^{55}$ Die namensspendenden Feuer waren also Anzeichen für Leben. Riveros greift den Namen auf und modifiziert ihn zu: Tierra sin Fuegos. Die Feuer und mit ihnen das Leben, für das sie gleichzeitig Symptom und Sinnbild waren, sind erloschen.

Obwohl sich der Titel auf das heutige (erloschene) Feuerland bezieht, beschwört Riveros mit seinem Text doch die ,Tierra con Fuegos“ herauf oder „Tierra del Fuego antes de su desaparición“, wie er selbst die vorangestellte Landkarte betitelt. Auf dieser Karte sind die Stammesgebiete der einzelnen Völker eingezeichnet, die einst Feuerland bewohnten: die Selk'nam, die Yámana und die Alacalufe. ${ }^{56}$

Riveros beschreibt das Leben der drei verschwundenen Volksgruppen, lässt ihre Götter und ihre Geister lebendig werden, beschreibt Bräuche und Rituale, schildert sowohl ihre Zeremonien als auch ihren Alltag und erzählt ihre Legenden. Durch empfindsame Landschaftsschilderungen, die den jeweiligen anthropologischen Betrachtungen vorangestellt sind, wird der Eindruck von enger Verbundenheit der Menschen mit ihrer Umgebung hervorgerufen. ${ }^{57}$

${ }^{54}$ „Im Süden der Meerenge erblickte Magallan nachts viele Feuer und nannte deshalb das Land Tierra de los fuegos = Feuerland.“ (Zitiert nach Koelliker 1908:115)

55 „Das Feuer wird von diesen Wilden immer lebendig erhalten, wo immer sie sein und gehen mögen, in ihren Wigwams, in ihren Hütten oder sogar in ihren Händen, in denen sie ein brennendes Stück Holz tragen.“ (Fitz-Roy 1839:187, zitiert nach Gusinde 1974:21)

${ }^{56}$ Riveros zeichnet auf seiner Karte das Gebiet eines weiteren Stammes ein, der Haush. Diese werden in der Literatur meist als eine Untergruppe der Selk'nam behandelt, die den Osten Feuerlands bewohnten. Auch in Riveros' Text finden sie nur im Glossar beiläufige Erwähnung. Nach anderer Meinung bilden sie eine eigene Volksgruppe, da sich zB ihre Sprache deutlich von der der Selk'nam unterscheidet (vgl. Los indios Haush 1999). Zur Notierung der Namen: Die Selk'nam werden auch Ona genannt, die Yámana Yahgana und die Alacalufe Qawashqar. Da Riveros in seinen Texten unterschiedslos jeweils beide Bezeichnungen verwendet, werde ich mich ebensowenig auf eine einzige festlegen, sondern mich in einzelnen Passagen der jeweiligen Wahl Riveros' anschließen.

${ }^{57}$ „Wegen seines rauhen, feuchten, stürmischen Wetters war es [Feuerland] verrufen, jeder mied und fürchtete es. Durch diese Vorurteile konnte sich kaum einer der flüchtigen Beobachter, die jene Inselwelt bereisten, zum Verständnis für eine überraschend vollkommene und allseitige Anpassung des Indianers an seine trostlose Heimat hinaufringen. Und doch ist dort das Verhältnis zwischen Natur und Mensch so innig, daß daraus sich tatsächlich für ihn ein angenehmes Dasein gestaltet hat.“ (Gusinde 1931:63) 
De la tierra sin fuegos ist auch eine Hommage an den Ethnologen Martin Gusinde. Dem Text sind eine Widmung an Gusinde (sowie an den Ethnologen und Archäologen Joseph Emperaire) und einige Worte Gusindes vorangestellt. Das letzte Gedicht ist mit Despedida de Gusinde betitelt. Neben diesen offenkundigen und formal exponierten Bezügen, stellt Riveros' mehr als 200 Seiten umfassende Versdichtung mit ihren Inhalten, Motiven, Zitaten und Bildern eine Huldigung an das Lebenswerk des Völkerkundlers dar.

Nach eigenen Angaben beschäftigte sich der Österreicher Gusinde (1886-1969) schon in seiner Jugend mit Feuerland und seinen Bewohnern ${ }^{58}$. Er lehrte an der Universität von La Plata in Argentinien und an der Universidad de Chile. Von 1918 bis 1924 machte er vier Forschungsreisen auf die Isla Grande und einige der vorgelagerten Inseln, um die noch lebenden Stammesangehörigen zu besuchen und studieren.

Vielmehr sah ich meine Aufgabe darin, nun noch in letzter Stunde, kurz vor dem Untergange jener Indianer, die Grenzen ihres Heimatgebietes und die Eigenart ihres Kulturbesitzes richtig festzustellen, die Lücken der vorliegenden Berichte auszufüllen und die kurzen Andeutungen früherer Forscher zu ergänzen oder durch neue Eigenbeobachtungen zu vertiefen. (Gusinde 1931:67)

Auf jeder seiner Reisen verlebte er Wochen oder Monate in Stammesverbänden der Feuerländer, lernte ihre Sprachen und durfte an rituellen Zeremonien teilnehmen. Das eindrucksvolle Ergebnis der Erfahrungen und Erkenntnisse dieser Reisen ist eine umfangreiche Darstellung der Selk'nam, der Yámana und der Alacalufe. In drei jeweils über tausendseitigen Bänden dokumentiert Gusinde detailliert die Geschichte, die Kultur, die Lebensgewohnheiten, die soziologische Struktur, die Religion und Weltanschauung der einzelnen Stämme.

De la tierra sin fuegos ist auch die Anklage von Verbrechen gegen die Menschlichkeit, genauer gesagt, zweier systematischer Massenvernichtungen von Menschenleben von Seiten der chilenischen Regierung. Neben dem offensichtlichen und für das zentrale Thema der Feuerländer unverzichtbaren Gegenstand der gezielten (sowie ungezielten) Ausrottung der Urbevölkerung durch die Weißen finden sich an verschiedenen Stellen Darstellungen von Folter, Deportation und Leben im Gefangenenlager während der Militärdiktatur. Die institutionalisierte Gewalt beider geschichtlicher Momente wird im Text parallelisiert.

58 „Mucho antes que este vapor entrara en el puerto de Río Grande, me habían llevado ya allí mis pensamientos y preocupaciones, mis esperanzas y el indescriptible entusiasmo de poder pisar luego la tierra (Tierra de Fuego), que vislumbrara ya en los espejismos de los ensueños de mi juventud y 
Schließlich ist De la tierra sin fuegos ein autobiographisches Zeugnis. Riveros ist auf verschiedenen Inseln des Feuerland-Archipels aufgewachsen. Eine besondere Rolle spielte dabei die Insel Picton, wo er seine früheste Kindheit verbrachte und wohin die Familie zurückkehrte, als Riveros sechs Jahre alt war: „Caminaba - cuando tenía seis años y la familia volvió a vivir en Picton- por la arena y encontraba arpones, puntas de flechas que su padre coleccionaba.“ (Maack 1987:53) Die Bücher von Gusinde (die spanische Übersetzung erschien 1982) wecken in Riveros Erinnerungen an diese Zeit: „Es Gusinde quien habla en De la tierra sin fuegos, pero soy yo también, porque a través de su relato reconozco paisajes de mi infancia.“ (Maack 1987:53) Im Spiegel von Gusindes ethnologischem Werk erkennt Riveros die Wurzeln seiner eigenen Sozialisierung, seiner eigenen Geschichte:

[...] comprendí, cuando él [Gusinde] describía la vida de los yámanas, que nosotros - mis padres y hermanos - habíamos vivido como ellos, que fuimos una familia que se trasladaba y recorría esos mares como un yámana, que nunca tiene casa, en definitiva. (Maack 1987:54)

In mehrfacher Hinsicht stellt Riveros sein Werk in den Dienst der Erinnerung. In erster Linie will er (mit Gusinde) verhindern, dass Kulturen in Vergessenheit geraten, die unwiederbringlich verschwunden sind. Zweitens ist das Thema des Textes mit seiner persönlichen Vergangenheit verbunden. Drittens will er dem Anthropologen Gusinde ein Denkmal setzen. Und viertens schließlich soll an die Verbrechen der Diktatur und an ihre Opfer erinnert werden.

Riveros selbst nennt den Gedichtzyklus ein canto épico. (Maack 1987:56) Bei den einzelnen Texten handelt es sich um Gedichte in reimlosen freien Versen. Die verwendete Sprache ist vorwiegend traditionell-lyrisch: Es finden sich Ellipsen, Metaphern, formelhafte Wiederholungen von Wörtern oder Syntagmen sowie Alliterationen. Eine andere Wirkung haben die Stellen, an denen Zitate oder detaillierte Beobachtungen und Beschreibungen von ethnologischer Bedeutung eingeflochten sind. Dort entsteht der Eindruck, als handele es sich um einen Prosatext mit wissenschaftlich-dokumentarischem Anspruch.

Die Texte, die inhaltlich eng miteinander verbunden sind, sind in sechs Kapitel unterteilt. In ihrer Abfolge beschreiben sie eine Reise, auf die Leserinnen und Leser den Erzähler begleiten. Nachdem die bereits erwähnte Karte uns geographisch situiert hat, berichtet der Erzähler in einem kurzen, ebenfalls den Gedichten vorangestellten Prosa-Text, wie er in eine andere Welt entführt wurde, in die Welt Feuerlands. Dieser Text ist die Schwelle, die beim Lesen überschritten werden muss, will man dem Erzähler nach Feuerland folgen. 
Zunächst schildern die acht Gedichte des Kapitels Naturaleza die natürliche Beschaffenheit des Feuerland-Archipels, die Landschaft, Tier- und Pflanzenwelt. Es folgt ein kurzes Kapitel, bestehend aus einem einzigen Text, das mit Precauciones, ,Vorsichtsmaßnahmen“ überschrieben ist und eine weitere Schwelle bildet. Nach dem Eintritt in die Geographie Feuerlands betreten wir nun den kulturellen Kosmos der Feuerländer. Mit dem Überschreiten dieser zweiten Schwelle gelangt der Erzähler langsam vom Äußeren der Landschaft und der ihn umgebenden Natur zum Innerem des Lebens der Menschen. Es folgen drei Abschnitte, die nach den Volksstämmen Selk'nam, Yámana und Quawashquar benannt sind. Sie zählen 35, 27 und 36 Gedichte und bilden die Herzstücke des Buches. In diesen Texten durchreist das Ich die Lebens- und Vorstellungswelten der drei Stämme und schlüpft in verschiedene Personen, die sich durch seine Stimme zu Wort melden. Den Schluss, mit dem der Erzähler die durchreiste Welt verlässt, bildet wiederum ein Kapitel mit nur einem einzigen Text: Despedida - der Gedichttitel präzisiert Despedida de Martin Gusinde.

Es folgen Documentos: 18 Fotos aus den 20er Jahren. Bis auf ein Bild handelt es sich ausschließlich um Portraits der letzten Überlebenden aller drei Stämme, die Gusinde auf seinen Reisen aufgenommen hat. Schließlich listet ein Glossar einzelne Begriffe mit ihren Bedeutungen auf. Es finden sich geographische Bezeichnungen, Namen der in Feuerland heimischen Tiere und Pflanzen und Begriffe der verschiedenen Sprachen, die Riveros in seinen Texten unübersetzt verwendet.

In seinem Artikel über den Gedichtzyklus bemerkt Mauricio Ostria González:

En Chile, el rescate de la verdadera historia ha sido tarea principal - si no exclusiva - de poetas y narradores (casos paradigmáticos son los de Neruda y Droguett, pero podrían citarse muchos ejemplos), de modo que la intrahistoria chilena hay que leerla, muchas veces, en su literatura.

De la tierra sin fuegos (1986), de Juan Pablo Riveros se inscribe en esa tradición y constituye, sin duda, la apertura de un espacio hasta ahora casi desconocido en la geografía poética chilena. (Ostria González 1992:171)

Inwieweit bei Riveros ein „rescate de la verdadera historia“ vorliegt, vorliegen kann oder soll, wird meine Leitfrage für dieses Kapitel sein.

\subsection{Der Kunstgriff des Cautiverio feliz: E in Augenzeugenbericht}

Dem eigentlichen Gedichtzyklus ist ein kurzer einleitender Prosatext ohne Titel vorangestellt. Er führt in die Atmosphäre des Buches ein und bedeutet gleichzeitig die erste Schwelle, die der Erzähler auf seiner Reise in die Welt Feuerlands überschreiten muss. Die Positionierung des dreiseitigen Vorwortes innerhalb des Gesamttextes und seine Funktion 
erinnern an den Prolog im Drama. Es besitzt eine eigenständige Handlung, expositorischen Charakter und eine Vorausdeutung auf das Ende: „Ésta es la razón más profunda que he logrado hallar de por qué ha desaparecido ya“ (S11).

Der Erzähler ist hier personaler Ich-Erzähler und Protagonist, durch dessen Bewusstsein wir die andere Welt erleben. Er beschreibt den Eintritt in die Welt der Feuerländer als eine Entführung. Zwar wird weder körperliche Gewalt angewendet, noch setzt sich der Erzähler zur Wehr, doch sagt er „fui detenido“ und spricht von „mis captores“. So gelangt er durch fremde Kräfte in einen anderen Erlebnisraum. Ob es sich lediglich um einen veränderten Kulturraum oder eventuell auch um einen anderen Zeitraum handelt, in den hinein er entführt wird, wird nicht vollständig aufgeklärt. Möglicherweise stellt die gesamte Episode die Erinnerung an eine zurückliegende Begebenheit dar. Ob Traum, Reise, Erinnerung - in jedem Fall beansprucht die Ich-Perspektive die Autorität eines Augenzeugen, was nicht nur die Spannung, sondern auch die Glaubwürdigkeit für den Leser und die Leserin erhöht. Das Ich ist Mittelpunkt unserer Aufmerksamkeit, es sind seine Gefühle und Wahrnehmungen, durch die wir einen ersten Eindruck von der beschriebenen Umgebung bekommen, der eigentlich sein erster Eindruck ist.

In der Erzählhaltung finden sich zwei einander widerstrebende Ansätze. Bereits nach wenigen Zeilen versucht das Ich, sich vom Geschehen zu distanzieren. Die ersten zwei Sätze der Entführung wirken unmittelbarer, während die folgenden Beschreibungen aus einer objektivierenden Distanz zu kommen scheinen. Er schildert das Dorf der Indígenas sehr nüchtern, fast unbeteiligt: „Penetramos a un pueblo pequeño, sin ninguna importancia si lo comparamos con las ciudades del mundo“. Für den gesamten Rest des Textes bleibt der Erzähler ein fast unbeteiligter Beobachter. Wir erfahren nichts weiter über seine Empfindungen, über sein Erleben, dafür umso mehr über die Bräuche und Gewohnheiten seiner Entführer. Der Erzähler berichtet mit der Distanz eines Wissenschaftlers. Es fließen in diesen Text über den ersten Kontakt mit einer fremden Kultur durchaus schon Dinge mit ein, die das Ich erst nach längerer Zeit seines Aufenthaltes erfahren oder erkannt haben mag, jedoch werden sie hier im Zusammenhang mit einem allerersten Eindruck geschildert. Der Erzähler steht dem, was er sieht, mit dem Staunen der ersten Begegnung gegenüber; gleichzeitig wird alles gefiltert durch das rationale Bemühen, Vergleiche mit der eigenen Kultur anzustellen.

Stellenweise scheint es, als habe Riveros versucht, sich in den Ethnologen Gusinde hineinzuversetzen, indem er die Situation einer Person darstellt, die sich zwar in dieser fremden 
Welt zurechtfinden muss, sich ihr aber schon mit wissenschaftlichem Erkenntnisinteresse nähert: „Sus rituales, sagrados, sólo en apariencia no existían: toda acción realizada u omitida en lo más recóndito de sus pensamientos se regía por cánones permanentes“.

Während sich aber Gusindes Aufzeichnungen als detaillierte ethnologische Berichte lesen, enthält Riveros’ Text - und hierin besteht die gegenläufige Erzählhaltung - hauptsächlich aus sehr subjektiv-unscharfen Wahrnehmungen. Es überwiegen verwischte, undeutliche Eindrücke:

Mis captores, de fisonomías extremadamente imprecisas y cuyas voces no recuerdo nada, [...] por su lengua desconocida [...] Un pueblo que, más acá de míticos canales o imposibles nieves, [...] Un sabor a tiranía anónima, dirigida desde el misterio y sobre la que no se tenía nada el menor derecho de consultar, envolvía la atmósfera de la aldea, como una red casi invisible [...] Algunos dicen, sin que yo jamás distingua sus voces [...]. (S9f.)

Der Eindruck, der sich einstellt, ist sehr verschwommen. Der Erzähler scheint weder optisch noch akustisch klare Wahrnehmungen artikulieren zu können. Die fehlende Eindeutigkeit charakterisiert nicht nur die Sinneseindrücke des Erzählers, sondern auch die Aussagen des Textes. Es finden sich geographische Angaben wie zu Beginn die vage Auskunft „Un poco más allá de los Cantiles del Sur“. Hinzukommen unbestimmte bis geheimnisvolle Aussagen wie „Un pueblo [...] acá de míticos canales o imposibles nieves“ oder „Un sabor a tiranía anónima, dirigida desde el misterio“.

Es findet sich ein Hinweis auf das Volk der Entführer, der zunächst eindeutig erscheint. Die direkte Rede „Were, winne wint" wird in einer Fußnote als Sprache der Selk'nam identifiziert. Allerdings überwiegen Beschreibungen, die den Ausführungen Gusindes über die Selk'nam widersprechen. So erfährt man: „estaba estrictamente prohibido recordar“ oder „Por ningún motivo permitíanse especulaciones sobre el futuro“, während Gusinde den Selk'nam sowohl ein sehr ausgeprägtes Erinnerungsvermögen als auch zumindest die grammatische Möglichkeit der Rede über die Zukunft zuschreibt. ${ }^{59}$

Trotz der Identifizierung des Satzes als Selk'nam-Sprache kann eine eindeutige Zuweisung zu einer realen Ethnie hier also nicht beabsichtigt sein. Stattdessen scheinen Aussagen wie das Verbot der Erinnerung und des Nachdenkens über die Zukunft vielmehr die subjektive Situation des Erzählers als die tatsächlichen Bräuche der Gastgeber zu charakterisieren. Um

\footnotetext{
59 „Eine natürliche Veranlagung und eine dauernde Übung, zu der diese Indianer, in Ermangelung von Schrift und Merkzeichen, gezwungen sind, lassen ihr G e d ä c h t n i s denkbar zuverlässig werden [Hervorhebung von Gusinde]. Dinge, die ihnen von Bedeutung erscheinen, alles, was sie erfeut oder betrübt, vor allem die Beleidigungen eines Feindes vergessen sie nie; auch die näheren Umstände eines Ereignisses, der Wortlaut einer Beschimpfung, der Entwicklungsgang eines Kampfes und die dabei Beteiligten schwinden nicht aus ihrer Erinnerung." (Gusinde 1931:1089) „Den Selk'nam fehlen die Begriffe für Vergangenheit, Gegenwart und Zukunft nicht; diese drücken sie durch Verbinden besonderer Adverbien mit einem Verbum aus." (Gusinde 1931:1107f.)
} 
in diese fremde Welt eintauchen zu können, muss er sich völlig darauf einlassen. Das fällt dem Erzähler jedoch schwer, seine Beschreibungen fallen vielmehr stark ethnozentrisch und voll kultureller Vorurteile aus. Besonders auffällig sind Vergleiche, die er mit der eigenen Kultur anstellt: „si lo comparamos con las ciudades del mundo“ klingt, als befände er sich gerade nicht in dieser Welt; „como un convento primitivo“; die Einordnung der Gemeinschaft als „extranjera“ aufgrund ihrer Sprache sowie aufgrund ihres Schweigens. Die Sprache nennt er „desconocida“, was ungefähr so ethnozentrisch und perspektivisch ist wie von der ,Entdeckung Amerikas ${ }^{6}$ zu sprechen. ${ }^{60} \mathrm{Ihr}$ Verhalten bezeichnet er als „peculiar“. Ihre heiligen Rituale „sólo en apariencia no existían“, was die Frage nach der Wahrnehmungsfähigkeit des Beobachters aufwirft, ebenso wie die Beurteilung „un tanto desagradable visto desde estas latitudes“, deren parteiische Perspektive wenigstens zugegeben wird.

Des Weiteren äußert sich der Perspektivismus des Erzählers im Aufzählen von Dingen, die der fremden Kultur seiner Meinung nach fehlen. Er vermisst jemanden, der das Volk regiert, Erinnerungen und Überlegungen die Zukunft betreffend, festgesetzte Zeiten für religiöse Handlungen sowie Schmuck in ihren heiligen Zeremonien. Er scheint nichts vorzufinden, das ihm neu wäre, da es keine Entsprechung in seiner eigenen Kultur fände, sondern ausschließlich Dinge, die umgekehrt bei den Fremden ,fehlen‘.

Ebenso zeugt die Äußerung „Además, por esas ya clásicas absurdidades, este pueblo también se ignoraba y negaba de las más diversas maneras“ davon, dass der Erzähler denen, von denen er redet, gewisse Kompetenzen abspricht. Ihre Weltvorstellung wird als defizitär dargestellt, wenn etwa von ihrem Zeitbegriff als Absurdität gesprochen wird. Die Behauptung, dass sie sich selbst nicht kennen und verleugnen, bedeutet, dass der Sprecher den Fremden eine bewusste Identität abspricht.

Die Ausführungen des Ich erinnern an den eurozentrischen Blick der Entdecker des 16. Jahrhunderts. Ohne die Sprache der fremden Völker zu verstehen, werden vermeintliche Übersetzungen von Aussagen wiedergegeben und interpretiert. Ebenso wie ihre Bräuche scheinbar (nämlich vor dem Hintergrund europäischen Wissens) verstanden, dabei aber völlig missinterpretiert werden. ${ }^{61}$

\footnotetext{
${ }^{60}$ Damit fällt er hinter die Einstellung zurück, die T. Todorov dem Franciscaner Bernhardino de Sahagún bereits Mitte des 16. Jahrhunderts zusprach: ,aucun jugement de valeur, mais aucune interprétation non plus; nous avons affaire à une pure description. [...] Dans la mesure même, pourrait-on dire, où son travail ou celui des autres savants moines ses contemporains, contenait des germes de l'attitude ethnologique, il était irrecevable par son époque.“ (Todorov 1982:235,245)
} 
In diesem ersten Eindruck, den der prologartige Text vermittelt, findet sich bereits ein komplexes Wechselspiel von subjektiver Bewegtheit, dem Versuch einer wissenschaftlichen Herangehensweise und Vorurteilen. Die Gefangennahme durch die Feuerländer kann verstanden werden als Metapher für die Faszination, für das ,Gefesselt-Sein` von dieser fremden Kultur, wie das Ich sie erfährt. Dass der Erzähler aber keine Angst zeigt, nicht zu fliehen versucht und seine Entführer neugierig und verwundert beobachtet, zeugt vom Bestreben, das Erlebte rational und objektiv zu erfassen. Diese objektive Herangehensweise gelingt wiederum nur zum Teil, wie die ethnozentrischen und unreflektierten Bemerkungen belegen.

Mit dem Ich treten uns drei Stimmen entgegen: die des Individuums, das auf das Geschehen emotional reagiert, die des Wissenschaftlers, der den rationalen, objektiven Ansatz vertritt, und die des Menschen, der aus seiner eigenen Kultur heraus wahrnimmt und reagiert. Da wir die beschriebene Welt durch seine Augen wahrnehmen, vermittelt er uns diese drei Aspekte seiner Begegnung. Es handelt sich dabei nicht um eine auktoriale Stimme, die ruhig und allwissend die Ereignisse wiedergibt, sondern um einen personalen Erzähler, der in das Geschehen verstrickt ist und der in etwas aufgeregtem Ton einzelne Beobachtungen aneinanderreiht. Durch die personale Erzählhaltung sollen sich Leser und Leserin miteinbezogen fühlen. Die Situation, mit der sie konfrontiert werden, ist für den Erzähler genauso neu und erstaunlich wie für sie, er hat ihnen nichts voraus. Das macht ihn zum Medium, zum Augenzeugen, zum Vermittler des Beschriebenen; er sagt nicht nur, was ist, sondern er übermittelt, was er erlebt. ${ }^{62}$

Innerhalb der chilenischen Literaturgeschichte muss das Motiv des von Indígenas Gefangenen ein über 300 Jahre früher geschriebenes Werk ins Gedächtnis rufen: El Cautiverio Feliz von Francisco Núñez de Pineda y Bascuñán. Dieser autobiographische Text beschreibt die Gefangenschaft des Erzählers bei den Mapuche - ebenfalls ein indigener Volksstamm in Südchile. Das 1672 beendete Werk wurde erst 1863 in der Reihe Colección de historiadores de Chile y Documentos relativos a la historia nacional mit Diego Barros Arana als Herausgeber veröffentlicht. In verschiedener Hinsicht ist El Cautiverio feliz ein erstaunliches Buch seiner Zeit, und da Riveros’ Kenntnis des Werkes vorausgesetzt werden kann, werde ich an dieser Stelle auf einige literarhistorische und historiographische Implikationen des

\footnotetext{
${ }^{61}$ Vgl. zur Problematik der Verständigung Todorov 1982: 69ff. oder Greenblatt 1988:86ff.

${ }^{62}$ Luis Muñoz G. spricht von zwei Perspektiven: ,„[..] vemos de nuevo la fusión de perspectivas: la del sujeto enunciante y otra que se manifiesta a través del enunciado.“ (Muñoz G. 1987:129)
} 
Textes eingehen, die Literaturwissenschaftler und Historiker aus mehreren Epochen beschäftigt haben. „Cautiverio feliz has long presented an enigma to historians of colonial Spanish American literature.“ (Bauer 1998:59)

Zunächst waren Pinedas Zeitgenossen überrascht von der Haltung, die der Erzähler seinen Entführern entgegenbringt. Das Oxymoron des Titels, in dem der Autor seine Gefangenschaft als „feliz“, also eine glückliche bezeichnet, ist ein typisch barockes Stilmittel, das geeignet ist, den Gemütszustand der inneren Zerrissenheit auszudrücken. Der Titel soll darauf hinweisen, dass Pineda seine Gefangenschaft, wennschon zunächst unfreiwillig, doch schon bald als eine durchaus gute Erfahrung versteht, „die durch warmherzige Gastfreundschaft und den Schutz des Häuptlings Maulicán gekennzeichnet war““. (Rössner 1995:92)

Ein freundschaftlicher Umgang mit der Urbevölkerung - noch dazu, wenn man von ihr gefangen gehalten wurde - war mehr als ungewöhnlich. Auch die Form des Textes gab Anlass zu Diskussionen:

[...] historians and literary critics have often been exasperated by the aesthetic unorthodoxies of Pineda's narrative, whose digressions from the narrative of his captivity into history, philosophy and religion account for about 80 percent of his 600-page work. (Bauer 1998:60)

Schließlich führt Bauer zwei spezifisch historiographische Aspekte an, unter denen Cautiverio feliz, Aufmerksamkeit erregte:

On the one hand, the captivity narrative's ethnographic appeal to the authority of the eyewitness authorizes in this context a colonial creole voice which aims to decenter the poetics of an imperial historiographic tradition in its Eurocentric geo-cultural imagination and division of labor. [...] On the other hand, the captivity narrative of an American creole's purifying pilgrimage of removal to and return from the „Other" world of America re-inscribes the transatlantic journey from a colonial point of view. (Bauer 1998:60f.)

Demnach untergräbt Pineda mit seiner Personalunion von Augenzeuge und Historiograph die traditionelle Arbeitsteilung der Geschichtsschreibung der Alten Welt. Darüber hinaus formuliert sein Text eine neue, kreolische Vorstellung von dem, was ,Neue Welt bedeutet, von dem, was ,das Andere“ ist und von dessen Entdeckung, die erst noch zu leisten sein wird - diesmal nicht aus der Sicht derjenigen, die kommen, um zu erobern, sondern derjenigen, die bleiben, um zu leben.

Mit dieser neuen Perspektive richtet sich Pineda gegen die imperiale Geschichtsschreibung spanischer Historiographen; in dem Zusammenhang spricht Bauer von El cautiverio feliz als von einer counter-history. ${ }^{63}$ (Bauer 1998:66)

${ }^{63}$ Zum Begriff der counter-history vgl. Kapitel 3.2. 
Roberto Castillo Sandoval sieht in dem Text einen doppelten Affront gegen die bestehende Ordnung. Dem Hieb Pinedas gegen die offizielle Geschichtsschreibung seiner Zeit, mit dem er auch politisch Stellung bezog, stellt er die historiographische Bedeutung an die Seite, die die Erstveröffentlichung im Jahre 1863 durch Barros Arana hatte:

[...] la publicación de un libro como el Cautiverio feliz comienza a verse como un sutil y complejo acto de activismo historiográfico [...] el ardiente desafío personal de Pineda y Bascuñán a los historiadores de su época [...] un recuento histórico que no sólo se limita a reflejar, sino que no teme cuestionar a los historiadores que lo preceden, enjuiciar sistemáticamente sus conclusiones y emitir un veredicto político con claras implicaciones prácticas. (Castillo Sandoval 1996:140f.)

Um mit einem historiographischen oder literarischen Werk eine derartige sozio-politische Signalwirkung zu erzielen, bedarf es einer gesellschaftlichen Situation, die sich entsprechend instabil darstellt, sich im Umbruch oder zumindest in Bewegung befindet. In Pinedas Fall befand sich die Kolonialherrschaft in einer Krise, ausgelöst durch die Rebelión de 1655. Die unterdrückte indigene Bevölkerung im Süden Chiles hatte in einem für beide Seiten verlustreichen Kampf gegen die Besetzer ihres Landes aufbegehrt. Gleichzeitig hatte sich die breite kreolische Masse gegen die von Spanien eingesetzte imperiale Ordnung erhoben. Das Ergebnis war eine klare Spaltung der Gesellschaft in zwei Lager unterschiedlicher sozialer Herkunft und sich bekämpfender politischer Ziele. Der kreolische Teil der Bevölkerung hatte begonnen, ein eigenes politisches Bewusstsein zu entwickeln, und dieses (Selbst-)Bewusstsein ist es, das durch Pinedas Werk unterstützt wird. Seine Sicht desjenigen, der die Neue Welt nicht erobern und ausbeuten will, sondern in und mit ihr lebt, stellt den imperialen Blick der spanischen Geschichtsschreiber von außen auf Amerika in Frage.

Der Herausgeber Barros Arana schaltet sich indessen ca. 180 Jahre später mit der Veröffentlichung des Werkes in eine historiographische Diskussion seiner Zeit ein: „el doble influjo de estas corrientes historiográficas que venían en pugna desde mediados del siglo XIX: [...] un afán documental conservador [...] y un activismo de prurito filosófico." (Castillo Sandoval 1996:132; Hervorhebung von Castillo Sandoval) Im Folgenden bezieht er Stellung:

Esas relaciones no tienen valor ni mérito alguno sino en la parte en que el autor refiere lo que ha visto, los sucesos en que ha sido testigo o actor. Fuera de allí, la generalidad de las crónicas no sirve para nada. (Castillo Sandoval 1996:133)

Im Jahre 1850 schreibt Barros Arana begeistert über Cautiverio feliæ:

Todo cuanto en ella vemos está lleno de animacion i colorido. Las descripciones de costumbres, las conquistas que hacia el cautivo para la fé de Cristo, no hai rasgo en fin que no nos interese. Las digresiones históricas, sus recuerdos i citas que podian hacer pesada e indigesta su obra, no hacen mas que aumentar su importancia. Difícilmente se pudo haber encargado a una mano mas hábil la ejecución de un cuadro tan completo i de tan variado colorido. (Zitiert nach Castillo Sandoval 1996:135) 
Wenn Riveros mit dem Motiv der Gefangenschaft intertextuelle Bezüge zu Pinedas Werk herstellt, aktualisiert er also gleichzeitig den Kontext von (Real-)Geschichte und Literaturgeschichte. Riveros' Gedichtzyklus will sicher nicht den Cautiverio imitieren oder in seine Fußstapfen treten. Allerdings ruft sein Motiv des gefangenen Berichterstatters unweigerlich bei der chilenischen Leserschaft das berühmte Vorbild wach - und mit ihm die Streitbarkeit eines wirkungsmächtigen Werkes. Riveros solidarisiert sich mit dem Schicksal der Ureinwohner Feuerlands, wie Pineda dies mit den Mapuche tat, und bezieht somit deutlich Position. Inwieweit Riveros' Gedichtzyklus als eine Gegenversion zur offiziellen Geschichte der Feuerländer und ihrer Vernichtung verstanden werden kann, wird noch zu untersuchen sein; auf jeden Fall sollte es schwerfallen, mit der wachgerufenen Präsenz Pinedas' eine unkritische Sicht auf die Geschichte abzufassen.

Zwar könnte sich Riveros auch einfach nur des Kunstgriffs des Augenzeugen bedient haben, um seinen Worten - wie schon Pineda dies tat - mehr Gewicht zu verleihen. ${ }^{64}$ Jedoch muss ihm bewusst gewesen sein, dass er durch die offenkundige Anspielung ein (literar-)historisches Szenario aufruft, das beim Lesen in ein bestimmtes Verhältnis zu den von ihm selbst berichteten Geschehnissen gebracht werden muss. ${ }^{65}$

Am Beispiel dieses Details von De la tierra sin fuegos wird deutlich, wie Literatur, Geschichtsschreibung und Literaturgeschichte miteinander verschmelzen.

In den besprochenen Textabschnitten ist die subjektive Perspektive des Erzählers das wichtigste Instrument, um Leserinnen und Leser an das eigentliche Thema heranzuführen. Mit den dramatischen Elementen der Entführung und dem Monolog des Entführten verstrickt Riveros sein Publikum in die Ausgangssituation dessen, der dabei ist, sich einem ihm fremden Volk zu nähern. Was Riveros mit der Art seiner Erzählung erreicht, ist genau das, was Geertz von einem Ethnologen erwartet. Er kann überzeugen, dass er dort gewesen ist, bzw. da es sich hier um eine Reise durch die Zeit handelt, dass er damals dort gewesen ist. Nun handelt es sich in der Tat um einen stark an den ethnographischen Details interessierten Text, trotzdem wird deutlich, dass es sich um eine Eigenschaft ethnographischer Beschreibungen handelt, die durchaus auf historiographische Darstellungen übertragbar ist.

\footnotetext{
64, ,...] Pineda was hardly in a position of authority to speak on matters of history and politics. His identity as a captive, however, lent his voice an authority which could bear considerable weight in his culture“. (Bauer 1998:65)

${ }^{65}$ Natürlich können Riveros' Gedichte auch ohne dieses literarische und historische Wissen gelesen werden, aber bei dem größten Teil der Leserschaft eines Gedichtzyklus' wie dem vorliegenden kann das Wissen vorausgesetzt werden, das notwendig ist, um die skizzierten Verbindungen herzustellen.
} 


\subsection{Der Erzähler als zeitreisender E thnologe}

Der Erzähler unternimmt eine Reise. Er nennt uns Anlass und Vorbereitungen, er muss seine gewohnte Umgebung hinter sich lassen und Schwellen überschreiten. Über den gesamten Text verteilt finden sich typische Momente einer Reise: das Entdecken des Unbekannten, das Staunen darüber, das Kennenlernen und Vertrautwerden damit bis hin zum Verstehen; aber auch der Versuch einer Objektivierung des Erlebten, das Sich-Lösen und der Abschied.

Von Form und Funktion des Prologs war bereits die Rede. Die geschilderte Entführung ist die zunächst unbeabsichtigte, sogar unfreiwillige, aber nicht unwillige Überschreitung der ersten Schwelle, der erste Schritt und sozusagen der Anlass der Reise.

Was ist das für eine Reise? Clifford Geertz würde sie als ethnologische Reise charakterisieren: zu ,anderen Menschen - mit anderen Schafen in anderen Tälern“. ${ }^{66}$ (Geertz 51997:43) Besonders die Beschreibungen der Lebensgewohnheiten fremder Menschen und die ständige Präsenz des Ethnologen Gusinde legen die Interpretation der Reise als eine ethnologische nahe. Aber es ist auch eine Reise in die Vergangenheit. Die Menschen, von denen Riveros berichtet, könnte er zum Zeitpunkt des Schreibens längst nicht mehr antreffen, bzw. die wenigen Stammes-Angehörigen, die eventuell noch leben, sind schon lange nicht mehr in der Lage, ein traditionelles Stammesleben aufrechtzuerhalten, wie der Erzähler es beschreibt. Da im gesamten Gedichtzyklus die Präsenz des Erzählers spürbar bleibt (zB in den subjektiven Landschaftsbeschreibungen oder in der Stimme Gusindes, dessen Rede in der ersten Person übernommen wird, S51), kann der Text in seiner Gesamtheit als Reise verstanden werden, als eine Reise in die Zeit Gusindes und noch viel weiter zurück in die Vergangenheit, wie die Jahreszahlen vor einigen Texten und die Anmerkungen zeigen. ${ }^{67}$

Darüber hinaus ist es eine Pilgerreise, wie das Motto von Thomas Merton ankündigt: „,...es una peregrinación, no es un viaje sentimental a un pasado romántico, sino un esfuerzo humilde, difícil y necesariamente incompleto $[\ldots . .]^{“(S 27) .68}$

\footnotetext{
${ }^{66}$ Bei Geertz ist das eine Chiffre für die Fremdartigkeit einer anderen Kultur, und die Aufgabe der Ethnologie ist es, sich mit den Antworten vertraut zu machen, die diese anderen Menschen gefunden haben.

${ }^{67}$ Das am weitesten zurückreichende Textdokument datiert aus dem Jahr 1557 (S148).

${ }^{68} \mathrm{Zu}$ Merton vgl. Kapitel 3.2, Fußnote 13.
} 
Das Motiv der Zeitreise bietet einer Erzählung mit historischem Inhalt die Möglichkeit, Unmittelbarkeit zu entwickeln, denn es wird ein Bericht aus erster Hand suggeriert. Dieser Methode hat sich auch Nelson Torres in seinem Gedichtband De Indias bedient. ${ }^{69}$ (Torres 1993) Insbesondere die mit Introducción überschriebene Seite 8 ist hier aufgrund ihrer Zeitreise-Thematik von Interesse. Torres' Erzähler berichtet, wie er eines Morgens verwirrt aufwacht „de pronto no era yo [...] Fue como si un gen hubiera roto su silencio para culminar su viaje por el tiempo, trasvasijando en mí toda su remota información“. Er sieht das Holz der Häuser wieder zu Bäumen werden, Straßen werden zu Wegen, zu Pfaden und verschwinden schließlich, Flüsse fließen zu ihrer Quelle zurück, die Schrift verschwindet, und Sprache wird wieder ausschließlich mündliche Kommunikation. Das Ziel der Zeitreise ist der Moment der Ankunft der Spanier. Das Ich findet sich in einem kleinen Boot oder Kanu wieder, von dem aus er die spanischen Schiffe beobachtet, die er kaum als Schiffe identifizieren kann und die Menschen in sein Land bringen werden, die er beschreibt als „luminosos, como llegados de otros tiempos“.

Hier dient die Zeitreise nicht so sehr der Glaubwürdigkeit des Textes, sondern vielmehr der Bezeugung von Anteilnahme. Der Eindruck wird noch gestützt durch die Erwähnung eines Gens, das in dem Erzähler nur geschlafen hat und nun die Information preisgibt und zugänglich macht, die immer schon Teil von ihm war. Er identifiziert sich mit den Ureinwohnern seines Kontinents, auf seiner Reise wird er zu einem von ihnen. Damit verleiht Torres nicht nur einer tiefempfundenen Solidarität mit den Indígenas Ausdruck, sondern ermöglicht es darüber hinaus dem Erzähler, deren Perspektive einzunehmen.

So weit geht Riveros nicht. Sein Erzähler kann nicht zu einem Feuerländer werden, er kann diesen Menschen nicht näherkommen, als dies in Gestalt des Ethnologen Gusinde möglich ist, dessen Sicht er an verschiedenen Stellen wiedergibt.

Das nächste Textelement ist ein Zitat des argentinischen Erzählers, Dichters und Essayisten H. A. Murena (*1923), gewissermaßen ein memento mori, mit dem Riveros die Leserinnen und Leser gemahnt, das mögliche Ende der Welt, Tod und Zerstörung, nie völlig zu verdrängen.

$\mathrm{Y}$, nosotros, como en el interior de un paréntesis, deberíamos „recuperar esa mirada apocalíptica que consiste en tener siempre presente la idea de que la creación entera puede terminar en el próximo instante“. (S13)

\footnotetext{
${ }^{69}$ Nelson Torres ist ebenfalls Südchilene, jedoch werde ich seine Dichtung im Rahmen dieser Arbeit nicht ausführlich behandeln, da ich glaube, die charakteristischen Elemente an anderen Texten besser zeigen zu können.
} 
Vor diesem Hintergrund wird die Ausrottung der Feuerland-Indianer zu etwas, das auf alle Menschen bezogen werden muss, und - insbesondere durch die religiöse Konnotation des Begriffes creación - zu etwas, für das alle Menschen eine gewisse Verantwortung besitzen. So deutet sich eine weitere Bedeutungsebene an, die jedoch vorerst vage bleibt.

Es folgt das erste Kapitel, das die Vorstellung der creación, der Schöpfung, insofern aufnimmt, dass es eine Natur beschreibt, in der Menschen noch fast keine Rolle spielen, uns sozusagen den sechsten Tag der Schöpfung zeigt. Zwar ist die Stimme des Erzählers eine eindeutig menschliche, was sich in der religiösen Ehrfurcht ausdrückt, die er der Natur entgegenbringt, doch diese Ehrfurcht gilt einer unberührten, unbewohnten Welt. ${ }^{70}$ Bevor der Erzähler nun weiterreist und in die Welt der Menschen eintritt, lesen wir ein Zitat von Thomas Merton, mit dem die Reise zu einer Wallfahrt wird:

„...es una peregrinación, no es un viaje sentimental a un pasado romántico, sino es un esfuerzo humilde, difícil y necesariamente incompleto por cruzar un abismo y llegar a una comunión con gentes a quienes, privadas en tan gran medida de su identidad y reducidas al silencio, queda poco o nada que decir en el lenguaje ordinario.“ (S27)

Das Zitat stammt aus dem Aufsatz Ishi: A Meditation, der Ishi, dem Letzten des Stammes der Yahi-Indianer gewidmet ist. Mit diesem Zitat zieht Riveros die Parallele zu einem anderen Volk, das mit der Zeit verschwunden ist. Thomas Merton schrieb den Aufsatz anlässlich der traurigen Berühmtheit, die der letzte Überlebende des Stammes der YahiIndianer erlangte. Dieser tauchte eines Tages im Jahre 1911 bei Oroville, California, auf und zog sofort die Aufmerksamkeit auf sich, da er eine niemandem bekannte Sprache sprach. Man quartierte ihn in einem Museum in San Francisco ein, wo er einige Jahre als „the wild man“ bestaunt und studiert werden konnte. Nachdem wir einige Seiten zuvor an die Vergänglichkeit der Welt und unseres Leben erinnert wurden, wirkt dieses Beispiel als weitere Bekräftigung der realen Gefahr einer Auslöschung.

Das Zitat selbst spricht aber nicht nur von dem Volk (,gentes a quienes, privadas en tan gran medida de su identidad y reducidas al silencio, queda poco o nada que decir en el lenguaje ordinario"), sondern auch von der Beschäftigung mit ihm (vgl. das Zitat von Merton: „un esfuerzo humilde, difícil y necesariamente incompleto“) und kann somit als Motto für die Reise verstanden werden, die Leserinnen und Leser gemeinsam mit dem Erzähler antreten. ${ }^{71}$

\footnotetext{
${ }^{70}$ Ebenso führt Neruda auf den ersten Seiten des Canto general zunächst die Landschaft, Pflanzen und Tiere ein. Die Randnotizen lesen sich folgendermaßen: „Vegetaciones [...] Algunas bestias [...] Vienen los pájaros [...] Los ríos acuden [...] Minerales [...] Los hombres“. (Neruda 21975:8ff.)

${ }^{71}$ Weitere Zitate aus demselben Aufsatz von Thomas Merton finden sich in zweien der Gedichte, die noch besprochen werden.
} 
Der Prolog erlebt eine Art Fortführung in dem Abschnitt Precaución des kurzen Kapitels Precanciones. Er steht zwischen dem ersten Kapitel, das Naturbetrachtungen enthält und in dem Menschen überhaupt keine Rolle zu spielen scheinen, und den drei Kapiteln über die einzelnen Völker von Feuerland, also direkt am Übergang von der Natur zum Menschen, an der Schwelle zur Kultur.

In dem kurzen Abschnitt befragt der Erzähler einen Seemann nach den Vorsichtsmaßnahmen, die zu ergreifen seien, wenn man tauchen will. Daraufhin spricht dieser von den Schönheiten des Tauchens, aber auch von den Risiken, die mit dem Tauchen verbunden sind. Insbesondere von zwei Gefahren ist die Rede: sich über die Sauerstoffversorgung zu vergiften und bei der Detonation von Sprengsätzen verletzt zu werden. Schließlich erläutert der Seemann, welches die einzige Vorkehrung sei, die zu treffen er für unerlässlich erachte: Man solle unbedingt mit einem Schlauch oder einer Röhre tauchen, die immer aus dem Wasser schaut, „con su hocico abierto al ancho mundo“ (S29).

Auch hier handelt es sich um einen personalen Erzähler, der sich in der Welt zu orientieren versucht. Durch die Art und Weise, wie der Seemann das Tauchen beschreibt („,como si alguien penetrara un paraíso oculto [...] cesa toda comunicación con el exterior [...]“, S29), drängt sich die Parallele zum Eintauchen des Erzählers aus dem Prolog in eine neue Welt auf. Der Abschnitt kann als Metapher für die Arbeit des Ethnologen verstanden werden. Die „manos nefandas“, die synekdochisch für diejenigen stehen, die das Wasser vergiften und den natürlichen Lebensraum unter Wasser gefährden, wissen nichts von der Schönheit der Natur, die sie zerstören, sie wollen nur profitieren; ${ }^{72}$ ebenso wie die Menschen, die die Selk'nam töteten, um sich an ihrem Land zu bereichern.

„El cordón“, die Schnur oder Röhre, hält den Taucher mit der Welt in Verbindung und soll dafür sorgen, dass er trotz der Faszination der Unterwasserwelt vor seinen Augen nicht vergisst, dass dies nicht sein Element ist, und dass er Luft zum Atmen braucht. Auf den Bereich des Ethnologen übertragen, hieße das, dass er sich immer seiner eigenen Kultur bewusst sein muss, und somit seiner notwendigerweise ethnozentrischen Sicht auf andere Völker. Aaußerdem darf er nicht vergessen, dass seine eigene Kultur eine Bedrohung für andere Kulturen darstellen kann.

\footnotetext{
72 Mit ,arrojan cargas de dinamita“ spielt Riveros vermutlich auf die Praktik des Dynamitfischens an, bei dem unter Wasser Dynamit gezündet wird, was dazu führt, dass den Fischen die Schwimmblase platzt. Die toten Tiere schwimmen in großer Anzahl an der Wasseroberfläche, wo sie aufgesammelt werden können. Die Methode ist äußerst effektiv, also lukrativ für die Fischer, jedoch werden die Fische dabei ungeachtet ihres Alters und ihrer Größe großflächig ausgerottet. Außerdem werden Teile der Unterwasserlandschaft wie Korallenriffe und die dort beheimatete Flora und Fauna zerstört. Allerdings ist nicht bekannt, dass diese Praktik in Chile bereits Anwendung
} 
Muñoz G. sieht die Precauciones als Fortsetzung, bzw. als Wiederholung der Entführung des Erzählers: „Estas ,Precauciones‘ se me ofrecen como una reiteración de ese rapto y del viaje subsiguiente del poeta en las profundidades del tiempo y de la historia." (Muñoz G. 1987:128)

Beide bisher vorgestellten Texte befassen sich mit dem Aufeinandertreffen zweier Kulturen und den Arten des Umgangs damit. Ohne dass es explizit wird, werden die Figur des Ethnologen und seine Tätigkeit hinterfragt. Ein kulturelles Aufeinandertreffen, das als firstcontact-Situation charakterisiert werden kann, und der Umgang damit stehen im Mittelpunkt. Insbesondere die Sprache und die Wahrnehmung von Zeit und Ort, die für uns Koordinaten bilden, ohne die wir uns schwer orientieren können, werden thematisiert. Außerdem erfahren wir etwas über den individuell-psychischen Aspekt sowie über den kulturell-sozialen einer derartigen Begegnung.

Aus dem Monolog ist ein Dialog geworden, in dem nicht nur die warnende Stimme des Seemanns, sondern auch Schriftsteller wie Murena und Merton zu Wort kommen. Alle tragen etwas zur Entdeckungsreise des Erzählers bei, der nun auch die letzten Schwellen überschritten hat. Beim Lesen werden wir nicht nur auf die Beschreibung der Vergangenheit vorbereitet, sonderen darauf, sie mitzuerleben.

\subsection{Momentaufnahmen der Vergangenheit in Wort und Bild}

pudimos ser papel lustre,
fotografías viejas de una raza ya extincta sin más huella
que las fotos obscenas del tiempo Tomás Harris

Bereits auf seiner ersten Reise erhielt Gusinde von den Selk'nam einen Namen in der Stammessprache, der, wie es üblich war, den Benannten einer signifikanten Eigenschaft gemäß charakterisieren sollte:

Mank'ácen (man: Schatten, Figur, Bild, k'ácen: fassen, ergreifen, auffangen) ,Schattenfänger'. Die Leute der Lago Fagnano-Gegend hatten mich deshalb mit diesem Namen bedacht, weil ich mit meinem Lichtbildkasten ihr Bild photographisch aufzufangen bemüht war. (Gusinde 1931:382)

Offenbar machte Gusindes Tätigkeit als Fotograf großen Eindruck auf die Selk'nam. Zunächst überwog ihre Angst: „Sie sagten ,Ich fange ihre Seele in mein schwarzes Kästchen ein, sie müssten danach sterben! “", später dann die Begeisterung darüber, sich selbst auf einem Bild zu erkennen. (Gusinde 1931:89, 712f.)

gefunden hat, so dass der Schluss naheliegt, dass es sich um eine Metapher für die Zerstörung und 
17 der 18 Fotografien im Abschnitt Documentos in De la tierra sin fuego stammen von Gusinde. Sie zeigen Portraitaufnahmen und einige Gruppenbilder von Selk'nam, Alacalufe und Yámana, zum Teil in traditioneller Bemalung. Auf einem Bild ist Gusinde selbst bei dem traditionellen Initiationsritus der Yámana, an dem er teilnehmen durfte, zu sehen.

Soledad Bianchi hebt die Parallele zwischen Bild und Text bei Riveros hervor:

Como las fotos, los poemas suspenden y fijan el instante. [...] Poemas y fotos fijan, detienen, inmovilizan la historia de onas, yaganes y alacalufes, y en su exterminio, la quietud se vuelve inmovilidad de la muerte, de ausencia, de desaparición. [...] Como Gusinde quien, con una máquina fotográfica y discos, conservó imágenes de estas etnias, el hablante conoce, reconoce y construye vestigios que son huellas originarias. (Bianchi 1992:288)

Bianchi macht die Parallelität von Bild und Gedicht daran fest, dass beiden ein und dieselbe Absicht zugrunde liegt:

Para evitar que los rastros de ona, yaganes y alacalufes, se evaporen para siempre en calidad de caspi [...] porque quiere hacer perdurar y desea impedir el silencio definitivo, el hablante escribe [...] y se identifica con el etnólogo austríaco, Martín Gusinde. (Bianchi 1992:288)

Um die Geschichte und Kultur der Völker festzuhalten, schrieb Gusinde sein umfangreiches Zeugnis Die Feuerland-Indianer, um aber ihre Gegenwart, ihre Lebendigkeit, ihre Unmittelbarkeit festzuhalten, machte er Fotos, die in den Textbänden mitveröffentlicht sind. Riveros greift die Fotografien sowohl optisch als auch sprachlich auf. Neben den abgedruckten Bildern scheint er in einigen Texten Bilder und Situationen zu beschreiben und erzielt dabei verschiedenartige Effekte.

Zunächst gibt es Texte, die uns ein Foto vor Augen zu stellen scheinen. Dazu gehören die Landschaftsschilderungen des Kapitels Naturaleza, die hier aber keine Berücksichtigung finden sollen. Andererseits finden sich Bilder wie zB die Hochzeitsbemalung einer Frau:

$[\ldots]$

ella pinta su rostro con finísimas rayas

blancas, transversales. Una ancha línea alba

atraviesa aletas, nariz y mejillas. (S79)

Oder es wird der Ort einer rituellen Handlung beschrieben:

Tres palos pintados de rojo

en triángulo,

cerca de la cabeza del moribundo.

Atado con las cuerdas del arpón,

si es hombre, y un emparrado en su cabeza.

Trenzas de plumas blancas

colgando de los piquetes

Ausbeutung der Natur handelt. 
con la paleta de extracción del molusco, si es mujer.

Telas blancas; una cabeza de albatros disecada en el interior. A la entrada de la choza, impidiendo el acceso de Ayayema, hachas oblicuas enterradas con sus filos hacia el cielo.

Un fuego claro arde en el centro. (S132)

Das folgende Beispiel schildert eine Totenwache:

Graves rostros herméticos.

Suspendida la caza, la pesca, recolección de leña.

Y, junto al cadáver: lentos elogios modulados por mujeres ancianas. (S136)

An diesen und anderen Stellen beschreibt Riveros einen einzigen Moment; allerdings nicht, wie üblicher in der Lyrik, in seiner Bedeutung für eine einzelne Person, ein Individuum, wie es in diesen Fällen die Person wäre, die heiratet oder trauert. Vielmehr wird der Augenblick repräsentativ für eine traditionelle Zeremonie nachgezeichnet, so dass er für eine kulturelle Praktik, ein Ritual steht. Diese Texte erinnern an Zeichnungen, die sich ein Ethnologe macht, wenn er ein Volk studiert. Und letztendlich stellt eine Menge von solchen Bildern oder Beschreibungen ritueller Augenblicke, wie Riveros sie zusammenstellt, den Versuch dar, den geistig-spirituellen Bereich einer ganzen Kultur abzubilden.

Daneben gibt es andere Arten von Momentaufnahmen. In vielen Texten werden nicht statische Bilder, sondern Wortwechsel wiedergegeben, die aus einem kurzen Dialog oder auch nur aus einer einzigen Äußerung bestehen. Während insbesondere die detaillierten Landschaftsbeschreibungen epische Züge tragen, finden sich in den Gesprächsszenen dramatische Elemente. Oftmals handelt es sich dabei um unpersönliche Redeweisen, in der Art von Sprichwörtern:

\footnotetext{
„Cuando el carancho lanza su grito ronco y estrepitoso, vendrá viento sur", dice un ona en silencio. (S58)

Y cuando una lluvia de estrellas cae como estampidas de luz, „la tribu va de cacería“, dicen los onas. (S63)
} 
In anderen Fällen wird die sprechende Person individuiert, hier sogar durch ihren Namen:

Lola Kiepja me dice:

„Yo soy nieve. Mi madre viento

y mi marido, lluvia.“ (S51)

Das Hinzuziehen der direkten Rede macht die Szenen lebendiger, manchmal anekdotenhaft, wie im Fall des Textes Traducción:

Pido a un joven alacalufe, traducir:

„la madre mace a su niño“.

De inmediato responde

en su lengua: „Porque

está llorando". (S144)

Indem Riveros einzelne Personen in einem bestimmten Augenblick ihres Lebens festhält, setzt er ihnen ein Denkmal, so wie Gusinde das mit seinen Fotos gelang. Die Fotos, die Riveros am Ende seines Buches sozusagen zitiert, indem er sie als Bildzeugnisse aufnimmt, zeigen Gesichter. Zwar sind sie meist ohne Namen abgedruckt („mujer yámana“, „jóven selknam“, „madre selknam y su hijo“, „padre alacalufe llevando al cuello el cordón umbilical de su hijo recién nacido“), jedoch verfügen sie über eine eindringliche Individualität.

Die meisten dieser Fotos, ebenso wie die Szenen oder anekdotenhaften Begebenheiten, hatten für Gusinde, eine fast ausschließlich ethnologische Bedeutung, weil sie Aufschluss geben über Gewohnheiten und Lebensweise eines anderen Volkes. Für Riveros hingegen sind sie bereits Geschichte, da keiner dieser Menschen mehr lebt. Jeder einzelne Ona steht nun exemplarisch für sein Volk. Durch ihre Ausrottung scheint jedes Individuum, von dem Riveros spricht oder dessen Foto er abdruckt, eine Transzendenz erreicht zu haben, die weit über das Individuelle und Anekdotenhafte hinausgeht und über den wissenschaftlichen Anspruch Gusindes hinausgeht. Das Wissen darum, dass die hier dargestellte oder beschriebene Person nicht mehr existiert, verwandelt sich in das Wissen um den Tod eines Volkes.

Die Augenblicke und Momentaufnahmen können als eine weitere Methode ethnographischen Schreibens bezeichnet werden. Geertz nennt folgende Merkmale der ethnographischen Beschreibung: „-- sie ist deutend, - das, was sie deutet, ist der Ablauf des sozialen Diskurses, - das Deuten besteht darin, das ,Gesagte‘ eines solchen Diskurses dem vergänglichen Augenblick zu entreißen." (Geertz 51997:30) Indem Gusinde die rituellen Handlungen der Feuerland-Indianer fotografiert, enthebt er sie der Vergänglichkeit, und was er festhält, kann als sozialer oder soziokultureller Diskurs verstanden werden. 
Noch eindringlicher als die Beschreibungen sind die Fotografien, die sich am Ende des Buches unter der Überschrift Documentos finden. Das ist in einem Gedichtband ungewöhnlich, aber kein Einzelfall. Auch Aristóteles España hat seinem Gedichtband Dawson $\mathrm{zu}$ dokumentarischen Zwecken Fotografien beigefügt. Das Buch entstand zwischen September 1973 und September 1974 im Konzentrationslager auf der Insel Dawson, wohin España siebzehnjährig nach seiner Verhaftung noch am Tage des Putsches gebracht wurde. Die oft tagebuchartigen Texte dokumentieren in freien Versen Españas Zeit im Lager, seine Angst, Fassungslosigkeit und Hoffnung. Die Bilder zeigen unter anderem politische Mit-Häftlinge, das Innere des Gefangenenlagers und Häftlinge bei der Zwangsarbeit. Der Text ist eines der bekanntesten chilenischen Beispiele für die Gattung der TestimonioDichtung. ${ }^{73}$

Im folgenden Abschnitt wird deutlich, dass der Text Dawson auch in inhaltlicher Hinsicht Bedeutung für Riveros hat, der España sogar zitiert. An dieser Stelle soll lediglich auf die Funktion der Bilder eingegangen werden. Sowohl España als auch Riveros verwenden Fotos, um ihren Texten Authentizität zu verleihen. Sie benutzen die Überzeugungskraft, die von den Bildern ausgeht. Was wir als Fotografie sehen, sind wir eher geneigt, für wahr zu halten als das meiste, was uns schriftlich mitgeteilt wird. Das Bild hat für uns eine größere Überzeugungskraft. Genau in diesem Bestreben unterscheiden sich diese beiden Texte (genauso wie jede poesía testimonial) von anderer Dichtung: Sie wollen vor allem dokumentieren und als wahr akzeptiert werden, darin liegt ihre Absicht.

\subsection{Palimpsest der Vemichtung}

Todos están ahí aniquilados por la insaciable codicia de la raza blanca

Gusinde estas inexplicables y múltiples historias de exterminio

Galindo/ Miralles

Der größte Teil der Gedichte Riveros' handelt von der Welt der Feuerländer zu einem Zeitpunkt, als sie noch intakt war, von der sie umgebenden Landschaft, von ihren Traditionen und Legenden. Viele Texte ahmen Gusindes anthropologisches Interesse an den betreffenden Völkern nach. Im eigentlichen Sinne geschichtlich sind die meisten dieser Texte nicht, da sie sich nicht auf historische Ereignisse beziehen, sondern nur sehr allgemein von einem mittlerweile unwiederbringlich vergangenen Zustand erzählen.

Bei einigen Texten ist das anders. So wird Geschichte zum Thema, wenn Riveros

${ }^{73}$ Zur Testimonio-Dichtung siehe Kapitel 3.3, S38f. 
ausdrücklich auf verschiedene Feuerland-Reisende aus mehreren Jahrhunderten Bezug nimmt, weiterhin wenn er von der Verfolgung und Ausrottung der Ureinwohner Ende des 19. Jahrhunderts schreibt, vom Dasein der Überlebenden in Lagern Mitte dieses Jahrhunderts und schließlich von der Diktatur in Chile seit 1973.

Das Thema der Diktatur mag in diesem Kontext überraschen. Es spielt nur in zwei Texten explizit ein Rolle, in beiden Fällen jedoch so eindringlich, dass es auch im Folgenden an vielen anderen Stellen mitgedacht werden kann und im Nachhinein den Gesamteindruck des Buches mitbestimmt. Im Gegensatz zu der Unvermitteltheit, mit der Leserinnen und Leser mit der chilenischen Militärdiktatur konfrontiert werden, ist das Ende der FeuerlandIndianer als historisches Geschehen bereits vorbereitet. Zunächst haben der einleitende Text (mit Prolog-Funktion) und die Motti das Thema angekündigt, später wird es durch die Vorausdeutung des Siedlers im Text Evocaciones (,....sin la presencia / de estos indios en la isla, la riqueza / de Magallanes sería hoy doble / de la actual“", S56) wieder präsent. Die Bezüge auf Gusindes Reisen nach Feuerland sowie frühere und spätere Feuerland-Reisende (aus dem 16., 18. und 19.Jahrhundert) stehen in den meisten Gedichten in einem engen Zusammenhang mit der Urbevölkerung. Sie legen über deren Existenz und Auslöschung Zeugnis ab und fügen sich fast übergangslos in den umgebenden Text ein.

Im Folgenden werde ich die einzelnen Texte mit explizit historischem Bezug untersuchen. Ein Vergleich der tatsächlichen geschichtlichen Abfolge der Ereignisse mit der im Text realisierten Reihenfolge ist aufschlussreich. Dazu stelle ich die Abfolge der historischen Bezüge so, wie sie im Text erscheinen (linke Spalte) der tatsächlichen historischen Chronologie (rechte Spalte) gegenüber. Die unterlegten Farben zeigen, welche Ereignisse historisch zusammengehören.

\begin{tabular}{|c|c|}
\hline $\begin{array}{l}\text { Abfolge der historischen Daten gemäß der Chronolo- } \\
\text { gie des Buches: } \\
\text { Seitenzahl: Gedichttitel, (ggf. Jahreszahl, [Art des Dokuments]) }\end{array}$ & $\begin{array}{l}\text { Abfolge der historischen Daten gemäß der geschichtli- } \\
\text { chen Chronologie: } \\
\text { Jahreszahl: Ereignis (Seitenzahl) }\end{array}$ \\
\hline S24: Dar & $\begin{array}{l}\text { 1557: Francisco Cortés Hojea segelt auf Befehl von } \\
\text { Valdivia nach Chile (S148) }\end{array}$ \\
\hline S51: Pertenencias (1920er Jahre), [Zitat Lola Kiepja] & $\begin{array}{l}\text { 1558: Fco. Cortés Hojea muss seine Erkundungsfahrt } \\
\text { abbrechen (S145) }\end{array}$ \\
\hline $\begin{array}{l}\text { S56: Evocaciones (1895), [Brief] } \\
\text { S64: Exterminio ona (1875-1905) }\end{array}$ & $\begin{array}{l}\text { 1766-1767: Padre García Martí bereist Südchile (S135) } \\
\text { 1822-1823: J. Lephay über das Klima Feuerlands } \\
\text { (S147) }\end{array}$ \\
\hline S64: Exterminio ona (1872), [Zitat Daily News] & $\begin{array}{l}\text { 1826-1836: Fitz-Roy durchquert den Beagle-Kanal } \\
\text { (S95) }\end{array}$ \\
\hline $\begin{array}{l}\text { S65: Exter } \\
\text { Concepció }\end{array}$ & 1830: Darwin in Feuerland (S102) \\
\hline S65: Exter & \\
\hline
\end{tabular}




\begin{tabular}{|c|c|}
\hline S67: Dawson (um 1973), [Zitat A. España] & ca 1833: Darwin in Feuerland (S93) \\
\hline S67-70: Dawson (1884-1898), [Briefe] & $\begin{array}{l}\text { 1872: Die Daily News (England) berichtet über die } \\
\text { Notwendigkeit, die Feuerländer zu beseitigen (S64) } \\
\text { 1875-1905: Systematische Ausrottung der Ona (S64) }\end{array}$ \\
\hline S70: Dawson (1977) & 1890: Brief von Braun an Nogueira (S72) \\
\hline S71: Gusinde (ca. 1897-1899) [Zitat] & $\begin{array}{l}\text { 1884-1898: Briefe von Verantwortlichen für die Aus- } \\
\text { rottung der Ona (S67-70) }\end{array}$ \\
\hline $\begin{array}{l}\text { S74: Fragmentos (1896-1897) [Zitat der Sociedad explo- } \\
\text { tadora de Tierra de Fuego] }\end{array}$ & $\begin{array}{l}\text { 1895: Brief von Verantwortlichen für die Ausrottung } \\
\text { der Ona (S56) } \\
\text { 1896-1897: Schreiben der Sociedad explotadora de Tierra } \\
\text { de Fuego (S74) }\end{array}$ \\
\hline S77: Selknam (1914), [Zitat Coiazzi] & $\begin{array}{l}\text { 1897-1899: Der Anthropologe F. Cook reiste auf einer } \\
\text { wissenschaftlichen Expedition in die Antarktis (S65) }\end{array}$ \\
\hline S85: A Ushuaia / Febrero 1919 / Sept & $\begin{array}{l}\text { 1907: Salesianer-Orden veröffentlicht Chronik } \\
(\text { S68/69) }\end{array}$ \\
\hline S93: Yámanas, (um 1832), [Zitat Dar & 1914: A. Coiazzi über Feuerland (S77) \\
\hline S95: Onashaga (1826-1836) [Zitat Fitz & 1919: Reise nach Ushuaia (S85) \\
\hline $\begin{array}{l}\text { S98: Watauinewa, El Archiviejo (1872-1922), [Bezug } \\
\text { auf John Lawrence] }\end{array}$ & $\begin{array}{l}\text { 1920er Jahre: Zitat Lola Kiepja gegenüber Gusinde } \\
\text { (S51) }\end{array}$ \\
\hline S102: Guardia / Darwin (1830) & $\begin{array}{l}\text { 1920-1923: Zweite Reise Gusindes nach Feuerland } \\
\text { (S119) }\end{array}$ \\
\hline S109 & 1923: Zitate Gusinde (S150, S155) \\
\hline S119: Segunda expedición (1920-1923) & um 1923: Zitate von Gusinde (S71, S72f.) \\
\hline o de Emperaire (1946), [Ta: & $\begin{array}{l}\text { zwischen } 1872 \text { und } 1920 \text { er Jahre: John Lawrence } \\
\text { predigt und missioniert in Feuerland (S98) }\end{array}$ \\
\hline $\begin{array}{l}\text { S135: El maleficio de los cabellos (1766-1767), [Zitat } \\
\text { Pater García Martí] }\end{array}$ & 1940: Über die Überlebenden in Lagern (S142) \\
\hline $\begin{array}{l}\text { S142: Extinción alacalufe (1940), [Zitat Emperaire] } \\
\text { S143: Perros del Campamento Edén (1963), [Zitat } \\
\text { Emperaire] }\end{array}$ & $\begin{array}{l}\text { 1946: Über die Überlebenden in Lagern (S128) } \\
\text { 1946/1952: Landschafts-/ Reisebeschreibung Caleta } \\
\text { Banner (S109) }\end{array}$ \\
\hline $\begin{array}{l}\text { S145: Domingo } 23 \text { de Enero 1558, [Zitat Francisco } \\
\text { Cortés Hojea] }\end{array}$ & 1952: Reisebeschreibung Ushuaia (S85) \\
\hline S147: Elementos (1882/1883) [Zitat J.Lephay] & 1963: Leben im Lager (1940?) (S143) \\
\hline $\begin{array}{l}\text { S148: Alacalufes en el Canal Fallos (1557), [Zitat } \\
\text { Francisco Cortés Hojea] }\end{array}$ & 1973-ca. 77: Internierungslager Dawson (S67) \\
\hline S150: Gusinde (1923), [Zitat Gusinde] & $\begin{array}{l}\text { 1977: Schließung des Internierungslagers Dawson } \\
\text { (S70) }\end{array}$ \\
\hline S155: Despedida de Martín Gusinde (1923) & $\begin{array}{l}\text { 1986: Verbrennung von Carmen Gloria Quintana und } \\
\text { Rodriguo Rojas durch Miliärs }\end{array}$ \\
\hline
\end{tabular}

\section{frühe Feuerlandreisende}

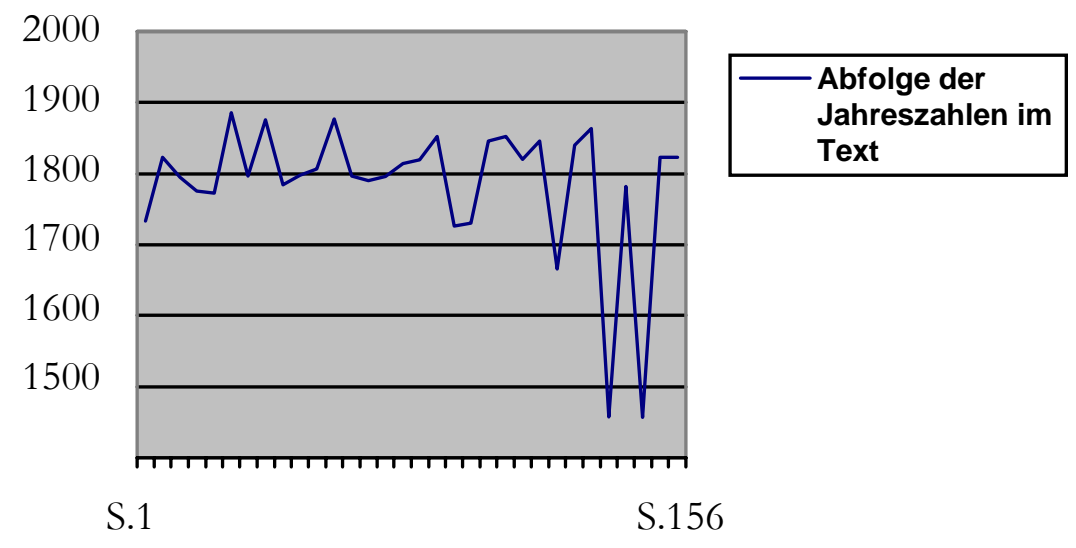


Zunächst fällt auf, dass die Reihenfolge der Bezüge im Text völlig unabhängig vom Verlauf der Geschichte ist. Eine Fieberkurve, erstellt aus den aufeinanderfolgenden Jahreszahlen, ergibt einen scheinbar recht willkürlichen Verlauf mit vielen jähen Spitzen in beide Richtungen. Zieht man auf der Suche nach einer zugrundeliegenden Ordnung das Kriterium der Kapitelaufteilung mit hinzu, ergeben sich Hinweise auf ein inhaltliches Schema. Das Kapitel Naturaleza ist, wie bereits angedeutet, in diesem Zusammenhang zu vernachlässigen, da es sich nicht mit menschlichen Dimensionen befasst und lediglich einen einzigen historischen Bezug, nämlich auf die Reise Darwins 1833, beinhaltet.

Die drei Abschnitte, die sich jeweils einem der Volksstämme widmen, weisen hingegen insgesamt über 30 Bezüge, meist historische Quellen, auf. ${ }^{74}$ Bei der thematischen Verteilung können einige Tendenzen festgestellt werden: Sämtliche Bezugnahmen auf die systematische Vernichtung von Menschen (sowohl Ende des 19. Jahrhunderts in Feuerland als auch etwa hundert Jahre später während der chilenischen Militärdiktatur) finden sich im Abschnitt über die Selk'nam. Der Abschnitt über die Yámana enthält neben den ethnologischen Texten und Naturbetrachtungen ausschließlich Reiseberichte aus dem 19. und 20. Jahrhundert. Das letzte Kapitel, Qawashqar, beinhaltet Bezüge auf das Leben der letzten Überlebenden der Alacalufe in Lagern um die Mitte dieses Jahrhunderts sowie auf frühe Reiseberichte aus dem 16., 18. und 19. Jahrhundert. Im Wesentlichen entspricht diese Verteilung der Darstellung der jeweils unterschiedlichen Geschichte der einzelnen Völker, wie auch Gusinde sie erzählt. Obschon in der Mitte dieses Jahrhunderts von keinem der drei Völker noch mehr als einige wenige letzte Überlebende existierten, waren doch die Selk'nam diejenigen, deren Vernichtung im großen und vor allem im öffentlichen Stil betrieben und propagiert wurde. Als Landnomaden bewegten sie sich ohne Gebietsbeschränkungen auf der gesamten Isla Grande, bis im letzten Drittel des 19. Jahrhunderts verschiedene Interessengruppen auf die Region aufmerksam wurden. Zunächst strömten Glücksritter und Abenteurer in die Region der Isla Grande, nachdem eine Expedition 1878/1879 unter Ramón Serrano im danach benannten Fluss Río del Oro Gold entdeckt hatte. (Gusinde 1931:53) Gusinde zufolge sind viele Selk'nam Goldsuchern, die als Straftäter aus Europa gekommen waren und nichts zu verlieren hatten, und ihrer Goldgier zum Opfer gefallen. Wo immer sie aufeinandertrafen, wurden Indígenas überfallen, misshandelt, getötet. (Gusinde 1931:154f.)

\footnotetext{
${ }^{74}$ In der Darstellung habe ich in einigen Stellen mehrere Bezüge zu einem Verweis zusammengefasst, wenn es sich etwa um mehrere Briefe ein- und desselben Briefwechsels handelt.
} 
Der Goldrausch war bereits wieder abgeklungen, als es die nächste Welle von Gewinnsüchtigen nach Feuerland zog. 1884 wurden die ersten Schaffarmen auf der Isla Grande errichtet. Chilenische und ausländische Siedler und Viehzüchter nahmen nach dem Vorbild Neuseelands immer größere Landstriche des Gebietes gewaltsam in Besitz, das ursprünglich die Heimat der Selk'nam bildete. Sie zäunten Stück für Stück des Geländes ein und nutzten es als Weideland für ihre Schafe. Die Situation war für die seit Jahrhunderten nomadisierenden Selk'nam unmöglich zu verstehen und gefährdete darüberhinaus ihre Subsistenz. Nicht nur ihr eigener Lebensraum wurde eingeschränkt, sondern auch derjenige der Guanacos, ${ }^{75}$ die ihre Ernährung sicherten und gleichzeitig die Versorgung mit Kleidung und Material zum Bau ihrer Hütten bildeten. Sowohl aus Rache als auch, um ihr Überleben zu sichern, erlegten die Selk'nam Schafe. Die Siedler, die daraufhin ihr Eigentum gefährdet sahen, begannen eine regelrechte Jagd auf die Nomaden. Der Höhepunkt des Mordens war in den 90er Jahren erreicht, als die weißen Siedler Kopfgeld auf die Selk'nam aussetzten, Treibjagden veranstalteten und ihre Kinder fingen, um sie mit tödlichen Krankheiten infiziert in ihre Lager zurückzuschicken. (Gusinde 1931:160)

Die Yámana und Qawashqar waren ebenfalls Nomadenvölker, sie zogen jedoch nicht wie die Selk'nam durch die Wälder und Ebenen von Feuerland, sondern bewegten sich hauptsächlich auf dem Wasser fort. Sie lebten an den südlichen Küsten der Isla Grande und auf den weiter südlich und westlich gelegenen Inseln und Halbinseln. Beider Völker Existenz war an das Meer geknüpft: Sie ernährten sich fast ausschließlich von Meeresfrüchten, Krabben, Fischen und dem Fleisch der erlegten Seelöwen und Robben. Sie verarbeiteten die Felle der Seelöwen, und die Yámana bauten um ihre Hütten herum Schutzwälle aus Muschelschalen. Einen großen Teil ihres Alltags verbrachten sie auf ihren Kanus. Aus diesem Grunde wurden sie schon sehr früh von vorbeisegelnden Seefahrern und Entdekkungsreisenden bemerkt, während die Selk'nam im Landesinneren höchstens durch Rauchzeichen gelegentlich auf sich aufmerksam machten. Das wiederum erklärt, warum Reiseberichte aus früheren Jahrhunderten auf die Kapitel der Yámana und der Alacalufe beschränkt bleiben.

Dass der inhaltlichen Anordnung ein größeres Gewicht gegeben wird als der chronologischen, zeigt sich weiterhin an den drei Stellen, in deren Zentrum Geschehnisse der Diktatur stehen. Sie befinden sich im direkten Kontext der Vernichtung der Selk'nam, so dass die Parallele zwischen den beiden organisierten und staatlich angeordneten Massenmorden nur allzu deutlich vor Augen geführt wird. Obwohl es sich tatsächlich nur um

\footnotetext{
${ }^{75}$ Guanacos werden die in Chile beheimateten Lamas genannt.
} 
insgesamt drei explizite Bezugnahmen in zwei Texten handelt, sprechen Galindo und Miralles im Anklang an Triviños über die Diktaturerfahrung als zweites Thema des gesamten Buches:

[...] De la tierra sin fuegos adquiere el carácter de una elegía por estas culturas, que el sujeto narrador busca comprender y valorar, pero al mismo tiempo, como plantea Gilberto Triviños, el texto opera como un palimpsesto de la historia de represión y persecusión [sic] sufrida en nuestro país a partir de 1973. (Galindo 1992:5)

Die in der Postmoderne strapazierte Metapher des ,Palimpsests' ist in diesem Fall sehr treffend. Die Tatsache, dass man beim linearen Lesen des Buches immer wieder auf Dokumente ganz unterschiedlichen Datums trifft, deren Anordnung eindeutig der geschichtlichen Chronologie zuwiderläuft, erinnert tatsächlich an mehrfach beschriebenes Papier, das an einigen Stellen die ursprünglichen Worte durchscheinen lässt. Bei den antiken und mittelalterlichen Schriftstücken, die als Palimpseste bezeichnet werden, handelt es sich zumeist um Briefe oder Urkunden, die später abgeschabt und überschrieben wurden. Auch Riveros legt seinen Texten viele offizielle Dokumente und Briefe zugrunde, die er dann zusammenfügt und teilweise überschreibt. Zur Verdeutlichung dieser Technik sollen im Folgenden die beiden Texte Exterminio ona und Dawson untersucht werden.

Von den 69 Versen des Gedichtes Exterminio ona bestehen etwa 47 aus 11 gekennzeichneten Zitaten. Der sprachlich und stilistisch sehr heterogene Text bildet neun im Druckbild voneinander abgetrennte Strophen. Die meisten Abschnitte umfassen ein Zitat und ein paar einbettende Worte, wobei das Zitat häufig eingerückt ist. Alle Zitate sind mit Fußnoten versehen; die entsprechenden bibliographischen Angaben finden sich im Anhang. Dieser wissenschaftliche Umgang mit Zitaten, wie er für Lyrik eher ungewöhnlich ist, unterstreicht den dokumentarischen Anspruch des Textes, ebenso wie die Jahresangabe im Titel (1875-1905). ${ }^{76}$

Riveros füllt den angekündigten Zeitraum von dreißig Jahren mit Zitaten aus, die Schlaglichter auf die Ereignisse werfen. Er stellt Verse von Ezra Pound, Thomas Merton und Saint-John Perse neben einen Zeitungsausschnitt der Daily News, einen Bericht der Abteilung für Menschenrechte der Erzdiözese von Concepción, ein Zitat des Anthropologen Frederick Cook, eines von Gusinde und zwei weitere früherer Reisender, von denen Gusinde berichtet. Zum Teil dokumentiert er die Geschehnisse lediglich durch die Zeugnisse selbst (Zeitungsartikel, Reiseberichte), zum Teil kommentiert oder interpretiert

\footnotetext{
${ }^{76}$ Wie die genauen Jahreszahlen zustandengekommen sind, wird nicht erläutert; lediglich die Rede von einer Zeitspanne von 30 Jahren wird am Ende des Gedichtes als Zitat Gusindes identifiziert.
} 
er sie (im Falle Gusinde und Merton), oder er setzt sie in Beziehung zu anderen Vorfällen (bei dem Menschenrechtsbericht und Merton).

Die erste Strophe benennt das Thema: die gewaltsame Begegnung zwischen Ona und Farmern. Riveros lässt keinerlei Zweifel daran, auf welcher Seite er steht. Die Farmer sind die „enemigos de los indios / más perversos y poderosos“ “. ${ }^{77}$ Das erste als solches gekennzeichnete Zitat dient Riveros dazu, seinen persönlichen Standpunkt zur Erschließung Feuerlands durch die Weißen, die er „colonización“ nennt, darzulegen: Er bezeichnet sie als ein Verbrechen. ${ }^{78,79}$ Die zweite Strophe verdeutlich den Standpunkt der Ona und wie unbegreiflich die Geschehnisse für sie sein müssen. Die Ebenen, ehemals „Extensas llanuras“, sind nun „cercadas“ (S64). Das Oxymoron drückt den früheren Zustand, den jetzigen Zustand und die Widersinnigkeit der Veränderung aus. Gleichzeitig konnotieren diese drei knappen Wörter die Sehnsucht nach Weite und die Gewalt der einengenden Zäune. Die Absurdität dieser Maßnahme wird augenfällig durch die Bezeichnung der ursprünglichen Jagdgründe der Ona als „bienes inmuebles“, Immobilien. Auch dieses Zitat stammt aus Thomas Mertons Essay Ishi, in dem Merton nicht nur über Ishi, sondern auch über das Verschwinden seines Volkes reflektiert. Die Begriffe „bienes inmuebles“ und „título legal“ stehen im krassen Gegensatz zur Lebenswelt der Yahi, sowie auch der Ona. Sie werden von Merton ironisch verwendet und hier von Riveros ebenso ironisch aufgenommen, um die Unangemessenheit der Behandlung der anderen Kultur zu verdeutlichen. Beide Begriffe sind rechtlich besitzregelnde Termini, bilden also eine Isotopie ${ }^{80}$, die in der Vorstellung eines Nomadenvolkes weitgehend bedeutungslos sein muss: „,ni siquiera sabían que fuesen bienes inmuebles“. Natürlich wussten sie nicht, dass es sich bei ihren Jagdgründen um Immobilien handelte, und natürlich haben sie kein Besitzrecht darauf erhoben, denn „they are not in the same universe of discourse“, wie Stephen Greenblatt über die Aruak sagt, die sich 1492 in einer vergleichbaren Situation den Spaniern gegenüber

In etwa umfassen die Jahreszahlen den Zeitraum der gezielten und systematischen Vernichtung der Ona, wie bei Gusinde beschrieben.

${ }^{77}$ Obgleich es sich hierbei nicht um ein direktes Zitat handelt, sei auf eine fast gleichlautende Stelle bei Gusinde hingewiesen: „Ein viel mächtiger Feind stand jetzt auf [...]: die Viehzüchter und Farmer." (Gusinde 1931:156)

${ }^{78}$ Als Quelle gibt Riveros die Cantos von Ezra Pound an.

${ }^{79}$ Das tatsächlich erste Zitat des Textes lautet „Auri Sacra Fames“ (aus: Vergil, Aeneis 3,57). Vermutlich kennzeichnet Riveros es nicht als Zitat, weil es die Qualiät eines Sprichwortes besitzt. Außerdem finden sich auch diese Worte bereits bei Gusinde in einem Kapitel mit den anderen übernommenen Zitaten. (Gusinde 1931:168) Trotz allem ist es eine weitere prominente Stimme, derer sich Riveros hier bedient.

${ }^{80}$ Zum Begriff der Isotopie vgl. Schulte-Sasse 51987:68ff. 
befanden. ${ }^{81}$ Greenblatt arbeitet dieselbe Unvereinbarkeit der Begrifflichkeiten, bzw. des dahinterstehenden Weltbildes zweier Kulturen bei der vierhundert Jahre früheren Begegnung heraus: ,„[...] the incompatibility of a bureaucratic system based on legal title and a way of life that does not conceive of the land as alienable ,real estate $[$ [... “".(Greenblatt 1988:59) Offensichtlich haben sich die Praktiken bei der Eroberung Amerikas in vierhundert Jahren nicht geändert. ${ }^{82}$

Die folgende Strophe besteht aus einem Zitat der Daily News, das das Denken und die Beweggründe der anderen Seite, der weißen Siedler, verdeutlicht. ${ }^{83}$ Feuerland bedeutet für sie in erster Linie geeignetes Gebiet für die Viehzucht - und die Feuerländer ein zu beseitigendes Hindernis. Das Zitat vermittelt das Gefühl, als blickte Europa in jenem geschichtlichen Moment auf Feuerland mit der Entschlossenheit, sich die Region einzuverleiben und für seine Zwecke zu nutzen. Das Zitat der vierten Strophe wird eingeleitet durch die ironische Preisung der kaufmännischen Fähigkeiten der Siedler - eine sehr makabere Umschreibung für den gutbezahlten Verkauf von Schädeln der Selk'nam an das anthropologische Museum in London, von dem wir durch das Zitat Ardemagnis erfahren. ${ }^{84}$ Während aus der Rede des nach Gusinde zitierten Ardemagni offene Missbilligung und Anklage sprechen („No se respetaban... mujeres... niños... ni ancianos...“, S64), übernimmt Riveros den Zynismus, der im Zitat von Merton bereits anklang und in der folgenden Äußerung - ebenfalls von Merton - fortgeführt wird. Der Bemerkung, die bei Merton den Yahi gilt, werden bei Riveros als Subjekt die Ona vorangestellt. In beiden Fällen werden die betreffenden Völker lächerlich gemacht, indem der Gedanke ausgesprochen wird, sie könnten einst die Bezeichnungen „Amos“ verdient haben. Im selben Atemzug wird die Äußerung als absurd wieder zurückgenommen: „,demás está decir que de una manera muy mística, primitiva e irresponsable, de una manera totalmente risible“ (S65). Die vermeintliche Überlegenheit der Weißen und ihr Handeln werden im Folgenden - wie meistens in

\footnotetext{
${ }^{81}$ Die Aruak waren die Ureinwohner von Jamaika, mit denen Kolumbus auf seiner zweiten Reise zusammentraf. Auch sie wurden durch die spanische Eroberung ausgerottet. (Greenblatt 1988:59)

${ }^{82}$ Das bedeutet jedoch nicht, dass den Indigenas nicht bewusst war, dass ihnen Unrecht geschah, wie Gusinde deutlich macht: „Das Vorgehen der Europäer gilt dem Indianer glattweg als Raub und Diebstahl. [...] Für die Begriffe: Stehlen, rauben, sich rächen, sein Recht sich verschaffen etc. fehlen die besonderen Ausdrücke nicht, auch gibt es Possessivpronomina." (Gusinde 1931: 425)

${ }^{83}$ Ich gehe an dieser Stelle von einem Versehen Riveros' aus. Als Datierung des Zeitungsartikels kann kaum ein Zeitpunkt vor 1880 angenommen werden, da die ersten Schafe (andere Viehzucht hat es in der Gegend nie in nennenswertem Umfang gegeben) erst 1877 nach Feuerland verbracht wurden. Dabei handelte es sich um ein Experiment nach dem Vorbild Neuseelands, das erst nach Verlauf von ein paar Jahren als geglückt gegolten haben dürfte. Außerdem widerspricht die Datierung $1872 \mathrm{dem}$ im Gedichttitel genannten Zeitraum. (Delaborde 1962:44ff.)

${ }^{84}$ Auch hier zitiert Riveros nach Gusinde. (Gusinde 1931:160)
} 
den entsprechenden einschlägigen Argumentationen von Eroberern und Kolonisatoren mit der Gnade und dem Willen Gottes gerechtfertigt: „un país que Dios nos había concedido a nosotros" (S65).

Die Worte Mertons, die Riveros hier in seinen Text einfließen lässt, sind der Verweis auf ein Ereignis in der Geschichte eines anderen Landes, das als Parallele dient und den Geschehnissen in Feuerland eine Bedeutung verleiht, die über die regionalen und nationalen Grenzen hinausgeht. Sie scheinen der Beweis dafür zu sein, dass das, was geschah, nicht zufällig geschah, dass es Wiederholungen und Regelmäßigkeiten der Grausamkeit in der Geschichte gibt. Mit dieser Parallele hebt Riveros den Blick einerseits über die Regionalität hinaus, macht aber andererseits auch die Regionalität seiner Heimat stark, indem er den Ereignissen die eventuelle Zufälligkeit nimmt und ihnen stattdessen eine transzendente Bedeutung gibt.

Die letzten vier Verse der fünften Strophe beziehen sich auf eine Äußerung des Arztes und Anthropologen Frederick Cook, ebenfalls zitiert nach Gusinde. Der folgende Satz soll im Text des Österreichers sicherlich eine Rechtfertigung für das Verhalten der Ona sein:

Sollen wir sie Diebe nennen, wenn sie sehen, wie ihre Weiber und Kinder und all ihre Lieben fast verhungern, und wenn sie deshalb mutig herabsteigen und vor den Rohren der Winchester-Büchsen das nehmen, was sie für das Produkt ihres eigenen Landes halten? (Gusinde 1931:158)

Trotzdem klingt die verkürzte Form bei Riveros etwas verächtlich. Insbesondere fällt hier das Verb „consideran“ mehr ins Gewicht, was die Ona ins Unrecht zu setzen scheint. Auch die beiden Zeilen, die noch nicht zur direkten Zitation zählen, sind klar derselben Aussage Cooks zuzuordnen, die bei Gusinde mit „Die vielen Tausende von ,weißen Guanacos‘, welche friedlich auf den indianischen Jagdgründen grasen“ beginnt und in der ebenfalls von verhungernden Frauen und Kindern die Rede ist. ${ }^{85}$ Ebenfalls Verachten drückt sich im Zitat der sechsten Strophe aus, diesmal allerdings in ironischem Tonfall, worauf auch die dazugehörige Fußnote hinweist. Riveros karikiert mit den Worten Mertons die Arroganz und Überheblichkeit der Weißen. Die siebte Strophe beginnt mit fünf Versen, die zwar nicht als Zitat gekennzeichnet sind, aber auf folgende Stelle bei Gusinde Bezug nehmen:

Inzwischen hatten einige Farmer starke Bluthunde aus Europa bezogen. Die Menschenjäger ließen diese gefährlichen Tiere los, wenn sie ein Lager überrascht oder umzingelt hatten. [...] sie brachten den Kindern schwere Wunden am Halse bei, an denen sie schnell verbluteten. (Gusinde 1931:160)

\footnotetext{
${ }^{85}$ Mit „weißen Guanacos“ sind Schafe gemeint.
} 
Ohne Vorankündigung oder formale Differenzierung innerhalb des Textes flicht Riveros anschließend an dieser Stelle ein Zitat aus einem anderen Kontext ein, mit dem sich der unvermittelte Szenenwechsel hin zur Militärdiktatur vollzieht:

[...] Innumerables niños onas

muertos a mordiscos.

„Entonces una camioneta militar

nos alcanzó. [...]“ (S65)

Das Szenario eines Indianer-Lagers vermischt sich mit einem Bericht aus der Zeit der Diktatur. Es handelt sich um den Auszug aus einem Bericht der Abteilung für Menschenrechte der Erzdiözese von Concepción. Dort wird geschildert, wie eine Militärpatrouille im Juli 1986 einem Mann und einer Frau schwerste Verbrennungen zufügte. Sie wurden aufgehängt, mit Benzin übergossen und angezündet. Der Mann, ein 19jähriger Fotograf, starb kurz nach der Tat, die Frau, die 18jährige Studentin Carmen Gloria Quintana, schwebte wochenlang in Lebensgefahr. Dieser Fall von Menschenrechtsverletzung und Grausamkeit wurde einer der bekanntesten der Militärdiktatur, die Opfer zu Märtyrern.

An dieser Stelle wird Riveros zwischen den Zeitzeugen der Vergangenheit, die er heranzieht, selbst zum Zeugen seiner Gegenwart. Im selben Jahr, in dem Carmen Gloria Quintana und Rodrigo Rojas verbrannt wurden, sollte De la tierra sin fuegos veröffentlicht werden. Wie bereits zweimal, überschreitet Riveros den Rahmen „Feuerland“, wieder scheint es, als stehe die Vernichtung dieser drei Völker nicht nur für sich, sondern darüber hinaus exemplarisch für andere Verbrechen. Dabei ist Riveros aber sehr konkret. Er meint keine globale Gefahr, die die Menschheit ausrotten könne (wie im Motto von Murena), sondern er spricht von Gefahren und Repressionen in seiner unmittelbaren Gegenwart, in seinem Land. Die Parallele, die er zwischen den Ereignissen herstellt, situiert Riveros' Text und seine Absichten zeitlich und geografisch neu. So ist zwar sicherlich eine partielle Übereinstimmung mit den Interessen Gusindes unbestreitbar: „el hablante [...] se identifica con el etnólogo austríaco“. (Bianchi 1992:288) Wenn jedoch die Parallele mit der Gegenwart ins Bild rückt, wird deutlich, dass der Sprecher sich nicht auf ein Alter Ego Gusindes reduzieren lässt. Das erklärt sich relativ einfach mit der Pluralität der Stimmen, die Riveros in seinen Text eingebunden hat. Mindestens eine der zahlreichen Erzählerstimmen des Buches, nämlich der Erzähler des Prologs, identifiziert sich mit Gusinde. Die Stelle jedoch, an der eine Parallele zur Diktatur gezogen wird, baut einen starken Kontrast zwischen den Perspektiven und Absichten Gusindes und denjenigen Riveros' auf. Riveros ist Chilene, und sein Interesse gilt Chile. So entspringt die Anteilnahme am Schicksal der Ureinwohner Südchiles in gleichem Maße der Verbundenheit mit seiner Heimat wie einem 
anthropologischen Interesse. Vor diesem Hintergrund erscheint die ganze groß angelegte Erzählung vom Leben und Verschwinden der Feuerland-Indianer in der Vergangenheit wenn nicht als Vorwand so doch als ein anderes Erscheinungsbild der eigenen schmerzlichen Gegenwart.

Ehe Riveros sich inhaltlich wieder den Indigenas zuwendet, zitiert er aus der Chronique von Saint-John Perse:

Gran edad, henos aquí. Frescor de la noche sobre las cumbres, soplo de alta mar sobre todos los umbrales, y nuestras frentes desnudas para más vastos circos. (S66)

Der hymnische Beginn der Dichtung von Saint-John Perse stellt wiederum einen harten Bruch zum Vorangegangenen dar. Der beschriebene Abend ist friedlich und atmet gleichzeitig Aufbruchsstimmung und den Beginn einer neuen Zeit. Direkt im Anschluss wird die Schilderung Gusindes fortgesetzt:

[...] daß sie den in ihre Hände gefallenen Kindern gewisse Krankheitsstoffe einimpften und sie damit in die Wälder zurücklaufen ließen. Ziel dieser Grausamkeit war es, auch die und Erwachsenen zu durchseuchen. (Gusinde 1931:160)

Selbst das Strychnin wurde zum Bundesgenossen in dieser traurigen Episode unserer Kulturbestien. (Gusinde 1931:161)

Die letzte Strophe beginnt mit vier Versen, in denen der Erzähler seine Hilflosigkeit ausdrückt. Die Frage nach der behördlichen Zuständigkeit oder dem Protest der Öffentlichkeit verhallt nur unbefriedigend beantwortet. Das letzte Zitat, mit dem das Gedicht schließt, schlägt den Bogen zurück zum Titel, indem der Zeitraum von 30 Jahren der Vernichtung von Menschenleben wiederaufgegriffen und als „horroroso drama de aquella planeada destrucción“ zusammengefasst wird. ${ }^{86}$ So wird trotz der unterschiedlichen Elemente und Themen, aus denen der Text sich zusammensetzt, durch den letzten Vers eine gewisse Geschlossenheit erzeugt. Die heraufbeschworenen Bilder der Diktatur wirken einerseits wie ein Zwischenspiel, lassen aber andererseits keinen Zweifel darüber, dass beide Ereignisse eng miteinander verknüpft sind - als Parallelen ein und derselben Geschichte.

Auch der folgende Text, Dawson, basiert auf der Zusammenschau zum einen des Schicksals der Ureinwohner und zum anderen der Ereignisse während der Diktatur. Diesmal sind es 
14 verschiedene Zitate, die etwas über die Hälfte der Verse ausmachen, das vorangestellte Motto nicht mitgerechnet. Die Parallele zwischen beiden Themen wird hier noch augenfälliger, da derselbe Ort Schauplatz verschiedener Ereignisse ist. Viele Selk' nam wurden in den 90er Jahren des 19. Jahrhunderts gewaltsam auf die Insel Dawson verbracht und in Lagern eingepfercht. Dies geschah, nachdem sich Mitglieder katholischer Ordensgemeinschaften vermehrt an die Behörden gewandt hatten, um gegen die Behandlung der Selk'nam durch die Siedler zu protestieren. Statt aber nun die Situation des Volkes zu verbessern, begann eine großangelegte Deportation der Menschen zu der kürzlich errichteten Mission auf der Insel Dawson. Der Transport und die Unterbringung erfolgten unter schlimmsten Bedingungen:

Offensichtlich bezweckte man damit, die Isla Grande von den Eingeborenen zu säubern. Mit Gewalt wurden sie aus ihrer Heimat entführt und auf jene Insel verschleppt. [...] Indem man sie auf eine andere Insel verschleppte, heuchelte man vor aller Welt Menschenfreundlichkeit und Gerechtigkeit für die Eingeborenen. In Wirklichkeit aber mehrten sich die Drahtgehege, die Umzäunungen nahmen an Umfang zu, der Winchester-Flinten wurden es immer mehr, und auf jeden brauchbaren Fleck stellte man Schafe oder Rinder. (Gusinde 1931:162f.) $)^{87}$

Während der Diktatur entstand auf derselben Insel ein Konzentrationslager, so dass heute der Name der Insel in einem Atemzug mit der Villa Grimaldi, mit Pisagua oder mit Tejas Verdes genannt wird. ${ }^{88}$

Im vorangegangenen Abschnitt fand Aristóteles España mit seiner Testimonial-Lyrik Dawson bereits Erwähnung. Hier erinnert Riveros unter Verwendung des Titels und eines Zitates von España noch einmal daran, dass Dawson zwar ein Konzentrationslager für Ona und Alacalufe war, aber eben nicht ausschließlich: „También campo de concentración / de onas y alacalufes“ (S67; meine Hervorhebung). Damit leitet er über zum Hauptthema. Die Rolle der Insel während der Diktatur wird nur mit einer Andeutung und schließlich am Ende des Textes wieder aufgegriffen. Wiederum wird als der Beweggrund für die Grausamkeiten gegenüber der Urbevölkerung Feuerlands der rücksichtslose Expansionswille der Farmer und Viehzüchter angeführt. Als Beleg dient ein Auszug aus einem Brief des Großgrundbesitzers Mauricio Braun, in dem er von der Notwendigkeit spricht, die

\footnotetext{
${ }^{86}$ Bei Gusinde 1931:154 heißt es: „Das gewalttätige Treiben der Weißen, die den lebensfähigen Volksstamm der Selk'nam innerhalb von drei Jahrzehnten erdrosselt haben, wird für immer als ekelhafter Schandfleck in der Menschheitsgeschichte stehen bleiben."

${ }^{87}$ Laut Gusinde existiert ein Vertrag, in dem festgelegt wurde, dass die Sociedad Explotadora der Mission auf Dawson pro überführten Indigena ein Pfund Sterling auszahlen würde. (Gusinde 1931:162)

${ }^{88}$ Die Villa Grimaldi ist der wahrscheinlich bekannteste Ort, an dem in Santiago Menschen gefoltert wurden.
} 
„indios“ von Feuerland auf die Insel Dawson zu bringen. ${ }^{89}$ Aus verschiedenen Briefwechseln Brauns stammen das dritte, das fünfte, das neunte, elfte und zwölfte Zitat. ${ }^{90}$ Bis auf ein Zitat nennen alle die Errichtung eines Lagers auf Isla Dawson als Lösung für den „asunto de los indios“. Die übrigen Zitate klagen die Haltung der Weißen an. José María Borrero, der Autor des Werkes La Patagonia Trágica, spricht von Massenmord: „[...] decidieron destruirlos en masa“ (V10); Gusinde schildert Einzelheiten: „pagaban una libra esterlina por cada indio asesinado [...] Sam Ishlop: Torturaba y profanaba luego los cadáveres“ (V18-20) und urteilt „Ninguna fiera se ha comportado de manera tan cruel como lo han hecho los blancos contra los indios indefensos“ (V36-38). Ein anderer Ausspruch Borreros wird nach einem Text der Salesianer zitiert: „[...] alcuni cacciatori de indii nella Terra de Fuoco" (V42-43).

Neben diesen eindeutig zuordenbaren historischen Zitaten bleiben 59 Verse, die manchmal die Stimme des Erzählers wiedergeben und manchmal Zitate aus anderen Kontexten darstellen. Bei den Erzählerkommentaren fällt insbesondere die Bemühung um Fakten, Namen und Zahlen auf. Ausführende und Geldgeber der Menschenjagd werden genannt: „Asesinato sistemático financiado / por las Grandes Compañías“ (V11f.), „Stubenrauch, Mc. Rae; Mr. Bond: / expertos cazadores de indios a sueldo“ (V16f.). Wir lesen, wie zunächst ein Kopfgeld für die Ohren, später für lebenswichtige Körperteile der Ona ausgesetzt wurde (V23-30). Verschiedene Arten der Verfolgung und Tötung werden aufgezählt: „eliminación del guanaco, / envenenamiento de alimentos, ropas, baleo indiscriminado. Fotografías“ (V39-41). Die Nennung von Fotografien in einem Atemzug mit dem Niederschießen von Menschen erinnert zum einen an die Angst der Ona davor, dass ihnen der Fotograf Gusinde die Seele rauben könnte, und ist zum zweiten als Anspielung auf den Goldsucher Julius Popper zu verstehen, der eine Truppe von Männern befehligte, mit denen er Jagd auf die Ona machte, wobei er sich als erfolgreicher Jäger mit seinen Opfern fotografieren ließ. Das letzte der beigefügten Fotos zeigt Popper auf der Jagd. Schließlich folgt eine Beschreibung der Salesianer-Mission im Telegrammstil:

1895: comienzo Misión Salesiana:

Alacalufes, 65; Onas, 111.

$[$.......................

Y en 1911, Septiembre, expiró el contrato de la Misión en Dawson con un cementerio de ochocientas tumbas. (S69f.)

\footnotetext{
${ }^{89}$ Mauricio Braun war einer der mächtigsten patrones Chiles jener Zeit. 1920 besaß er 1.376 .160 Hektar Land. Er und sein Zeitgenosse José Menéndez werden als dueños y señores en el sur beschrieben. (Pfleiderer 1998)

${ }^{90}$ Die Briefe sind nicht chronologisch geordnet.
} 
Der letzte Abschnitt kommt auf die in Titel und Motto angedeutete jüngere Geschichte der Insel zurück. Es handelt sich wiederum um ein Zitat, das etwa im selben nüchternen Stil mit Daten und Zahlen die Fortsetzung der Geschichte der Isla Dawson als Konzentrationslager unter Pinochet zusammenfasst.

Sehr viel stärker als im vorangehenden Text steht ein sachlicher Ton im Vordergrund. Mit Ausnahme der Briefe sind die einzelnen Abschnitte im Einklang mit der historischen Chronologie, Riveros scheint großen Wert auf präzise Angaben zu legen, die vermutlich eine klare Schuldzuweisung ermöglichen sollen. Die einzige Stelle, an der er sich größere Freiheit in der Zusammenstellung der Textfragmente nimmt, sind die Zeilen 31-35:

Grandes cacerías en la Patagonia.

¿Derechos humanos? ¿Derechos humanos Parada, Guerrero, Nattino? „Degollad a cuantos indios encuentren“

„Gran edad, henos aquí, tomad medida del corazón del hombre“. (S68)

Zunächst beschreibt er die Menschenjagden in Patagonien, erwähnt dann unvermittelt in einer Zeile die Namen von drei bekannterweise während der Diktatur ermordeten Kommunisten, (El degollamiento 2000) und fügt ein einzeiliges Zitat aus einem Brief von Braun aus dem Jahre 1896 an. Es folgen die beiden Verse, mit denen die Chronique von Saint-John Perse endet (deren erste beiden Verse sich bereits im vorigen Gedicht an die Bezugnahme auf die Diktatur anschlossen), und schließlich nimmt Riveros mit dem Gusinde-Zitat der nächsten Zeile den Faden der Chronik von der Ausrottung der Feuerländer wieder auf.

Über die dargelegten Stellen der beiden Texte Exterminio ona und Dawson hinaus finden sich keine weiteren direkten Anspielungen auf die Diktatur. Dennoch erlangt das Thema eine Präsenz in De la tierra sin fuegos, die in keinem Verhältnis steht zu der geringen Anzahl von expliziten Anspielungen. ${ }^{91}$ Das liegt zum einen daran, dass die Diktaturerfahrungen in Chile bei vielen Veröffentlichungen immer mitgedacht werden müssen. Zum anderen hat Riveros die betreffenden Anspielungen geschickt platziert und ihnen durch die Komposition des Textes besonderes Gewicht verliehen. Die Anspielungen stehen in

\footnotetext{
${ }^{91}$ Ich habe schon auf Galindo/Miralles hingewiesen, die das politische Anliegen dem anthropologischen an die Seite stellen. (Galindo 1992) Daneben sei Mauricio Ostria González angeführt: „[...] el texto asume un doble carácter elegíaco: dos historias de fuegos extinguidos, la de los antiguos fueguinos; la de los chilenos en los sucesos de 1973 se funden para exhibir la continuidad
} 
Gedichten, die das Schicksal der Selk'nam und der Alacalufe drastisch schildern. In beiden Fällen geht es um die Gewalt, die Menschen anderen Menschen antun. Inhaltlich ist der Querverweis zur Diktatur also folgerichtig. Durch die Konzentration der Verweise in zwei aufeinanderfolgenden Texten verdichtet sich die Koppelung, und die Assoziationen mit Ereignissen der Diktatur verlieren den Charakter der Zufälligkeit oder eines Zwischenspiels zugunsten einer Art ständig präsenten Parallelhandlung. Durch die Engführung mit zwei Zitaten aus Saint-John Perses Chronique wird das $\mathrm{Maß}$ an auktorialer Intentionalität noch erhöht. Nach dem Zitat aus dem Bericht der Erzdiözese fügt Riveros die ersten Verse der Chronique, nach dem Hinweis auf Opfer der Diktatur den letzten Vers des Werkes ein. Dadurch werden beide Stellen miteinander verknüpft, es wird ein Bogen geschlagen, der gleichzeitig eine gewaltige Ellipse impliziert. Da über 70 Strophen von Saint-John Perse ausgelassen werden, lässt sich leicht denken, dass auch die Verse über die Diktatur nur zwei Beispiele, Platzhalter oder Eckdaten einer umfangreichen Geschichte darstellen. Der Titel Chronique weist auf die Verankerung von Ereignissen im Lauf der Zeit und auf die Unumkehrbarkeit ihrer Abfolge hin. Die Auswahl gerade des Anfangs- und Endpunktes des Textes verstärkt den Hinweis auf die Linearität der Zeit. Das geht nicht konform mit dem Strukturprinzip des Textes, der die Verbrechen der Militädiktatur in gewisser Weise als eine Wiederholung oder Parallele zu den Verbrechen an den Selk'nam, Yámana und Qawashqar darstellt.

Auch die Tatsache, dass Riveros sich auf den Text von España bezieht, geht über ein rein inhaltliches Zitat hinaus. Riveros betont damit nicht nur die Parallelität der Ereignisse, dass also zweimal am selben Ort zu unterschiedlichen Zeiten Konzentrationlager existierten. Indem Riveros España aufgreift, zitiert er darüber hinaus die Gattung der TestimonioDichtung. Dadurch wird zwar sein eigener Text nicht zu einem Testimonio, doch nimmt er die Funktion des Testimonio in seinen Text mit auf, indem er sie benennt. Das Testimonio ist die Form der Literatur, die am deutlichsten Anklage erhebt. Im Gegensatz zu Texten, die ihre wahre Aussage verschleiern (Camouflage) oder verschweigen, dokumentieren Testimonios die Ereignisse unmissverständlich und konnten daher meist überhaupt nicht veröffentlicht werden, sondern wurden unter der Hand verteilt. Riveros' Text ist anders, aber das Zitat aus Dawson reicht aus, um eindeutig Stellung zu beziehen und den wenigen Hinweisen auf die politische Situation ein größeres Gewicht zu geben.

de un sacrificio en el que el verdugo es siempre el mismo: la codicia del Kolliot.“ (Ostria González 1992:183) 
Ich möchte noch einmal auf den Vergleich des Textes mit einem Palimpsest zurückkommen. Bei einem Palimpsest wird der alte Text ausgelöscht, um einen neuen auf demselben Material niederschreiben zu können. Wenn wir mit den Kritikern neben dem Verschwinden der Völker von Feuerland die Diktaturerfahrung als zweites großes Thema des Textes (und nicht nur zweier einzelner Gedichte) annehmen, wären die Geschehnisse der Diktatur der Inhalt des neuen Textes. Riveros kann diesen Text aber im Jahre 1986, also noch während der Diktatur, nicht so schreiben, wie er es vielleicht gerne getan hätte. Deshalb deutet er die Ereignisse der Diktatur nur spärlich mit drei Hinweisen an und lässt umso mehr vom alten Text in seinem Palimpsest stehen - von einem Text, der ebenfalls von Verbrechen erzählt und durch seine Nähe zu den aktuellen Ereignissen weit über sich hinausweist. Ein Ereignis aus der Vergangenheit zu erzählen, um auf Geschehnisse der Gegenwart hinzuweisen, ist eine der zahlreichen Camouflage-Techniken, derer sich die Schriftstellerinnen und Schriftsteller während der Diktatur bedienten, um mehr verstehen geben zu können, als sie offen sagen durften.

\subsection{Im Schatten der Vergangenheit}

Riveros präsentiert die Geschichten und die Geschichte, die er erzählen will, in einer eposartigen Versdichtung mit dokumentarischem Anspruch. Poesie und Zeugnis sind eng miteinander verflochten. Das betrifft nicht nur seine eigene Dichtung, sondern auch die Zitate anderer Dichter, die neben Auszügen aus historischen Quellentexten stehen.

Zwei große Themen sind es, die sich in Riveros' Text gegenseitig verstärken und in ihrer Wirkung unterstützen. Zum einen hat er das ethnographisch motivierte Anliegen, die Erinnerung an die Indígenas von Feuerland lebendig zu erhalten. Zum anderen will er aufschreiben, was er in der Gegenwart der Diktatur sieht und erlebt - und das auf den ersten Blick möglichst unauffällig. Das gelingt ihm insbesondere durch den Einsatz vieler verschiedener Stimmen und zudem von Stimmen, die wiederum mit den Stimmen anderer sprechen. Riveros zitiert häufig nach einer anderen Quelle. Das ist möglicherweise Zufall, da er die Originaltexte nicht vorliegen hatte. Möglicherweise ist es aber auch ein stilistischer Kunstgriff, um die Verschachtelung der Perspektiven und seine Technik der indirekten Aussagen zu verdeutlichen.

Dies ist eine Art, counter-history zu schreiben. Zunächst sticht die ethnographische Dimension des Textes von Riveros ins Auge. Erst beim näheren Hinsehen zeigt sich insbesondere in der Verflechtung der Geschichte der ehemaligen Feuerlandbewohner mit Anspielungen auf die Diktatur ein anderes historisches Anliegen, das beim Weiterlesen gar nicht mehr so 
verschieden zu sein scheint vom ersten. Vielmehr entsteht durch die Koinzidenz des Ortes (Dawson) der Eindruck, dass beide Formen der gewaltsamen Ausschreitungen Teile derselben Geschichte oder, fatalistisch formuliert, zwei Ausdrücke desselben Schicksals sind. Diese letzte Konnotation verstärkt sich angesichts der Präsenz des Werkes La patagonia trágica, aus dem Riveros im Text Dawson zitiert und dessen Titel das Gefühl von Unausweichlichkeit und Tragik evoziert. Trotzdem entsteht nicht der Eindruck, dass Riveros diese fatalistische Haltung übernimmt. Seine drastischen Zitate wirken eher wie der Versuch, die Leserinnen und Leser wachzurütteln. Die Anklage der politischen Situation seiner Gegenwart, die nicht ganz deutlich ausgesprochen werden kann, wird durch die Anklage der vergangenen Verbrechen mitgetragen, in seiner Gesamtheit entsteht ein offensiver und engagierter Text. 


\section{ROSABETTY MUÑ OZ: BAILE DE SEÑ ORITAS}

Rosabetty Muñoz ist 1960 in der Stadt Ancud auf der Insel Chiloé (X. Region) geboren, wo sie auch aufwuchs. Mit sechzehn ist sie an der literarischen Gruppe Chaicura beteiligt und später während ihres Studiums in Valdivia Mitgründerin der Gruppe Índice. Heute lebt sie wieder in Ancud, wo sie als Lehrerin arbeitet.

Fünf Bücher von Muñoz wurden bereits veröffentlicht, und in allen spielt ihre Heimat eine große Rolle. Im Zusammenhang dieser Arbeit ist insbesondere der Band Baile de Señoritas von Interesse.92 In dem 1994 erschienenen Gedichtzyklus erzählt Muñoz die Geschichte Chiloés, bzw. die der Menschen auf der Insel - aus der Sicht der Frauen: „Cómo ven y cómo se sitúan en la historia y en esta historia particular de Chiloéc. (Trujillo 1993b:Kap.3.5) Dabei geht es immer wieder um das Wechselspiel von einerseits dem Ursprünglichen, Indigenen, Eigenen und andererseits dem Fremden, Anderen, das von außen die Insel betritt und in die Welt Chiloés eindringt. Es sind Geschichten des Besetzt-, Eingenommen- und Verführtwerdens, Geschichten zwiespältiger Annäherung, meist im bildlichen Rahmen der Geschlechtermetaphorik gehalten. Das eigentlich historische Element erschließt sich beim Lesen jedoch nicht auf den ersten Blick. Zwar enthält der Text eindeutig historisch konnotierte Begriffe an exponierten Stellen, nämlich die Gedichttitel Conquista (S11) und Colonizadores (S58). Doch beim näheren Hinsehen scheint das eine Fährte zu sein, die in die Irre führt, da weiterführende Hinweise zunächst schwierig zu entdecken sind. Dieses Kapitel will aufdecken, inwieweit das Buch doch recht konstant Geschichte erzählt und durch seine eigenwillige Perspektivierung gleichzeitig das Erzählen von Geschichte problematisiert.

Zunächst werde ich mit einem Überblick über die Geschichte der Insel Chiloé die nötigen Hintergrundinformationen liefern, um in den folgenden Abschnitten 5.2 bis 5.4 mit Hilfe von Textanalysen die spezifische Historizität des Zyklus herauszuarbeiten.

\footnotetext{
${ }^{92}$ Muñoz weist in einem Interview darauf hin, dass ihr die Idee zum Titel Baile de Señoritas durch die Bilder ihrer kleinen Tochter kam: „Ella siempre está dibujando a un montón de señoritas que están como inclinadas hacia el sol y siempre a sus dibujos los llama ,Bailes...' o ,Fiestas de señoritas'. Esto tiene mucha relación con lo que yo estoy haciendo, mostrar como viven su historia las mujeres de Chiloé. (Trujillo 1993b:Kap.3.5)
} 


\subsection{Die Geschichte Chiloés}

Mit Chiloé ist meistens nicht allein die Isla Grande gemeint, sondern der gesamte Archipel, zu dem zahllose kleine Inseln gehören, die sich um die Hauptinsel herumgruppieren. Die Geschichte von Chiloé ist geprägt durch kulturelle und gesellschaftliche Eigenständigkeit, insbesondere die Unabhängigkeit vom Festland, später dann die Unabhängigkeit gegenüber Chile bis hin zur politischen und gesellschaftlichen Isolation: „Este archipiélago presenta características de tan descollante diferenciación con el resto del país, que revelan una personalidad destacada e inconfundible.“ (Montiel 2000:Historia/Historia de Chiloé)

Über das Volk der Chono, die ursprünglichen Bewohner der Insel, weiß man wenig. Sie waren Nomaden zu Wasser und ernährten sich hauptsächlich vom Fischfang und von Meeresfrüchten. Bis heute tragen viele Inseln des Archipels die ursprünglichen ChonoNamen, so Apiao (,wo die Erde aufhört') oder Caguache (,andere Falle).

Als das Volk der Huilliche (auch Veliche) nach Chiloé kam, wurden die Chono nach Süden gedrängt und verschwanden schließlich vollständig. Die Huilliche lebten von Landwirtschaft und Fischfang und prägen bis heute Kultur, Tradition, Sprache und das gesellschaftliche Zusammenleben auf Chiloé.

[...] en contraste con otros pueblos que fueron sojuzgados por los europeos, los de Chiloé continuaron desarrollando sus tradiciones ancestrales, muchas de las cuales compartieron con el invasor por todo el período colonial y han sobrevivido hasta el presente. (Montiel 2000:Historia/Historia de Chiloé)

1553 durchquerten mehrere spanische Expeditionen den Kanal von Chacao. Als Entdecker von Chiloé gilt jedoch der Seefahrer Francisco de Ulloa, da er sich in eben jenem Jahr als einziger der Erkundung des Archipels widmete, Orte benannte und genaue Aufzeichnungen anfertigte. Fünf Jahre später gelangte der Dichter Alonso de Ercilla mit einem Vortrupp der Spanier nach Chiloé. Seine angenehmen Erinnerungen an die Insel sind in der Araucana nachzulesen:

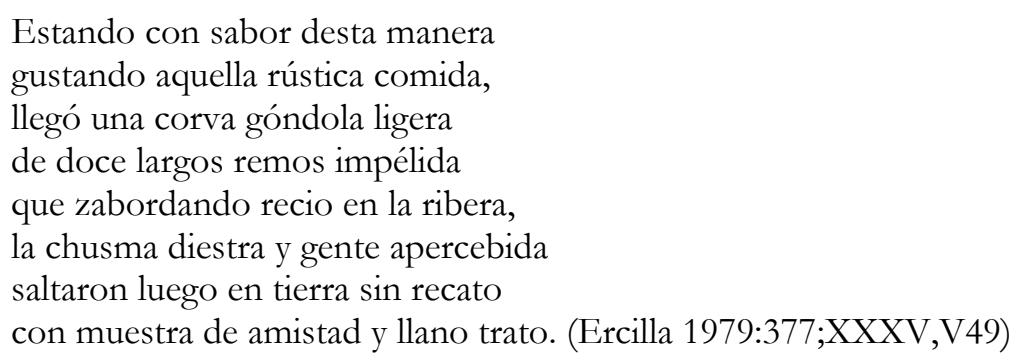

Im Rahmen der Expansionspolitik Pedro de Valdivias nahm 1567 Martín Ruiz de Gamboa den Archipel in Besitz, nannte ihn Nueva Galicia und beanspruchte die Inseln für Spanien. In allen Begegnungen hatten sich die Huilliche als friedfertige und gastfreundliche Menschen erwiesen, und auch Gamboa knüpfte sofort freundschaftliche Beziehungen zu den Bewohnern von Chiloé. 
Nach zwei Monaten hatte sich Gamboa mit der Insel vertraut gemacht, die Hauptstadt Castro gegründet und begonnen, das Land unter seinen Leuten aufzuteilen. Einen weiteren Monat später kehrte Gamboa nach Valdivia zurück. Unterdessen wurden die ursprünglichen Eigentümer des Landes, die Huilliche, gezwungen, das ihnen geraubte Land für die Spanier zu bearbeiten. Es fiel nicht schwer, das System der encomienda durchzusetzen, ${ }^{93}$ da die friedliebenden Huilliche schnell bereit waren, sich unterzuordnen:

Con el corazón ligero y alegre, sin sospechar siquiera que cooperaban a la pérdida de su libertad, les entregaban sus víveres y casas, sus piraguas y servidumbre „sin rescate, sin cuenta ni medida“. (Weber 1998)

Nicht nur die Ureinwohner, auch die natürlichen Ressourcen wurden in den folgenden Jahren ausgebeutet. Goldvorkommen wurden gefunden und geplündert, Wollprodukte sowie das Holz der Lärche (alerce) wurden nach Lima exportiert. Neben dem materiellen Gewinn erzielten die Spanier mit der Eroberung Chiloés einen strategischen Erfolg. Durch die Errichtung eines Vorpostens, den alle Schiffe passieren mussten, die vom Atlantik her um die Südspitze Amerikas herumgesegelt waren, meinten sie, ihr neues amerikanisches Reich nach Süden hin ausreichend abgesichert zu haben.

Chiloé fue desde los albores de la conquista española un punto estratégico de interés geopolítico para consolidar la ruta austral a las Indias Orientales y a los océanos ignotos al otro lado de la América Hispana. (Montiel 2000:Historia/Historia de Chiloé)

Die ohnehin schwierige Kommunikation mit den Städten Osorno, Valdivia oder Concepción wurde nach dem Aufstand der Mapuche von 1598-1604 auf dem Festland vollends unterbrochen. Im sogenannten desastre de Curalaba (1598) zerstörten die Ureinwohner die sieben spanischen Orte und Stützpunkte südlich des Bío-Bío „eliminando todo vestigio de ocupación hispana y rompiendo el contacto que permitía al núcleo histórico de la zona central una relación regular con las fronteras de conquista [sid]“. (Montiel 2000:Historia/Historia de Chiloé) Die Situation verschärfte sich durch gleichzeitige Übergriffe von Piraten auf Chiloé. Der indigenen Bevölkerung Chiloés war mittlerweile deutlich geworden, dass die Spanier ihr Volk und ihre Kultur unterdrückten, und ermutigt durch den Aufstand der Mapuche und die dadurch geschwächte Position der Kolonisatoren verbündeten sie sich 1600 mit den holländischen Freibeutern unter Simón de Cordes gegen den gemeinsamen Feind Spanien. Mit Hilfe der Huilliche gelang es den Holländern, Castro einzunehmen; viele Spanier wurden getötet oder gefangengenommen. Eineinhalb Monate später konnten Spanier, vom Festland kommend, die Stadt in einem Überraschungsangriff zurückerobern.

\footnotetext{
${ }^{93}$ Encomienda bezeichnet das institutionalisierte Abhängigkeitsverhältnis zwischen spanischen Landherren und hörigen Indigenas, ähnlich dem mittelalterlichen Frondienst.
} 
Als Folge dieser Ereignisse blieben etwa 200 Spanier auf Chiloé zurück, abgeschnitten auf dem Land, das sie eingenommen hatten. Dante Montiel stellt fest:

En síntesis, los dos hechos coincidentes: la rebelión mapuche del continente y el asalto corsario a la ciudad de Castro, produjo el aislamiento geográfico y cultural acentuado por la condición de Isla, desvinculándose del núcleo histórico [...]. Separación que marcó el origen de un largo proceso de desemejanza entre chilotes y chilenos. Circunstancias históricas que más significación tuvieron en la configuración del perfil del mundo insular. (Montiel 2000:Historia/Historia de Chiloé)

Die spanischen Kolonisten waren auf der Insel gefangen, und es gab kaum eine Möglichkeit, in die von Spanien kontrollierten Gebiete auf dem Festland zu gelangen. Aufgrund der kriegerischen Natur der Mapuche wagten es die Chiloten nicht, auf dem Landwege in Richtung Norden zu reisen. Die Überfahrt in kleinen Booten von Chiloé bis nach Concepción war beschwerlich und gefährlich, und die Mitfahrt in einem Handelsschiff war sehr teuer. Außerdem kam im 17. Jahrhundert oft nur ein einziges Handelsschiff im Jahr von Lima herunter bis nach Chiloé.

Im Laufe der nächsten Jahrzehnte verschlechterte sich die Situation für die Bewohner von Chiloé drastisch. Sie litten Hunger und Armut, es konnten drei oder vier Jahre verstreichen, ohne dass ein Schiff vom Festland gekommen wäre. 1615 und 1643 erfolgten weitere Angriffe von Piraten, diesmal ohne Beteiligung der Huilliche. Im Jahre 1646, nach einem verheerenden Erdbeben, wandte sich die spanische Bevölkerung an den Vizekönig in Lima und bat um Erlaubnis, die Insel verlassen zu dürfen; es wurde ihnen nicht gestattet. Die anschließende unfreiwillige Isolation im 17. und 18. Jahrhundert prägte die Kultur und Mentalität der Chiloten:

Del punto de vista cultural, los chilotes mostraban un acentuado arcaísmo en usos y costumbres, en su visión de mundo, en su lenguaje y en sus concepciones políticas, debido al aislamiento e incomunicación con otras poblaciones de españoles y, por lo mismo, quedan al margen del proceso histórico que se vivía en el centro del Reino de Chile o en el Perú. [...] El desenvolvimiento de la vida en la „popa del mundo“, como decían los chilotes, se hacía „puertas adentro“, en contacto cotidiano con los indígenas posibilitando intercambios culturales entre unos y otros. (Montiel 2000: Historia/Período colonial)

In der Abgeschiedenheit Chiloés fand einerseits eine starke kulturelle Vermischung statt, in der die spanischen Kolonisten Lebensgewohnheiten, Kleidung, Bräuche, Mythen und Teile der Sprache der Huilliche übernahmen. Andererseits bewahrten sie sich eine zT unzeitgemäße Einstellung, insbesondere ihre Haltung Spanien gegenüber betreffend. Ungeachtet der Behandlung, die der Vizekönig den Siedlern auf Chiloé hatte angedeihen lassen, behielten die Chiloten eine treue Ergebenheit der spanischen Krone gegenüber bei. Ihre besondere Loyalität zu Spanien bewies die starke königstreue Fraktion auf Chiloé, indem sie sich nach der 1817 erkämpften Unabhängigkeit Chiles neun Jahre lang weigerte, sich 
dem Land anzugliedern und unterzuordnen. Sie baten stattdessen sogar Großbritannien darum, ins Empire aufgenommen zu werden. Erst als Großbritannien ablehnte, ergaben sich die Royalisten der Republik: „Y cosa extraña, fueron los pobres milicianos Chilotes los que defendieron hasta el último momento la bandera Española y los que libraron las batallas de Ahui, de Lechagua y Pudeto.“ (Weber 1998)

Aber auch noch viele Jahre später trauerten die Chiloten um die verlorene Zugehörigkeit zur Monarchie, und bis heute ist bei vielen Chiloten das Gefühl, Chilote zu sein, sehr viel stärker ausgeprägt, als das Gefühl, Chilene zu sein. ${ }^{94}$

Die jüngste Geschichte Chiloés ist geprägt von starken Veränderungen. Bis vor zwanzig Jahren gab es auf dem Archipel keine Marktwirtschaft im modernen Sinn, keine Arbeiterklasse, keine Ausbeutung. Erst durch die Ausbreitung von transnationalen Unternehmen ist innerhalb einer Gesellschaft von Bauern und Fischern ein Proletariat entstanden. Rosabetty Muñoz äußert hierzu in einem Interview:

Nosotros no tenemos ni pobreza ni riqueza en los términos en que lo entienden ellos [los no-chilotes]. Nuestro nivel de vida en Chiloé - como nosotros lo entendemos - es lo que nos lleva a apreciar los valores personales mucho más que lo que económicamente podamos tener. Nosotros, desde hace unos seis o siete años, hemos venido viendo la invasión de modelos económicos; antes no.

Jamás un chilote se vio en la indignidad de andar pidiendo limosna, tenía su pedacito de tierra fértil, su mar fértil. Nunca habíamos visto el mar cercado en propiedad privada, jjamás! Y lo estamos viendo ahora. (Trujillo 1993b:Kap.3.5)

Mittlerweile wird Chiloé nicht nur industriell, sondern auch touristisch erschlossen, und viele Chiloten fürchten, dass die Insel ihr individuell gewachsenes Wesen verlieren könnte.

\subsection{Invasiones: Männer kommen übers Meer}

Der erste Teil des Zyklus' Baile de Señoritas ist Invasiones, Invasionen, überschrieben. Er enthält 30 der insgesamt 48 Gedichte und insbesondere fast alle jene Texte, in denen historische Situationen dargestellt werden. Im zweiten Teil Baile de Señoritas steht das Leben der Frauen auf Chiloé heutzutage im Mittelpunkt.

Dieser Abschnitt beschäftigt sich im Wesentlichen mit den ersten sieben Gedichten des Buches.

Muñoz nennt an keiner Stelle eine Jahreszahl oder einen Namen, mit dessen Hilfe man die Ereignisse historisch festmachen könnte. Stattdessen beschreibt sie einzelne Szenen, die

\footnotetext{
${ }^{94}$ So äußert Julio R. Norambuena Jipoulou auf seiner Webseite Breve Historia de la Isla de Chiloé: „en realidad primero soy chilote, después chileno“. (Norambuena:1998)
} 
oftmals nicht mehr als Anspielungen auf tatsächliches Geschehen beinhalten. Mit dem Motto des ersten Teils existiert hingegen von Anfang an eine geographische Verortung: „Chiloé es un navío enceguecido / dando vueltas sin parar / sobre remolinos de agua“.

Diese Verse führen gleich zwei der Isotopien ein, die den gesamten Band beherrschen: Zum einen Meer und Seefahrt („navío“, „remolinos de agua“, die Insel Chiloé), zum anderen das Sehen/Nicht-Sehen („,enceguecido“). Die erste Isotopie gehört zur natürlichen Umgebung Chiloés selbstverständlich dazu; die zweite ist ein alltäglicher Bereich des menschlichen Lebens und Zusammenlebens und bildet im Allgemeinen für den Menschen die wichtigste Instanz, wenn es darum geht, seine Umwelt wahrzunehmen. Beide erhalten ebenfalls schon in den vorangestellten Versen zusätzlich zu der konkreten eine metaphorische Bedeutung: Die Erblindung des Schiffes drückt Orientierungslosigkeit aus, und das aufgewühlte, wirbelnde Wasser, in dem Chiloé sich dreht, könnte die wechselhafte Vergangenheit der Insel symbolisieren, in der sie zum Spielball der Geschichte wurde und/oder eine bewegte Gegenwart.

Die sieben Texte, die das Buch eröffnen, erzählen vom ersten Kontakt zwischen zwei Gemeinschaften: In El Arribo (S9) beobachtet eine Gruppe von Frauen voll sprachloser Anspannung („mudas y palpitantes“), wie ein fremdes Schiff an ihrer Küste anlandet. Grammatisches Subjekt der ersten drei Zeilen ist nicht das Subjekt der Handlung, des Beobachtens, also die Frauen, aus deren Perspektive berichtet wird, sondern das Objekt der Beobachtung, die Männer. Deren Äußeres lässt auf eine lange und beschwerliche Überfahrt schließen („el mar metido en la coyuntura“). Die Finger und Gelenke sind eingesteift von Kälte und Feuchtigkeit („los dedos agarrotados`), ihre Augen scheinen überzufließen, zum einen sicher vor Freude und Erwartung, zum anderen ist in „desbordados“ der Schiffsbord enthalten, über den hinaus die Blicke nun dem „borde“, dem Ufer zustreben. Das ist als erster Eindruck zu verstehen, den die Frauen von den Ankömmlingen haben. Es fällt auf, dass nicht die Rede davon ist, ob die Fremden Waffen tragen, dass keine Spekulationen angestellt werden, ob sie in friedlicher oder feindlicher Absicht kommen. Stattdessen erfährt man etwas über ihre Finger und Augen. Während dieser Beobachtungen verschwindet die alltägliche Landschaft um die Frauen herum („Desaparecieron árboles, cercos, todas / las minucias"), sie scheinen völlig in den Bann dieser Fremden gezogen und verfolgen deren Verrichtungen beim Anlanden des Schiffes.

Im zweiten Gedicht Voladores de Luces (S10) verdichten sich die beiden Gruppen der einheimischen Frauen und der fremden Männer zu einem yo und einem él. („Lo vi asomado 
a la borda"). Was das Ich beschreibt, ist ein Flirt, ein Spiel von Spannung und Erwartung: Beide betrachten sich aus der Ferne und erwarten, dass ihre Blicke sich treffen (,ambos expectantes / un enfrentamiento de ojos" ${ }^{\star}$ ). Dieser scheinbar individuelle Blick in die Augen des anderen wird jedoch bewirken, dass sich die gesamte Insel kollektiv den Eindringlingen ergibt: „que provocó la rendición de la isla“.

Das Gedicht Conquista (S11) knüpft an das Thema des Flirts an und bleibt in der Perspektive einer ersten Person Singular: Der Fremde nähert sich „con maestría“ dem Ich, also der Frau, sein Verhalten wird mit dem eines Vogels verglichen, der sich das Gefieder putzt („ordena el plumaje de sus alas"). Die beschriebene Szene will an einen balzenden Vogel erinnern, also an ein vermeintlich natürliches und instinktives Verhalten zwischen den Geschlechtern. ${ }^{95}$ Andererseits konnotiert das Bild auch schon den geflügelten Amor, der in den nächsten Zeilen erscheint. Zunächst ist er noch „sostenido en una cuerda“, dann versucht er, alle Zurückhaltung und Widerstände zu überwinden („Sin frenos, de dientes afilados / asidos -graves- al hilo del amor").

Durch den Titel Conquista wird der Text doppeldeutig, es bildet sich eine Parallele zwischen der emotionalen Hingabe einer Frau gegenüber einem Mann und dem Fall der Insel in die Hände ihrer Eroberer. Neben der Beschreibung einer sexuell konnotierten Annäherung zweier einzelner Menschen, neben dem individuell-privaten Bereich also, erkennen wir eine historische machtpolitischen Situation und das Schicksal einer Gesellschaft. Der Text legt nahe, dass die Eroberung der Insel wie ein Flirt, wie eine Verführung vor sich gegangen sei.

El mujerío (S12) knüpft an den Moment des ersten Anblicks an und beschreibt etwas genauer, was eigentlich passiert zwischen den Ankömmlingen und den Frauen: Er (der Fremde, der Eroberer, der Geliebte) erscheint am Bug des Schiffes und „todas las grietas del pueblo / salieron a la superficie“. Risse werden sichtbar innerhalb des Dorfes, innerhalb der Gesellschaft. Ängste und Sehnsüchte brechen auf, die vorher unter der Oberfläche verborgen waren. Zunächst ist es die Furcht, es könne sich um Piraten handeln, die die Frauen in Atem hält (,,rogando sin voz, todas juntas / para que no sean piratas“). Dann ist es die Gestalt der Fremden selbst: Der Glanz ihrer Helme blendet und macht blind („,Y enceguecieron también unidas / por el brillo del sol sobre el casco / gigantesco"). Im Zusammenhang mit den vorangehenden Texten ist es nicht so sehr die Angst der Frauen, die Sprünge und Brüche entstehen lässt, sondern vielmehr das verwirrende Strahlen des Helms, das sie blind macht. Noch wird nicht deutlich, wofür sie blind werden. Aber

\footnotetext{
${ }^{95}$ In ganz Südchile existiert eine sehr artenreiche Avifauna, so dass der Vergleich einem einheimischen Menschen naheliegen mag.
} 
aufgrund der historischen Entwicklung kann man bereits ahnen, dass es sich um Blindheit für eventuelle Feindseligkeiten der Fremden handelt, für die egoistischen Absichten der Männer, aber auch um die Blindheit für ihr eigenes Verlangen, das sich möglicherweise gegen das Wohl ihres Volkes richten könnte.

In den Texten Mujerío I-III (S13-15) setzen sich die widersprüchlichen Gefühle den fremden Männern gegenüber fort. Verschreckt durch das Licht, das sie mit sich bringen, ziehen sich die Frauen zurück und beobachten nun hinter ihren Gardinen weiter („Retrodecimos intimidadas por la luz, / [...] / Después, seguimos mirando entre las cortinas`). Dann beginnen die Frauen, die Fremden mit ihren eigenen Männern zu vergleichen:

Tanto hombre de lejos que venía.

Y con ellos

la remota promesa de borrar

a estos mezquinos nuestros

que comen y duermen demasiado. (S14)

Die Fremden imponieren durch ihre (vermeintliche) Männlichkeit, durch ihre Entschlossenheit und durch das Geheimnis, das ihre Herkunft umgibt. Über ihre eigenen Männer wissen die Frauen nichts zu sagen, als dass sie zu viel essen und schlafen.

In Mujerío III zeigen sich die Frauen nach außen noch immer befangen und zurückhaltend, wenn auch bereits ,a la punta de la esperanza“. In diesem Text erfahren wir, dass die Frauen allein sind: „Han visto partir a sus hombres“. Und wieder wird die erste Begegnung aufgenommen:

Ellas, las primeras en avistar

a los ajenos que venían.

Sólo alzaron ligeramente los brazos:

un resignado gesto que lo mismo valía

para llamar a sus niños. (S15)

Eine resignierte Geste, aber auch eine unentschiedene, eine doppeldeutige Gebärde. Sie kann eine Begrüßung sein, ebensogut ist es denkbar, dass die erhobenen Arme die Fremden verscheuchen sollen.

Wie bereits erwähnt, gibt es keine Daten oder Namen, aufgrund derer sich das beschriebene Geschehen mit Bestimmtheit historisch einordnen ließe. Jedoch: Fremde Männer, die auf einem Schiff von weit her kommen, Helme tragen, und in diesem Kontext der Gedichttitel Conquista sind klare Anspielungen auf die Ankunft der Spanier in Amerika. Die Helme, die im Text El mujerío Erwähnung finden, sind Teil der Rüstung, die auch die 
Mexikaner unter Moctezuma beeindruckten. ${ }^{96}$ Mit der zusätzlichen Blendwirkung der sich auf den Helmen spiegelnden Sonne macht Muñoz das herannahende Schiff zu einem Anblick, der Ehrfurcht, Angst und Bewunderung hervorrufen muss. ${ }^{97}$ Mit ähnlichen Gefühlen haben die Azteken den spanischen Schiffen engegengeblickt, da sie die Rückkehr des Gottes Quetzalcoatl erwarteten, der alten Prophezeihungen nach aus Osten wiederkommen würde, wohin er auch verschwunden war.

Los indígenas fueron, al principio, derrotados por el asombro. El emperador Moctezuma recibió, en su palacio, las primeras noticias: un cerro grande andaba moviéndose por el mar. [...] Moctezuma creyó que era el diós Quetzalcoatl quien volvía. Ocho presagios habían anunciado, poco antes, su retorno. (Galeano ${ }^{61985: 23 f .)}$

Die Fremden haben leichtes Spiel: Eine einzige Begegnung der Blicke bewirkt, dass sich ihnen die gesamte Insel ergibt. Das entspricht ungefähr der Anstrengung, die Ruiz de Gamboa aufwenden musste, um Chiloé zu unterwerfen. Übereinstimmend werden - wie erwähnt - die Ureinwohner Chiloés, die Huilliche, als friedfertig, gastfreundlich, arglos beschrieben. Sie haben zunächst genauso wenig Widerstand geleistet wie die Frauen bei Muñoz dies tun.

Diese Feststellung führt direkt zur nächsten Beobachtung: Die Insel in den Texten von Muñoz ist ausschließlich von Frauen bewohnt. Zunächst erfährt man nichts über die dazugehörigen Männer. In Mujerío III stellt sich dann heraus, dass sie fortgegangen sind. Im Verlauf der Geschichte Chiloés gab es in der Tat Zeiten, in denen ein großer Teil der männlichen Bevölkerung die Insel verließ, um auf dem Festland Arbeit zu finden. In der ersten Zeit der spanischen Kolonialisierung, Ende des 16. und Anfang des 17. Jahrhunderts, wurden viele Huilliche, die aufgrund ihrer kooperativen Haltung von den Spaniern als Arbeitskräfte herangezogen wurden, aufs Festland gebracht, wo sie als abhängige Landarbeiter eingesetzt wurden.

Von Beginn des 20. Jahrhunderts bis in die 70er Jahre gingen viele Chiloten als Landarbeiter nach Osorno, für verschiedenste Arbeiten in den Süden nach Punta Arenas oder in den argentinischen Teil Patagoniens oder aber in den Norden Chiles, um im Salpeterabbau Arbeit zu finden. Oftmals blieben sie zehn Jahre oder länger von ihrer Familie getrennt.

Muñoz äußert zur aktuellen Situation der Frauen auf dem Archipel:

[...] aquí en Chiloé las mujeres siempre han dominado la situación y esto está muy presente en Baile de Señoritas. Para percibirlo bastaría visitar las islas; Quenac, por ejemplo, es prácticamente una isla de mujeres. Allá son ellas quienes toman todas las decisiones. Los

\footnotetext{
${ }^{96}$ Man kann mit dem glänzenden Helm, der für die Menge der Eroberer steht, auch die uniformierten Militärs unter Pinochet assoziieren.

97, „.... traían armaduras y cotas de malla, lustrosos caparazones que devolvían los dardos y las piedras.“ (Galeano 61985:24)
} 
hombres se van, vuelven, invernan durmiendo y ellas son las que manejan a los niños, las casas, las siembras. (Trujillo 1993b:Kap.3.5)

Die Gesellschaft von Frauen, wie Muñoz sie beschreibt, kann sich aber nicht auf die Zeit direkt nach der spanischen Eroberung Chiloés beziehen, wenn wir annehmen, dass es sich bei den Ankommenden um die Spanier handelt. Wenn es sich andererseits auf das 20. Jahrhundert bezieht, stellt sich die Frage, wer die Männer sind, die von weit her übers Meer kommen.

Hier eröffnet sich eine neue Bedeutungsebene, die berücksichtigt werden muss: Seit der zweiten Hälfte des 20. Jahrhunderts greift ein entscheidender gesellschaftlicher und wirtschaftlicher Wandel auf Chiloé um sich. Die globale Marktwirtschaft beginnt, auf der Insel, die so lange Jahre praktisch völlig abgeschnitten vom Rest der Welt war, Fuß zu fassen. ${ }^{98}$ Hinzu kommt, dass das Archipel zu einem touristischem Anziehungspunkt geworden ist. Beide Entwicklungen bringen es mit sich, dass in den letzten zwanzig Jahren viele Fremde die Insel besucht haben. Auch diesen Fremden gegenüber sind die Chiloten aufgeschlossen und gastfreundlich, obwohl mittlerweile Stimmen laut werden, die beklagen, dass die Insel beginne, ihre Eigenart zu verlieren, ihr besonderes historisch gewachsenes Selbstverständnis.

Da Muñoz sich aktiv für die Erhaltung der traditionellen Strukturen auf Chiloé und gegen die Vereinnahmung durch fremde wirtschaftliche, kulturelle und gesellschaftliche Entwicklungen einsetzt, kann man davon ausgehen, dass auch diese aktuelle Invasion in ihren Texten gemeint ist. In einem Artikel über die lokale Kultur auf Chiloé verdeutlicht Muñoz ihren Standpunkt gegen die Globalisierung und Vereinheitlichung von Kultur:

[...] habría un pensamiento y un lenguaje que „conquistaría“ los espacios, lenguajes y cultura particulares para homogenizar una cierta cultura del desarrollo en que los hombres compartirían las características del „ciudadano del mundo“. Aparte de los borrosos contornos que adquiere este sujeto y que en ocasiones se parece peligrosamente a un ser que habla inglés, come en hamburguerías, juega en parques de Fantasilandia o, en su defecto, desprecia las carnes por las verduras, abjurando del todo lo que no sea culto al cuerpo, defiende a las minorías pero habla desde el poder, etc. (Muñoz 1993a:47)

Muñoz prangert hier eine Lebensweise an, die in erster Linie als US-amerikanisch gekennzeichnet ist, aber schon vor Jahren ihren Siegeszug um die Welt angetreten hat und heute allgemein zum Ausdruck moderner Konsumgesellschaften geworden ist: Hamburger, Vergnügungsparks und Körperkult, Vegetarismus und Minoritätendiskurse sind als Modeerscheinungen von den USA ausgegangen und haben sich praktisch überall auf der Welt verbreitet.

\footnotetext{
${ }^{98}$ Vgl. die Studie der Regierung der Provinz Chiloé. (Gobernación provincial de Chiloé 1997:5)
} 
Im Folgenden macht Muñoz deutlich, wie eng der Zusammenhang ist, in dem ihrer Meinung nach diese kulturelle Eroberung mit der Conquista vor über 500 Jahren steht:

¿Qué tiene en común? Lo reduciría a dos rasgos fundamentales: un afán de conquista o criterio del conquistador según el cual pueden entrar en un espacio cultural y „educarlo“ según sus propias concepciones del mundo: y el desprecio solapado por la cultura invadida a la que califican de „provinciana“, „mediocre“, „atrasada“. (Muñoz 1993a:47)

Diesmal sind es nicht die Spanier, sondern es ist das kapitalistische System, hinter dem die USA, Europa, aber auch Chile stehen. ${ }^{99}$ Insbesondere die abwertend gemeinte Bezeichnung als provinciana beschreibt die Sichtweise der Chilenen nahe der Metropole gegenüber Südchile und Chiloé.

Da beide Invasionen der Suche nach neuen Wirtschaftsräumen entspringen, fällt eine Parallelisierung dieser ähnlichen Phänomene verschiedener Zeiten nicht schwer. Man muss davon ausgehen, dass beide Invasionen im Text gemeint sind, und auch dort, wo eindeutig ein Kontext aktualisiert wird, die jeweils andere conquista mitgedacht werden muss.

Für eine dritte Antwort auf die Frage nach den abwesenden Männern ziehe ich einen weiteren Text heran, das elfte Gedicht Bucaneros (S19). Hier steht nicht das Verhältnis zwischen den Frauen und den Fremden im Vordergrund, sondern das zwischen den Frauen und angreifenden Piraten (auch hier kann man von einer rein männlichen Gruppe als Gegenüber ausgehen). Es ist eines der wenigen Gedichte im Zyklus, in dem nicht das Wir, sondern eine erste Person Singular spricht. Das Ich steht auf einem Hügel und erlebt oder erinnert den Überfall der Piraten, bei dem der Ort Castro vollkommen niedergebrannt wird. Die Piraten werden als brutal und rücksichtslos beschrieben: „Los bucaneros saltan de isla en isla / celebrando la bastedad del fuego que les brota“. Im auffälligen Gegensatz dazu steht die Reaktion der anderen Seite, in diesem Fall der personifizierten Inselgruppe:

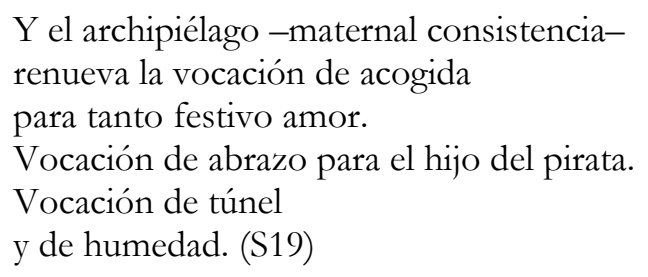

Die Insel nimmt eine Mutterrolle ein und steht somit symbolisch für die Frauen der Insel. Trotz der Gewalt, die ihr entgegengebracht wird, reagiert „Mutter Chiloé“ mit einem Willkomm, mit Liebe, mit Umarmung. Die Umarmung ist für den Sohn des Piraten vorgesehen, ein Hinweis darauf, dass auch die Kinder mit Liebe aufgenommen werden, die 
vermutlich aus Vergewaltigungen durch die Piraten hervorgegangen sind. Das Wort vocación deutet an, dass Chiloé und die Frauen gar nicht anders können, es ist ihre Natur.

Männer und Frauen stehen einander im gesamten Gedicht-Zyklus als Antagonisten gegenüber, und zwar in einer radikalen Form: ,Wir, das sind immer die Frauen und nur die Frauen, ,sie ${ }^{6}$ sind immer nur Männer, und beide bilden die Pole oder Fronten des Geschehens. Diese Aufteilung innerhalb des Textes ist derart apodiktisch, dass die beiden Lager als symbolische Gegner verstanden werden können. Das soll heißen, dass den beiden Gruppen mit unterschiedlichen Interessen Eigenschaften zugeordnet werden, die traditioneller- und klischeehafterweise als ,typisch männlich` oder ,typisch weiblich` gelten.

Die Invasoren, Entdecker und Eroberer sind männlich: Sie streben nach Expansion, erobern Länder und Frauen und sind im Bereich der Familie abwesend. Das unterworfene Volk ist weiblich, indem es bereit ist, die Anderen aufzunehmen, zu beherbergen und zu umsorgen (besonders deutlich im Text Bucaneros). Es geht um zwei Einstellungen oder Lebensformen, die einander widersprechen, und, wo sie aufeinandertreffen, zu Diskriminierung und Ausbeutung führen, sowohl im Umgang der Geschlechter als auch der Völker miteinander. ${ }^{100}$

Die dritte Interpretation der abwesenden Männer würde also implizieren, dass gar nicht tatsächlich von einer Begegnung zwischen Männern und Frauen die Rede ist, sondern dass es sich um den Kontakt zwischen Huilliche und Spaniern - und später der zwischen Chiloten und den Fremden, die als neue Kolonisatoren empfunden werden, - handelt, der symbolisch durch den Konflikt zwischen den Geschlechtern dargestellt wird. So wie bei den Vögeln die Männchen durch auffälliges Federkleid und imponierendes Gehabe Aufmerksamkeit bei den Weibchen erregen (vgl. Conquista), so gelang es den Spaniern, die Menschen der Neuen Welt mit ihren Rüstungen, Waffen und Kleidern zu beeindrucken. In noch stärkerem Maße trifft dieser Vergleich auf die gegenwärtige Verführung der Chiloten durch die europäisch-nordamerikanische Konsumgesellschaft zu. Sicherlich ist es verlockend, das traditionelle und zT beschwerliche Leben aufzugeben, und unter Umständen geht dabei das Bewusstsein dafür verloren, dass es sich auch hierbei um eine Eroberung und Kolonisierung handelt.

Das Element der Verlockung und die Vorstellung, dass das, was von weit her kommt und fremdartig ist, das Althergebrachte übertrifft, wird besonders deutlich in dem Text Mujerío

${ }^{99}$ In Chile hat sich der neoliberale Konsum-Boom insbesondere auf Betreiben der Militärregierung durch die Politik der sogenannten „Chicago-Boys“ etabliert. 
III: „Tanto hombre de lejos que venía [...]“ (S15). Sie bringen für die Frauen das Versprechen mit sich, deren Männer und ihre Mittelmäßigkeit auszulöschen und (vermutlich) zu ersetzen. Auch diese Zeilen können auf verschiedenen Bedeutungsebenen verstanden werden. Zum einen lässt sich klischeehaft verkürzt eine typische Verhaltensweise innerhalb einer Partnerschaft erkennen: Durch die Dauer einer Partnerschaft und die Gewöhnung aneinander verliert der Partner an Attraktivität, beide Seiten geben sich keine Mühe mehr. Das Erscheinen von anderen Männern eröffnet neue Möglichkeiten und kommt dem Versprechen einer neuen Liebe gleich.

Eine historische Interpretation würde darauf hinweisen, dass die Spanier mit ihrer fortschrittlicheren Schifffahrt und der weiterentwickelteren Waffentechnik und Kriegsführung den Inselbewohnern auf eben jenen Gebieten tatsächlich weit überlegen waren. So war es den Spanier (zumindest mit Verstärkung vom Festland) zB leicht möglich, Castro in einem Überraschungsangriff nach der Einnahme durch Piraten im Jahre 1600 zurückzuerobern.

Gleichzeitig lassen sich die Verse auf die interkulturelle Begegnung beziehen: Der konkrete Vorwurf „que comen y duermen demasiado“ spiegelt bereits eine importierte Sichtweise, nämlich die klischeehaft gewordene europäische Vorstellung, dass die Urbevölkerung faul sei. ${ }^{101}$ Muñoz sagt über den äußeren Einfluss auf Chiloé:

[...] hablo de un exitismo a nivel económico, profesional, cultural; de estructuras elitistas y formación de áreas privadas. Estas ideas son rápidamente absorvidas [sic] por una comunidad inerme frente a la atractiva avalancha de íconos pertenecientes a la cosmovision dominante. (Muñoz 1993a:47)

Auch hier steht die Gemeinschaft einer Fülle von verlockenden Bildern gegenüber. Bilder zudem einer Kultur, die diejenige Chiloés als provinciana, mediocre oder atrasada bezeichnet, was in der Rede von „estos mezquinos nuestros“ bereits in die eigene Sichtweise übernommen ist.

Thematisch gehört der letzte Text des Buches ebenfalls zum Komplex der Invasionen, und schließt somit den Bogen, den die ersten Texte, wie oben erläutert, geöffnet haben:

Colonizadores

El primero irreconocible

ha fundado un linaje

acurrucado en mí.

Se suceden los desembarcos.

Las áreas de reserva disminuyen. (S58)

\footnotetext{
${ }^{100}$ Manche Bilder sind dabei biologisch-sexuell konnotiert (Vocación de túnel / y de bumedad), so dass es nicht möglich ist, das semantische Feld, weiblich-männlich' rein metaphorisch zu verstehen.

${ }^{101}$ Eine Eigenschaft, die ihnen durchgehend zugeschrieben wurde, wenn auch von manchen Chronisten zurückgeführt auf die Unterlegenheit, von anderen auf das Klima (vgl. Todorov 1982:244).
} 
Es ist das einzige Mal, dass ein Begriff konkret auf den Vorgang des Kolonisierens hindeutet. Die ersten drei Verse beziehen sich zurück auf den ersten Abschnitt, in dem von der Ankunft der Fremden berichtet wurde, von der Anziehung, die sie auf die Frauen ausübten und von der Aufgabe und gleichzeitigen Hingabe der Frauen an die Fremden. Aus dieser Verbindung ging ein neues Geschlecht hervor. Die beiden letzten Verse sprechen von der heutigen Situation: Der ersten Anlandung Fremder sind weitere gefolgt, und was eine Art Schutzgebiet für einen besonderen Lebensraum mit einer eigenen Kultur bildete, schwindet dahin.

Als ein erstes Ergebnis kann festgehalten werden, dass die Texte sehr deutliche Bezüge auf die historische Vergangenheit der Eroberung und Kolonialisierung Chiloés enthalten. Diese historische Ebene stellt jedoch nur eine von mehreren Interpretationsmöglichkeiten dar. Daneben stehen oft gleichberechtigt die semantische Ebene neuerer Entwicklungen auf Chiloé und die Ebene der Beziehungen zwischen Frau und Mann. Gemeinsam ist allen Bedeutungsebenen des Textes die Problematisierung der Begegnung - Begegnung von Kulturen oder von Geschlechtern. In allen drei Fällen führt die Begegnung in fast fatalistischer Weise zu Sieg und Niederlage, zu Eroberung und Unterwerfung und in der Folge zu Diskriminierung.

\subsection{Schuld des sehenden Auges, Schuld des blinden Auges}

Eine Isotopie durchzieht das gesamte Buch auffällig, insbesondere aber den ersten Abschnitt. Sie deckt den semantischen Bereich des Sehens ab und wird gebildet von verschiedenen Lexemen, die ,sehen', ,Augen`, ,Blicke` und ,Blindheit' bezeichnen oder umschreiben.

Das Buch beginnt mit der Situation, in der die Frauen am Ufer stehen und die Männer beobachten: „mirando sus faenas de atraque“ (S9). Ein „enfrentamientos de ojos“ entscheidet über die Unterwerfung der Insel (S10). Veränderungen gehen im Dorf vor sich „desde que se asomó a la proa“, und der überwältigende Anblick der Fremden führt dazu, dass die Frauen geblendet sind, erblinden (S12). Auch weiterhin beobachten die Frauen die Eroberer („seguimos mirando entre las cortinas“, S13). Sie haben ihre Männer fortgehen und die Fremden kommen sehen („Ellas, las primeras en avistar a los que venían“, S15) und beobachten weiter: „observando / cada nuevo movimiento / de los que llegan“ (S16). „En la noche, el silencio / reprime miradas detrás de las pupilas“ (S18). Die Kinder sehen aus der Vergangenheit ,antiguos ojos encendidos de odio“ (S21). Es folgen „un ojo sobre otro“ (S23) und „ojos abatidos“ (S24). „Donde se fija la mirada“ (S25), „un ojo abierto 
hacia los otros“ (S25), „sobrevolando la ceguedad“ (S25), „muertos de ojos vaciados“ (S26), „Vacías las cuencas de los ojos y blanco“ (S28), „mirándolos caer sobre las siembras“ (S29), „Algunos vuelven la vista“ (S30), „Miradura“ (S31), „Se asoma a la cara del hermano / la herida“ (S34), „la visión no el clara“ (S36), „y ojos circulando clandestinos“ (S36).

Die Auflistung zeigt, dass es im ersten Abschnitt des Buches kaum einen der kurzen Texte gibt, der nicht ein Semem beinhaltete, das ihm die Isotopie des Sehens einschreibt.

Ich beginne eine Untersuchung dieser Isotopie ausgehend von dem Gedicht Perspectiva (S25):

Donde se fija la mirada

aparece una herida.

La grieta palpitante, un ojo abierto hacia los otros.

La culpa es un cuervo sobrevolando la ceguedad. (S25)

Wo auch immer der Blick hinfällt, erscheint eine Wunde, ein pulsierender Riss. Man denkt an die Risse innerhalb des Dorfes, die mit dem Eintreffen der Fremden an die Oberfläche kamen (ElMujerio). Und auch hier kommen die Risse nicht eigentlich mit ihrem Eintreffen, sondern damit, dass sie gesehen werden („Desde que se asomó a la proa“). Das Auftreten von Schäden und Wunden scheint direkt mit dem Sehen und Wahrnehmen zusammenzuhängen, mit dem „ojo abierto hacia los otros“. Dieses Auge auf die Fremden ist neugierig („observando / cada nuevo movimiento / de los que llegan“ S16), etwas ängstlich (,mudas y palpitantes / mirando sus faenas de atraque“, S9), aber insbesondere steht es für das Betrachten des Anderen, das den Blick auf das Eigene verstellt. Die Blicke auf die Fremden und ihre vermeintlichen Geschenke sind es, die die Unzufriedenheit mit dem Eigenen erst aufkommen lassen, und schließlich das Gefühl der eigenen Unzulänglichkeit.

Die Männer wecken erotische Sehnsüchte in den Frauen; die Fremden wecken Bewunderung der anderen Kultur gegenüber und gleichzeitig das Empfinden, dass die eigene Kultur unterlegen, die eigene Identität schwach sei. ${ }^{102}$

Durch ihr Verhalten und dadurch, dass sie sich von den Fremden verführen lassen, machen sich die Frauen zu Komplizinnen ${ }^{103}$ und in gewisser Weise schuldig. Muñoz klagt

102 Das andere Geschlecht und die andere Kultur werden hier weitgehend parallelisiert.

103 Die Frau als Komplizin ist seit der bekannten Geschichte der Malinche zu einem Topos geworden. Malinche war eine junge Aztekin, die als Sklavin an die Maya verkauft und von diesen Cortéz zum Geschenk gemacht wurde. Nachdem sie bereits die Sprache der Azteken (Nahuatl) und diejenige der Maya beherrschte, lernte sie bald Spanisch. Mit ihren Sprach- und Kulturkenntnissen wurde sie für die Spanier eine wichtige Figur in der Eroberung der Maya. „,On peut imaginer qu'elle garde une certaine rancune envers son peuple d'origine, ou envers certains de ses représentants ; toujours est-il qu'elle choisit résolument la camp des conquistadores." (Todorov 1982:106) Als 
die Frauen deshalb nicht an, eher solidarisiert sie sich mit ihnen dadurch, dass sie weiterhin ihre Perspektive teilt. Es ist kein wertendes Schuldigsein, das aus dem Text hervorgeht, sondern eher eine Feststellung. Es besteht eine Komplizenschaft von Seiten der Frauen, vielleicht nicht bewusst, vielleicht nicht einmal vermeidbar. Auf diese Weise schuldlos schuldig geworden zu sein, konstatiert Muñoz im Jahr 1993 für ihre eigene Kultur in dem bereits zitierten Artikel: „Nuestra cultura vive y como ser viviente que es, corre el peligro de enfermar gravemente de males foráneos demasiado cercanos.“ (Muñoz 1993a:47)

Doch es ist keine Lösung, die Augen gegenüber dem Fremden zu verschließen, denn auch das Nicht-Sehen macht schuldig: „La culpa es un cuervo sobrevolando la ceguedad“ (S25). Das Nicht-Sehen-Wollen kann ein Zeichen für das eigene schlechte Gewissen sein, wie in den Versen „Algunos vuelven la vista, incómodos / frente a la imagen de los intumidos / que se abrazan“ (S30). Und um das Verhältnis zwischen Sehen, Nicht-Sehen und Schuld noch komplizierter zu machen, kann sogar das Sehen zur Blindheit führen: „Y enceguecieron también unidas / por el brillo del sol sobre el casco / gigantesco“ (S12).

Das Sehen hat seine schädliche Wirkung nur dann, wenn es kein erkennendes Sehen ist. Die Sehenden erkennen nicht, was ihr Schauen, Betrachten, Beobachten bewirkt, merken nicht, wie der Glanz der Fremden sie verblendet. In der Blindheit gegen ihre eigene Mitwirkung an der Zerstörung ihrer Welt liegt die Schuld, die hiernach die Frauen (die Menschen) von Chiloé trifft. Das Thema der schuldigen Blicke und Augen führt zum Text Pisadas en la Arena:
La visión no es clara pero supone un pueblo hundido por el peso de la culpa.
El enrarecido aroma de huesos deshechos y ojos circulando clandestinos. (S36)

Bisher war schon häufig die Rede von Schmerzen, Wunden und Zerstörung. Aber das Bild eines Volkes, das unter der Last seiner Schuld versinkt, ist in seiner Endgültigkeit durch den bisherigen Kontext noch nicht ausreichend motiviert. Auch der Geruch nach zersplitterten Knochen ist ein Eindruck, der in seiner Stärke und Verzweiflung unvermittelt kommt. Zwar prägen bisweilen Demütigung, Dulden und Erleiden die Stimmung der Gedichte, aber ein derartig resignativer Ton ist kaum mit dem Gesamtgeschehen zu vereinbaren. Schließlich schildert die Geschichtsschreibung, wie im Kapitel 5.1 dargestellt, die Eroberung und die anschließende Zeit der Kolonie als ein meist friedliches Zusam- 
menleben, das zwar auf Hierarchie und Unterdrückung basierte, aber doch üblicherweise nicht physische Gewalt als Mittel einsetzte.

Die Zeilen im Text Pisadas en la Arena haben einen Beiklang, der den Hintergrund einer größeren Tragödie spürbar macht. „Huesos desechos“ sind das Ergebnis von roher Gewaltanwendung, gleichzeitig impliziert das Bild Anonymität. Man weiß nicht, um wessen Überreste es sich handelt, nicht einmal, ob es ein einzelner Mensch ist oder eine größere Menge von Knochen, wie zB in einem Massengrab. Dieser anonyme, gewaltsame Tod in Verbindung mit dem Wort clandestinos weckt unweigerlich die Assoziation der Diktatur. In diesem Zusammenhang macht die Erwähnung einer Schuld des Volkes an seinem Untergang Sinn, denn eine Diktatur wie die chilenische kann über eine so lange Zeit nur funktionieren, wenn genügend Menschen aus der Bevölkerung dahinterstehen, die Regierung unterstützen und entschuldigen oder wenigstens wegsehen, wenn Unentschuldbares geschieht. Der Text spricht auf engstem Raum von einer Zeit der Gewalt, der Heimlichkeiten, der Schuld und dem Gefühl, die Heimat verloren zu haben. In Anbetracht des geschichtlichen Kontextes Chiles scheint sich an dieser Stelle eine neue geschichtliche Dimension innerhalb des Gedichtzyklus' abzuzeichnen, nämlich die 70er und 80er Jahre des 20. Jahrhunderts.

Es gibt nur wenige andere Gedichte, in denen ebenfalls auf die Diktaturerfahrung angespielt wird: Einer davon ist der bereits erwähnte Text El Sitio Donde Palpita el Mapa (S30), in dem sich angesichts des Bildes „de los entumidos que se abrazan“ der Schrecken unter den Menschen verbreitet („El espanto encuentra ranuras / y se cuela“).

Der zweite Text ist Barrio de Viudas (S52). Das Viertel, das beschrieben wird, besteht aus der „calle de las pobres hermanas“, der Straße der „,madres llorosas“ und der „pasaje de las esposas solas“. Die Frauen dort sitzen in abgetragenen Kleidern im unaufhörlichen Regen auf der Straße und warten auf die Rückkehr ihrer Männer, Söhne und Brüder. Zwar sind auch die Frauen aus den ersten Gedichten allein, weil ihre Männer fortgegangen sind, aber hier gibt es deutliche Hinweise darauf, dass die Männer nicht mehr am Leben sind:

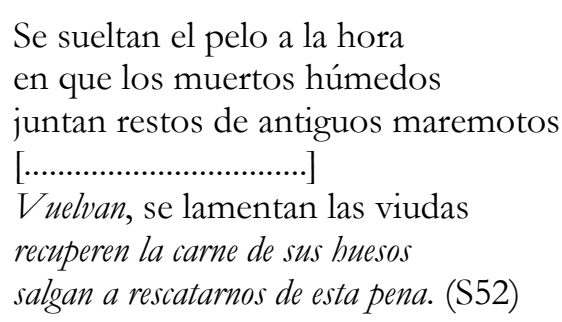

in die Hand nimmt und Chancen ergreift, bis hin zur Verräterin. 
Die Klage von Frauen um Abwesende ist spätestens seit den Zusammenkünften der Madres de la Plaza de Mayo in Buenos Aires zur schweigenden Anklage und zum Symbol des öffentlichen Widerstandes gegen ein totalitäres Regime geworden.

Vor dem Hintergrund dieser beiden Texte eröffnet sich auch für andere Gedichte die Möglichkeit, die Diktaturerfahrung als Konnotation mit einzubeziehen. So bekommt das visionäre Bild eines „aparato de vuelo ennegrecido / de estos brujos que nos sobrevuelan“ (S28) im Kontext der Diktatur die klare Gestalt von militärischer Luftüberwachung durch Flugzeuge und Hubschrauber, wie sie während der Diktatur eingesetzt wurden.

Zu den Invasiones, die dem ersten Abschnitt seinen Namen geben, gehören somit nicht nur die Conquista española, die Übergriffe von Piraten und die Versuche von Männern, Frauen für sich zu gewinnen. Vielleicht nicht auf den ersten Blick zu erkennen, aber doch deutlich sind die Anspielungen auf das Einbrechen der Diktatur wie eine Invasion in das Leben auf Chiloé.

\subsection{Das tanzende Schiff}

Chiloé es un navío enceguecido

dando vueltas sin parar

sobre remolinos de agua. (S7)

Die drei Zeilen sind dem ersten Abschnitt des Buches als Motto vorangestellt. Sie stellen die prekäre Situation der Insel dar. Das Schiff Chiloé treibt führungslos auf dem Meer und dreht sich auf Strudeln im Kreis. Schon im Motto manifestiert sich also die Isotopie des Sehens und Erblindens. Die ganze Insel ist blind geworden, ohne Kurs und ohne Ziel.

Das Bild gibt zunächst die geographische Situation, aber auch die historische Entwicklung Chiloés wieder: Es liegt vom Festland abgeschnitten, also auf sich selbst gestellt an einer sehr exponierten Stelle des Ozeans, nämlich sozusagen an der Haustür, die fast alle Besucher durchschreiten müssen. Die Wasserstrudel versinnbildlichen die wechselvolle Geschichte der Insel, die verschiedentlich eingenommen und wieder preisgegeben wurde. Diese sich wiederholende Bewegung drückt sich in „dando vueltas“ aus. Chiloé dreht sich im Kreise und kommt nicht von der Stelle. Die Geschichte geht nicht voran, die Verse beklagen das Fehlen einer Entwicklung.

Ein Grund dafür ist sicherlich die Tatsache, dass es sich um eine Insel handelt, die für eine lange Zeit kaum mehr ist als ein im Stich gelassener Außenposten. Diese Situation schildern die beiden Texte Expuesta und Vuelo y Caída. Der Titel Expuesta spricht für sich, 
und der dazugehörige Text erinnert an den Angriff der Piraten, die trotz Gewalt und Brandschatzung willkommen waren:

Prontos a herir

se amontonan en las afueras de mí.

Un ojo sobre otro.

Me voy a ellos con los brazos abiertos. (S23)

Wie bereits im Gedicht Bucaneros wird der Aggression mit Wehrlosigkeit und offenen Armen begegnet.

Der folgende Text Vuelo y Caída (S24) endet mit den beiden Versen „La profunda indefensión / de las vivientes que expusimos el pecho“. Hier wird die Frau wieder als Mutter dargestellt, die anderen Leben und Nahrung gibt. Zum anderen kann man an an das christliche Symbol des Pelikans denken, der seine Brust anderen ausliefert. In der Emblematik des Barock werden Pelikane dargestellt, die, um ihre Jungen vor dem Verdursten zu retten, sich die eigene Brust verletzen und sie ihr Blut trinken lassen. Sie symbolisieren das Martyrium Christi die seine selbstlose Liebe für die Menschen, die er mit seinem Blut errettet. Ich möchte nicht unterstellen, dass Muñoz die Fabel Der Pelekan von Lessing kennt, ${ }^{104}$ aber doch auf eine erstaunliche Parallele aufmerksam machen. In dieser Fabel wird die bedingungslose, sich aufopfernde Liebe als Blindheit dargestellt - so wie auch das Verhalten der personifizierten Insel und der Frauen bei Muñoz als blind oder verblendet charakterisiert ist. Außerdem lässt sich auch hier ein Bogen zu Bucaneros schlagen: „Vocación de abrazo para el hijo del pirata“ scheint vor diesem Hintergrund nichts anderes zu sein als die Fürsorge der Frauen für ihre Kuckucks-Kinder.

In der christlichen Symbolik ist der Pelikan ein ausgesprochen positives Symbol: Er steht für Frömmigkeit, häufig auch für Jesus, der sich für die Menschen opferte. Muñoz kommt aus einer gläubigen Familie. „Rosabetty Muñoz [...] desarrolla una escritura que evidencia marcas de un sujeto femenino católico.“ (Mansilla 1996:Introducción) Jedoch hat sie sich schon in ihrem Buch Canto de una oveja del rebaño kritisch mit der traditionellen Religiosität, mit der sie aufwuchs, auseinandergesetzt. Von der traditionellen Bedeutung des christlichen Symbols des Lammes bleibt in diesem Gedichtband nicht viel übrig, sie wird hinterfragt

${ }^{104}$ Lessing lässt in seiner Fabel Der Pelekan den Adler dies Geschehen beobachten: „Ein frommer Pelekan, da er seine Jungen schmachten sahe, ritzte sich mit scharfem Schnabel die Brust auf, und erquickte sie mit seinem Blute. Ich bewundere deine Zärtlichkeit, rief ihm ein Adler zu, und bejammere deine Blindheit. Sieh doch, wie manchen nichtswürdigen Kuckuck du unter deinen Jungen mit ausgebrütet hast!“ (Lessing 1997:312) 
und aufgeweicht. ${ }^{105}$ Etwas Ähnliches geschieht mit der Geste der dargebotenen Brust, die als Arterhaltungstrieb des Pelikan in der Religion mystifiziert wurde und im Text von Muñoz etwa im Sinne von Lessing als Kritik verstanden werden muss.

Hier komme ich wieder auf die im Kreise verlaufende Geschichte Chiloés zurück: Weder das politisch-geographische Ausgeliefertsein noch das instiktive Sich-selbst-Ausliefern werden als der Hauptgrund für die stagnierende Entwicklung nahegelegt, wie das Bild des trudelnden Schiffes sie darstellt. Die eigentliche Ursache der Ziel- und Orientierungslosigkeit liegt den Versen des Mottos nach in der Blindheit. Chiloé ist blind gegenüber den wiederholten Invasionen und Übergriffen, blind gegenüber der eigenen Mitschuld.

Es ist fraglich, inwieweit man diese Feststellung auf die Eroberung der Insel beziehen kann. Ganz sicher ist es jedoch ein Appell der Autorin an die Frauen, ihren eigenen Beitrag am Sexismus und an der Diskriminierung der Frau zu erkennen. Und wahrscheinlich ist ebenso die Blindheit gegenüber Verbrechen der Militärdiktatur gemeint, also die Mitschuld der schweigenden Bevölkerung oder das Versäumnis - wie Sergio Mansilla es ausdrückt -, die Zeichen nicht erkannt zu haben. (Mansilla 1996c:41)

Muñoz weiß in diesem Zusammenhang auch um ihre eigene Blindheit gegenüber der Diktatur:

Delante de nosotros sí que sacaron - pero lo sé ahora - a profesores, desde el mismo liceo, para llevárselos. Y yo no supe entonces ni lo supe hasta muchos años después y sé que mis compañeros tampoco lo supieron. No fue un tema que se conversara.

Lo que pasaba en el país estaba mediatizado por tres o cuatro muros: la condición insular de Chiloé, los años que teníamos, nuestros hogares y ambientes. Me tocó estar justamente en un grupo en el que el tema no tenía ninguna relevancia. ¡Yo no sé cómo, pero no lo tenía! De manera que todo ese eco no me llegó hasta que salí de Chiloé. (Trujillo 1993b:Kap.3.5)

Muñoz’ Worte machen deutlich, dass die geographische Isolation Chiloés zur Blindheit und zur Ignoranz bestimmten Entwicklungen gegenüber geführt hat.

An zwei Stellen werden die Frauen direkt mit der Insel identifiziert: („,un enfrentamiento de ojos / que provocó la rendición de la isla“, S10; „Y el archipiélago -maternal consistencia“, S19), durchweg ist jedoch eine starke Verbundenheit der Frauen zu ihrer Heimat zu spüren. Es ist, als beteiligte sich Chiloé, indem es sich im Wasser im Kreise dreht, am Tanz der Señoritas. Dieser Tanz der Geblendeten entsteht aus der Begegnung der Kulturen und aus der Begegnung der Geschlechter:

\footnotetext{
${ }^{105}$ Vgl. hierzu: „Canto de la oveja del rebaño asume la eficacia de la imagen religiosa del pastor y su rebaño para una representación alegórica de la historia colectiva y personal en el Chile de fines de los años 70 y comienzos de los 80،“ (Mansilla 1996:Kap.4)
} 
La presencia de los extranjeros crea las condiciones para que ocurra el "baile de señoritas", que no es sino remedo grotesco de los sofisticados baile [sic] de sociedad y a la vez remedo de las danzas para la fertilidad, que en el caso de la mitología de Chiloé, hace alusión a la Pincoya. (Mansilla 1996:Kap.2)

Da Chiloé bekannt ist als Hort von Legenden und Mythen, sollte die Anspielung auf die Figur der Pincoya erläutert werden. Die Pincoya ist eine mythologische Gestalt, Tochter einer Frau und des Meeres-Königs, eines Zwitterwesens, halb Mann, halb Seelöwe. Sie wird beschrieben als hellhäutig und blond, worin sich bereits der europäische Einfluss manifestiert. Von ihrem Vater hat sie die Fähigkeit, das Meer fruchtbar zu machen. Tanzt sie am Strand mit dem Gesicht zum Meer, so ist beim Fang von Fischen und Meeresfrüchten reiche Beute zu erwarten. Wendet sie jedoch beim Tanz das Gesicht dem Land zu, so werden die Fischer mit leeren Netzen nach Hause kommen. Normalerweise ist sie dem Volk von Chiloé wohlgesonnen: Sie rettet Schiffbrüchige und bringt die Ertrunkenen zum Geisterschiff Caleúche, wo sie in immerwährender Zufriedenheit ein neues Leben beginnen. Wenn jedoch jemand einem anderen Menschen oder dem Meer ein Leid zufügt, so bestraft die Pincoya die Menschen mit ihrem Tanz. (Quintana Mansilla:23ff.)

So zweischneidig wie der Tanz der blonden Pincoya ist auch der Tanz, bzw. das Verhalten der Frauen der Insel und letztlich der Insel selbst: Einerseits tanzen sie für die Fremden, die ihre Faszination ausüben und die Insel in ihren Bann ziehen, andererseits ist der Tanz Ausdruck der Traditionen und Bräuche von Chiloé. Im Tanz blicken sie vorwärts, und blicken zurück. Doch es fällt schwer, beides miteinander zu vereinbaren. Mansilla formuliert das im Ton der Hoffnungslosigkeit:

Como la poesía de Muñoz efectivamente lo explicita, la representación lírica se vuelve despliegue de una identidad fragmentada que sabe que sus raíces ya no obedecen ni a pureza ni a homogeneidad cultural alguna. La pérdida del pasado premoderno activa el deseo, contradictorio, por el pasado como reacción contra un presente donde la "pena" y lo espectral tienen sus dominios: el pasado no es sino el triste espectáculo de la locura por lo imposible. (Mansilla 1996:Kap.2)

Im Text Miradura ist ein Aufbruch beschrieben. Zunächst machen die Bewohner aus ihrem Dorf ein Schiff:

trabajamos calladamente
$\quad$ disfrazando el pueblo.
Le armamos cuadernas
cubrimos aparejos
desplegamos un velamen invisible
para impulsarlo mar adentro. (S31)

In den letzten fünf Versen sehen sie die Küste hinter sich verschwinden. „Navegamos / sensuando con las olas / en roce erizado y espumante“.

Das Dorf - oder auch die ganze Insel - löst sich nun vollends vom Festland, von Chile. Da die Bewohner aktiv an dieser Loslösung arbeiten, ist kaum die unfreiwillige Isolierung 
Chiloés Anfang des 17. Jahrhunderts gemeint. Das Geschehen erweckt eher den Eindruck von symbolischer Bedeutung durch die surreale Komponente: Chiloé scheint sich mit der sinnbildlichen Entfernung vom Festland von der Realität zu lösen. Dafür spricht auch der Begriff „disfrazando“. Die letzten Verse legen nahe, dass es nicht darum geht, auf dem Seeweg ein Ziel zu erreichen, sondern die chilenische Küste aus den Augen zu verlieren und eins zu werden mit dem Takt der Wellen. So könnte man den Zustand der Menschen auf Chiloé während der Diktatur beschreiben, für die das galt, was Muñoz von sich selbst berichtet: „el tema [de la dictadura] no tenía ninguna relevancia. ¡Yo no sé cómo, pero no la tenía! De manera que todo ese eco no me llegó hasta que salí de Chiloé“. (Trujillo 1993b:Kap.5.3)

Ob die Menschen von dem tatsächlichen Geschehen im Land abgeschirmt wurden oder ihre Augen davor verschlossen, ihre Situation ähnelt in jedem Fall der einer Besatzung auf einem Schiff weit draußen auf dem Meer.

Im vorletzten Gedicht Deseo findet sich noch einmal das Bild des Schiffes: „El deseo es un barco poderoso / arriando anclas y cadenas / en medio de la noche“. Dieses Schiff steht für den Wunsch und die Sehnsucht. Es ist gewaltig und sticht in See „con el estrépito de las posibilidades“ (S57) und erinnert an das Schiff, das die Menschen bauten, um damit aufs offene Meer zu segeln (,impulsarlo mar adentro“). Aber das Sehnen kann auch eine andere Gestalt annehmen:

Es también, el despliegue de luces en las islas de canales tan angostos donde un barco, más que navegar acaricia. (S57)

Dieses Bild ist dem des Schiffes auf hoher See entgegengesetzt: Es beschreibt die engen Kanäle mit zahllosen kleinen Inseln. In der Nacht, in der das Sehnsuchts-Schiff seinen Hafen verlässt, wecken die Lichter auf den Inseln das Gefühl von Geborgenheit und Heimat. Alles ist vertraut, alles ist Nähe; eine zärtliche Nähe, in der das Schiff bei der Fahrt durch die schmalen Kanäle die Inseln streichelt. ${ }^{106}$

Es sind die Sehnsucht nach der Ferne, der Fremde, dem Neuen und der Wunsch nach Heimat, Geborgenheit und Althergebrachtem, die miteinander um Chiloé wettstreiten und das blinde Schiff sich im Kreise drehen lassen.

106 Das Bild erinnert an die sexuell konnotierte Metaphorik im Text Bucaneros. 


\subsection{Paradies und Prophetie}

Im früheren Büchern (En lugar de morir, 1986 und Hijos, 1991) zeichnet Muñoz ein Bild von der Vergangenheit, das im Gegensatz zu der als schwierig erlebten Gegenwart stehen soll. Es entsteht vor den Augen der Leserinnen und Leser ein verlorenes Paradies, oftmals explizit mit einer religiösen Komponente versehen:

Eramos los elegidos

la gran familia del pan inagotable

que cantaban a voz en cuello los profetas. (Muñoz 1986:24)

In Baile de Señoritas ist ein solches, goldenes Zeitalter" nicht so deutlich zu erkennen. Statt dessen erinnert alles, was Muñoz beschreibt, - um in der Terminologie zu bleiben - an ein eisernes Zeitalter: Es gibt Leid, Angst, Trauer und Unsicherheit. Da wir nichts von der Zeit vor der Ankunft der Fremden erfahren, steht diese implizit für ein unwiederbringliches besseres Zeitalter. Schon im Text El Atisbo ist die Rede von einer Veränderung im Zusammenhang mit den Fremden:

Deste lado del Canal, los días han cambiado.

Nos sorprendemos hablando de antiguos vaticinios.

En nuestro propio lecho

vivimos agazapadas, observando

cada nuevo movimiento

de los que llegan. (S16)

Etwas hat sich geändert. Die Frauen fühlen sich beengt, sie leben „zusammengekauert“, also nicht mehr aufrecht, sondern ducken sich unter der Anwesenheit und Herrschaft der Anderen, die nun den Kanal überquert haben. Sie fühlen sich eingeschränkt in allem, was sie tun, und beobachten voller Anspannung alles, was die Fremden tun. Das Bild von Jäger und Beute drängt sich auf. Dies alles impliziert, dass im Vergleich das Leben vorher nur besser gewesen sein kann.

In dieser Situation beginnen die Menschen, von alten Weissagungen zu sprechen. Die „antiguos vaticinios“ erinnern an die „profetas“ aus dem Text Eramos los elegidos. Das ist kein Zufall, folgende Passage schließt sich im Text Eramos los elegidos an:

[A los profetas] escuchamos, no para creernos el viejo paraíso (tenemos demasiados siglos de intemperie encima)

pero sus palabras tienen la solemnidad

que queremos para nuestras pobres esperanzas

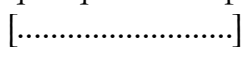

Hoy, que no tenemos profetas

y apenas podemos con la desgracia

de estar abandonados,

los escuchamos

con la terrible convicción

de que el dolor es el único lenguaje

que traspasará la historia. (Muñoz 1986:24) 
Warum erinnern sich die Leute an alte Prophezeihungen? Sie geben ihnen die Hoffnung, dass sie doch noch eintreffen könnten und dass die Gegenwart, die sie erleben, noch nicht die Zukunft ist, von der die Propheten sprachen. Das „viejo paraíso“ ist also gleichzeitig die Vision von einer besseren Welt. Vielleicht liegt darin schon die Paradieshaftigkeit der Vergangenheit: dass sie das Hoffen auf die Zukunft noch zuließ.

Mansilla kommentiert diese Verse folgendermaßen:

Ecos de un pasado, voces sin cuerpo; promesas de un futuro que nunca se cumplieron. Pero no fue error ni engaño de los profetas; ellos anunciaban lo que en verdad iba/debía ocurrir; sólo que la historia avanzó en otra dirección. Fuerzas disociadoras (que en Muñoz toman la forma de fuerzas demoníacas en el sentido religioso católico) irrumpieron torciendo el rumbo del devenir histórico temporal, generando un insalvable y creciente divorcio entre el espacio de la experiencia y el horizonte de las expectativas. (Mansilla 1996:Kap.3.3)

Es gibt also eine Geschichte, so wie sie sein sollte, die irgendwo geschrieben steht und von weisen Frauen und Männern verkündigt wird, aber diese Geschichte ist unzuverlässig, sie kann von ihrem Gang abgebracht werden.

Auch in Baile de Señoritas hat die Geschichte für die Menschen auf Chiloé einen Lauf genommen, der ihnen falsch vorkommen muss. Sie registrieren die Veränderungen, die vor sich gehen, und gedenken im selben Moment der alten Prophezeihungen. Dies passiert unbewusst: Sie überraschen sich dabei, wie sie darüber sprechen. Es liegt nahe anzunehmen, dass die Weissagungen auch hier Zuversicht geben sollen, dass alles wieder gut wird, so wie vorher - oder besser. Daneben machen sie aber auch schmerzlich deutlich, dass die verheißene Zukunft noch fern ist.

Die Prophezeihungen geben den Menschen Halt, ebenso wie der „Gran Sacho“107 (S20) oder die Namen ihrer Vorfahren:

Debajo del altar fue colocada una piedra.

Le hicimos un hoyo en el centro

y ahí colocamos una botella de barro

con todos los nombres de los antiguos.

También tiene moneda de oro la botella.

Quedarán intactas nuestras posesiones. (S37)

Im Gedicht Herencia klammern sich die Menschen verzweifelt an ihrer Vergangenheit fest.

Die Namen sollen der Nachwelt überliefert werden, um etwas zu erhalten von der Vergangenheit, die ihnen längst schon zwischen den Fingern zerronnen ist. Sie sind angetrieben

107 Sacho ist ein Anker aus Holz mit einem Stein im Inneren, der ihm das nötige Gewicht gibt. Diese Art Anker ist angeblich polinesischen Ursprungs und aus Zeiten, in denen Metall sehr teuer war. Es handelt sich um einen traditionellen Gebrauchsgegenstand, der gleichzeitig bei Stürmen lebensrettend sein konnte. Der Gran Sacho, hier sogar mit Majuskeln, steht im übertragenen Sinn für etwas, das unerschütterlichen Halt bietet. 
von dem Wunsch, ihre eigenen Wurzeln zu dokumentieren, vor dem Vergessen zu erretten. Es scheint ein verzweifelter Versuch zu sein, bereits im Wissen um das, was im Text Eramos los elegidos über den Bestand von Sprache und Erinnerung gesagt ist:

los escuchamos

con la terrible convicción

de que el dolor es el único lenguaje

que traspasará la historia. (Muñoz 1986:24)

Der Text El Atisbo ist - wie viele andere - völlig zeitlos. Er kann genauso gut auf die Zeit nach der spanischen Kolonialisierung wie auf die Gegenwart der Dichterin bezogen werden. Alte Prophezeihungen wird es immer geben, ebenso wie die Hoffnung auf eine bessere Zukunft. Texte wie dieser lassen den Eindruck von Stagnation und Resignation entstehen, als befinde man sich in einer immerwährenden Gegenwart, die immer nur Abglanz einer Vergangenheit und Ahnung einer Zukunft sein kann. Dazwischen bleibt Leiden, Dulden und Hoffen; eine christliche Vorstellung der Geschichte.

\subsection{Hybridität und Identität}

Mit dem Gedicht Colonizadores schließt das Buch. Es zeichnet den Bogen vom ersten Ankömmling („el primero irreconocible“) bis zum gegenwärtigen Zustand nach:

El primero irreconocible ha fundado un linaje acurrucado en mí.

Se suceden los desembarcos.

Las áreas de reserva disminuyen. (S58)

Da das Ich noch einmal spricht, denkt man bei dem Genannten an den Mann, den sie in den ersten Gedichten beschrieb: „Lo vi asomado a la borda“ (S10), „Con maestría el forastero se me acerca a la orilla“ (S11), „Desde que se asomó a la proa“ (S12). Mit ihm hat sie ein neues Geschlecht gegründet. Die ersten drei Zeilen sprechen von einem Beginn, von etwas Neuem, sie klingen hoffnungsvoll. Im vierten Vers kommen andere Fremde nach, sie landen auf der Insel und verändern das dortige Leben weiter. Und im letzten Vers lesen wir schon vom Niedergang, er kündet vom nahen Ende: Die Gebiete des Ursprünglichen, in die sich die Menschen zurückziehen könnten, um sich auf sich selbst zu besinnen, schwinden dahin.

Das lyrische Ich erzählt nicht die schon so oft erzählte Geschichte von Eroberern, die alles, was sie in der Neuen Welt vorfinden, anpassen oder zerstören, nicht die einseitige Geschichte von Aneignung und Vergewaltigung. Die Geschichte, die sie erzählt, ist schwieriger und differenzierter. Sie handelt vom Wunsch nach gegenseitiger Entdeckung und 
Eroberung, von Annäherung und von der möglichen Entstehung von etwas Neuem, das erst aus der Verbindung zweier Menschen oder Kulturen hervorgehen kann („,ha fundado un linaje / acurrucado en mí"). Doch mit dieser Formulierung verfällt die Erzählerin schon wieder in vorgeprägte Muster, in die Vorstellung des aktiven Mannes und der passiven, nur empfangenden Frau.

Ihre Eigentümlichkeit bekommt die Darstellung insbesondere durch die durchgehend weibliche Perspektive. Aus der Sicht der Frauen werden nicht nur die Ereignisse berichtet, sondern gerade die Schwierigkeiten, Missverständnisse und Schuldgefühle geschildert. Muñoz entwirft keine Utopie einer besseren hybriden Gesellschaft, vielmehr lässt sie beide Seiten gleichermaßen schuldig werden an Schmerz und Zerstörung. Ich habe gezeigt, dass Muñoz eine Gefahr darin sieht, dass die Frauen ihre Mitschuld nicht erkennen. Allerdings würde ich nicht so weit gehen wie Carrasco:

[El invasor] aparece más bien como un coagente, el agente de una acción recíproca, puesto que si la mujer no lo hubiera aceptado, la interculturalidad no habría sido posible. Un conquistador sólo puede tener el dominio de un territorio si en él encuentra cómplices o colaboradores. (Carrasco 1996a:55)

Wenn im Falle Chiloés der Einfall der Spanier ohne Gewaltanwendung und Blutvergießen vor sich gegangen ist, so liegt das zum einen an der erwähnten besonderen geographischen und historischen Situation und zum anderen an der Tatsache, dass die Männer, die den Spaniern unter Umständen mit Waffengewalt Widerstand geleistet hätten, nicht auf der Insel waren. Die Situation lässt sich aber sicherlich nicht verallgemeinern und auf die gesamte Conquista übertragen.

Die Geschichte der Eroberung Chiloés durch die Spanier Mitte des 16. Jahrhunderts und die Geschichte ihrer Eroberung durch die Modernität, den Tourismus und die konsumorientierte Marktwirtschaft in der zweiten Hälfte des 20. Jahrhunderts gehen bei Muñoz ineinander über. Trotz der gut 400 Jahre, die zwischen beiden Invasionen liegen, zieht Muñoz klare Parallelen. In beiden Situationen bleibt die chilotische Identität nicht unversehrt, ein Verlust, den Muñoz beklagt. Baile de Señoritas ist ein Seiltanz der Identität, und mehr: Es ist ein Kampf um die eigene Identität. Manchmal ist es ein moderner Tanz, in dem die Tanzenden versuchen, sich selbst zu erkennen und auszudrücken, und dann wieder ein traditioneller Tanz, vielleicht ein ritueller oder magischer Tanz, verbunden mit der Insel und ihrem Volk. Er ist die Chance auf Weiterentwicklung und gleichzeitig der Verlust des Ursprünglichen.

El libro entero es un alegato contra los efectos alienantes del consumismo fomentado por la economía autoritaria neoliberal. Se arremete, por un lado, contra una modernización de 
utilería basada en el brillo cegador de sus superficies tecnologizadas; aunque, por otro, se reconoce que, dadas las condiciones del nuevo escenario político-existencial, el ,aturdimiento“, el abandono acrítico a la fiesta del consumir, abre la posibilidad de un nuevo orden de armonía y de anulación de las contradicciones, aun cuando sea una solución falsa. (Mansilla 1996:Kap.4)

Im Artikel „Situación de la cultura local“ formuliert Muñoz klare Ziele ihres Kampfes um die Kultur und Identität von Chiloé. Einer dieser Punkte lautet: „Difundir textos, escritos que son la voz expresa de la conciencia colectiva [...]“. (Muñoz 1993a:47) Mit ihrem Text über die Geschichte Chiloés aus der Sicht der Frauen hat sie einen solchen Text geschrieben. 


\section{Clemente Riedemann : KarRa MaW'N}

No era baldía aquella tierra. Bastaba con mirarla, sostenidamente durante tres o cuatro lunas y reventaban en los tallos las metáforas.

\section{Clemente Riedemann}

Clemente Riedemann ist 1953 in Valdivia geboren, wo auch sein dichterisches und kulturelles Schaffen verwurzelt ist. Er war Mitgründer der Kultur-Werkstatt Matra und arbeitete eng mit der studentischen Literatur-Werkstatt Índice zusammen. ${ }^{108}$ Zunächst wurde Riedemann hauptsächlich als Verfasser von Theaterstücken bekannt (La bija de Lot, La Hamaca). Seine lyrischen Texte wurden überwiegend durch öffentliche Lesungen und nichtkommerzielle Tonbandaufnahmen bekannt. Gedichte von ihm erschienen in Zeitschriften und Anthologien. Einen Namen machte Riedemann sich insbesondere als Texter für das populäre Gesangsduo Schwenke \& Nilo. Im Zusammenhang dieser Arbeit ist es sicherlich nicht unwichtig, zu erwähnen, dass Riedemann Geschichtslehrer ist und einen Abschluss in Anthropologie hat.

1984 erschien der erste Gedichtband von Clemente Riedemann mit dem Titel Karra Maw'n, was in Mapudungun, der Sprache der Mapuche, ,Ort des Regens' bedeutet. Karra Maw'n ist der Name der Ortschaft, die sich ursprünglich etwa an der Stelle befand, wo heute Valdivia liegt. In seinem Buch erzählt Riedemann die Geschichte von Karra Maw'n/Valdivia, „[] []as conquistas de Valdivia“. (Bianchi 1990c:2) Dabei durchquert er die Jahrhunderte von der prähispanischen Zeit bis hin zur Gegenwart. Wie schon bei Riveros und Muñoz stehen auch bei Riedemann die Begegnungen und Auseinandersetzungen der verschiedenen Kulturen im Mittelpunkt, die sich im Laufe der Geschichte in derselben Gegend angesiedelt haben. Federico Schopf nennt den Gedichtband Riedemanns bomenaje a los indios americanos und zieht somit eine Parallele zur Dichtung Cardenals. ${ }^{109}$ (Schopf 1991) Dieser anerkennende Vergleich erklärt sich zum einen aus der Thematik, da der Gedichtband Karra Maw'n als Huldigung an die Urbevölkerung Südchiles, die Mapuche, verstanden werden kann (was sich bereits im Titel ankündigt) und als eine Solidarisierung

\footnotetext{
${ }^{108}$ Mitgründerin der Gruppe Índice war Rosabetty Muñoz.

${ }^{109}$ In Homenaje a los indios americanos erzählt Ernesto Cardenal in einer collageartigen Zusammenstellung die Geschichte Amerikas, vgl. Kapitel 3.2, S34f.
} 
mit deren Schicksal. Darüber hinaus verbirgt sich in Schopfs Bemerkung eine Anspielung an Riedemanns stilistische Nähe zu dem nicaraguanischen Dichter.

Karra Maw'n ist aber nicht nur regionale Geschichte, sondern ebenso ein persönliches Zeugnis sowohl von Riedemanns individueller Biographie als auch von seiner Familiengeschichte. Oscar Galindo betont daher die ,intersección de la historia colectiva y personal“. (Galindo 1992:81)

Riedemann schrieb den Text Karra Maw'n ursprünglich als eine Reaktion auf das Musikstück Oratorio 1850 des chilenischen Komponisten Luis Advis. Das Oratorium vertritt eine sehr konservative Version der Geschichte Südchiles:

El Oratorio 1850 [...] presenta una visión de Chile como fundacional, desde el momento en que llegan los alemanes, los colonos. Y lo anterior es un período obscuro [sic], inexpugnable, sencillamente un caos: la selva, la nada... Es como el surgimiento de occidente en el fondo, eso desde el punto de vista cultural puede tener una explicación y puede ser válida... Es decir, los mapuches están al margen de la historia, me refiero a la historia de occidente. (González Cangas 1999:151)

Riedemann fühlte die Notwendigkeit, auf dieses Werk zu reagieren, das seinen persönlichen Überzeugungen widersprach und sich darüber hinaus problemlos in die „offizielle“ Geschichte der Militärregierung integrieren ließ: „me pareció vergonzante porque era complaciente con el nuevo liderazgo político, particularmente los militares y las clases dominantes que la forman“ (González Cangas 1999:151)110. Er wusste jedoch, dass er unter den gegebenen kulturpolitischen Bedingungen keine Chance hatte, mit einer direkten Kritik die Zensur zu umgehen. Stattdessen schrieb er mit Karra Maw'n eine Gegendarstellung mit künstlerisch-poetischen Mitteln. Riedemann selbst betont die historisch-politische Dimension seines Buches gegenüber der dichterischen:

Tal vez rudimentariamente Karra Maw'n puede vivificar la capacidad que hay en la región de poder construir un mundo verbal, pero expresa más bien la primera señal de humo en esa dirección y, en ese sentido, estéticamente no es una obra refinada, no tiene validez en sí misma, aún necesita apelar a ciertos referentes históricos o políticos o culturales para ser bien comprendida. (González Cangas 1999:147)

Um eben jene geschichtlichen Bezüge verständlich zu machen, werde ich zunächst, ehe ich auf den Text genauer eingehe, die Geschichte und Kosmogonie der Mapuche skizzieren, insoweit sie für das Verständnis der Texte als wichtig erachtet werden müssen.

\footnotetext{
${ }^{110}$ Die Einschätzung Riedemanns ist erstaunlich, da Luis Advis, der Komponist der Cantata de Santa María de Iquique, im Dezember 1973 von der Militärregierung zum Tode verurteilt wurde. (Bartsch 1974:116) Das Urteil wurde nie vollstreckt.
} 


\subsection{Die Mapuche ${ }^{\text {II }}$}

Esta es una historia acerca de la intolerancia. ${ }^{112}$

José Bengoa

Während der zweiten Hälfte des 15. Jahrhunderts expandierte das Inkareich bis tief in den Süden Chiles. Im größten Teil des Landes installierten die Inka ihre Herrschaft, die auf einer straffen Organisation beruhte und in allem strikt der Hauptstadt des Reiches Cuzco unterstand. Auf der Höhe des Flusses Maule trafen sie 1485 jedoch auf die Mapuche, die dort als Jäger und Fischer ihre Reviere gegen die Eindringlinge verteidigten. Alle weiteren Bestrebungen, das Land einzunehmen, wurden von diesem Punkt an durch den zähen Widerstand der Mapuche vereitelt. Die Inka nannten ihre standhaften Gegner aukas oder purun aukas, was soviel bedeutet wie ,Feinde‘, ,Widerständige‘ oder ,Wilde‘.

Als dann einige Jahrzehnte später die Spanier ebenfalls von Norden aus Chile eroberten, hatten sie zunächst leichtes Spiel. Mit Cuzco hatten sie bereits das administrative und politische Zentrum des Inkareiches eingenommen, so dass ihnen ein freier Durchmarsch bis in den Süden Chiles sicher war - bis sie zur Reichsgrenze kamen, auf deren anderer Seite die Mapuche standen und sich gegen die neuen Eroberer ebenso erbittert zur Wehr setzten, wie sie es gegen die Inka getan hatten.

Unter dem Befehl von Pedro de Valdivia gelang es den Spaniern, den Widerstand der Mapuche zu durchbrechen und bis zur Insel Chiloé nach Süden vorzudringen. Wie bereits in Kapitel 5 ausgeführt, konnten sie das Land südlich von Concepción nicht ausreichend sichern. Es kam zu einer Reihe von Aufständen und Angriffen der Mapuche, unter anderem auch die Kämpfe unter Caupolicán und Lautaro ${ }^{113}$, bei denen Ende des Jahres 1553 die Truppen Pedro de Valdivias geschlagen wurden und Valdivia selbst an Neujahr 1554 den Tod fand. Ihren Höhepunkt erreichten die Rebellionen in der Niederlage von Curalaba, wo die Spanier vernichtend geschlagen, ihre Ortschaften zerstört und ihr Rückzug bis jenseits des Flusses Bíobío erzwungen wurden. Heute spricht man davon, dass Spanien im Araukanischen Krieg mehr Soldaten und Ressourcen verlor als in allen anderen amerikanischen Eroberungszügen zusammengenommen. Als offensichtlich geworden war, dass sich der Einsatz für die Spanier nicht rentierte, begannen sie zu verhandeln. (Bengoa 1991:28ff.)

111 „Mapuche“ bedeutet „das Volk der Erde“ (mapu=Erde, che=Mensch, Leute, Volk).

${ }^{112}$ Mit diesem Satz beginnt José Bengoa seine Historia del pueblo Mapuche. (Bengoa 1991:5) 
1641 legte das parlamento von Quillín den Bíobío als Grenze des Gebietes der Mapuche gerichtlich fest und sicherte ihnen im Territorium südlich des Flusses Autonomie zu. Das sollte sich während der Kolonialzeit nicht mehr ändern und sogar noch 70 Jahre nach der Unabhängigkeit Chiles unangetastet bleiben (Aldunate del Solar 1986:44) - allerdings nur auf dem Papier. Zwar waren der Frieden von Quillín sowie folgende parlamentos, die die Rechtmäßigkeit des Vertrages von Quillín mit der spanischen Krone und somit die Autonomie der Mapuche mehrmals bestätigten, wichtige Schritte für die Mapuche in diesem Krieg. Jedoch hatten sie diese Erfolge mit rund einer halben Millon Menschenleben teuer bezahlt. (Bengoa 1991:33) Außerdem wurde die Grenze und somit der Friede de facto vom Jahre 1641 an fortwährend verletzt:

Todos los veranos se organizaben incursiones al interior de la Araucanía, ya para escarmentar a un grupo de mapuches por algún supuesto atropello, o simplemente para hacer ,piezas' (cautivos) que eran vendidos como esclavos en Santiago o a los encomenderos del norte del país. (Bengoa 1991:34)

Bis zur Unabhängigkeit Chiles funktionierte die Araucanía wie ein autonomer Staat, der offizielle Beziehungen zur Kolonialregierung unterhielt und eigene Steuern erhob. Die Mapuche lebten auf einem verhältnismäßig großen, ihnen offziell zugestandenen Territorium, wo sie mittlerweile Viehzucht trieben. Somit hatten sie schon lange vor den Chilenen ihre offizielle Unabhängigkeit gegenüber Spanien erkämpft. Ihre Anzahl war allerdings nicht nur durch die Kriegshandlungen gesunken, sondern insbesondere durch Infektionskrankheiten wie Masern und Windpocken stark dezimiert worden. Diese Krankheiten, gegen die die Mapuche keinerlei Abwehrkräfte besaßen, waren von den Spaniern eingeschleppt worden. (Bengoa 1991:30)

Dem parlamento de Quillin folgten weitere parlamentos, die immer in dessen Sinne entschieden, jeweils mit verschiedenen Zusatzklauseln bezüglich etwa der Handelsbeziehungen zwischen Spanien und der Araucanía. Insbesondere im Gebiet um Valdivia entstanden rege Kontakte und der Austausch von Waren zwischen Mapuche und Spaniern, während weiter nördlich zwischen den Flüssen Bíobío und Toltén, also im Herzen der Araucanía, die Mapuche ihr traditionelles Leben verfolgten. Zum letzten Male vor der Unabhängigkeit Chiles 1810 wurde die Grenze am Bío Bío im parlamento de Negrete 1803 von Spanien anerkannt.

${ }_{113}$ Caupolicán und Lautaro waren siegreiche Anführer der Mapuche im Kampf gegen die Spanier. (vgl. Fuentes 51978:117f., 308) Zu Lautaro siehe auch Kapitel 7.2, S166f. 
Mit der Unabhägigkeit Chiles (und gleichzeitig der Argentiniens) änderte sich die Situation der Mapuche radikal. Der Vertrag von Quillín wurde für gegenstandslos erklärt. Per Erlass wurde das Gebiet der Mapuche teils Chile und teils Argentinien zugesprochen. In der mündlichen Überlieferung der Mapuche heißt es:

Todos les decían:

„El rei es mejor;

tiene muchas tierras.

Los chilenos son pobres;

te robarán las tuyas“. (Bengoa 1991:141)

Für die Spanier war der Krieg gegen die Mapuche bald unverhältnismäßig geworden. Ganz anders für die Chilenen: Sie begriffen ihr Staatsterritorium als bis zum Kap Horn reichend und wollten auf dem gesamten Gebiet ihre Souveränität ausüben. Damit begann la guerra a muerte, ein erbitterter Kampf zwischen der Republik Chile und den Mapuche.

Erst Ende des 19. Jahrhunderts sollte der chilenischen Regierung die sogenannte pacificación de la Araucanía gelingen, ${ }^{114}$ mit der sie die Mapuche vollständig der Staatssouveränität unterwarfen. Südlich des Flusses Toltén, in der región de los lagos, wo der Widerstand gegen die Spanier von Beginn an nicht so erbittert war wie in der Araucanía, hatte bereits Ende des 18. Jahrhunderts die Kolonialregierung mit Hilfe von Militärposten und Missionen die Herrschaft übernommen. Eine wichtige Rolle bei der Unterwerfung spielte die Einwanderungspolitik, die die chilenische Regierung seit der Mitte des 19. Jahrhunderts forcierte. Sie benutzte die europäischen Siedler indirekt, um den Süden des eigenen Landes in den Griff zu bekommen, die Mapuche zu unterwerfen und das Grenzgebiet zu Argentinien zu sichern. 1845 wurde ein Gesetz erlassen, das die Grundlage für eine großangelegte Besiedelung des Südens bildete. Es wurden sogenannte agentes eingesetzt, die insbesondere in Deutschland für das Einwanderungsland Chile warben. Den Siedlerfamilien wurden Darlehen für die Überfahrt, für Land und Material zu dessen Bebauung gewährt, sie waren sechs Jahre steuerfrei und bekamen bei der Einreise die chilenische Staatsbürgerschaft. (Singer 1998:14) Die größte Gruppe von Siedlerinnen und Siedlern waren Deutsche, die in der Zeit zwischen 1846 und 1875 ihr Land verließen. Bis heute gibt es Ortschaften im Süden Chiles, in denen viel Deutsch gesprochen und deutsches Kulturgut gepflegt wird. Delia Domínguez spricht 1987 in ihrer Rede über die deutsche Kolonisation sehr pathetisch über das deutsche Erbe der Region:

114 Der Begriff der pacificación, also der ,Befriedung, stellt in diesem Zusammenhang einen menschenverachtenden Euphemismus dar. Wenn ich die Bezeichnung im Folgenden an manchen Stellen übernehme, beziehe ich mich damit auf die Sicht der chilenischen Regierung, bzw. auf den Wortlaut Riedemanns. 
[...] quiero hablar de la gente del sur, de los antepasados que a mediados del siglo XIX partieron el bosque en dos mitades para que la luz entrara en la semilla, para que el sol calentara la matriz de las mujeres y nacieran los hijos, y se poblara la tierra de nidales, para crear praderas fértiles donde los trigos no sólo tiñeran de claridad las cabezas, sino también las esperanzas. (Domínguez 1988:115f.)

Die geschichtliche Rolle der Deutschen bei der Kolonialisierung Südchiles wird kontrovers diskutiert und im Rahmen dieses Kapitels noch aus verschiedenen Perspektiven beleuchtet werden. Von besonderem Interesse ist dabei das Verhältnis zwischen den Einwanderern und den Mapuche.

Die sogenannte pacificación beinhaltete die Versteigerung von 55 Millionen Hektar Land im Jahre 1881, das zum Gebiet der Mapuche gehörte. Zwischen 1884 und 1910 wurden weitere Gebiete an Privatleute versteigert und die dort lebenden Indigenas in reducciones (Reservate) umgesiedelt. In der guerra a muerte hatten sie große Teile ihrer Viehherden verloren, auf die sich ihre materielle Existenz gründete, und in den viel zu kleinen gepachteten Parzellen zum Ackerbau gezwungen, verarmten sie innerhalb kürzester Zeit.

Una vez, que los mapuche fueron vencidos, sus territorios pasaron a manos del Estado. Este a su vez les entregó tierras, de acuerdo a sus normas, dentro de áreas denominadas reducciones. Mientras, a los colonos se les entregaba entre cuarenta y cuatrocientas hectáreas, las familias mapuches recibían un promedio de seis a veinte hectáreas, las cuales en gran parte correspondían a terrenos infértiles. Mientras en 1540, los terrenos de los mapuches llegaban a los 31 millones de hectáreas, hoy en día estas han sido reducidas a sólo 350,000 hectáreas. (La fundación Cholchol:Los mapuches)

Sie hatten bisher nur wenig Erfahrung mit der Landwirtschaft und waren nicht in der Lage, schnell genug eine Subsistenzwirtschaft aufzubauen, um ihren Lebensstandard zu halten. Hinzu kam die Taktik der chilenischen Regierung, weitere Stücke Land an Privatleute zu verkaufen, so dass immer mehr Mapuche-Familien völlig isoliert wurden. In dem Moment, in dem sie ihr eigenes Grundstück verließen, waren sie gezwungen, das Land von Siedlern zu betreten. Dies provozierte Konflikte und Auseinandersetzungen, die meistens mit dem Faustrecht ausgetragen wurden. Um zu überleben, verkauften viele Mapuche ihre Besitztümer wie traditionellen Schmuck und wanderten schließlich in die Städte ab.

Die Mapuche waren bei der Ankunft der Spanier ein Volk von Jägern und Kriegern, sie definierten sich über ihre Siege und Niederlagen. Der einzelne Mapuche-Krieger errang in der Schlacht Anerkennung und Frauen. In Friedenszeiten hatte jeder größere Familienverband sein eigenes Oberhaupt, einen lonko, der die Geschicke der Gruppe leitete. Für Kriegszeiten schlossen sich viele einzelne Gruppen unter einem einzigen Anführer, dem toki, zusammen. Durch die Veränderungen seit der Conquista hat ihre Gesellschaft viele Veränderungen erfahren. Zunächst wurden sie zu Viehzüchtern und -händlern innerhalb 
der ihnen seit 1641 zugesicherten Grenzen. Mit dem Verlust großer Teile ihrer Herden und der Umsiedlung in Reservate seit 1881 musste sich die Struktur ihrer Gesellschaft noch einmal grundlegend ändern. Sie wurden zu Bauern, die auf reine Subsistenzwirtschaft angewiesen waren: „Como dicen los viejos mapuches: ,Antes éramos guerreros, nos transformaron en sembradores‘“" (Bengoa 1991:365ff.)

Bengoa spricht schließlich von der sociedad mapuche postreduccional, womit das Leben der Mapuche im 20. Jahrhundert gemeint ist. Er sieht die einzig mögliche Reaktion der Mapuche auf die ihnen entgegengebrachte Gewalt im kulturellen Widerstand. Dieser Widerstand beinhaltet einerseits eine grundlegende und tiefverwurzelte Ablehnung gegenüber den Weißen, ihrer Art zu leben und ihren Werten und andererseits eine Aufwertung der eigenen Kultur:

Los mapuches se transforman en una cultura de resistencia, que ve en la mantención de sus costumbres, tradiciones, cultos y lengua, su sobrevivencia. Para sobrevivir [...] es necesario poner la barrera de la cultura, entre los chilenos invasores y los sobrevivientes. La cultura mapuche adquiere una función de coraza frente a la violencia, a la usurpación, a la muerte. (Bengoa 1991:371)

Bengoa geht mit seiner Betrachtung nicht über die erste Hälfte des 20. Jahrhunderts hinaus Im siebten Kapitel dieser Arbeit werden die Bemühungen der Mapuche um die eigene Kultur gegen Ende des Jahrhunderts noch eine Rolle spielen.

Die Kosmogonie der Mapuche eine Vielzahl von Mythen und rituellen Handlungen. Neben der Welt, in der die Menschen leben, gibt es in ihrer Vorstellung die Welt der Götter, wenu mapu, und die Welt des Bösen, minche mapu. Die oberste der insgesamt sieben Gottheiten der Mapuche ist Ngenechen, die über Erde und Menschen herrscht. Zu ihren Eigenschaften gehören Gegensatzpaare: Sie ist zugleich männlich und weiblich, zugleich jung und alt. Dieser Dualismus zeichnet alle Gottheiten und viele der mythologischen Figuren der Mapuche aus und gehört somit zum Gesamtkonzept ihrer Kosmogonie. Ebenso gibt es Priester (machi) beiden Geschlechts und verschiedenen Alters. Sowohl ihr Glaube an mehrere Gottheiten mit unterschiedlichen Zuständigkeiten, als auch an deren dualistisches Wesen wurden erschüttert durch die Ankunft der Spanier und das Wirken ihrer Missionare.

Das Blau des Himmels ist die heilige Farbe der Mapuche. Als Sitz der Götter gilt pillán, ein religiöser Ort im Osten, sowie der Süden, beides die Herkunft der guten Winde.

Neben der göttlichen Welt gibt es die Welt des Bösen, die unter der Erde liegt. Dort leben monströse Wesen, die sich vom Fleisch und Blut der Menschen ernähren. Dem Bösen wird die Farbe schwarz und der Norden zugeordnet, von wo der Wind schlechtes Wetter bringt, sowie der Westen, wo die Sonne verschwindet. Ein Sammelbegriff für alle bösen Mächte 
ist wekufu (oder wekufe), oft auch personifiziert als teuflisches Wesen. So wie die machi in Verbindung stehen mit den Gottheiten, gibt es Menschen, die mit der Welt des Bösen Kontakt haben: die kalku. Die Vorstellung vom Norden als Herkunft des Bösen gab dem Konflikt zwischen Spaniern und Mapuche von Anfang an zusätzlich eine mythische Dimension. ${ }^{115}$ (Aldunate del Solar 1986:81ff.)

\subsection{Die Vertreibung aus dem Paradies}

Obschon Karra Maw'n als das Werk eines „cronista temporáneo“ bezeichnet wird (Bianchi 1990c:2) und Riedemann sogar selbst von einem „cronista“-Erzähler spricht (S14 und S64), findet sich im Text nur ansatzweise eine Chronologie der Ereignisse. Zwar setzt das erste Gedicht des ersten Abschnittes vor dem Eintreffen der Spanier in Südchile ein, gefolgt von Texten, die die ersten Begegnungen zwischen beiden Kulturen beschreiben. Aber schon der letzte Text im ersten Abschnitt Un blue Mapuche blickt bereits auf vierhundert Jahre Unterdrückung zurück („100+100+100+100 años de matanza“, S24). Abschnitt II beginnt mit der Einwanderung der Deutschen Mitte des 19. Jahrhunderts und endet mit der Rede von der pacificación von Seiten der chilenischen Regierung. Der dritte Abschnitt handelt von dem Erdbeben 1960. Abschnitt IV ist relativ kurz und stellt Riedemanns Gegenwart dar. Der letzte Abschnitt Infancia del cronista fokussiert das Jahr 1953 und die unmittelbar folgende Zeit, eben die Jahre, die Riedemann als Kind erlebt hat. Auch innerhalb der einzelnen Texte gibt es durchgehend Rückgriffe und Vorausdeutungen, die eine lineare Darstellung konterkarieren. Die eigentliche Struktur des Buches entsteht also nicht durch eine stringente zeitliche Abfolge, sondern durch inhaltliche Schwerpunkte, angeordnet von einem Erzähler, der aufgrund seines auktorialen Wesens in der Lage ist, die inhaltlichen Zusammenhänge über die zeitliche Abfolge zu stellen.

Mit der Strukturierung in fünf Kapitel orientiert sich Riedemann an dem Langgedicht The Waste Land von T.S. Eliot: „Mi conocimiento de la Tierra Baldía de T.S. Elliot [sic], condiciona la división de toda la estructura del libro, capítulos que van interactuando...“ (González Cangas 1999:151)

Im Verlauf des Textes Karra Maw'n wird erkennbar, dass sich die intertextuellen Referenzen nicht allein auf die Komposition des Gedichtes beschränken. Es gibt Motive (Regen, Turm, rote Erde/roter Stein, Frucbtbarkeit), die in beiden Texten zentral sind. Auf derartige Bezüge wird jeweils an den entsprechenden Stellen einzugehen sein. Hier sei lediglich der Aufbau des Gedichts von Eliot skizziert.

${ }^{115}$ Auf eine umfassendere Beschäftigung mit der Kosmogonie der Mapuche muss ich im Rahmen 
Das implizite Hauptthema in The Waste Land ist der Legendenstoff der Suche nach dem heiligen Gral. Das Auffinden des Grals, bzw. das Einsetzen des Gralskönigs Parzifal ist in der zugrundeliegenden Sage gleichbedeutend mit dem Anbruch eines neuen Zeitalters, in dem Frieden und Gerechtigkeit herrschen. Der Anbruch dieser glücklichen Ära wird durch Zeichen der Fruchtbarkeit in der Natur symbolisiert. In Eliots Text ist das „waste land“ Symbol für die moderne, europäische Großstadt: Ödland in emotionaler und spiritueller Hinsicht. Der Text ist Ausdruck für das Warten und Hoffen auf den lebenspendenden Regen, der den Beginn einer neuen Zeit repräsentiert.

Das Wechselspiel von alter und neuer Zeit, von Tod und Neubeginn innerhalb eines ständigen Zyklus' der Fruchtbarkeit hat insbesondere im ersten Abschnitt von The Waste Land eine wichtige Funktion. Die ersten 76 Verse sind von Jahreszeiten-, Tageszeiten- und Naturmetaphorik durchzogen, die gleichzeitig in einen deutlichen Zusammenhang mit dem Tod gebracht wird. Der zweite Abschnitt hingegen handelt von Stagnation und Unfruchtbarkeit. Bilder aus der Natur sind völlig zurückgenommen, dagegen finden sich unzusammenhängende Dialoge, die nur die alltägliche Absurdität des modernen menschlichen Zusammenlebens miteinander gemeinhaben. Es handelt sich um sinnentleerte Gespräche entwurzelter Menschen in der Großstadt, die sich die Zeit vertreiben. Der dritte Abschnitt, der Fire Sermon, bringt die Krise (symbolisiert durch das Feuer) und deutet gleichzeitig eine Lösung an, indem der Text-Horizont um die buddhistische Spiritualität erweitert wird. Der Text ist in enger Anlehnung an eine Predigt Buddhas entstanden. Außerdem ist dies der einzige Abschnitt, in dem wir eine Perspektivfigur finden: Tiresias, der den Szenarien jedoch auch nur als Zuschauer beiwohnt. Der kurze vierte Abschnitt bringt das Gegenelement, das Wasser, ins Spiel. Im letzten Abschnitt stellt sich der erlösende Regen ein, doch es bleibt fraglich, ob es gelingen wird, das Land wieder fruchtbar zu machen. Trotz des Regens bleibt das Ende unbestimmt (V425,430): „Shall I at least set my lands in order? [...] These fragments I have shored against my ruins“. (Eliot 1998:69)

Der Regen, der bei Eliot das Element der erhofften Erlösung darstellt und mit dem gewissermaßen der Text schließt, ist bei Riedemann bereits im Titel präsent (Karra Maw'n = Ort des Regens). Er ist ein Teil der Landschaft, in der der Text angesiedelt ist: „De lo que acontece cuando el cronista se aleja de su tierra // [...] la lluvia / se ha quedado sin poeta“ (S14).

Weiterhin findet sich eine Anspielung auf den Titel von Eliots Text in der allerersten Zeile von Riedemann: „No era baldía aquella tierra“. Dieses Land war nicht öd. Den folgenden 
Zeilen nach zu urteilen, war das Land ganz im Gegenteil sehr fruchtbar. Trotzdem lautet die erste Zeile nicht „Dieses Land war sehr fruchtbar“, sondern äußert ihre Botschaft mit Hilfe einer untertreibenden Negativaussage. Diese ungewöhnliche Formulierung legt die Frage nahe, was dadurch ausgedrückt wird, was mit einer affirmativen Aussage nicht ebenso hätte gesagt werden können. Zum einen ist natürlich nur so die Konnotation mit The Waste Land möglich. Gleichzeitig impliziert die Verneinung, dass sich dieses Land von einem tatsächlich öden Land unterscheidet. Entweder bezieht man die Verneinung dabei auf ,aquella tierra“, dann geht man davon aus, dass ein anderes Stück Land gemeint ist, das dem Ort des Regens gegenübergestellt wird, wie zB das wüste Land, das bei Eliot erst durch den Regen erlöst werden muss. Oder man bezieht die Verneinung in dem Vers auf die zeitliche Einordnung („,no era“) und setzt so den ursprünglichen Zustand des Gebietes vom gegenwärtigen ab. Der weitere Verlauf des Textes legt die zweite Interpretation näher, wie im Folgenden noch deutlich wird.

Fest steht, dass durch exponierte Elemente wie Titel und Schlüsselmotive bereits sehr schnell die enge Verwobenheit beider Texte, bzw. eine vielfache Bezüglichkeit des chilenischen Gedichtes auf den englischen Text ins Auge fällt.

Der erste Abschnitt von Karra Maw'n beschreibt zunächst den Ort des Regens, Karra Maw'n, vor dem Eintreffen der Spanier. Es gibt die Landschaft (aquella tierra) mit ihrer roten Erde (roja tierra), ihren Pflanzen (tallos) und Früchten (cerezas); es gibt natürliche Zyklen wie Mondphasen (durante tres o cuatro lunas), es gibt den Ostwind (puelche) und die Fische (peces del estero). Aber auch Menschen sind bereits anwesend, nämlich Mapuche („el habitante de la ruca“, „respirar de cara al puelche“, „sacar peces del estero"). Neben einerseits dem semantischen Feld des Naturreiches und andererseits dem Bereich des Menschen ist noch ein dritter Komplex im ersten Text dominant. Die Ausdrücke „las metáforas“, „hablar en mapudungu“, „la canción de la tierra“, „poesía hermética“ und „poesía elemental“ referieren direkt auf den Bereich des Sprachvermögens. Schon die erste Zeile „No era baldía aquella tierra“, verweist implizit auf Sprache, indem sie auf ein Stück Weltliteratur anspielt.

In dieser Konstellation der semantischen Felder ,Naturreich', ,Mensch“ und ,Sprache` ist man versucht, die Sprache dem Menschen zuzuordnen, insbesondere wenn von „metáforas“, „mapudungu“ und „poesía hermética“, also von Bestandteilen der menschlichen Sprache die Rede ist. Im vorliegenden Text aber ist die Sprache enger an den Bereich der Natur geknüpft als an den Menschen. Die Metaphern sprießen aus den Stengeln, Mapudungun ist die Sprache und das Lied der Erde, sie ist wie ein Vibrieren der Luft. Die Land- 
schaft spricht, die Erde singt, die Pflanzen dichten. Und das Gedicht, das entsteht, ist ein hermetisches, unverständliches Gebilde für den Akademiker, aber eine elementare Erfahrung für die Mapuche.

Hablar en mapudungu,

murmurar apenas la lengua de la tierra era hacer vibrar en el aire

la canción de la tierra. (S13)

Menschen und Natur sprechen dieselbe Sprache, leben in Harmonie und Einklang. Entsprechend dieser Harmonie wird Karra Maw'n als locus amoenus präsentiert. Sergio Mansilla beschreibt die ersten Texte des Buches als „la representación de un espacio geográfico en el pasado prehispánico (es decir, premoderno) de evidentes connotaciones edénicas, con un estado de vida que era al mismo tiempo un estado de poesía permanente“. (Mansilla 1996:Kap.3.4) Die Konnotation eines paradiesischen Zustandes verstärkt sich wiederum durch die erste Zeile „No era baldía aquella tierra“, in der sich der Sündenfall, bzw. die Vertreibung aus dem Paradies bereits ankündigt, zumindest wenn man davon ausgeht, dass ein Vergleich mit dem heutigen Zustand gezogen werden soll.

Der zweite Text, De lo que acontece cuando el cronista se aleja de su tierra (S14) bleibt im Bereich der Natur und der Landschaft: „tierra de sorpresas y admiración climática“, „el torrente de Neltume“, „la luna nueva“, „la niebla“, „tus bosques“, „la nube“, „los almécigos“, „la lechuza“, „la vaca“, „los cachorros“, und schließlich wieder „la lluvia“. Alles in dieser Landschaft scheint zu trauern, weil der cronista, der poeta fort ist. Die Überschrift kündigt an, dass im Text erzählt würde, was passiert, wenn der Chronist seine Heimat verlässt, der letzte Vers aber spricht davon, dass der Dichter nicht mehr da ist. Chronist und Dichter werden hier also synonym verwendet.

Auch die erste und die dritte Person verschmelzen miteinander. Während es im Titel noch heißt „,cuando el cronista se aleja de su tierra“ steht in Vers 6 ,cuando me alejo de tus bosques“. Der letzte Vers findet wieder zur dritten Person zurück: „la lluvia se ha quedado sin poeta“.

Im Gegensatz zum ersten Text entsteht hier ein Bruch zwischen Mensch und Natur, bzw. zwischen Dichter/Sprache und Natur, da der Dichter fortgeht, sein Land verlässt. Gleichzeitig wird seine enge Bindung an die Natur dadurch umso deutlicher. Der Wolke und dem Regen wird hier die Trauer zugeschrieben, die der Dichter beim Fortgehen selbst empfindet. So wie er in der Lage ist, die Schönheit der Natur durch Worte auszudrücken, so leiht die Natur dem Dichter und seinem Schmerz hier ihre Ausdrucksformen. Auch wenn der Dichter fortgeht, bleibt doch die enge Verbundenheit zwischen ihm und seiner heimat- 
lichen Landschaft bestehen. In den beiden ersten Texten stehen somit Einheit und Harmonie sowie eine intakte Kommunikation (zwischen Mensch und Natur) im Vordergrund.

Mit dem dritten Text La maldad del Wekufe (S16) ändern sich die beschriebenen Umstände und die beschreibende Sprache grundlegend. Zwar besitzen auch die ersten beiden Texte weder eine einheitliche Strophenform noch Reime, doch sie vermitteln - insbesondere durch das Druckbild - eine klare Strukturiertheit. Die kurzen Strophen der ersten Gedichte stellen sich als Textblöcke dar, die ungeraden Zeilen sind eingerückt. Auf diese Weise entstehen optisch ein gleichmäßiger Rhythmus und ein ruhiger Eindruck. La maldad del Wekufe hingegen ist ein zerrissener Text, das Druckbild ist unruhig. Außer den Zeilen, die ganz links beginnen, gibt es vier verschiedene Einrückungen. Es gibt wörtliche Rede, die wie auch der Ausdruck EL SER DIVINO - mit Großbuchstaben vom übrigen Text abgehoben ist. Die fünf Strophen sind nur bei genauem Hinsehen als Einheiten zu erkennen.

Auch die sprachliche Darstellung hebt sich von den ersten beiden Texten ab. Es handelt sich nicht mehr um die Beschreibung von Landschaft, sondern um die Wiedergabe von Handlung. Adjektive sowie Genitivattribute und Infinitive verringern sich merklich zugunsten von flektierten Vollverben.

Was inhaltlich beschrieben wird, ist zunächst eine first-contact-Situation, d. h. zwei Kulturen, die bisher nichts voneinander wussten, begegnen einander. Der Wekufe ist ein mythologisches Wesen der Mapuche, ein Teufel oder böser Geist. Vers 14 erklärt die Figur: „Wekufe -lo diabólico“. Bei den Mapuche wird Wekufe für alles Böse sowie für Krankheit und Tod verantwortlich gemacht. Auch das Eintreffen der Spanier im Gebiet der Mapuche wird unmittelbar mit dem sein Unwesen treibenden Wekufe in Verbindung gebracht, wie bereits der Titel ankündigt. Die ersten Verse sprechen zunächst über eine Veränderung innerhalb der Gesellschaft der Mapuche: „Los indios desconfiaron de Chaw-Ngënechén / EL SER DIVINO“. Die Tatsache, dass ein Volk seinem obersten Gott nicht mehr vertraut, muss als Zeichen großer Verwirrung verstanden werden. Der Grund wird nachgeschoben: „cuando vieron muchos hierros / y caballos“. Sie sehen Waffen und Tiere, die ihnen unbekannt sind und Menschen, die scheinbar nur an den Händen und im Gesicht Haut tragen. Diese Eindrücke lassen die Mapuche an ihrer Weltordnung zweifeln.

Zum einen sind es Sicherheit und Zuversicht der Mapuche, die erschüttert werden („desconfiaron, sintieron temor"), zum anderen leidet die Kommunikation: „enviaron mensaje con saludos / que no fue respondido“. Die Grüße wurden aufgrund sprachlicher 
oder kultureller Barrieren nicht beantwortet, sprachliche Interaktion scheint nicht möglich. Und schließlich wird aus der bislang vorherrschenden Harmonie das Empfinden der Unterschiedlichkeit: „Diferencia económica / diferencia política y moral / religiosas diferencias“.

Das Problem der Kommunikation wird im Text durch die Verwendung verschiedener Sprachen abgebildet:

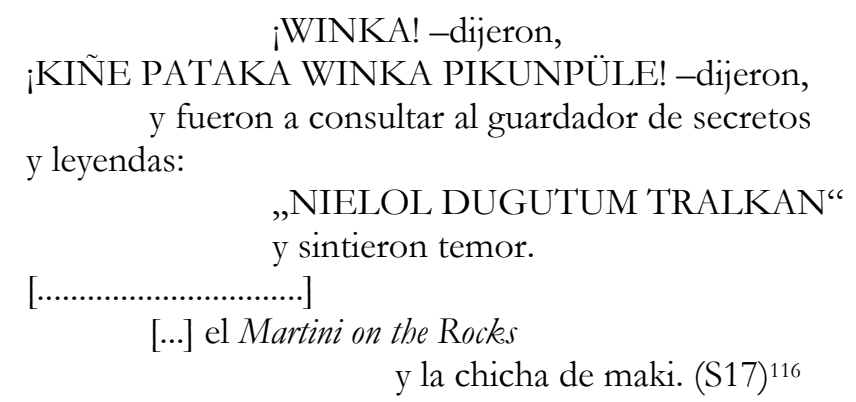

Riedemann streut in seinen Text einzelne Ausdrücke in Mapudungun ein. Bis auf das Wort winka, mit dem die Mapuche abfällig von den Weißen sprechen, sind die Begriffe keineswegs allgemein verständlich. Da der Text keine Übersetzung anbietet, liest er sich für die meisten Leserinnen und Leser nur mit blinden Flecken, die eine Ahnung davon vermitteln, wieviel mehr Un- und Missverständnis in der historischen Situation geherrscht haben muss. Indem Riedemann die Wörter nicht ins Spanische übersetzt, also nicht der ,herrschenden“ Sprache anpasst, werden die Zeilen zu einer Demonstration seines Respektes gegenüber den Mapuche und ihrer Kultur. ${ }^{117}$ Die Erwähnung des „Martini on the Rocks“ weckt andere kulturelle Assoziationen. Der Drink stammt aus einer Zeit, in der die Sprache keine große Barriere mehr darstellt, wohl aber der kulturelle Kontext, den die Sprache noch immer symbolisiert. Es ist nun nicht mehr die spanische Kultur, die die Mapuche vereinnahmen möchte, sondern die nordamerikanische. Demgegenüber steht die „chicha de maki“, angegorener Apfelmost: ein traditionelles chilenisches Getränk.

„Ñielol dugutum tralkan“ heißt etwa „Der Berg Nielol spricht mit Donnern.“ Der Berg Nielol ist ein heiliger Berg der Mapuche, heute ist es der Name eines Parkes in Temuco. Dass dieses Heiligtum der Mapuche donnert, muss als eine Drohung gegen die Fremden verstanden werden, die sie jedoch ignorieren. Letztendlich machen sie aus dem donnernden Nielol einen zahmen Park mit Picknickstellen und Spielplätzen.

116 „Kiñe pataka winka pikunpüle“: 100 Winkas aus dem nahen Norden (oder: 100 Winkas nähern sich aus dem Norden). „Nielol dugutum tralkan“: Der Berg Nielol spricht mit Donnern. 
Wurde in den ersten beiden Texten ein paradiesähnlicher Zustand beschrieben, beginnt mit dem dritten Gedicht die Vertreibung aus dem Paradies. Allerdings müssen die Menschen hier den Ort nicht verlassen, sondern der Ort wird umgestaltet, er verliert seine Vertrautheit und seine Unschuld. Im Gedicht La maldad del Wekufe kann man dies insbesondere an drei Dingen festmachen. Zunächst bringt das Erscheinen von Wekufe dem Glauben der Mapuche nach das Böse in die Welt. Zweitens gelangt mit den Spaniern die „diferencia“ nach Karra Maw'n (im Gegensatz zu der vorher herrschenden Einvernehmlichkeit). Schließlich schlägt die Kommunikation fehl.

Spätestens jetzt wird deutlich, dass die ersten zwei Texte eine prähispanische Zeit beschreiben und dass die paradiesische Harmonie und das fruchtbare Land Bestandteile dieser Zeit waren. Die Ankunft der Spanier beginnt, das Gleichgewicht zu zerstören und aus dem Land ein ,wüstes Land‘ zu machen.

Der Text El árbol del mundo (S18ff.) verfolgt den Gedanken der Unterschiedlichkeit der Kulturen weiter. Optisch sind die Verse ähnlich uneinheitlich wie im vorigen Text. Wieder gibt es Begriffe in Majuskeln, Zitate, Kursiva, verschiedene Einrückungen, und wieder ist die strophische Einteilung nur schwierig zu erkennen. Der Text wirkt insgesamt zerrissen. Viel Neues und Unbekanntes kommt mit den Fremden nach Karra Maw'n: „Llegaron ideas desde el norte“ (S18). Die Ideen kommen von Norden her, so wie in der Anschauung der Mapuche alles Böse aus dem Norden kommt. Und es sind nicht nur andere Vorstellungen, es sind Menschen mit seltsamer Kleidung und seltsamen Gewohnheiten („más gente con ropas extrañas / costumbres extrañas“, S19), es sind ungewohnte Lebensmittel („bochas / semejantes a los granos de mostaza“, S19) und Gerätschaften („cráneos y cacharros de metal“, S19). Mit alldem hätte man sich vermutlich arrangieren können, aber sie bringen außerdem Kriege („nuevas guerras“, S20) und unerwünschte gesellschaftliche Veränderungen, wie die Herausbildung einer Randgruppe in der Bevölkerung, einer Unterschicht: „la primera población marginal“ (S20).118 Im Verlaufe des Gedichtes wird ein Bruch im Ton deutlich. Der naive Anachronismus vom Beginn des Textes wird schließlich von der kritischen Haltung einer sozialökonomisch orientierten Analyse abgelöst.

Zwischen den Bereicherungen einerseits, etwa durch neue Lebensmittel und neue Materialien, und dem Unheil des Kriegs andererseits bringen die Fremden „otras técnicas“, womit insbesondere architektonische Fertigkeiten gemeint sind:

117 „Riedemann se remonta al idioma primero y no traduce (ni ahora ni más adelante) para respetar el lenguaje original, previo al conquistador“. (Bianchi 1992:283) 


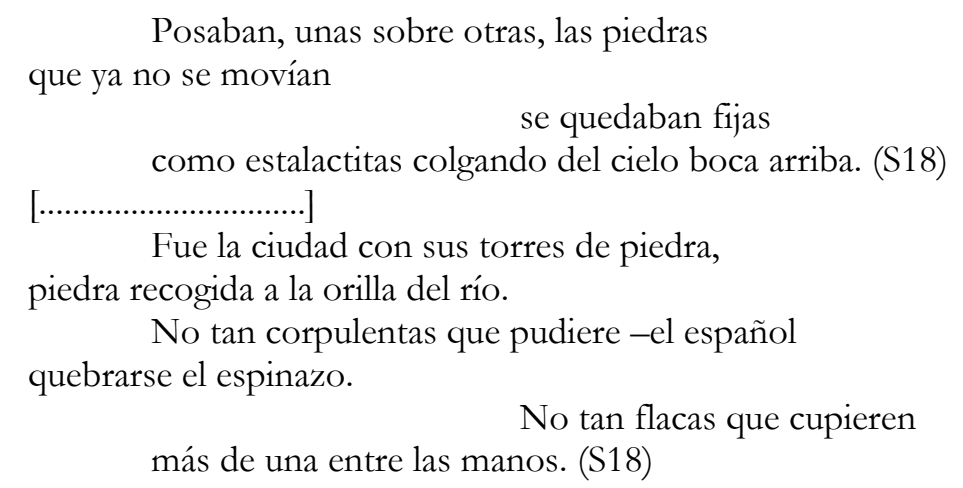

Das klingt wie eine Anleitung zum Häuserbau. Sowohl das Material als auch die Höhe der Gebäude scheint hier den Erzähler zu beeindrucken, also bislang unüblich gewesen zu sein. Von Türmen ist ab Vers 27 wieder die Rede:

Las torres árboles catatónicos en la estructura de un bosque defensivo. Una torre
EL ÁRBOL DEL MUNDO ,agredir para no ser agredido‘. (S19)

Das bislang unbekannte Gebilde des Turms wird mit einem Baum verglichen, allerdings mit einem kranken, einem wahnhaften Baum („catatónico“). Wir erfahren die Funktion der Türme: Verteidigung und Angriff. Die folgenden Verse nennen Turm und Baum nur noch in der Einzahl. Auch der Gebrauch von Artikeln variiert (von „[] []as torres“ zu „,[u]na torre“ und von ,árboles“ zu „EL ÁRBOL“). Dadurch entsteht der Eindruck einer Assoziationskette, die von den erbauten Türmen ausgeht.

Dem Turm wird der Baum des Lebens (in Majuskeln) an die Seite gestellt. Noch ist nicht klar, ob es sich um einen Vergleich oder um eine Entgegensetzung handelt. Zwar kann Verteidigung Leben bedeuten, doch sind Stein und Baum, künstliches Erbauen und natürliches Wachsen einander eher entgegengesetzte Motive.

El Árbol del Mundo es recurrente en los contextos chamanísticos de todo el mundo. De todas formas, funciona como un soporte que de hecho no lo es ni del cielo ni de la tierra, sino que sirve como punto de ingreso a las dimensiones terrestre y sobrenatural del universo. Crece desde un centro cósmico existencial -un axis mundi- que también simboliza el ombligo de la Gran Madre (el Inframundo). El árbol que emerge desde aquí es una clase de depósito de almas. Intersecta todos los mundos y dominios en la medida que atraviesa el universo, y tiene entradas a los otros mundos en ciertos lugares sagrados. (RipinskiNaxon, zitiert nach Pulido Biosco)

Wenn die Vorstellung, die hinter dem árbol del mundo bei Riedemann steckt, eine ähnlich religiös-mythologische ist, wie Michael Ripinski-Naxon es darstellt, ist schwer vorstellbar,

${ }^{118}$ Vgl. die Einschätzung Muñoz', dass erst durch die Invasion der modernen Marktwirtschaft auf Chiloé eine Unterschicht entstehen konnte (Kapitel 5.1, S92). 
dass dieser Lebensbaum, der der Weltachse entspringt, etwas mit den Verteidigungstürmen gemeinsam haben soll, zu denen die Spanier mittelgroße Flusssteine übereinander stapeln. Mit den beiden Versen 31/32 wird zunächst der für die Indigenas eindeutig positiv besetzte árbol del mundo eingeführt und gleich darauf mit dem als Zitat markierten ,agredir para no ser agredido“ kontrastiert. Bis hierher könnte die Begegnung der Kulturen als Bereicherung verstanden werden, die zu einem Austausch von Wissen, Fähigkeiten und Technik führen könnte. Die anschließenden acht Verse machen die Möglichkeit eines friedlichen Miteinanders jedoch zunichte: „Las castellanas plumas en la cumbre de los cascos / no sirvieron para barrer la sangre de los nativos [...] nuevas guerras / mucha sangre antes del trigo“. Daraufhin werden die Worte der Mapuche anklagend: „¡WEÑEFE! / ¡ÑIÑOKO! -airaban los indios / pero nadie se dio por aludido.“ Die Spanier werden hier als Diebe beschimpft (weñefe), würden sich aber sicherlich auch dann nicht angesprochen fühlen, wenn sie Mapudungun verstehen würden.

Ein letztes Mal begegnen Türme (diesmal wieder im Plural) und der Lebensbaum einander in den Versen 48/49: „Y LAS TORRES DE SANGRE BAILABAN / EN TORNO AL ÁRBOL DEL MUNDO“. Die Verteidigungstürme sind zu Bluttürmen geworden, zum Werkzeug oder zum Symbol für den Krieg, der von den Spaniern ausgeht. Nun stellt sich nicht mehr die Frage, ob Lebensbaum und Turm miteinander verglichen werden sollen: Dieser steht für Tod und Gewalt, jener für das Leben. Der Lebensbaum steht still, während die Türme um ihn herumtanzen.

Da Riedemann ein besonderes Augenmerk auf die Erbaunng der Türme legt, liegt es nahe, dies als eine Anspielung auf den Turmbau von Babel zu verstehen (Genesis 11.1-9).119 Die Bluttürme, die über den Lebensbaum triumphieren, symbolisieren fraglos Unrecht und Überheblichkeit einer Kultur gegenüber einer anderen. Durch die biblische Assoziation wird der Bau der Türme zum Zeichen von ketzerischer Anmaßung und Hybris. Zugleich scheint vor diesem Hintergrund das Unterfangen des Turmbaus zum Scheitern verurteilt zu sein. Darüber hinaus werden mit der Bedeutungsebene sprachliche Probleme, Missverständisse und missglückte Kommunikation konnotiert. Der Turm zu Babel konnte nur erbaut werden, weil den Menschen ihre einheitliche Sprache eine große Macht verlieh.

Und der Herr sprach: Siehe, es ist einerlei Volk und einerlei Sprache unter ihnen allen, und dies ist der Anfang ihres Tuns; nun wird ihnen nichts mehr verwehrt werden können von allem, was sie sich vorgenommen haben zu tun. (Genesis 11.6)

${ }^{119}$ Durch weitere Anspielungen auf verschiedene biblische Szenen wird diese Lesart im Folgenden gestützt. 
Die Strafe für ihr anmaßendes Verhalten war die Verwirrung ihrer Sprache. Die Spanier gehen ähnlich vor. Sie erbauen Türme zu militärischen Zwecken, die neben ihrer konkreten Funktion (Angriff und Verteidigung) auch als Symbol und Demonstration ihrer Macht gedeutet werden müssen. Jegliche Kommunikationsprobleme werden indessen ignoriert.

Eine weitere Anspielung auf die Bibel, diesmal auf das Neue Testament, findet sich in V19: „Y luego se lavaban las manos en las aguas del río“. Nachdem Pilatus Jesus verurteilt und Barrabas auf die Entscheidung des Volkes hin freigelassen hat, „nahm er Wasser und wusch die Hände vor dem Volk und sprach: Ich bin unschuldig an seinem Blut; sehet ihr zu!“ (Matthäus 27.24) Plausibel wird diese symbolische Beteuerung der Unschuld im Gedichttext erst durch die nachfolgenden Verbrechen, die durch die dreimalige Erwähnung von Blut angedeutet werden („la sangre de los nativos“, V34; „mucha sangre antes del trigo“, V37; „LAS TORRES DE SANGRE“, V48).120

Türme sind auch in The Waste Land ein wichtiges Motiv. So erinnert das Bild der Verse 6/7 „se quedaban fijas / como estalactitas colgando del cielo boca arriba“ an V382 bei Eliot: „And upside down in the air were towers“. (Eliot 1998:68) In beiden Fällen ist oben und unten vertauscht worden, und die Türme wachsen aus dem Himmel heraus hinunter in Richtung Erde. An einer anderen Stelle spricht Eliot von „falling towers“ (V373). Der brennende oder zusammenstürzende Turm ist ein Motiv aus dem Tarot, also symbolisch stark aufgeladen. Da Eliot in seinem Gedicht das Tarotspiel und einige der Karten explizit anspricht, (V43-59) wird ihm auch die Bedeutung des Turmes nicht unbekannt gewesen sein. (Eliot 1998:56) Diese Karte ist eine der wenigen im Tarot, die meist ausschließlich negativ gedeutet wird. Sie steht für Ende, Zusammenbruch, Verzweiflung und Schicksalsschläge. Inwieweit Riedemann diese Konnotation im Blick hatte, ist jedoch schwer zu sagen.

Zwischen den Symbolen, intertextuellen Querverweisen und biblischen Konnotationen findet sich ein handfestes historisches Dokument: ein Ausschnitt aus einem der Briefe von

\footnotetext{
${ }^{120}$ Beim genaueren Hinsehen funktioniert die Übertragung des Bildes nicht ohne Probleme. Im bildspendenden biblischen Kontext sind es Menschen aus Jesu eigenem Volk, an die Pilatus die Verantwortung für das Todesurteil abtreten kann, was zum oben zitierten Ausspruch führt. Dass die Christen in Chile ohne eine vergleichbare Möglichkeit, die Schuld von sich abzuwälzen, metaphorisch an Pilatus' Stelle gesetzt werden, könnte darauf hindeuten, dass sie sich keiner Schuld bewusst waren. So würde das Waschen der Hände zu einem Akt tiefempfundener Selbstgerechtigkeit.
} 
Pedro de Valdivia, in dem von der Stadtgründung Valdivias berichtet wird. ${ }^{121}$ Dieses Stück einer historischen Quelle steht inmitten der Beschreibung der Türme aus Sicht der Mapuche, zwischen einem Vers, in dem Türme wie Stalagtiten vom Himmel hängen, und der Beschreibung der zum Bau verwendeten Steine. Hier treffen zwei unterschiedliche Blickwinkel aufeinander. Die Ureinwohner betrachten staunend, wie die Spanier ihren Lebensraum verändern mit Techniken, die ihnen bislang unbekannt waren. Pedro de Valdivia dokumentiert und datiert unterdessen die Stadtgründung, schätzt die Einwohner und äußert sich über demographische Fragen. Während in historischen Quellen wie dem Brief Valdivias planerisch-organisatorische Überlegungen, Zahlen, Statistiken und Bürokratie eine Rolle spielen (Wann wurde Valdivia gegründet? Wie viele Menschen leben dort? Wie sind sie am besten zu verwalten und zu ernähren?), nimmt die hier von Riedemann eingenommene Perspektive der Mapuche die konkrete Ausführung in den Blick: Wie bauen die Fremden ihre Häuser? Wie groß sind die verwendeten Steine? Aus welchem Material sind ihre Gerätschaften? Dabei entsprechen sowohl die Methode der Berücksichtigung einer Quelle als auch deren Inhalt (Daten, Zahlen) der traditionellen Geschichtsschreibung. Demgegenüber steht der Versuch sich in die Mapuche hineinzudenken und die Ereignisse aus ihrer Sicht zu dokumentieren.

Der folgende Text De cómo la indiada perdió el respeto a los caballeros (S21) ist im Vergleich zu den beiden vorhergehenden ruhiger und geschlossener. Das Druckbild ist sehr einheitlich: Zeilen mit und Zeilen ohne Einrückung alternieren wie in den ersten beiden Texten.

Der Titel kündigt eine Art kleine Geschichte an. „De cómo“ war ein typischer Titelanfang für Kapitel spanischer Ritterromane. Später begannen so die meisten Kapitel der Werke über die Neue Welt. In der Historia general de las cosas de la Nueva España von Bernardino de Sahagún oder auch in den Naufragios von Alvar Nuñez Cabeza de Vaca beginnen fast alle Kapitel mit „de“, mit „como“ oder eben mit „de como“. In der Kapitelüberschrift sollte eine Vorausschau auf den Kapitelinhalt gegeben werden. ${ }^{122}$ Es handelt sich somit um eine Zitat der Gattung des Romans oder der Reisebeschreibung.

Der Text gliedert sich in fünf Strophen. Die erste Strophe handelt von der Vorstellung der Mapuche, der Spanier und sein Pferd seien ein einziges, wundersames Wesen. Gleichzeitig wird angedeutet, dass dieser Irrglaube bald aufgegeben wurde. Humorvoll erzählen die folgenden Strophen, wie es dazu kam. Nachdem die Indigenas einen Spanier zu Pferde gejagt und schließlich das Pferd erlegt hatten, brieten und aßen sie das Fleisch. Doch der

\footnotetext{
${ }^{121}$ Carta XII an den Príncipe don Maximiliano. Santiago, 26. 10. 1552.
}

${ }^{122} \mathrm{Zu}$ synoptischen Kapitelüberschriften vgl. auch Stanzel 1989:58f. 
Reiter „cual cola de lagarto / continuaba aún en movimiento“ (S21). Die Moral dieser Erzählung, oder die Erkenntnis, die die Mapuche aus der Begebenheit ziehen konnten, beginnt in V16. Ironisch wird die Erleichterung geschildert, mit der sie feststellten, dass die Fremden ihnen sehr viel ähnlicher waren, als sie gedacht hatten. Sie glichen ihnen physisch („también tenían pelos“, S22) und sie glichen ihnen psychisch („y miedo en los bolsillos“, S22). Die wichtigste Erkenntnis war sicherlich ihre Sterblichkeit („Y que caían al suelo / y se podrían“, S22) - und somit ihre Überwindbarkeit. Die letzte Strophe spielt auf ironische Weise mit dieser Feststellung.

Entonces, los indios construyeron el siguiente silogismo: „TODOS LOS WINKAS SON MORTALES“ (S22)

Tatsächlich ist der Satz nur einer von den drei Teilen, aus denen sich ein Syllogismus zusammensetzt. Er spielt auf den Satz „Alle Griechen sind sterblich“ an. Dieser wiederum ist der Schlusssatz eines von Aristoteles' untersuchten Syllogismus', der zum Paradebeispiel für den logischen Schluss werden sollte. ${ }^{123}$ Sobald die Mapuche erkennen, dass die Spanier Menschen sind, können sie zusammen mit der ihnen bekannten Prämisse, dass alle Menschen sterblich sind, die abendländische Philosophie gewissermaßen gegen die Spanier ausspielen. Einer der Sätze, die die Disziplin der Logik begründen, dient hier in verfremdeter Form dazu, die Europäer auf eine Ebene mit den Bewohnern der Neuen Welt herabzuholen. Es ist, als müssten die Spanier selbst an die Wahrheit erinnert werden, dass sie menschlich sind, da sie sich nicht mehr wie Sterbliche benehmen, sondern wie „demonios ataviados / con las camisetas del cielo“ (S22).

Durch den fiktiven Ausspruch, den Riedemann den Mapuche in den Mund legt, werden die Spanier und ihr kultureller Dünkel lächerlich gemacht, und die Eindringlinge werden mit den Verteidigenden ausdrücklich auf eine Stufe gestellt. Dass die Mapuche ihre Ebenbürtigkeit entdecken, und gewissermaßen in ihren Köpfen die unmäßige Überlegenheit der Spanier getilgt wird, schlägt sich in der schon erwähnten ruhigen Struktur des Textes nieder. Die Mapuche haben ihre Fassung und ihr Selbstvertrauen zunächst wiedererlangt.

Seiner Struktur und Wirkung nach kann der Text als Anekdote beschrieben werden. Er erzählt eine einzelne, kurze Begebenheit, deren Mittelpunkt die psychologische Entmystifizierung der Spanier bildet. Humorvoll bis satirisch wird die zentrale, etwas absurde Szene geschildert, in der die Jäger das erbeutete Reittier braten und verzehren und der Reiter 
daneben wie ein Eidechsenschwanz zappelt. Am Ende steht eine Moral, aus der man eine Lehre ziehen soll. (Hess 1989:7) Vor diesem Hintergrund handelt es sich bei De cómo la indiada le perdió el respeto a los caballeros um einen stilisierten Text. Durch die anekdotische Umsetzung des dargestellten Geschehens ist die Erzählhaltung in diesem Text distanzierter als in den vorangehenden Gedichten. Der Erzähler betrachtet seinen Stoff von außen und schreibt zu didaktischen Zwecken.

Der letzte Text des ersten Abschnittes Un Blue Mapuche knüpft wieder an den unruhigen Stil vorheriger Texte an. Nicht ein einziger Erzähler spannt den Bogen der dargestellten Ereignisse, sondern viele Stimmen berichten aus verschiedenen Perspektiven. Oft sind es nur Andeutungen und verkürzte Darstellungen, die es aufzulösen gilt.

Der Blue Mapuche ist der Blues der Mapuche:124 der „canturreo triste“, der die Trauer über das Schicksal ihres Volkes ausdrückt, wie der Blues in Nordamerika der Gesang der von den Weißen unterdrückten Farbigen war. Gleichzeitig ist Blau die heilige Farbe der Mapuche. ${ }^{125}$ Die Verse 12-17 führen den Gedanken vom Blues der Mapuche gewollt kitschig aus. Leiser Singsang in der Abenddämmerung unter einem Mond, der sich in der Mündung des Flusses spiegelt. Man fühlt sich an das Klischee von singenden Farbigen am Ufer des Mississippi erinnert. Dieses atmosphärische Panorama kontrastiert mit den vorangegangenen Zeilen, in denen von der ständigen Präsenz der Kanonen der Festung die Rede ist ${ }^{126}$. Um die Gestalt dieser bislang unbekannten Gegenstände zu beschreiben, werden die Kanonen (wie vorher die Türme) mit Bäumen verglichen. Der Vers „día y noche apuntando hacia el pacífico mar“ drückt aus, wie absurd die Indígenas die Einrichtung der Festung vermutlich empfunden haben.

In Vers 24 wird deutlich, dass die Perspektive mittlerweile die eines heutigen Betrachters ist: „Fueron cuatro siglos“, und ein paar Zeilen weiter „100+100+100+100 / años de matanza“. Kurz danach wird das Motiv des vergossenen Blutes wieder aufgegriffen (V3137). Die Vertreibung aus dem Paradies scheint abgeschlossen, viel Blut wurde vergossen, und viel wurde darüber geschrieben:

${ }^{123}$ Der vollständige Syllogismus lautet: A: Alle Menschen sind sterblich (Obersatz), B: Alle Griechen sind Menschen (Untersatz), und C: Alle Griechen sind sterblich.

${ }^{124}$ Möglicherweise handelt es sich im Text von 1985 um einen Druckfehler. Als Karra Maw'n zehn Jahre später nocheinmal veröffentlicht wird, diesmal in einer Ausgabe zusammen mit anderen Gedichten, steht an derselben Stelle Un blues Mapuche. (Riedemann 1995:19)

${ }^{125}$ Der Mapuche-Dichter Elicura Chihuailaf erklärt die Bedeutung der Farbe Blau für sein Volk folgendermaßen: ,[...] del Azul del oriente venimos y es lo que está en el corazón y en el espíritu de cada mapuche. Y hacia el Azul del poniente nos iremos, a encontrarnos con los espíritus de nuestros antepasados, nos dicen." (Guerrero 1996) 


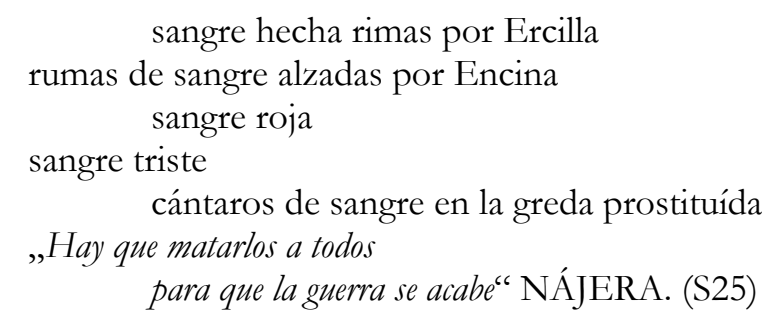

Riedemann macht deutlich, dass wir heute nicht nur auf 400 Jahre Geschichte, sondern auch auf 400 Jahre Geschichtsschreibung zurückblicken. Stellvertretend für die Historiographie nennt er den Dichter Ercilla, dessen Araucana am Anfang der Geschichte Chiles stand, neben dem Historiker Francisco Antonio Encina, der von 1940 bis 1952 die 20bändige Historia de Chile veröffentlichte. Anschließend hebt er den Chronisten González de Nájera durch Majuskeln hervor und zitiert eine Aussage, in der dieser sehr radikal Stellung bezieht. Das Zitat ist kein Einzelfall innerhalb Nájeras Schriften. Nájera kommt als hoher Militär mit der Expedition von Alonso de Ribera Anfang des 17. Jahrhunderts nach Chile, wo er sich sieben Jahre aufhält. Bei seinen Beobachtungen fokussiert er immer wieder die militärischen Fertigkeiten, die Kriegsausrüstung und Kriegführung der Mapuche. An anderer Stelle heißt es über sein Werk Desengaño y reparo de la guerra del reino de Chile (1614) und die darin enthaltenen Beschreibungen der Indígenas: „La distancia cultural abonó el surgimiento de estereotipos, que pueden sintetizarse en el juicio de González de Nájera: ,es gente indigna de llamarse racional, porque es ajena a toda virtud, supersticiosa, agorera, sin justicia...' y continuaba largamente la letanía descalificadora.“ (Zapater 1997)

Durch verschiedene Anspielungen sind bereits 400 Jahre Kolonisation thematisiert worden: die ersten Begegnungen, die ersten Missverständisse, aber auch schon die anschließenden Verbrechen, Mord, Krieg, Dezimierung und Marginalisierung der Ursprungsbevölkerung.

Meistens ist die vorherrschende Perspektive die der Mapuche, bzw. eine Perspektive, die der Erzähler als solche konstruiert, denn über die tatsächliche Wahrnehmung der Ereignisse aus der Sicht der Indigenas wissen wir wenig. Die Stimme eines der Kolonisatoren hören wir nur ein einziges Mal, nämlich im Ausschnitt des Briefes von Valdivia. Mit diesem Perspektivwechsel liegt ein deutlicher Bruch mit der jahrhundertelangen Tradition der geschichtlichen Darstellung vor, für die Spanier, für die Chilenen, aber auch für die Mapuche.

De tal manera, una historia que siempre se ha oído en castellano, se inicia en mapudungún, „la lengua de la tierra“. Un relato abierto casi siempre por los conquistadores y, con frecuencia, con la descripción de la Provincia o Reino de Chile, perteneciente al Imperio

${ }^{126}$ Gemeint sind die Festungen von Niebla, Corral und Mancera in der Mündung des Flusses Valdivia, wo noch heute die schweren Geschütze der Besatzermacht besichtigt werden können. 
español, o con el relato de su „descubrimiento“, se inaugura ahora con la Calidad del suelo, del agua y del aire en Karra Maw’n, cuando todavía son gozo exclusivo de „el habitante de la ruka“. (Bianchi 1990c:2)

„Una historia que siempre se ha oído en castellano“, das heißt, dass die Version der Eroberer von der Geschichte für alle zur offiziellen Version geworden ist. Darüber hinaus habe die historische Erzählung in Südamerika überhaupt erst mit dem Auftreten der Spanier zu existieren begonnen. (Bianchi 1990c:2) Das erinnert an die Aussage im Text von Contreras Vega: „Y entonces entramos a la historia“"127. Auch hier findet sich der Gedanke, dass die Geschichte für Amerika eigentlich erst mit der Ankunft der Spanier beginnt. Gerade dieser Tatsache steht Riedemanns Text entgegen, wenn er mit einer Beschreibung der prähispanischen Zeit einsetzt.

Bei allen verschiedenen Schreibstilen und berücksichtigten Perspektiven bleibt fast durchgehend die Figur des Chronisten erhalten. Dieser hat es sich zwar zur Aufgabe gemacht, unterschiedliche Stimmen zu Gehör zu bringen und somit ein Gegengewicht zur offiziellen Geschichtsschreibung zu schaffen, allerdings wahrt er bisher Distanz.

Eigentliches Thema des ersten Abschnittes ist - so kann zusammengefasst werden - die Vertreibung der Mapuche aus ihrem Paradies und die Invasion der Spanier. Die aktuelleren Einsprengsel betonen, dass es sich dabei nicht um einen punktuellen Konflikt handelt. Ob wir heute die Folgen oder die Fortsetzung der ersten gewaltsamen Begegnungen erleben in jedem Fall handelt es sich bei der Machtverteilung um ein strukturelles Problem.

\subsection{Los cabezas amarillas: Die Deutschen in Südchile}

Den Schwerpunkt des zweiten Abschnittes von Karra Maw'n bildet eine weitere Station in der Geschichte Südchiles: die Kolonisation durch die Deutschen. El hombre de Leipzig, der Text, der den Abschnitt eröffnet, ist in verschiedener Hinsicht bemerkenswert. Zunächst hebt er sich formal von allen anderen Texten des Buches dadurch ab, dass er als einziger nicht in Versform geschrieben ist. Zusätzlich steht er vollständig in Kursiva. Inhaltlich fällt auf, dass sich hier das einzige Mal ein Erzähler mit persönlichen Charakteristika äußert. Hinter den Worten des Erzählers steht nicht nur eine Position, eine Meinung, die er stellvertretend für andere Menschen - verficht. Vielmehr wird er durch die Details seiner Familiengeschichte, in die er uns einweiht, zum unverwechselbaren Individuum. Wir erfahren, dass sein Urgroßvater ein Zimmermann aus Leipzig war, der mit anderen deutschen Auswanderern zusammen nach Chile kam. Die Namen der vier Schiffe, die damals 
die Überfahrt machten, werden genannt. ${ }^{128}$ Ein Foto wird erwähnt, das die Ankömmlinge zeigt. Es ist bekannt, dass die Vorfahren Riedemanns Mitte des 19. Jahrhunderts aus Deutschland kamen, so dass Erzähler und Autor einander hier sehr nahe kommen.

Die Sprache dieses Textes ist poetischer als die der meisten in Versform verfassten Texte des Buches. Die ersten beiden Sätze machen bereits deutlich, dass der Erzähler nicht einfach über seinen Urgroßvater spricht, sondern gleichzeitig über eine Figur, die von symbolischer Bedeutung für ihn ist und eine große Anziehungskraft auf ihn ausübt: „El padre del padre de mi padre traía todo el mar en sus mejillas. Trajo un cormorán en la mirada y una flauta dulce en los bolsillos“ (S29). Das Fernweh, vielleicht auch das Heimweh, stehen ihm ins Gesicht geschrieben, auf den Wangen haben Wind und Salzwasser der Überfahrt ihre Spuren hinterlassen. Der Kormoran ist ein Wasservogel, der sowohl in Mitteleuropa als auch in Südamerika heimisch ist. Die Blockflöte ist der einzige Gegenstand, den er bei seiner Ankunft in Chile noch bei sich hat. Sie ist zum einen ein typisch europäisches Instrument, zum anderen wird sie als Symbol für Musikalität und Sensibilität („dulce“) zum Attribut des Mannes.

Durch die poetische Beschreibung des Urgroßvaters wird Sympathie geweckt. Die folgenden Sätze fügen Mitgefühl hinzu: „No trajo papeles, ni osamentas. Le quitaron su historia en las aduanas y venía de lejos“. In dem Moment, in dem er nach Chile kommt, verliert er seine offizielle Identität: seine Papiere, seine Heimat und seine Geschichte. Während also die Spanier, die nach Südamerika kamen, ihre eigene Geschichte und ihre Perspektive der Neuen Welt aufzwangen, kommt dieser Mann aus Leipzig, seiner Identität und Geschichte beraubt. Dadurch ergibt sich eine Parallele zwischen den Mapuche und dem deutschen Einwanderer. Dieser Eindruck verstärkt sich in den folgenden Sätzen, wenn es weiter über die Deutschen heißt: „Todos buscando el paraíso. Para todos, desengaño y selva“. Die Einwanderer kamen mit großen Hoffnungen: Sie waren auf der Suche nach dem Paradies. Vermutlich war ihnen fruchtbares Ackerland versprochen worden, und nicht die „selva“,

\footnotetext{
${ }_{127}$ Vgl. Kapitel 1, S1f.

${ }^{128}$ Drei davon finden sich ebenfalls in der Rede von Domínguez (vgl. dieses Kapitel, S120): „Pero fue en 1850 cuando la emigración comenzó en forma regular con la llegada de numerosas familias contratadas por don Francisco Kindermann. Ese año entraron a Corral más de diez buques. El orden de atraque fue el siguiente: [...] - En octubre, el velero „Steinwaerder“, con quince almas a bordo. - En noviembre atracó el „Herrmann“, con las familias Anwandter, Kindermann, Schelegel, Keller, Kayser, Winkler y Schmidt, junto a muchas otras de igual importancia. - En diciembre tocó tierra el „Susanne“, procedente de Hamburgo, con ochenta y ocho personas contratadas por el Gobierno de Chile y que costearon ellas mismas sus pasajes; es decir, venían como inmigrantes libres. Entre ellas cabe recordar a las familias Schilling, Neumann, Boehmwald, Israel, al preceptor Belzer y a Carlos Muschgay.“ (Domínguez 1988:119f.)
} 
die die Weitgereisten vorfanden. ${ }^{29}$ Außerdem waren sie offensichtlich über die wahren Besitzverhältnisse nicht aufgeklärt worden, wie die folgenden Zeilen nahelegen: „Les prometieron la tierra, pero la tierra tenía dueños falsos. Falsas estacas de papel y no auténticos auténticos rewes milenarios“. Die chilenische Regierung gab sich als Besitzer des Landes aus, dessen sie sich unberechtigterweise bemächtigt hatte. Tatsächlich handelte es sich um „rewes milenarios“, um Land, das den Mapuche gehörte. Der rewe ist der Altar, das heilige Zentrum innerhalb einer Mapuche-Gemeinschaft. Er liegt meist unterirdisch in einer gegrabenen Höhle, in die eine heilige Treppe oder Leiter hinabführt. Der Begriff soll hier deutlich machen, dass es sich eben um das ureigene und heilige Land der Mapuche handelt.

Nachdem der Leipziger Zimmermann seiner Identität, seiner Heimat und seiner Geschichte beraubt und um sein Land und seine Hoffnung betrogen worden ist, muss er schließlich auch seine Sprache aufgeben: „El padre del padre de mi padre hubo de hablar en otra lengua“. Mit der Beschreibung all dieser Verluste und Schicksalsschläge gelingt es dem Erzähler, eine Parallele zwischen dem Los der deutschen Einwanderer und dem der Mapuche zu ziehen. Wie schon bei den Mapuche findet sich auch hier das Motiv des Paradieses, das zwar nicht verloren, aber doch versprochen und dann vorenthalten wird. In gewisser Weise werden beide Gruppen Opfer der chilenischen Einwanderungspolitik. Die Mapuche werden ihres Landes beraubt, die Deutschen werden um das Land betrogen, für das sie bezahlen und das ihnen als Eigentum in Aussicht gestellt wird. Beide verlieren ihre Vergangenheit und ihre Heimat, und schließlich müssen sich beide an eine neue Sprache gewöhnen (die Mapuche genau genommen an zwei: spanisch und deutsch). Somit weist der Text von Riedemann den deutschen Einwanderern mehr Gemeinsamkeiten mit den Mapuche als mit den Spaniern zu, ohne sie dadurch zu Leidensgenossen zu machen, die durch ihr Schicksal verbunden wären. Dabei handelt es sich aber nur um einen vorübergehenden Zustand, wie noch deutlich wird.

Die letzten beiden Abschnitte von El hombre de Leiprig rücken den Erzähler deutlicher in den Mittelpunkt. „Corral, después de un siglo [...]“ (S30). An Corral vorbei führte die

\footnotetext{
${ }^{129}$ Das Motiv der betrogenen Einwanderer findet sich auch bei Jorge Teillier im Zusammenhang mit französischen Immigranten - seinen Vorfahren, die etwa drei Jahrzehnte später nach Südchile kamen: „Mis abuelos llegaron a Quillón el año 1885. Eran unos 600 colonos. [...] Les aseguraron que Chile era un país de viñas y como ellos eran agricultores de Bordeaux, especializados en viñedos, se interesaron, pero llegaron aquí a una zona donde las tierras estaban recién cultivadas, donde llovía demasiado para sembrar viñedos, donde no había nada“. (Olivárez 1993:20)
} 
Schiffe der deutschen Einwanderer ihr Weg nach Valdivia. ${ }^{130}$ Der Erzähler steht hundert Jahre später an derselben Küste und begreift die vergangenen Ereignisse als Teil seiner eigenen Geschichte: „El hombre de Leipzig, el carpintero, me trajo a tierra en el lápiz de su oreja, de donde he bajado para organizar el mundo con palabras“.

Der folgende Text De por que los nativos no eran perezosos según se creía kommt wieder auf die Besetzung durch die Spanier zurück. Es scheint, als sollte die Kolonisierung durch die Spanier einerseits und durch die Deutschen andererseits klar unterschieden werden:

Creció como maleza el español sobre la tierra.

Brotaron, de a caballo, significantes de mal agüero:

$$
\begin{gathered}
\text { yelmo castillo } \\
\text { y pica, } \\
\text { sanza } \\
\text { sobre el valle de Karra Maw'n. (S31) }
\end{gathered}
$$

Utensilien des spanischen Militärs wie Kanonen, Festungsbauten, Helme und Lanzen sprießen aus dem Boden und verändern das Landschaftsbild. Durch ihre Anordnung im Druckbild werden sie aus dem Text hervorgehoben, so wie sie sich aus der einst friedlichen Landschaft von Karra Maw'n hervorhoben. Rein optisch führt eine Treppe aus Worten von links unten nach rechts oben hinauf, beim Lesen ist man allerdings gezwungen, die Treppe abwärts zu lesen, da die Richtungsangabe durch die Zeilenanordnung von oben nach unten schwerer wiegt als die „normale“ Lesart von links nach rechts. Dadurch verkehrt sich unsere Leserichtung und wir steigen von rechts oben nach links unten herab, bis wir am Fuß der Treppe umkehren und wie gewohnt nach rechts weiterlesen dürfen. Die Gegenstände werden zu Sinnbildern für die Bedrohung, zu unheilverkündenden Vorboten, die auf etwas hindeuten, das noch bevorsteht (,significantes de mal agüero“).

Auffällig ist die Pflanzenmetaphorik: „Creció como maleza el español sobre la tierra“, „Brotaron, de a caballo, significantes de mal agüero“. Vor der Ankunft der Spanier wurde die Harmonie in Karra Maw'n ebenfalls mit Bildern aus der Botanik beschrieben. Die Spanier sind jetzt das Unkraut, das die Metaphern und die Poesie der Landschaft überwuchern und zu zerstören drohen. ${ }^{131}$ Die Bildwahl naturalisiert die Ereignisse, es scheint sich eher um eine Naturgewalt zu handeln als um Menschen, die die Gewalt ausüben. Daraus resultiert das Gefühl von Hilflosigkeit im Umgang mit der Gewalt.

Als eine Folge der wuchernd sich verbreitenden Eindringlinge führt der Text den Anschein

\footnotetext{
${ }^{130},[[. .$.$] en 1844$ arribaron las primeras familias a Corral.“ (Domínguez 1988:119)

${ }^{131}$ Zumindest aus deutscher Sicht wäre eine solche Wortwahl seit den Verbrechen im Dritten Reich undenkbar.
} 
von Verwahrlosung und Faulheit unter den Mapuche an. Als Erklärung oder Kommentar bildet ein Prosa-Zitat des Anthropologen Milan Stuchlik die Mittelachse des Textes, in dem diese unterstellte Faulheit auf die kulturelle Perspektive des Anderen zurückgeführt wird. ${ }^{132}$ Aber diese Erläuterung wird in Klammern stehengelassen, sie bleibt die nicht wahrgenommene Randbemerkung eines Einzelnen. Stattdessen werden im letzten Teil des Textes viele weitere Vorurteile gegenüber den Mapuche aufgezählt.

Valientes guerreros heroicos libertarios

bandidos sangrientos

flojos

borrachos

taciturnos

ignorantes

retrógrados. (S32)

Optisch spiegelbildlich zu den Attributen der Spanier werden aus den mutigen Kriegern nun über sechs Stufen abwärts nach rechts erst die Verbrecher, die zwar nicht zu achten, aber noch zu fürchten sind, schließlich die rückschrittliche Menschen. Die militärische Stärke der Eroberer wird visuell der vermeintlichen Schwäche der Mapuche gegenübergestellt. Dabei entspringen diese Schwächen der kulturell festgelegten Sichtweise der Europäer („flojos“, „,retrógrados“), andere sind überhaupt erst auf die Ankunft, bzw. die Anwesenheit der Spanier zurückzuführen („borrachos“, „taciturnos“), und als „,ignorantes“ entpuppen sich die Spanier selbst durch ihre ahnungslose Beurteilung der fremden Kultur.

Der Text Importancia económica de los cabezas amarillas en el valle de Karra Maw'n (S33) wendet sich wieder dem Thema der deutschen Besiedelung zu. Es werden Veränderungen beschrieben, die mit dem Eintreffen der deutschen Siedler in der Region einsetzten und bis zum heutigen Tag das Leben prägen. Die Deutschen begannen, brachliegendes Land vom Unkraut zu befreien, mit Zäunen in Parzellen einzuteilen und zu bebauen. Sie erbauten „grandes rukas blancas / con techos de color púrpura y paredes de mazapán“. Die Häuser sind völlig anders als die ruka, die Hütte der Mapuche: groß und weiß mit roten Dächern. „Paredes de mazapán“ legt nahe, dass die Häuser den Mapuche kaum fremder und wunderbarer vorgekommen wären, hätten sie Wände aus Marzipan, das sie auch erst durch die Deutschen kennenlernten, gehabt. Ebenso fantasievoll-bewundernd klingen „vacunos celestes que otorgaban / bifes estelares“. Dieser Ton zieht sich durch die erste Hälfte des Textes: „La mantequilla y el queso eran magníficos / así como las diversas maneras de preparar el téc. Klischeehaft geht es weiter:

${ }^{132}$ Vgl. Kapitel 2.1.2, S10f. 
Las muchachas lucían pechos enérgicos y eran bellas como una vaca Holstein pastando al sol en primavera en octubre, cuando todo está verde y se sonría porque la vida es buena. (S34)

Sowohl das Bild eines (deutschen) Mädchens als auch das einer Holsteiner Kuh, die in der Frühlingssonne grast, sind schablonenhaft und kitschig, wie man sie in einer Werbung für Milchprodukte erwarten würde. Wie bereits in der Episode, in der die Mapuche die Sterblichkeit der Spanier entdecken, wählt Riedemann auch hier einen humorvollen Umgang mit seinem Thema. Durch die Ironie und Respektlosigkeit des für das Mädchen wenig schmeichelhaften Vergleichs mit einer Kuh schafft er Distanz zum Gegenstand. Im Folgenden weist er darauf hin, dass es die Deutschen waren, die die bis dahin unbekannte Milchwirtschaft nach Chile brachten. Außer Steaks, Butter, und Käse brachten die Deutschen noch andere Dinge in ihre neue Heimat:

Se produjo escuelas particulares

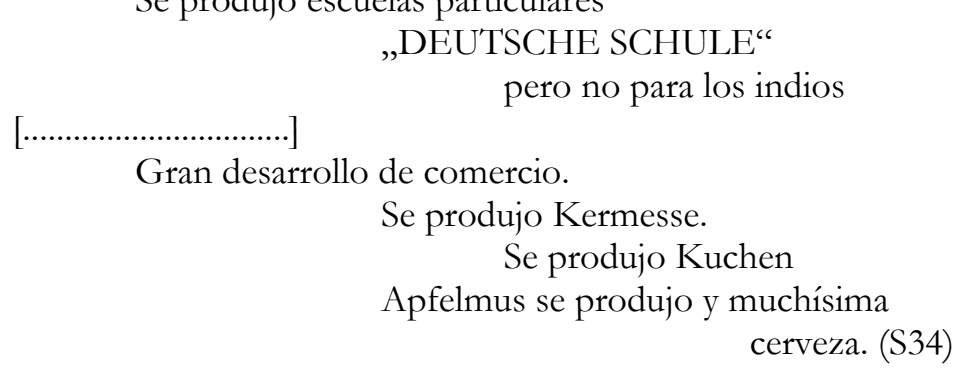

Die Deutschen scheinen aus Südchile ein Schlaraffenland zu machen und als Beweis wird auf Postkarten der Gegend hingewiesen. Nur einige Details trüben das Bild: „,mejor comunicación con un garrote / con municiones de Winchester [...] alambre de púas [...] ni una gota de limón cae sobre la herida“. Mit der Paronomasie von „comunicación“ und „,con munición“ macht Riedemann deutlich, wie das eine den Platz des anderen einnimmt. Meinungsverschiedenheiten und Missverständnisse zwischen beiden Kulturen werden (sicherlich nicht nur) aufgrund des Sprachproblems durch Waffengewalt gelöst. Die Zäune, die die Felder voneinander trennen und die vor allem die Mapuche von den durch die Deutschen in Besitz genommenen Felder fernhalten sollen, sind aus Stacheldraht. Und die Schule, die die Deutschen errichten, ist nicht für die Indígenas.

Die zweite Gedichthälfte macht einen Sprung in das zwanzigste Jahrhundert. Die Gemeinschaft der deutschen Siedler ist inzwischen stark angewachsen („Había tanta gente que algunos no se saludaban entre si““, S35), die Straßen sind mittlerweile gepflastert („Primero estuvo el barro, después hubo adoquines“, S35). Aber dies wird als oberflächlich abgetan, denn ,„...] quedó la fiebre debajo. / Debajo está el sudor y la peste / [...] debajo quedó también el sueño“ (S35). Trotz den deutlichen Spuren von Weiterentwicklung und soge- 
nanntem Fortschritt (und zwar „más rápido de lo provisto“) haben sich die Menschen in Karra Maw'n nicht geändert. Hinter den Fassaden stehen der Traum und die Anstrengung des Siedlers, die sich in jedem einzelnen Pflasterstein zu spiegeln scheinen.

(Si levantaras un adoquín entre tus manos verías los ojos del colono mirarte desde el fondo del oscuro cuadrado). (S35)

Demgegenüber stehen die Klischeehaftigkeit und Oberflächlichkeit der deutschen Lebensweise in Karra Maw'n, wie sie im letzten Teil von Importancia económica de los cabezas amarillas en el valle de Karra Maw'n beschrieben wird. Für die Freizeitgestaltung sind Sport- und Erholungsmöglichkeiten entstanden, außerdem werden kulturelle Aktivitäten organisiert. Die juegos florales sind ein Dichterwettbewerb, mit dem alljährlich an wechselnden Orten in Chile die Ankunft des Frühlings gefeiert wurde. ${ }^{133}$ Auch hier spielt also die Poesie - wie einst im paradiesischen Zustand Karra Maw'ns - eine Rolle. Aber sie hat ihre innige Bindung an die Natur verloren, wie die Verwendung des Begriffs „metáfora“ im Folgenden zeigt. „Siúticas metáforas donde la primavera / era sólo una fiesta y no tiempo de mieses, verdaderas mieses cogidas con decoro“ (S35). ${ }^{134}$ Die Verse machen den Unterschied zwischen Schein und Sein deutlich. Der Frühling, der eigentlich Saatzeit sein sollte, die alle verfügbaren Arbeitskräfte fordert, wird als ein großes Fest verbrämt. Wie schon einmal im Eingangsgedicht Calidad del suelo, del aire y del agua en Karra Maw'n ist scheinbar unvermittelt von Metaphern die Rede. Die Siedler machen aus dem Frühling eine Metapher, allerdings eine kitschige Metapher, die blenden und einen falschen Eindruck erwecken soll. So werden - wie bereits zu Beginn des Zyklus' - die Isotopien der Natur und der Sprache miteinander verknüpft. Im ersten Text waren die Metaphern Bestandteil einer Landschaft, in der sich die Sprache und der Kreislauf der Natur in Einklang befanden (S13), nach der Ankunft der Spanier wurde die Verständigung problematisch, und gleichzeitig begann das Unkraut, das Land zu überwuchern (S31). Nun wird der Frühling zum Inhalt aufgesetzter Metaphern, in denen Arbeit und Natur ausgespart werden: „no [...] verdaderas mieses cogida con decoro“. Die Metaphern, die hier vorherrschen, sind verlogen geworden, unaufrichtig, und verfälschen das Verhältnis des Menschen zur Natur.

In ähnlicher Weise machen die letzten Zeilen auf das gekünstelte Verhalten der Deutschen aufmerksam:

\footnotetext{
${ }^{133}$ Heute finden die juegos florales immer in Santiago statt.

134 „Las mieses“ muss hier als Saatzeit verstanden werden, gebräuchlicher ist der Singular „la mies“ für die Ernte.
} 


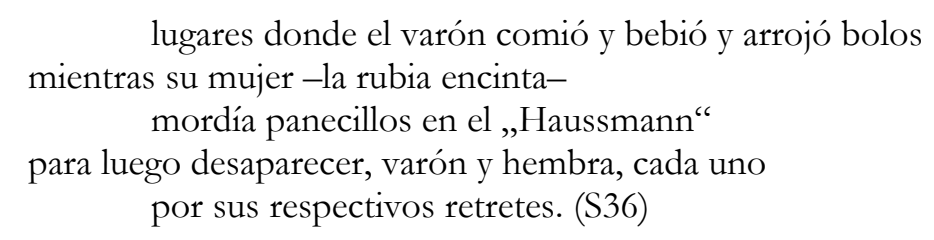

Dieses Szenario soll verdeutlichen, wie fremd die Lebensart der Deutschen den Mapuche geblieben ist. Es wird der typische Zeitvertreib des Mannes beschrieben, der außer Haus isst, trinkt und spielt, während seine Frau - typischerweise blond und schwanger - im Gasthaus sitzt und Brötchen isst und wie schließlich beide auf ihre sittsam getrennten Toiletten gehen. ${ }^{135}$ Diese Schilderung scheint insbesondere Kritik am getrennten Alltag von Mann und Frau üben zu wollen, der sich zum Teil aus den unterschiedlichen Interessen, zum Teil aus ihrer Prüderie ergibt. Aber nicht nur die Eheleute verbringen ihren Tag hiernach getrennt, sondern auch die verschiedenen Kulturen leben weiterhin in eigenen Welten. „Centro Español, Club Alemán, / Peña Folklórica de los hijos de la Meica“ (S36) bezeichnen die jeweiligen Freizeiteinrichtungen. Die Kegelbahn und das Café Haussmann dürften fast ausschließlich von Deutschen besucht worden sein.

Insbesondere in den beiden besprochenen Texten El hombre de Leiprig und Importancia económica de los cabezas amarillas en el valle de Karra Maw'n wird die deutsche Besiedelung Südchiles zum zentralen Motiv. Darüber hinaus gibt es auch in späteren Texten noch vereinzelte Hinweise auf die ständige Präsenz der deutschen Kultur in Karra Maw'n: „Schubertwerke“ (S45), „el vesperbrot“ (S49), „Dämmerung, / dämmerung niederkommend./ No me queda nada. / De todo lo que me dieron / no me queda nada. / Dämmerung, dämmerung / alles auslüschend [sic]“ (S52), „el milagro alemán propiciado por Herr Erhard“ (S66), „Kindergarten, primer día“ (S67).

Das Verhältnis des Erzählers zu den Deutschen ist offenbar sehr viel komplizierter als das zu den Spaniern, die nur als gewalttätige Eindringlinge und maleza auftreten. Die deutsche Einwanderung hat die Kultur von Karra Maw'n stark geprägt. Aus dem Text gehen zahlreiche Produkte hervor, mit denen die Siedler ihre neue Heimat bereicherten. Im Gegensatz zu den Spaniern brachten die Deutschen - dem Text nach zu urteilen - weniger Gewalt, dafür umso mehr Kultur und Lebensqualität mit. Allerdings wird auch nicht verschwiegen, dass diese vermeintliche Lebensqualität (wie die Deutsche Schule oder eine Mahlzeit im Café Haussmann) im Wesentlichen den Deutschen vorbehalten blieb. Die Unterdrückung und Diskriminierung, die die Spanier mit Waffengewalt nach Karra Maw'n

\footnotetext{
135 „Haussmann“ ist ein alteingesessenes Gasthaus in Valdivia.
} 
brachten, wird von den Deutschen auf ökonomischem und kulturellem Gebiet fortgesetzt. Der Erzähler nimmt aufgrund seiner deutschen Abstammung ohne Zweifel eine parteiische und emotionale Position ein. Es sind seine Familiengeschichte und seine Kultur, die er beschreibt. Zwar ist er bemüht, viele Dinge aus der Sicht der Mapuche zu beschreiben, doch wird durch den Text El hombre de Leipzig die Tatsache, dass er persönlich keineswegs unbeteiligt ist, nicht nur aufgedeckt, sondern ausdrücklich zum Teil des Inhalts gemacht. Er gehört einer bestimmten Zeit an, im Hinblick auf die er die historischen Ereignisse betrachtet, und er fühlt sich einer bestimmten kulturellen Gruppe zugehörig. Durch den Gebrauch der ersten Person Singular legt Riedemann seine eigene biographische Anteilnahme offen.

\subsection{Erschütterungen: Das E rdbeben und der Golpe de Estado}

Ya es suficiente. Es preciso estropear un poco el Paraíso.

Clemente Riedemann

Etwa in der Mitte des Buches steht der bedrohlich vorausweisende Text Pacificación y angustia. Das Gedicht mach einen Zeitsprung ins 20. Jahrhundert. Ein vermeintlich stabiler Zustand Chiles scheint erreicht zu sein. Doch alle Assoziationen, die der Text nahelegt, alle Vergleiche, die er heranzieht, stellen den Frieden oder das friedliche Zusammenleben in Frage. Das in der Bevölkerung entstandene Schweigen wird mit dem Kampf Galvarinos gegen die Conquistadores verglichen. ${ }^{136}$ Düstere Visionen von weinenden Lindenbäumen und Salamandern, die ihre sagenhafte Unempfindlichkeit gegen das Feuer verloren haben und zerschmelzen, bemächtigen sich der Menschen. Konkret-politisch drückt sich der schmale Grat eines unsicheren Friedens im folgenden Zitat des ehemaligen US-amerikanischen Aussenministers Henry Kissinger aus: ${ }^{137}$ „The foundation of a stable order is the relative security and therefore the relative insecurity - of its members" (S44; Hervorhebung von Riedemann). ${ }^{138}$ Das aus seinem Zusammenhang gerissene Zitat lässt offen, ob es sich bei der „stable order“ um

\footnotetext{
${ }^{136}$ Der toki Galvarino wurde am 18. November 1557 von spanischen Truppen gefangengenommen. Als abschreckendes Beispiel wurden ihm beide Hände abgeschlagen, eine Strafe, die er den Erzählungen nach mit äußerster Tapferkeit erduldete. Danach wurde er wieder auf freien Fuß gesetzt. Da er trotz seiner Verstümmelung weiterkämpfte, wurde er am 30. November erneut gefangen und erhängt. In der Araucana (Ercilla) wie auch in Arauco Domado (Pedro de Oña) wird er als Held der Mapuche gerühmt. (Fuentes 1978:221)

${ }^{137}$ Sicherlich ist es nicht unwichtig, auf den Umstand hinzuweisen, dass Kissinger einer deutschen Familie entstammte. Das steht zwar in keinem direkten Zusammenhang mit dem verwendeten Zitat, bildet aber innerhalb von Riedemanns Text einen Rückbezug auf den Einfluss von Deutschen auf die kulturelle und wirtschaftliche Entwicklung Chiles. (Vgl. Kapitel 6.3)

138 Ich konnte die Herkunft des Zitates nicht ermitteln, stütze mich in der Interpretation also im Wesentlichen auf die Kontextualisierung durch Riedemann.
} 
diejenige der Vereinten Nationen handelt, zu deren „members“ Chile seit ihrer Gründung 1949 zählt, oder um eine innerstaatliche Ordnung. Im Gedichtkontext legt die Äußerung nahe, anzunehmen, dass konkret Chile immerfort vom Zusammenbrechen einer vermeintlichen Sicherheit bedroht ist. Dass diese Bedrohung gerade vom Repräsentanten der USamerikanischen Aussenpolitik ausgesprochen wird, muss im Zusammenhang mit der Tatsache verstanden werden, dass die USA den Sturz der Regierung Allende massiv unterstützt haben.

In den folgenden Zeilen verkehren sich die Vorstellungen von richtig und falsch: „De este modo, lo normal devino en la locura. El entusiasmo en una suerte de ingenuidad. La agudez intelectual, por extensión, se confundía con la franca estupidez“ (S45). Es folgt einmal mehr der Hinweis auf den sozialen Zündstoff, der nach wie vor in der kulturellen Heterogenität der Bevölkerung steckt. Während die Deutsch-Chilenen ihr Kulturgut pflegen, müssen die Mapuche darum bangen, dass ihnen ihre Hütten in Brand gesteckt werden: „DEJENME AL MENOS MI RUKA / NO ME LA QUEMEN“. In dieser Atmosphäre von Zwietracht und Bedrohung endet der Text mit den sarkastischen Versen „El Wekufe dijo: ,Ya es suficiente. Es preciso estropear un poco el Paraíso“ “ (S45).

Noch immer - oder wieder - ist vom Paradies die Rede. Karra Maw'n hat noch nicht genug gelitten, Wekufe, das Böse, wird wieder zuschlagen. Folgerichtig ist das anschließende Gedicht Destrucción de Karra Maw'n betitelt. Wekufe hat ernst gemacht und seine Drohung in die Tat umgesetzt.

Das sechsseitige Gedicht Destrucción de Karra Maw'n beschreibt das Erdbeben von 1960, das bis heute als das schwerste überhaupt bisher gemessene Erdbeben gilt, und seine Folgen.

2.000 personas murieron ( 4.000 a 5.000 en toda la región), 3.000 resultaron heridas. 2.000.000 perdieron su hogar. Los ríos cambiaron su curso. Las montañas se movieron. Nuevos lagos nacieron. En los minutos posteriores un Tsunami arrasó lo poco que quedaba en pie. El mar se recogió por algunos minutos y luego una gran ola se levantó destruyendo a su paso casas, animales, puentes, botes y, por supuesto, muchas vidas humanas. La geografía, como nunca se había visto, se modificó marcadamente. Algunas naves fueron a quedar a kilómetros del mar, río arriba. (Terremotos)

Riedemanns Text versucht gar nicht erst zu beschreiben, was passiert ist. Gleich der erste Vers macht deutlich, dass die Katastrophe bereits geschehen ist: „iOh Karra Maw'n destruida!“ Die Zeilen 4-6 geben zu verstehen, dass angesichts einer solchen Naturgewalt alle Bewohner Karra Maw'ns einander gleich werden: „aquel día de mayo cuando se detuvo / el mudai, el vesperbrot / la merienda“ (S49). ${ }^{139}$ An jenem Nachmittag im Mai wurde für alle das Leben unterbrochen, gleichgültig, welches ihre Muttersprache war. 
In Rückblicken werden verschiedene Eindrücke und Erlebnisse jenes Abends geschildert. Dabei verfolgt der Text das Augenzeugen-Prinzip. Zunächst fragen die Zeilen 2-4 „Qué fue lo que vieron / los que vieron / aquel día de mayo“ (S49). Etwas später liefern die Zeilen 28 bis 55 dann den gewünschten Augenzeugenbericht: „Yo estaba allí [...]“ (S50). Die Person berichtet, wie sie als Kind das Erdbeben erlebte, wie im Garten die Blumen und das Dreirad in einem stinkenden Loch versanken und der Vater ihnen befahl zu beten. Und obwohl sie tagelang beteten, ließ sich die Katastrophe nicht ungeschehen machen: „No rodó de vuelta a casa / la silueta amada del triciclo“ (S51). Nichts kam zurück, nichts konnte werden wie vorher. ${ }^{140}$

Einige der verschiedenen geschilderten Stadien des Erdbebens erinnern an Prophezeihungen aus der Offenbarung. Im Bibeltext der Offenbarung 8.5 heißt es: „Und der Engel nahm das Räuchergefäß und füllte es mit Feuer vom Altar und schüttete es auf die Erde. Und da geschahen Donner und Stimmen und Blitze und Erdbeben. “ Abgesehen davon, dass auch im Bibeltext von Erdbeben die Rede ist, findet sich bei Riedemann ebenfalls ein Aschenregen: „Y sobre Karra Maw’n caían / lluvia y chimeneas“ (S50) und „cayó ceniza“ (S51). In Offenbarung 9.2 liest man „Y abrió el pozo del abismo, y subió humo del pozo como humo de un gran horno, y se oscureció el sol y el aire por el humo del pozo“. Auch im Gedicht wird es dunkel: „Se oscureció de pronto“ (S49), und die Erde tut sich auf: „se dejaba ver un precipicio“, „zanja voraz“, „hoyo pestilente“ (S51). ${ }^{141}$ Einige Formulierungen gehen weit über eine Beschreibung hinaus:

$$
\begin{gathered}
\text { [...] como una tierra sin dioses. } \\
\text { Fue más exigua la vida } \\
\text { el año no pudo parir todos sus soles } \\
\text { ¡Valía tan poco la muerte! (S49) }
\end{gathered}
$$

Riedemann bringt seine eigene Hilflosigkeit der Naturgewalt gegenüber zum Ausdruck, gleichzeitig gibt er sicherlich auch die Reaktionen der anderen Menschen wieder und die Beobachtung, dass viele Menschen das Geschehene nur als einen Streich der Hand Gottes zu begreifen vermögen.

139 „Mudai“ ist die Bezeichnung in Mapudungun für die Chicha (vgl. Kapitel 6.2, S127).

${ }^{140} \mathrm{Vgl}$. hierzu auch die Augenzeugenberichte, die La Tercera genau 40 Jahre nach der Katastrophe veröffentlichte (La Tercera 2000).

${ }^{141}$ In der Offenbarung des Johannes wird auch von der Zerstörung Babylons berichtet. Dies führt wieder zurück zum Thema der Türme als Mahnmal und Zeichen des Bösen, das nun zu Fall gebracht wird. (Im folgenden Text El sueño del Wekufe schläft der böse Geist Wekufe in einem Turm.) Demzufolge kann das Erdbeben als die Vollstreckung einer gerechten Strafe durch eine moralische Instanz interpretiert werden. 
Da Riedemann im Verlauf des Textes bisher allerdings schon mehrfach Bibelstellen in seine Gedichte hat einfließen lassen, kann man davon ausgehen, dass ihm die Parallele seiner Zeilen zum Text der Offenbarung bewusst war. In jedem Fall erlangt das Erzählte durch Formulierungen wie „Se oscureció de pronto / como una tierra sin dioses“ oder „el año no pudo parir todos sus soles“ eine Bedeutung, die über das natürlich Erklärbare hinausgeht. Eine ähnliche Transzendenz erzielen die beschriebenen Empfindungen der Menschen, die das Erdbeben miterlebten. Leben und Tod nähern sich hier einander an, bis sie nur noch durch einen kleinen Schritt voneinander getrennt werden: „Todos querían alejarse / de sus cuerpos“, „Fue más exigua la vida“, „¡Valía tan poco la muerte!“, „La muerte era una vida inesperada“" (S49f.).

Ab Vers 56 richtet Riedemann den Blick auf die Folgen, und darauf, wie es in Karra Maw'n nach der Naturkatastrophe weitergeht. Zunächst ist von denjenigen die Rede, denen es gelingt, aus dem Unglück der anderen Nutzen zu ziehen: „Algunos hubo que / nacidos para dominar / descendieron de la tragedia / a la comedia“. Sehr viel ausführlicher fällt jedoch die Huldigung an all jene aus, die bei dem Erdbeben zu Schaden kamen. Erst heißt es unbestimmt „los que sudaron / labraron / edificaron, / desposeídos“. Dann erhebt sich ein vielfaches „Gloria“ für alle Opfer und Helden des Bebens in Karra Maw'n: die Bauern, die ihr Land verloren haben; die Fischer, die ihre Boote und Hütten verloren haben; die Zugführer, deren Züge aus den verschobenen Gleisen gesprungen sind; der Kranke, der, an sein Bett gefesselt, nicht in der Lage war, vor dem Unglück davonzulaufen. Aber das Lob des Erzählers gilt auch den ansässigen Produktionsbetrieben, den Hochöfen, der Schuhfabrik und der Brauerei, die durch das Erdbeben zerstört wurden.

Die letzten 24 Verse sprechen vom Neuaufbau und davon, dass das Leben weitergeht: „Pero salió el sol / Y Karra Maw’n es agradable. / ¡Oh Padre Ngënchén!“ (S53). Nachdem sich in den Versen 21-27 noch Wekufe, die Verkörperung des Übels, in den Trümmern versteckte, inmitten des Unheils, das er angerichtet hatte, erscheint nun Ngënchén mit der wiederkehrenden Sonne und gibt den Menschen Mut, sich wieder aufzurichten. Die Häuser werden wieder aufgebaut, die Toten begraben, die Kranken geheilt, der Alltag kehrt zurück: „,continuaron en Karra Maw'n / la vida / y sus anécdotas“ (S54).

Die Textsorte des Augenzeugenberichtes hat in der Form der Auswertung von oral history Eingang in die Geschtsschreibung gefunden. Die oral history unterstützt insbesondere die (Auto-) Biographie-Forschung, die Alltags-, Familien-, Regional- und Sozialgeschichte. Ihre Etablierung stellt den Versuch der modernen Geschichtswissenschaft dar, eben jenen 
Menschen eine Stimme zu verleihen, deren Aussagen nicht in Biographien und anderen Dokumenten zu finden sind. Die oral history berücksichtigt also „die konkreten Bedingungen individueller Gedächtnisse und Identitätskonstitutionen“ und bereichert die Geschichtsschreibung um diese. (Rüsen 1996)

Wir erfahren nicht, ob es sich in Riedemanns Text um einen authentischen Augenzeugenbericht handelt, jedoch ensteht ein Einblick in persönliches Erleben der Ereignisse jenes Nachmittags. Riedemann selbst war sieben Jahre alt zur Zeit des Erdbebens. Es ist also denkbar, dass es sich um seine eigenen Erinnerungen handelt, oder doch zumindest um vergleichbare Erlebnisse, deren Schilderung er hier gewählt hat.

Ich komme zum letzten Teil Otros escritos de suyo pertinentes en el plan jeneral desta obra. Diese ,anderen Schriften` sind ein längerer Text, überschrieben mit Infancia del cronista. Die ersten zwei Verse „1953 / aquí comienza la Edad Dorada“ (S64) deuten wiederum auf die Person des Autors Riedemann hin, der 1953 zur Welt kam. Er erzählt, wie das Wasser die Straße hinabläuft - vermutlich die Straße, in der sein Geburtshaus steht - und fügt den Vers von Verheißung und Erfüllung hinzu: „y entre paréntesis es que venía, llegó“ (S64). In drei Versen beschreibt er seine eigene schwierige Geburt.

Im gesamten Text verdichten sich persönliche Erinnerungen mit historischen Ereignissen nationaler sowie internationaler Tragweite zu einem heterogenen Zeitzeugnis. So erfährt man von dem Verwandten eines gewissen Parragué, der zufrieden die Osterinsel (Rapa Nui) erreicht hat: „Sólo Parragué goza de un relativo contento: su Pájaro de la Suerte yace echado en los cráteres / de Rappa Nui [sic]“ (S65). Hintergrund ist der Flug eines Piloten der Fuerza Aerea de Chile, Roberto Parragué, der 1951 für Schlagzeilen gesorgt hatte. Am 19. Januar flog Parragué mit einem Wasserflugzeug in 17 Stunden vom chilenischen Festland auf die Osterinsel. Dieses Ereignis liegt zum Zeitpunkt der Geburt Riedemanns bereits zwei Jahre zurück. Ob Riedemann sich mit den Jahreszahlen vertat oder aber auch zwei Jahre später noch von jenem denkwürdigen Flug des tollkühnen Piloten gesprochen, ist nicht klar.

Im Weiteren fällt der Name des Generals Carlos Ibáñez del Campo, der Chile von 1927 bis 1931 und ein zweites Mal von 1952 bis 1958 regierte und von dessen Militärherrschaft bis heute insbesondere die Verfolgung von Minderheiten in Erinnerung geblieben ist. ${ }^{142}$ Auf Seite 66 verbindet der Erzähler den Tod seines Vaters, eines Automechanikers, mit der

\footnotetext{
${ }^{142}$ Erst im Mai 2000 wurde am Rande einer Theateraufführung an die Ermordung von Homosexu-
} ellen unter Carlos Ibáñez del Campo erinnert. (Jösch 2000) 
Entdeckung der Doppelhelix als Stuktur des menschlichen Erbgutes durch James Watson und Francis Crick, die ihre Erkenntnisse im Jahr 1953 erstmals veröffentlichten. Daran schließt sich das „milagro alemán“, das deutsche Wirtschaftswunder unter dem Wirtschaftsminister Ludwig Erhard (1949-1963). ${ }^{143}$ Die Erinnerungen der nächsten Seite sind wieder privater Natur: Es wird vom ersten Tag im Kindergarten erzählt und von den GuteNacht-Geschichten, die die Mutter vorliest.

Darauf folgt die Erinnerung an zwei bedeutende Ereignisse der Raumfahrt: an den ersten Menschen im Weltraum an Bord der Vostok I im Jahre 1961 und an den ersten, bzw. den zweiten Menschen auf dem Mond, Edwin Aldrin, der direkt nach Neil Armstrong den Mond betrat. Mit „ahora salta sobre un charco de alcohol“ spielt der Erzähler darauf an, dass Aldrin ein zweites Mal Jahre später als Alkoholkranker in die Schlagzeilen geriet.

Ein weiterer Schwenk nimmt die US-amerikanische Rüstungs- und Abschreckungspolitik sowie die Waffenentwicklung in den Blick.

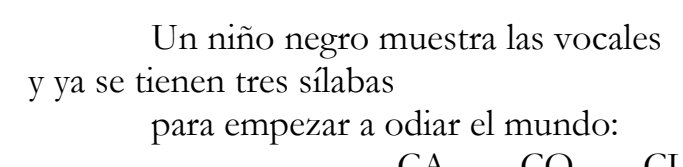

$$
\mathrm{CA} \quad \mathrm{CO} \mathrm{CU}(\mathrm{S} 70)
$$

Die drei Silben, die den Hass in die Welt bringen, könnten für drei wichtige Faktoren in der Geschichte der Neutronenbombe stehen: CA für Californien, wo die Waffe entwickelt wurde, CO für Colorado Springs, von wo aus sie gesteuert wurde und CU für Cuba, das Land, auf das sie - als geographisch nächstem Feind - nach dem zweiten Weltkrieg gerichtet war.

Die nächsten Verse widmen sich der Wirtschaftspolitik Chiles. Es wird über die Chilenen gespottet, die angeblich alle Bemühungen um Effektivität umdrehten und „la menor cantidad / de buenos frutos en el máximo tiempo posible“ produzierten. Er wirft ihnen einen „fatalismo sonriente“ vor, ${ }^{144}$ mit dem sie sich von den übrigen Andenstaaten immer weiter entfernten.

Schließlich findet die ley mordaza (Knebelgesetz) Erwähnung, die 1964 unter Jorge Alessandri Rodríguez ${ }^{145}$ eingeführt wurde, um die Sensationspresse mundtot zu machen. Öffentliche Berichte von Verbrechen sowie Aussagen, die die Würde oder den Ruf von

\footnotetext{
${ }_{143}$ Auch hier werden die Deutschen wieder mit Wirtschaft und Produktivität in Verbindung gebracht, wie bereits in den Schilderungen der deutschen Besiedelung Südchiles.

144 Octavio Paz bezeichnet so die Haltung, mit der die Menschen sich in kommunistischen Systemen für ihr Land opferten.

${ }^{145}$ Alessandri war von 1958 bis 1964 chilenischer Präsident.
} 
Personen verletzen könnten, wurden untersagt. (Human Rights Watch 1998:Freedom of expression and public order)

Nach diesen zahlreichen historischen Schlaglichtern finden sich auf Seite 73 Überlegungen über die Geschichte im Allgemeinen, in Verbindung mit einem anekdotischen Detail:

La Historia sólo recolecta

monedas falsas.

Es la sangre que corre

a nuestras espaldas.

Es un esqueleto colgado

en el closet como un traje.

La chapa de gaseosa

que perfora los zapatos.

La Historia no es esta historia

ni la vuestra, se supone

(LADY ASTOR: „¿Hasta cuándo seguiréis matando?“

PEPE STALIN: ,„Hasta cuando sea necesario!“)

La Historia es el gallo matutino

en los almanaques de la patria. (S73) ${ }^{146}$

Der Unterschied zwischen der Historia - großgeschrieben - und esta historia wird betont. In Klammern gesetzt steht dazwischen ein kurzer authentischer Dialog Lady Astors, der Frau des damaligen britischen Botschafters in der Sowjetunion, mit Stalin aus dem Jahr 1931. Dieser Dialog illustriert, wie diejenigen, die die Macht haben, Geschichte zu schreiben, mit Menschenleben umgehen. Dabei ist die großgeschriebene Geschichte diejenige, die am Schreibtisch entschieden wird, die Geschichte der Politiker, die nicht die Konsequenzen für die einzelnen Menschen berücksichtigt, während „esta historia“ die erlebte und erlittene Geschichte ist. Sicherlich wird man in diesem Zusammenhang an die Diktatur Pinochets denken, denn der Kontext eines solchen Dialoges ist austauschbar. Die „Historia“ wird verlogen genannt, sie ist blutig und erschreckend. All das bezieht sich auf die großgeschriebene Geschichte, die in den traditionellen Geschichtsbüchern steht und von der der Text sagt, sie sei nicht identisch mit „vuestra historia“. Aber das nachgeschobene „se supone“ stellt auch dies wieder in Frage. Mit der Anrede „Pepe Stalin“ verharmlost Riedemann die Person des sowjetischen Diktators. Diese Respektlosigkeit soll helfen, sich von dessen Verbrechen zu distanzieren.

Die Zeilen gipfeln in der pointierten Metapher von der Geschichte als „gallo matutino / en los almanaques de la patria“. Man denkt an einen stolzierenden Gockel, der sich mit geschwollenem Kamm und lautem Gekrähe wichtig macht. Es ist diejenige Geschichte, in deren Zusammenhang man von der „patria“ spricht, einem Begriff, in dem immer Stolz

\footnotetext{
146 Dokumentiert zB in Yancey 1997:144.
} 
auf das Vaterland mitschwingt und den man kaum im Zusammenhang mit unrühmlichen Ereignissen nennen würde.

Bisher ist im Zusammenhang mit Karra Maw'n noch nicht die Rede gewesen von der Diktatur, da an keiner Stelle eine eindeutige Bezugnahme ausgemacht werden kann. Wenn allerdings ein Autor, der in seinen Texten im Allgemeinen eine kritische Haltung beweist und darüber hinaus seine Missbilligung gegenüber der Regierung durchaus zum Ausdruck bringt, ${ }^{147}$ in einem Werk über die Geschichte Südchiles kein einziges Wort zum Staatsstreich und der während des Schreibens andauernden Militärdiktatur verliert, ist dies ein sehr beredtes Schweigen. „[H]echo que [el Golpe de Estado], significativamente, no se lo nombra en forma explícita en el libro, pero que es el tema central del volumen oblicuamente referido en todas las páginas“. (Mansilla 1996a:48)

Die oben besprochenen Zeilen über das Wesen der Geschichte stehen im Zentrum des langen Gedichtes Infancia del cronista. Sie werden eingerahmt von 100 vorangehenden Zeilen und 101 Zeilen, die sich anschließen und wiederum konkrete historische und politische Ereignisse aneinanderreihen. Jorge Alessandri versuchte im Zuge der „buen socio“-Politik Eisenhowers und Kennedys die Export-Gewinne Chiles zu steigern, Kennedy lehnte jedoch eine Zusammenarbeit ab. 1963 starb Kennedy, was dem Text zufolge eine etwas absurde Trauer im entferntesten Winkel des US-amerikanischen ,Hinterhofes` hervorrief:

$Y$ unos pobres niños latinoamericanos perdidos en un patio azul del sur de Chile, lloraron por la muerte del Presidente de los EE.UU. (S77)

Schließlich kommt das Gedicht wieder nach Karra Maw'n/Valdivia ins Jahr 1953 zurück, wo es auch begann:

\footnotetext{
pasaron y pasaron los trenes

Tal vez era uno solo el tren eterno

que por instantes los ojos no veían.

Se recuerdan vagones aislados perdiéndose en la niebla de Valdivia.

Se le prendían fogatas a los viajeros. (S78)
}

Der nächste Vers scheint das Gesagte als nicht-authentisch enttarnen zu wollen: „;Oh cliché, horrible necesidad!“ (S79). Es ist nicht Karra Maw'n, was der Erzähler vor sich sieht und beschreibt, sondern nur noch ein Klischee davon, eine Welt aus Worten und falschen

\footnotetext{
${ }^{147}$ Und dass er die Geschehnisse in der Tat missbilligt, geht aus seinen Ausführungen zum Oratorio hervor, das Riedemann Stein des Anstosses und Anlass für Karra Maw'n war (vgl. Kapitel 6.1, S116).
} 
Vorstellungen. ${ }^{148}$ „Karra Maw'n abortó su poema“. Karra Maw'n hat sein Gedicht abgestoßen, das Gedicht, das einst zu seinem Wesen gehörte. Die Eule aus dem Gedicht De lo que acontece cuando el cronista se aleja de su tierra („La lechuza que dormita en el tinglado“, S14), der Vogel der Weisheit, ist zum „buho absurdo“ (S79) geworden.

Soledad Bianchi beurteilt den Riedemanns Umgang mit Stereotypen folgendermaßen:

Más de algunos versos incorporan y acentúan la escasa validez de frases hechas, visiones preestablecidas, lugares comunes, tópicos, clichés, y subrayan el abismo semántico producido entre un significado habitual en su inconsciente uso cotidiano y el referente al que alude. (Bianchi 1992:285)

Diese Sprache steht in deutlichem Gegensatz zu der Poesie des ursprünglichen Karra Maw'n. Auch die fünf Verse auf Seite 80 betonen den Wandel, der sich durch die Jahrhunderte in Karra Maw'n vollzogen hat:

Se quiso versos como árboles

y se amó palabras como pájaros.

Karra Maw'n, qué pena dan estos pájaros

que se vienen abajo

mientras se sacude el árbol. (S80)

Schließlich beschwört der Erzähler noch einmal das Jahr 1953, als sei es der definitive Anfang vom Ende von Karra Maw’n gewesen („Destruidos están para siempre / los negativos de la aurora“, S81) und kommt zu zwei Schlussfolgerungen: „Sólo se tienen las palabras / para defenderse de la muerte“. Und: „Se envidia a las locomotoras / porque saben a donde van“. Mit der Sehnsucht nach einem Weg und einem Ziel, dass es zu erreichen gäbe, schließt das Buch.

Diese letzten 24 Verse heben sich deutlich vom Anfangsszenario ab. Der Tod ist allgegenwärtig, während Wille und Kraft, sich ihm zu stellen, geschwunden sind („No se puede más con todas estas muertes“, S79). Das eigene Schicksal wird als sinnlos empfunden („No se puede con ellas agitar / las alas del inútil destino“, S79). Die Poesie ist verschwunden, es bleiben nur noch Worte, um sich dem Tod entgegenzustellen. In den ersten Gedichten war der Tod hingegen nicht existent, stattdessen bestand das Land aus fruchtbarem Boden und Poesie: „No era baldía aquella tierra“.

\subsection{Riedemanns Version der Geschichte}

Clemente Riedemann schreibt in den fünf Abschnitten des Buches Karra Maw'n eine eigene Version der Geschichte seiner Heimat. Schon durch den äußeren Rahmen, der an The

\footnotetext{
${ }_{148}$ Züge gehören zu dem romantisch-nostalgischen Bild von Südchile, das Jorge Teillier maßgeblich mit erschaffen hat durch seine Gedichte von verlassenen Bahnhöfen und langen Zugfahrten.
} 
Waste Land angelehnt ist und dessen formale wie auch inhaltliche Struktur in weiten Teilen übernimmt, gibt Riedemann der Geschichte eine Richtung und unterstellt den Ereignissen eine gewisse Folgerichtigkeit oder Kausalität. Das geschieht durch die Umkehrung der Gralssuche und Erlösungsgeschichte Eliots: Statt auf die Erlösung steuert Karra Maw'n auf Zerfall und Verderben zu, das Land wird öd.

Eine weitere Bewegung, die im Text angelegt ist und ihn organisiert, ist die Individualisierung der Stimme des Erzählers. Von einer dominierenden kollektiven Perspektive im ersten Abschnitt über die stark familiär gebundenen Betrachtungen in El hombre de Leiprig gelangen wir zum Subjekt in Infancia del cronista, das seine Geburt als den Beginn der Welt begreift („1953 / aquí comienza la Edad Dorada / la Época de la más lúcida locura“) wenngleich mit unverkennbarer Ironie vorgetragen.

Insbesondere die implizite Vorstellung von Erlösung und Verderben innerhalb des Ganges der Geschichte, die durch die Bibelanspielungen gestützt wird, geben den Ereignissen einen erzählerischen Rahmen und legen die Interpretation und subjektive Bewertung durch den Erzähler offen.

Zu Riedemanns eigener Version der Geschichte gehört auch die Integration von Anekdoten, von Alltäglichkeiten sowie von Personen, die eher aufgrund ihrer Unauffälligkeit ausgewählt werden anstatt aufgrund besonderer Taten, wie die traditionelle Geschichtsschreibung dies tut (vgl. Alltagsgeschichte und Mikrogeschichte, Kapitel 2.2.2.3, S23).

No hay advertencia ni equivocación por parte del poeta cuando elige ingresar su intimidad en los versos. Por el contrario, en Karra Maw'n, Riedemann busca y desea integrar la historia de todos los días, la cotidiana, individual y hasta familiar con aquella otra que se considera importante y trascendente; esta que permanece, la anterior que se disipa y prescribe... ¿Quién es el actor (olvidado) de la historia que persiste?, ¿quién ha elaborado y escrito esta historia?, parece preguntarse, negándose a conservar y repetir miradas y funciones tradicionales, este cronista que se propone fusionar y confundir Historia e historia para que, asociadas e integradas, formen, conformen y constituyan un nuevo relato, una historia inédita, una memoria desconocida y olvidada, Karra Maw'n. (Bianchi 1992:284)

Neben den Bemühungen um eine eigene Version der Geschichte finden wir gleichzeitig die Leugnung der Möglichkeit einer einheitlichen Version durch den konsequenten Einsatz verschiedenster Stimmen und Blickwinkel: „El cronista opta, entonces, por entregar diversas versiones, por no limitarse a un único punto de vista, por ubicarse en distancias y en momentos diversos, por abarcar lo vario, por interrogarse frente a lo establecido..." (Bianchi 1992:285f.)

Auch in den Texten von Contreras Vega und Riveros hat sich dieses Verfahren bereits nachweisen lassen. Was zeichnet nun aber Riedemanns Dichtung aus?

[L]a poesía de Riedemann - especialmente su libro Karra Maw'n [...] puede verse como una especie de neoépica que busca, por una parte, deconstruir las "mitologías oficiales" de la memoria colectiva y, por otra, proponer una ruptura de la linealidad histórica tradicional en 
términos de concebir el pasado como proyección del presente y viceversa. (Mansilla 1999:Kap.5)

Sergio Mansilla erkennt zwei Vorhaben in den Texten Riedemanns. Zum einen die Demontage der offiziellen Geschichtsschreibung, die sich als eine Art Mythologie bereits im kollektiven Gedächtnis verankert hat. Als solche erfüllt sie ihren Zweck, die Staatsideologie in den Köpfen der Menschen zu festigen. Zum anderen sieht Mansilla den Versuch, die traditionelle Linearität von Geschichte zu durchbrechen und Vergangenheit und Gegenwart als mögliche Projektionen oder Repräsentationen des jeweils anderen zu verstehen.

Auch Bianchi spricht von einem Bruch, „una ruptura“, der traditionellen Vorstellungen, wenn sie Riedemanns Geschichtsdarstellung beschreibt:

Su versión de lo contado será, entonces, una ruptura, consciente y buscada, de lo que la Historia conservó y transmitió como supuestamente permanente y, por lo tanto, eterno, inmodificable y fijo. (Bianchi 1992:285)

Mansilla meint im obigen Zitat aber nicht nur den Bruch mit einer konventionellen Geschichtsschreibung, sondern auch den Bruch mit gewohnten Wahrnehmungsmustern. Vergangene Ereignisse können als Vorausweisungen auf eine Gegenwart verstanden werden, gegenwärtiges Geschehen als Spiegel der Vergangenheit. An einer anderen Stelle sagt er aus: „La memoria del pasado es al mismo tiempo un testimonio del presente desagradado“. (Mansilla 1996b:63) In dieser Vorstellung liegen Gegenwart und Vergangenheit ganz dicht beieinander und überlagern sich zum Teil. Diese Verbundenheit geht über Kausalzusammenhänge hinaus und setzt sie eine Art von Identität zwischen beiden voraus.

Dasselbe Prinzip verwendet Riveros, wenn er unvermittelt zwischen der Beschreibung der Morde an der patagonischen Ursprungsbevölkerung und der von Mord und Folter durch die Militärregierung hin- und herwechselt. Doch ist bei Riedemann die Parallelisierung von Gegenwart und Vergangenheit nicht so offensichtlich, zumindest fehlen explizite Hinweise auf die Diktatur.

Zur Schilderung des Erdbebens verwendet er eine historiographische Methode. Aus der oral history entlehnt er die Berücksichtigung des Augenzeugenberichts, den er zur Veranschaulichung einflicht, vielleicht auch um die Aufmerksamkeit der Leserinnen und Leser zu steigern. Auf jeden Fall wächst der Eindruck von Authentizität durch besagten Einschub. Die oral history ist mittlerweile eine etablierte Form der Geschichtsschreibung und forschung, doch sie hat sich erst in den letzten vier Jahrzehnten diesen Platz innerhalb der Geschichtswissenschaft erkämpft. Noch 1986 heißt es in einer Studie von William W. Moss über oral history: „It was developed partly to remedy deficiences in written records, but it 
has been viewed by many traditional historians as an undisciplined, rebellious, and perhaps even irresponsible child of documentary history“. Und weiter:

Oral history became necessary, at least in part, because many historians came to believe that written records were excessively limited to the documentation of a ruling government or elite class, or to a dominant national function such as religion or law. Thus, much social history went unrecorded or was recorded incident to other purposes which diminished the usefulness of the record for social history. Whole classes of people were poorly represented in great national annals, and the perspective reflected in those annals tended to be highly legalistic, formal and bureaucratic. (Moss 1986:2f.)

Dem Geschichtslehrer Riedemann sind die Implikationen von oral history sicherlich bekannt. Das Bestreben, den in der Geschichtsschreibung vernachlässigten Personengruppen gerecht zu werden, hat sich schon in den Texten des ersten Abschnittes gezeigt, in denen die Besetzung von Südchile durch die Spanier und später durch die Deutschen Einwanderer zu großen Teilen aus der Sicht der Mapuche beschrieben wird.

Ein anderer im obigen Zitat aufgeworfene Aspekt ist die Bestrebung, durch Berücksichtigung mündlicher Dokumente einer parteiischen Geschichtsschreibung der Mächtigen $\mathrm{zu}$ begegnen. Auch das ist ein Ziel, das Riedemann mit seinem Zyklus verfolgt. Jedoch verwundert es, dass er das Instrument des Augenzeugenberichtes gerade zur Illustration eines weitgehend unpolitischen Kapitels, nämlich des Erdbebens in Valdivia, einsetzt. Meine These ist, dass gerade das Erdbeben bei Riedemann nicht nur ein einschneidendes Ereignis in der Geschichte Südchiles darstellt, sondern darüber hinaus als Symbol für den Staatsstreich von 1973 gesehen werden kann.

Riedemann selbst äußert sich folgendermaßen zum Verhältnis von Literatur und Geschichte:

Concibo la literatura como instrumento de intervención en las historias consideradas oficiales, con el propósito no de cuestionarlas de modo explosivo, sino, más bien, de recuperar aquello que esa historia, por distintas razones, no registró, no incorporó o desechó por negligencia o deliberadamente por expresiones de intereses creados o por decisiones políticas institucionales. (Mansilla 1999:Entrevista Riedemann)

Sicherlich kann Karra Maw'n allein als Geschichtsbuch nicht ausreichen. Viele Kenntnisse werden bei der Leserschaft vorausgesetzt und Ereignisse nur beispielhaft oder metaphorisch für die historischen Entwicklungen angeführt. Die Textanalysen haben gezeigt, dass Riedemann mit sehr ähnlichen Mitteln arbeitet wie Contreras Vega, Riveros oder Muñoz, indem er die Vergangenheit und die Gegenwart als zwei verschiedene Manifestationen derselben treibenden Kräfte in der Geschichte darstellt. Was Karra Maw'n von den bisher untersuchten Werken abhebt, ist zum einen der persönliche und humorvolle, bisweilen sarkastische Ton. Riedemann versucht, durch (oft ironischen oder zynischen) Humor, 
Distanz zu den Geschehnissen zu schaffen und sie scheinbar zu verharmlosen. Diese Art des Umgangs mit Geschichte verbirgt im Kern eine hilflose Haltung. Hilflosigkeit zeigt sich auch in der Naturalisierung des Prozesses der Conquista (Pflanzenmetaphorik) oder der Diktatur (Erdbeben).

Die Tatsache, dass über die einfache Darstellung von Ereignissen hinaus eine Haltung der Geschichte gegenüber deutlich wird, zeigt, dass Karra Maw'n zurecht „,reescritura poética de la historia de Chile“ genannt werden kann. (Mansilla 1996b:61) 


\section{Elicura ChiHUAilaF: EN EL PAÍS DE LA MEMORIA}

Verdaderos los escondidos ríos de la Historia vienen a mi encuentro.

Elicura Chihuailaf

Sowohl die Texte von Juan Pablo Riveros als auch die von Rosabetty Muñoz und Clemente Riedemann zählen zur poesía etnocultural Südchiles. ${ }^{149}$ Dieser Begriff wurde 1989 von Iván Carrasco geprägt, der ihn zum ersten Mal in seinem Aufsatz Poesía chilena de la última década (1977-1987) verwendet. In diesem Text hebt Carrasco aus der heterogenen Gesamtheit der chilenischen Lyrik des betreffenden Zeitraums vier Strömungen heraus, „que me parecen ya establecidas y predominantes“. Eine jener dominanten Tendenzen bezeichnet Carrasco als poesía etnocultural.150 Als Entstehungskontext dieser Dichtung führt er die interkulturellen Konflikte in Südchile an, insbesondere die „superposición de culturas que no se han integrado totalmente, sino sólo lo han hecho en forma parcial y en algunos niveles, permaneciendo hasta hoy en un estado de conflicto latente o manifestado de modo ocasional“. (Carrasco 1989a:32) Für den Zeitraum seiner Untersuchung (1977-1987) zählt Carrasco zu dieser Richtung im Wesentlichen Dichterinnen und Dichter, die sich, wie Juan Pablo Riveros und Rosabetty Muñoz aus europäisch-chilenischer Sicht um größeres Interesse und mehr Toleranz gegenüber den indigenen und prähispanischen Kulturen bemühen. Als wichtigste Vorläufer dieser Richtung nennt er allerdings mapuchestämmige Autoren: Luis Vuillamy, Los rayos no caen sobre la hierba (1963), Eric Troncoso mit Maitenes bajo la lluvia. Poesía Mapuche (1965) und Pedro Alonzo Retamal, Epu mari quiñe Ülcatun (1969).

In seiner Studie zweiteilt Carrasco die ethnokulturelle Dichtung in einerseits die um interethnische Beziehungen bemühten Texte und andererseits diejenigen, in denen die Randständigkeit insbesondere der Region Chiloés innerhalb Chiles thematisiert wird, alle aufgeführten Titel sind jedoch chilenischen, also spanischsprachigen Ursprungs. Noch im selben Jahr erweitert er in einem anderen Aufsatz die ethnokulturelle Dichtung um eine weitere Gruppe, die vorher nur als antecedentes in Erscheinung getreten war:

Un sector representativo de esta poesía [la poesía etnocultural] es la de escritores mapuches que usan su propia lengua para redescubrir sus tradiciones, cantos y relatos: Aguilera Milla, Ancán Pranao, junto a ellos, otros más jóvenes que escriben en español sobre sus vivencias indígenas: Elicura Chihuailaf y Leonel Lienlaf. (Carrasco 1989b:7)

\footnotetext{
149 Siehe hierzu Kapitel 3.4, S46.

${ }^{150}$ Die anderen drei Strömungen, die Carrasco unterscheidet, sind „la poesía neovanguardista“, „la poesía religiosa apocalíptica“ und „la poesía testimonial de la contingencia“. (Carrasco 1989a:32)
} 
Die beiden jungen Dichter, die Carrasco erwähnt, sollten in den folgenden Jahren zu den bekanntesten Lyrikern der Mapuche werden. Beide haben begonnen, ihre Texte weitgehend zweisprachig zu verfassen: in Mapudungun und in Spanisch.

Elicura Chihuailaf hat bisher vier Gedichtbände veröffentlicht: El invierno y su imagen (1977), En el país de la memoria (1988), El invierno, su imagen y otros poemas azules (1991) und De sueños azules y contrasueños (1995). Bei der Textanalyse beschränke ich mich auf die Untersuchung von Gedichten aus En el país de la memoria.

\subsection{Literatur und Geschichte der Mapuche}

Das Kapitel über die Dichtung Riedemanns hat unter anderem gezeigt, dass die Kultur der Mapuche einen nicht geringen Einfluss auf die Weltanschauung der übrigen Bevölkerung und auf die gesamte Kultur und Literatur Südchiles nimmt. Daher soll in einem ersten Abschnitt dieses Kapitels gezeigt werden, inwieweit sich die Vorstellungen der indigenen Kultur gerade in Bezug auf die beiden hier zentralen Begriffe der Literatur und der Geschichte von den spanisch-europäisch-chilenischen Konzepten unterscheiden und wo sie begonnen haben, sich einander anzunähern.

Ursprünglich gab es bei den Mapuche ausschließlich die mündliche Tradition, ein Alphabet existierte nicht. Der mündlichen Überlieferung wird somit ein wesentlich höherer Stellenwert beigemessen und der mündliche Vortrag wird in einem hohen Maße gepflegt und verfeinert. Die eigene Sprache, das Mapudungun, wird als Poesie an sich empfunden: „Para mí el idioma mapuche en si es poesía y está íntimamente ligado con la parte estética, la belleza." (Lienlaf 1990:39) Sprachgewandt zu sein, ist bei den Mapuche eine geschätzte Fähigkeit und kommt der eines Dichters in der traditionellen europäischen Vorstellung gleich. Zudem werden über die sprachliche Fertigkeit kollektive Werte transportiert:

La capacidad de „hablar bien“ (ser un weupin), significa conservar la „lengua de la tierra“ (el mapudungu) y con ella los contenidos que determinan una cosmovisión, una manera de entender el mundo, las cosas y las relaciones entre ellas. (Montecino 1992:156)

Die Mapuche unterscheiden in ihren mündlichen Überlieferungen zwischen epeu, nütram und ül (auch ülkatún). Epeu sind Geschichten, die wir als fiktiv bezeichnen würden (meistens angelehnt an mythologische Erzählungen), während nütram tatsächliche Ereignisse wiedergeben: „Son relatos ,verídicos“ casi testimoniales, que cuentan algo que ha ocurrido en la historia o narran sucesos ,reales‘“ (Montecino 1992:156) Dazu zählen zB biographische Erzählungen aus dem Leben berühmter lonkos (Stammesoberhäupter) und Episoden aus dem Widerstand der Mapuche gegen die Kolonialisierung. Ül bezeichnet sowohl die Dichtung als auch den Gesang. 
Die Grenze zwischen gesprochener und gesungener Sprache ist fließend: „En nuestra tradición, cuando uno va de visita se saluda cantando.“ (Cea 1990:39) Man geht davon aus, dass sich die Lyrik in den verschiedenen uns bekannten Kulturkreisen mit der Zeit aus dem Gesang entwickelt hat. Die Funktion der Melodie, die Verse (ursprünglich Gebete, Beschwörungs- oder Segensformeln, kultische Lieder) mnemotechnisch besser im Gedächtnis zu verankern, entfiel in den meisten Kulturen mit der Zeit durch die Entwicklung einer schriftlichen Fixierung. Bei den Mapuche hingegen sind Sprache, Gesang und Lyrik bis heute an manchen Stellen nicht voneinander zu trennen.

Así, mantenida al abrigo de la tradición oral, lo que podría llamarse una literatura mapuche sobrevivió hasta nuestro siglo unida íntimamente al ceremonial y al ejercicio cotidiano del mapudungun, un idioma de rica musicalidad y dinamismo. (Guerrero 1994:3; Hervorhebung von Guerrero)

Heute ist es sicherlich schwierig, die ursprünglichen Kategorien und Funktionen sprachlicher Akte des Mapudungun zu benennen, da die kulturelle Interaktion mit den Usurpatoren unterschiedlicher Nationalität ihre Spuren hinterlassen hat. Es ist anzunehmen, dass die Einteilung in ,Sprache‘, ,Dichtung', ,Gesang“ oder ,Gebet ${ }^{\star}$ in der Schärfe, in der wir sie gewohnt sind, für die Mapuche erst mit dem europäischem Einfluss entstanden ist.

[...] la lengua mapuche, la que es prácticamente toda poesía, lo que no significa que se hable estructurado y todo sea en verso, sino que en forma natural el idioma se expresa a través de símbolos y metáforas que ya en el castellano pasan a ser poesía. (Chávez 1990:A10)

Diese Aussage macht deutlich, wie problematisch es ist, einen Mapuche-Text als ,poesía' zu klassifizieren. Die Alltagssprache der Mapuche weist bereits Charakteristika auf, die in europäischen Sprachen Merkmale für Lyrik sind. Daraus ergibt sich die Frage, ob diese auf so andere Art und Weise entstandene Lyrik mit demselben Maßstab gemessen werden kann wie die Lyrik in unserem Sinne, die mit dem Vorsatz verfasst wurde, Literatur zu schreiben. ${ }^{151}$

Ein weiterer Streitpunkt das Mapudungun betreffend ist ebenfalls erst durch den kulturellen Kontakt entstanden, nämlich die Frage, was diese Sprache mit der geplanten Einführung einer Verschriftlichung gewinnt oder verliert. ${ }^{152}$

151 Vgl. hierzu Ignacio Valente: „Es imposible -sería injusto- calibrar los versos de este poeta mapuche de 19 años [Leonel Lienlaf] con el criterio que normalmente usamos para juzgar la nueva producción poética del país. Pues Leonel Lienlaf pertenece a una tradición cultural distinta, que yo en gran parte ignoro (imea culpa!).“ (Valente 1989:1f.; Hervorhebung von Valente)

152 Es existieren bereits sieben verschiedene Vorschläge zur Verschriftlichung des Mapudungun, wovon jedoch noch keine Version offziell ist. Die bekanntesten Varianten sind das Alfabeto Ranguileo und das Alfabeto unificado. 
Diesen und anderen Fragen geht Yanko González Cangas in einem Interview mit Elicura Chihuailaf nach:

Elicura, ¿es posible la apropiación de una expresión cultural occidental como lo ,literario', que está en la médula de occidente, del logos, de la racionalidad -no es propiedad absoluta de occidente, pero la ha monopolizado-, sin perder la identidad? En ese sentido, ¿ves alguna distancia cultural entre el canto -los ül-y la poesía? ¿Cuáles son los criterios con los cuales podemos evaluar responsablemente la calidad de una obra mapuche, sin pertenecer a esa cultura? (González Cangas 1999:66) ${ }^{153}$

Chihuailafs Antworten sind aufschlussreich im Hinblick auf seine persönliche Einstellung, wenn sie auch nicht unbedingt zu einer Klärung der Sache beitragen. Zunächst stellt er fest, dass er canto (ïl) und poesía bedeutungsgleich behandelt (,en mi traducción vienen hacer [sic] lo mismo"). Das erklärt sich aus der Tatsache, dass es im Mapudungun nur das eine Wort ül für Gesang und Dichtung gibt. Das sagt aber nichts darüber aus, wie sich die Poesie im europäisch-literarischen Sinne und die $\ddot{u} l$ der Mapuche zueinander verhalten. Auch in Bezug auf die Kriterien für literarische Qualität hält er beide Kulturen für vergleichbar. Trotz etwa eines sehr unterschiedlichen Verhältnisses zur Natur erkenne er universelle Ähnlichkeiten in den ästhetischen Ansprüchen: „Hoy no podemos olvidar que el arte en general, más allá de las distintas culturas, tiene puntos afines en lo que considera como bello“ (S66f.). Außerdem führt er die philosophische Transzendenz einiger Mapuche-Texte an, was ebenfalls ein Argument für die geistige Nähe und Vergleichbarkeit der beiden Literaturen darstelle: „Si uno analiza muy someramente el kantum [...], te das cuenta que entra en profundidades, en implicaciones filosóficas que tienen que ver con el texto literario conocido en el mundo occidental“ (S68).

Für Chihuailaf gilt noch mehr als für Lienlaf, dass die Vermischung der Kulturen bereits tief im eigenen Denken verankert ist: „Pero entramos, como decía anteriormente, a este mundo que es el occidental y conocemos su complejidad. Allí parte para mí una visión del libro que va a ser importante.“ (González Cangas 1999:67) Er gehört zu der Generation von Dichtern,

que combinan formas de la oralidad mapuche con expresiones literarias occidentales. Su voluntad de escribir, de producir textos, evidencia la „otra realidad“ que compone al pueblo mapuche: los urbanos, los profesionales, los intelectuales indígenas que sin negar su identidad, la rearticulan en un "proyecto“ cultural que „supera y conserva“ la tradición. (Montecino 1992:161)

\footnotetext{
${ }^{153}$ Ich habe versucht, die Rede von einer ,westlichen“ Kultur, Politik etc. zu vermeiden. Üblicherweise wird diese Begrifflichkeit - wie hier von González Cangas („occidental“) - verwendet, ohne dass problematisiert würde, dass es sich dabei um eine zutiefst eurozentrische Bezeichnung handelt.
} 
Montecino weist auf das gespaltene Subjekt in Chihuailafs Dichtung hin: „un sujeto con una densidad cultural ,otra' de la occidental, pero que también comparte símbolos de ésta“. (Montecino 1992:162) Er bringt bewusst den europäisch-chilenisch geprägten Teil seiner Persönlichkeit in die Dichtung mit ein. Und es klingt nicht sehr verschieden von einem europäischen Konzept der Poesie, wenn Montecino über ihn anmerkt: „Para este escritor la poesía mapuche, como su propia poesía, es un campo de entrecruzamiento de la tradición oral, la historia, las experiencias personales y familiares, los peuma (sueños), etc.“. (Montecino 1992:162; Hervorhebung von Montecino) Hier scheinen sich die europäisch-nordamerikanische Vorstellung vom Wert der Individualität und die Bedeutung der indigenen Kollektivität jedenfalls keineswegs auszuschließen. Und wenn Chihuailaf sagt „Todas las formas del arte nos ayudan a asumirnos en las profundidades de la identidad“ (González Cangas 1999:71), so meint ,Identität ${ }^{\star}$ vermutlich ebenso die kollektive Zugehörigkeit wie die individuelle Existenz.

In ähnlicher Weise wie der ursprüngliche Gebrauch ihrer Sprache ist den Mapuche ihr eigener Umgang mit der Geschichte in den Jahrhunderten der Unterdrückung und erzwungenen Anpassung genommen worden. Heute gibt es verschiedene Versuche, mit diesem Verlust von Traditionen umzugehen. So sind die Mapuche einerseits bestrebt, die eigene Sprache und Kultur wiederzubeleben, andererseits wäre es eine Illusion zu glauben, ihre Kultur könnte sich in absehbarer Zeit gegen die chilenische durchsetzen. Stattdessen streben viele Organisationen der Mapuche eine Annäherung beider Kulturen an. Dazu gehört zum Beispiel der zweisprachige Schulunterricht oder die Verschriftlichung ihrer Sprache und damit die Möglichkeit, ihre eigene Kultur und Geschichte in Mapudungun aufschreiben zu können.

Die Skepsis vieler Mapuche gegenüber einer Verschriftlichung ihrer Sprache spricht aus dem Gedicht Rebelión von Leonel Lienlaf:

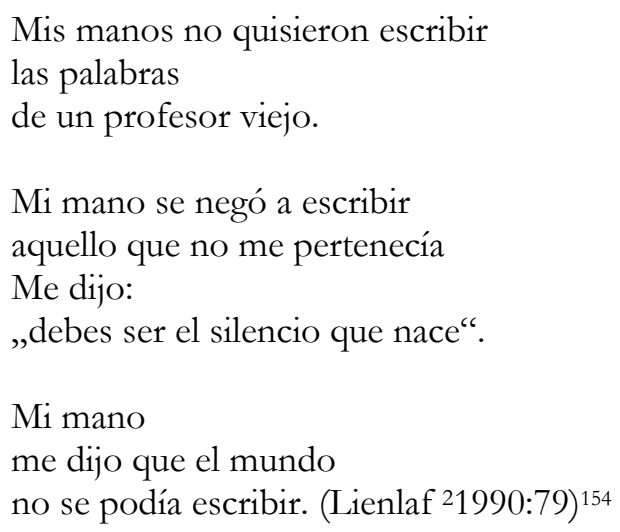

${ }^{154}$ Seine kritische Haltung gegenüber der Schriftlichkeit hat ihn aber nicht davon abgehalten, das Buch Se ha despertado el ave de mi corazón zu schreiben und zu veröffentlichen, aus dem diese Gedichtzeilen entnommen sind. (Lienlaf 21990) 
Obwohl auch Chihuailaf gewisse Vorbehalte gegen die Verschriftlichung seiner Sprache hat („este proceso de apropiación ,obligada“ de la escritura“) (Gómez López 1995:4), ist er aufgeschlossen und sieht darin eine Chance für seine Kultur. Diesen Optimismus im Zusammenhang mit der Einführung einer Schrift äußert er insbesondere im Hinblick auf die Geschichtsschreibung:

Se trata de una cultura tan válida como cualquier otra en el mundo, que tiene derecho a existir como todas las demás. Pertenece a un pueblo que quiere mantenerla a través de la lengua y de la recuperación de su historia real; ésa que se encubre a través de palabras como „pacificación“ o „civilización“. Nosotros sabemos otra historia y la hemos mantenido vigente en la oralidad. Ahora queremos también escribirla y así ayudar a los hermanos que viven en las ciudades a recuperarla. (Moreno 1993:3)

Die Mapuche hatten lange Zeit eine sehr intakte mündliche Geschichtstradierung. Diejenigen, die der Historie kundig waren, die sogenannten bueipife, erzählten in eigens hierfür veranstalteten Zeremonien den anderen Menschen die Geschichten der Geschichte.

La historia no estaba dejada a la improvisación, ni al buen recuerdo de unos pocos; era una actividad reglementada por la sociedad; tenía sus especialistas, y no se permitían las interpretaciones antojadizas. Un código estricto reglamentaba su uso social. Había ceremonias en que los hueipife relataban al pueblo, sentado en redondel, las historias de los antiguos, llamándolo a defender sus tierras, tal como lo habían hecho sus antepasados. (Bengoa 1991:11)

Die so überlieferte Geschichte begann mit den Mythen der Welterschaffung bzw. der Entstehung des Volkes der Mapuche ${ }^{155}$ und berichtete dann ausführlich über den Widerstand gegen die Inka sowie über die Ankunft der Spanier und den Kampf um die Araucanía.

Dieser Brauch ist heute weitgehend verloren gegangen. Es gibt nur noch wenige bueipife, die die alten Geschichten mit all ihren Details kennen und weiterzugeben in der Lage sind. Stattdessen lernt das Volk die chilenische Version der Geschichte oder die Menschen eignen sich die mythifizierte Darstellung aus Ercillas Araucana an. Das Versepos bietet sich als „Ersatzgeschichte“ für die Mapuche insbesondere durch seine heroische Schilderung der Volkshelden wie Caupolicán oder Galvarino an. ${ }^{156}$ (Bengoa 1991:11)

Die Geschichte, die die Mapuche mündlich lebendig hielten, als die Spanier in ihr Land kamen, beschreibt Patricio Cerda als absolut unvereinbar mit der europäischen Vorstellung:

${ }_{155}$ Der bekannteste und wichtigste Mythos der Mapuche ist die Geschichte von Trentren und Kaikai, der beiden Schlangen, die als das Prinzip des Guten und des Bösen um die Menschen kämpfen. Kaikai (auch Herrscherin des Meeres) schickt eine Sintflut, um die Menschen zu ertränken und Trentren (Herrscherin über das Land) schafft Berge, die als rettende Inseln über der Wasseroberfläche bleiben. So entstand der Sage nach die Inselgruppe von Chiloé.

${ }_{156} \mathrm{Zu}$ Caupolicán vgl. Kapitel 6, S118 (Fußnote 113), zu Galvarino vgl. Kapitel 6, S144 (Fußnote 136). 
En efecto, la idea cristiana del devenir histórico tiene fundamento teológico, lineal, [...] El misticismo mapuche percibe la historia como un „eterno retorno“, sujeta al ciclo cósmico, en que se debate la humanidad mapuche como un elemento más de la naturaleza, donde luchan energías positivas y negativas. (Cerda 1990:24)

Die indigene Welt sei nach dem Vorbild der Jahreszeiten und der Natur in ständigem Wandel begriffen, und jeder lebe das kollektive Leben einer Gemeinschaft, die in den ewigen Kreislauf natürlicher Zyklen eingebettet ist. Diese Vorstellung stehe dem europäischen Geschichtsbild linearer Prägung der Renaissancezeit, in dem Ereignisse auf einer Zeitachse vor oder nach der Geburt Christi angeordnet seien und in dem die Individualität der Handelnden eine große Rolle spiele, diametral gegenüber. Beide Geschichtsvorstellungen seien religiös motiviert. Während bei den Mapuche der Mensch immer Teil des ewig sich wandelnden Kosmos' sei und als solcher immer bereits sein Schicksal erfüllt habe, müsse der Mensch im teleologisch bestimmten Christentum ein Ziel erreichen, die Gnade Gottes erst erringen.

Heute muss diese klare Zuordnung von linearer und zyklischer Geschichtsvorstellung als klischeehafte Einteilung erscheinen, da die Grenzen durch jahrhundertelange kulturelle Kontakte an Schärfe verloren haben und in beide Richtungen durchlässig geworden sind. ${ }^{157}$ In vielen Teilen der Welt wurde Menschen das lineare Verständnis der europäischen Logik aufgezwungen.158 Umgekehrt haben zyklische Weltanschauungen und philosophische Systeme wie der Buddhismus Einfluss auf das europäische und nordamerikanische Denken genommen. ${ }^{159}$ In jedem Fall aber hat die Gegenüberstellung historisch ihre Berechtigung und gewinnt immer dort an Bedeutung, wo sich Menschen auf ihre ursprüngliche Spiritualität zurückbesinnen.

In diesem Sinne ist eines der Ziele, für die sich Chihuailaf einsetzt, die Rettung und Bewahrung der Geschichte und der Geschichtserzählungen der Mapuche. Er möchte damit einen Beitrag zum Erhalt ihrer Kultur und Identität leisten. Dazu nimmt er gerne die Verschriftlichung in Kauf und in Anspruch, genau wie zur Veröffentlichung und Verbreitung der Geschichte der Mapuche, worin er einen politischen Auftrag sieht:

Chile, especialmente su oligarquía, sólo se „identifica“ (es sabido) -en el extranjero- con el araucano mítico, pero en ningún caso con el mapuche, a quien por sus luchas por reivindicar sus territorios, su idioma, su cultura, su autonomía -el desarrollo de su historia actual- ve como a un „subversivo“. [...] Chile, como casi todos los países de este conti-

\footnotetext{
${ }^{157}$ Zur zyklischen Zeit- und Geschichtsvorstellung siehe Barthold 1981.

${ }^{158}$ Eben jene Logik ist es, über die sich Riedemann im Gedicht De cómo la indiada perdió el respeto a los caballeros lustig macht (vgl. Kapitel 6, S132f.).

${ }^{159}$ Ein augenfälliges Beispiel ist der bereits hervorgehobene Text The Waste Land von T. S. Eliot. Ich möchte in diesem Zusammenhang an die Jahreszeitenmetaphorik Eliots erinnern sowie an die Rolle, die das buddhistische Denken für ihn spielt (vgl. Kapitel 6.2, 122ff.).
} 
nente, está aún lejos de aceptar - de manera real y profunda la diversidad cultural y su propia morenidad. [...] Ello implicaría -entre otras muchas cosas- un cambio en el enfoque de la historia chilena, que ya no podría hablar, por ejemplo de „Pacificación de la Araucanía“. [...] ¿Pero hay otra historia que se contraponga a la oficialista ya conocida? Recordemos que hasta la historia del movimiento obrero chileno permanece en el desconocimiento de los estudiantes.

Por eso, también los mapuches tenemos una tarea fundamental que realizar: La escritura de la historia de nuestro pueblo, por nosotros mismos. (Gómez López 1995:3)

Im Folgenden wird untersucht, inwieweit Chihuailaf der Forderung nach einer anderen Geschichtsschreibung in seiner eigenen Lyrik nachkommt.

\subsection{Schreie aus der Vergangenheit und Träume von der Zukunft}

1988 erschien Chihuailafs zweiter Gedichtband En el país de la memoria. Im Nachwort beschreibt Chihuailaf den Charakter dieses Buches folgendermaßen: „,...] libro blanco que toma conciencia de la historia y que quiere ser el primer grito de un pueblo al que no dejan nacer“. (Chihuailaf 1988:76) Das Buch besteht aus 41 Gedichten, davon fünf Übersetzungen ins Mapudungun.

\section{Estación de ferrocamiles (S14)}

Aufschluss über Anlass und Thema dieses Textes gibt seine Widmung. Die Zueignung „A los asesinados en Ranquil (Alto Bío Bío)“ erinnert an die bei einem Massaker in Ranquil im Jahre 1934 getöteten Mapuche. ${ }^{160}$ Der Ausgangspunkt der Ausschreitungen, eine Auseinandersetzung der ansässigen Mapuche mit Regierungstruppen um den Besitz der Anbauflächen, war nur einer von vielen Kämpfen um Land in dieser Zeit. Die Regierung verkaufte und versteigerte immer mehr von den ursprünglich den Mapuche und anderen Kleinbauern zugestandenen Gebieten an Großgrundbesitzer. Wo ihnen ein bisschen Land gelassen wurde, wurden sie durch Verkauf des angrenzenden Bodenbesitzes isoliert und unter Druck gesetzt. Die Bauern lehnten sich auf, und die Regierung setzte ihre AgrarPolitik mit militärischer Gewalt durch. Der größte Teil der an diesen Unruhen beteiligten Bauern waren Mapuche, die dagegen angingen, dass ihr Land fortschreitend reduziert und sie selbst immer weiter vereinzelt wurden.

\footnotetext{
160 Patricio Manns hat über dieses Massaker das Buch Actas del alto Bío-Bío geschrieben. Auffällig ist die Form seines Textes, in dem der Erzähler, ein Winka, mündliche Berichte der Geschehnisse auf Tonband aufzeichnet. „La narración restablece así ficticiamente la forma ritual que toma la transmisión de la memoria oral, pero indica al mismo tiempo las circunstancias extraordinarias de esta transmisión: la presencia de un forastero con su grabadora, condición para la aparición de un texto escrito." (Lienhard 1990:305) Auch in Manns Text findet sich die Problematik der schwindenden mündlichen Tradierung und der möglichen - sowie fragwürdigen - Unterstützung von außen, um mit Hilfe kulturell fremder Elemente (Tonband, Schrift) die Überlieferung zu bewahren. (Manns 1985)
} 
Der Text beginnt mit einem scharfen Lärm, der von Zügen herrührt: „Gritos estridentes de trenes madereros“. Da es sich nicht um Personenzüge handelt, könnte man zunächst an das schrille Kreischen der Bremsen eines Zuges denken. Da aber die Widmung ein Verbrechen ankündigt, werden spätestens beim nächsten Vers aus den Bremsen gellende Schreie: „recuerdan viajeros taciturnos de Lonquimay“. Das durchdringende Geräusch erinnert an schweigsame Reisende. Das Paradox von Schreien und Schweigen löst sich auf, wenn man weiterdenkt, dass die Opfer, denen der Text gewidmet ist, für immer zum Schweigen gebracht wurden.

Eines der bekanntesten Opfer des Massakers von Ranquil war der Cacique Ignacio Maripe, der über 15 Jahre früher sein Land in Lonquimay verloren hatte. Die Erwähnung von Lonquimay soll daran erinnern. Die folgende Zeile gibt die Jahreszahl des Ereignisses an. Sie ist in Worten ausgeschrieben, was ihr ein größeres Gewicht gibt.

Die drei letzten Zeilen eröffnen einen neuen Aspekt: „Por quienes aún suele posarse / el sonar de arcabuz / en los barrancos“. Die schweigsamen Reisenden hören das Geräusch von Arkebusen. Die Arkebuse, auch Hakenbüchse genannt, ist eine mittelalterliche Feuerwaffe, ursprünglich eine Armbrust, und eine der Waffen, mit denen die Spanier Amerika eroberten. Einer Legende nach feuerte einer von Pizarros Leuten bei der Ankunft in Tahuantinsuyu seine Arkebuse ab, was bei den Inka großen Eindruck hinterließ, und sie in ihrer Vorstellung noch bestärkte, dass es sich bei den Fremden um Viracocha, den bärtigen Schöpfergott und sein Gefolge handele, auf dessen Rückkehr aus dem Osten sie warteten. (Delanoir 2000:Kap.1)

1565 wurde die Arkebuse zur Muskete weiterentwickelt, die die Arkebuse im Heer bald vollständig ersetzen sollte. Kleinere Kompanien, die dem jeweiligen Landsherrn unterstanden, benutzten diese Waffe durchaus noch länger. Es kann allerdings ausgeschlossen werden, dass sie im 20. Jahrhundert noch irgendwo zum Einsatz gekommen sein soll. Wenn hier das Massaker von Ranquil 1934 mit dem Geräusch von feuernden Arkebusen untermalt wird, so soll eine Parallele zwischen den blutig niedergeschlagenen Arbeiter- und Bauernaufständen in der ersten Hälfte des 20. Jahrhunderts und dem frühen Widerstand der Mapuche gegen die Conquista gezogen werden. Für jene Reisenden aus Lonquimay sind die Arkebusen der Spanier noch nicht verstummt. Wenn es sich auch schon längst nicht mehr um tatsächliche Arkebusen noch um Spanier handelt, so ist doch die Unterdrückung durch die chilenische Regierung vergleichbar und der Kampf der Unterdrückten derselbe.

Eine weitere Parallele beider Szenarien findet sich in der Art der Darstellung der unterschiedlichen historischen Ereignisse. Wie im Kapitel 7.1 (S163f) bereits zitiert, zieht 
Chihuailaf in seiner Kritik an der offiziellen Geschichtschreibung einen Vergleich zwischen dem Umgang mit der Geschichte der Mapuche und der Arbeiterbewegung in Chile. Beides würde zu wenig und zu tendenziös dargestellt und in der Öffentlichkeit meist tabuisiert. Insofern funktioniert der Vergleich im Gedicht auf verschiedenen Ebenen. Die Gruppe der „asesinados en Ranquil“, denen das Gedicht gewidmet ist, bezieht durch die Parallele auch die in den knapp 400 Jahren vorher getöteten Mapuche mit ein, ohne dass diese ausdrücklich erwähnt werden müssten.

Mit dem Titel wird der Ort des Geschehens, ein Bahnhof, besonders hervorgehoben. Damit greift Chihuailaf ein rekurrentes Motiv der südchilenischen Larendichtung auf. Besonders in der Dichtung Jorge Teilliers spielen einsame oder verlassene Bahnhöfe und in der Ferne verschwindende Züge als Symbol der Nostalgie und der Vergangenheit eine große Rolle (vgl. Kapitel 6.4, S152f, Fußnote 148). Und auch Riedemanns Gedichtzyklus Karra Maw'n (der sicherlich nicht zur Larendichtung gezählt werden kann), endet mit der Metapher „se envidia a las locomotoras / porque saben a donde van“.

Die Larendichtung ${ }^{161}$ - oder zumindest die Diskussion um sie - ist so eng mit dem Süden verbunden, dass auch Chihuailaf Stellung beziehen muss: „Yo me pregunto, ¿no será que lo ,lárico' chileno, hablando de todos sus representantes en la poesía, ha sido influido por la cultura mapuche y no al revés?“" (González Cangas 1999:71) Im selben Interview wird er kurz danach mit der Frage konfrontiert: „Luis Ernesto Cárcamo, crítico y académico, hoy radicado en E.E.U.U., decía en una ponencia exactamente todo lo contrario, que la poesía mapuche, específicamente la tuya, era la proyección del discurso lárico..." (González Cangas 1999:72) Wird also die Larendichtung in der Mapuche-Lyrik aufgegriffen oder war die Dichtung der Mapuche Vorbild für die Larendichter?

Das Gedicht Estación de ferrocarriles spricht weder für das eine noch für das andere, sondern hat eher die Qualität eines sarkastischen Seitenhiebs auf den Larismo. Zwar geht es auch hier um Gegenwart und Vergangenheit, aber eben gerade nicht um den unwiederbringlichen Verlust einer im Nachhinein verklärten Vergangenheit, sondern um die Parallelen und um die Vergleichbarkeit von Gewalt und Willkür in zwei sehr unterschiedlichen Zeiten.

\section{El sueño de Lautaro (S15)}

Lautaro (oder ursprünglich ,Lautraru' wie in Zeile 14) war der Krieger, dem der siegreiche Ausgang der Schlacht von Tucapel zugeschrieben wird. An der Seite des lonkos Caupolicán

\footnotetext{
161 Vgl. Kapitel 3.4, S46.
} 
führte Lautaro die Mapuche im Jahre 1553 in die Schlacht, in der sie die Truppen Valdivias besiegten und Valdivia selbst Neujahr 1554 töteten. (Fuentes 51978:308) Der besondere Verdienst Lautaros war es, dass er den Mapuche nach seiner Gefangenschaft bei den Spaniern vieles über den Feind beibringen konnte. Zum einen hatte er die Schwächen der Spanier studieren können, ihre angreifbaren Stellen, zum anderen hatte er die wertvolle Fähigkeit erlernt, mit dem Pferd umzugehen. Die ersten Schlachten gegen die Spanier hatten die Araukanier verloren, weil sie große Angst vor den Pferden bzw. den Reitern hatten. Lautaro nahm ihnen nicht nur die Angst vor den berittenen Feinden, sondern lehrte sie, selbst zu reiten und das Pferd in der Schlacht zu nutzen. (Encina 1983:217f.) 1557 starb Lautaro in der Schlacht am Río Mataquito. Ercilla besingt den Helden Lautaro in der Araucana, und bis heute wird er in Chile nicht nur von den Mapuche als Freiheitskämpfer und Volksheld verehrt.

Von dem 15-zeiligen Gedicht stehen die ersten 13 Zeilen in Anführungszeichen, nach einem Absatz folgen die letzten beiden Verse in Klammern: „(Lautraru, lonko: abre los ojos / y ¡deja de soñar!)“ (S15). Die vorangegangenen Zeilen beinhalten also vermutlich das, was Lautaro träumt, eine nicht-reale Situation, die er erwünscht oder - in diesem Fall wahrscheinlicher - fürchtet: „Griterío de treiles y guairaos / vienen trazando una huella ruidosa / y espeluznante“. Das Geschrei von zwei in Südchile heimischen Vögeln legt eine Spur. Was sie rufen, ist laut und der Inhalt lässt die Haare zu Berge stehen. Sie schreien: „Volvieron los ,pacificadores“ [...] / de cuello y corbata y sonrisa oscura“. Das Vogelgeschrei ist so erschreckend, weil es die Rückkehr der ,pacificadores' ankündigt. ,Pacificadores" bezieht sich auf die euphemistisch sogenannte Pacificación de la Araucanía und auf die Chilenen, die diesen Frieden in der zweiten Hälfte des 19. Jahrhunderts gewaltsam erzwungen haben (vgl. Kapitel 6.1, S120). Ihre Wiederkehr, die Lautaro in seinem Traum erlebt, findet in Chihuailafs Gegenwart statt: Sie kommen mit Kragen und Krawatte „en el ocaso del siglo veinte“. Sie kommen nicht allein, sondern „Con sus, indios auxiliares“ / carne de cañon / fotografiados en los periódicos“. Indios auxiliares werden die Einheimischen genannt, die von den Spaniern auf ihren Eroberungszügen durch Amerika zwangsrekrutiert wurden. Sie werden im Text als „modernos yanaconas“ bezeichnet, also mit den Indigenas verglichen, die zu Frondiensten gezwungen wurden. Bei den Schlachten standen die auxiliares in vorderster Linie und waren nichts anderes als - wie Chihuailaf sagt - „,carne de cañon“: Kanonenfutter. ${ }^{162}$

\footnotetext{
${ }^{162}$ Insgesamt verloren die Spanier im Araukanischen Krieg 50.000 eigene Soldaten und schickten 60.000 auxiliares in den Tod. „Many Spanish historians referred to Mapuche soil as the Spanish soldiers cemetery [sic] of The Americas.“ (Marhikewun 1998: The Long Mapuche War)
} 
Schließlich versucht jemand, Lautaro aus seinem Traum zu reißen. Er solle die Augen öffnen und aufhören zu träumen. Dieser Ruf kommt aus seiner eigenen Zeit, Mitte des 16. Jahrhunderts, was die Schreibung seines Namens - im Gegensatz zur Schreibung im Titel verdeutlicht.

Wir wissen, dass es mehr als ein Traum ist, eher ein Gesicht, eine Vision, die Lautaro hat, als er die Vögel hört. Auch hinter diesem Text steht der Gedanke der Wiederholung im Gang der Geschichte. Wie hätte Lautaro reagiert, hätte er gewusst, dass sein Kampf auf lange Sicht die Unterwerfung seines Volkes nicht würde verhindern können? Und wie, wenn er gewusst hätte, dass sich das Schicksal wiederholen würde? Diese Fragen wirft der Text auf, und eine mögliche Umgangsweise mit diesen Zweifeln ist eine fatalistische Weltsicht, in der der Mensch aus Wissen um die Vergeblichkeit seines Handelns in Reglosigkeit verharrt. Aber dies ist nicht die Reaktion, die der Text anbietet. Die letzten zwei Verse sollen nicht nur Lautaro auf den Boden der Tatsachen zurückholen, sondern auch diejenigen, die sich zu sehr in die Vergangenheit zurückziehen. Es scheint ein Aufruf zu sein, der daran erinnert, dass der Kampf immer gerade jetzt stattfinden muss, ungeachtet der Ahnungen oder Ängste die Zukunft betreffend. Denn gerade jetzt „,en el ocaso del siglo veinte“ kommen die „pacificadores por infaustos caminos de sangre“.

\subsection{Temuco: Die Stadt und ihre Straßen}

Ein sich häufig wiederholendes Thema innerhalb des Buches ist das Leben der Mapuche in der Stadt. Wenn Mapuche von der Stadt sprechen, ist damit oft synonym Temuco gemeint. Trotzdem lebten gemäß der Volkszählung von 1992 bereits 44,1 Prozent aller Mapuche in Santiago. (Marhikewun 1998)

Chihuailaf zeigt uns die Stadt als Brennpunkt der kulturellen Heterogeneität. Auf engem Raum existieren verschiedene Kulturen, verschiedene Sprachen und verschiedene Traditionen nebeneinander. Weiterhin wird der Unterschied zum Leben außerhalb der Städte thematisiert, das Spannungsverhältnis zwischen zwei Lebensräumen und der Kulturschock, den Menschen erleben, wenn sie vom Land in die Stadt ziehen. Sowohl im Text La ciudad als auch in Temuco findet sich das Wortfeld Tod/Friedhof/Sterben. Die gesamte Stadt wird mit einem Friedhof verglichen, auf dem jeder sein Grab hat: „Ese cementerio donde todos tienen su sepulcro“ (S16). Man assoziiert Häuser oder Wohnungen mit Zellen, in denen die Menschen lebendig begraben sind. Die Städter sind allesamt Tote: „Cómo son y quiénes son los muertos / que la habitan?“ (S16) Es ist ihr Verhalten, das dem Erzähler diesen Eindruck vermittelt: „qué forzada sonrisa de esqueleto“, „qué secreto sueño de resurrec- 
ción“. Menschen werden in der Stadt zu „ensombrecidas sombras“. Die figura etymologica intensiviert das Bild.

Im Gedicht Temuco wird die Stadt selbst näher beschrieben. Das Bild wird von Attributen der beiden in gewisser Weise rivalisierenden Kulturen beherrscht. Zum einen finden sich bestimmte Begriffe, wie sie die europäische oder nordamerikanische (Groß-)Stadt des späten 20. Jahrhunderts beschreiben: „tecnología“, „hedor inconfundible“, „oxidadas máquinas“, „imprenteros“, „computadoras“, „cemento“, „metales“ (S17). Zum anderen nimmt die Kultur der Mapuche sprachlich und inhaltlich einen großen Raum ein: „Konun Wenu (las puertas del cielo)“, „metawes“, „malones“, „Pascual Coña“, „Caupolicán“, „el puelche“, „trutrucas“, „yerba mate“, „el Árbol“, ,,agua de temos“..163

Die Vergangenheit ist unwichtig geworden: „Ya nadie se interesa por fundar lejanos pueblos“. Alles, was innerhalb der Stadt von der Vergangenheit geblieben ist, sind Friedhöfe und Museen: „y joyas y metawes y muertos / desfilan en las vitrinas de museos tristes“. Die typischen Gegenstände der Mapuche wie ihr Silberschmuck oder ihre Keramik liegen nur noch in Museen und sind damit auch tot wie ihre ursprünglichen Besitzer. Die Menschen und ihre Utensilien sind von Leblosigkeit gekennzeichnet. Was hingegen lebt, ist die Stadt - wenn auch paradoxerweise in Gestalt eines Friedhofes. Anstelle von Orten werden Straßen gebaut („Hoy se fundan avenidas“), so dass die Stadt unaufhörlich anwächst: „El cemento crece-ahora-crece“.

Der Text versucht, die beiden Kulturen, aus denen sich Temuco zusammensetzt, miteinander zu versöhnen, einander anzunähern. Das Nebeneinander innerhalb des Alltags beider Gruppen in der Stadt wird deutlich.

avenidas con costumbres, utensilios e historiadores de malones con champagne música rock y delikatessen. (S17f.)

In diesen Zeilen liegt zusätzlich ein Hinweis auf den Einfluss der französischen und deutschen Einwanderer, sowie auf die US-amerikanische Populärkultur. Doch gegen diese

163 „Konun Wenu“: der Mapuche-Name eines Berges bei Temuco (span.: las puertas del cielo); „metawes“: ein typisches Gefäß der Mapuche aus Ton, in dem Flüssigkeiten aufbewahrt werden (meist in der Form eines Tieres); ,,malones“: Überfälle der Indígenas; „Pascual Coña“: ein berühmter lonko; „el puelche“: Mapuche-Name für den Ostwind, „trutrukas“: Trommeln; „yerba mate“: das Blatt, aus dem der Mate-Tee zubereitet wird; „el Árbol“: vgl. El Árbol del Mundo in Kapitel 6.2, S129f.; ,agua de temos“, auch temu: Übersetzung des Mapuche-Namens für Temuco, das Wasser, in dessen Nähe temu wachsen. „Temu“: Ein Baum aus der Familie der Myrtengewächse mit sehr hartem Holz. 
sprachliche Umsetzung einer Schmelztiegel-Atmosphäre, in der Menschen unterschiedlicher Herkunft aufgefangen werden und denen es schließlich gelingt, das Bild einer Stadt gemeinsam zu prägen, sprechen andere Verse:
Pascual Coña viaja en su carreta tras el muro invisible de Temuco
y la tolerancia es una estatua corroída
que sólo nos hace añorar
cuando en un costado de Caupolicán
el puelche gime. (S18)

Die unsichtbare Mauer trennt die Ethnien in Temuco voneinander. Der lonko Pascual Coña bewegt sich hinter dieser Mauer, es existiert kein wirklicher Kontakt zwischen den Bevölkerungsgruppen und keine Toleranz. Von einem verständnisvollen Miteinander kündet nur noch das Monumento a la Araucanía, eine Statue auf der Plaza de Armas in Temuco, die einen Mapuche, einen spanischen Eroberer, einen deutschen Siedler und den Dichter Ercilla friedlich vereint darstellt. Das Monument ist bereits von Wind und Regen zersetzt. Der Wind pfeift auch der um das 19-geschossige Gebäude, das nach dem Freiheitskämpfer der Mapuche Torre Campolicán benannt wurde. Puelche ist die Bezeichnung für den Ostwind, der in der Kosmogonie der Mapuche das Gute mit sich bringt. Vor diesem Hintergrund tritt umso deutlicher die beißende Ironie zutage, die darin liegt, dass zum einen die Eroberer aus dem Osten kamen und zum zweiten, dass ein solches Bauwerk, ein Büro- und Geschäftsgebäude, einem Helden des unterdrückten und geringgeachteten Teils der Bevölkerung seinen Namen verdankt. ${ }^{164}$

Pascual Coña war ein lonko, der durch seine Biographie Memorias de un cacique mapuche bekannt wurde. Der Geistliche Wilhelm de Moesbach zeichnete sie in der ersten Hälfte des 20. Jahrhunderts nach Coñas Erinnerungen auf. (Coña 1973) Sie wird gelobt als

the greatest work within the testimonial genre of Mapuche literature. Coña tells about his past cultural experience, including childhood; up bringing [sic]; rituals; flora and fauna; Mapuche medicine and much more. In the second half of the 20th century, many Mapuche writers have emerged, producing all types of written work, including riddles, short life histories, daily life experiences, tales and poems. (Catrileo 1999: María Catrileo)

Der Einzelne zählt in der Stadt nicht, sein Schmerz und sein Ärger werden von der Technologie und der Anonymität geschluckt, und sogar seine Erinnerung fällt der Datengesellschaft zum Opfer:

Ciudad: no importan mis dolores ni mis iras

si tus imprenteros no se coluden con computadoras

que intentan cavar túneles en la memoria. (S18) 164 Man denkt an die Türme, die auch bei Riedemann Zeichen der Besatzermacht waren, vgl.
Kapitel 6.2., S129ff. 
Das künstliche Gedächtnis zerstört die menschliche Erinnerung, so wie die Geschichtsüberlieferungen der Mapuche den Geschichtsbüchern der Spanier und Chilenen weichen mussten. Die folgenden Zeilen begehren gegen diese schmerzliche Erkenntnis auf und drücken den Wunsch nach einem Miteinander aus. Sie führen das Volk der Erde, die Mapuche, und die Siedler, die über das Meer kamen, zusammen, als wollten sie die Elemente Erde und Wasser zusammenfügen: „¡Somos tu raíz! Sangre mapuche-española / dueños de la tierra y habitantes dispersos / por el mar“"(S18).

In den letzten 13 Versen vermischen sich Fortschrittsgläubigkeit und Fortschrittsskepsis, es mischen sich die Materialien der Stadt mit den Attributen der Gesellschaft der Mapuche („el Árbol“, „,trutrukas“, ,,agua de temos“) und Optimismus mit Pessimismus bezüglich der Bewertung der Entwicklung der Stadt: „Todo está bien / [......................] / indudablemente no todo está bien“ (S19).

Die Schlussverse kehren der Stadt den Rücken: „(El río Cautín murmura y llovizna / coronan el Ñielol con arco iris) “. ${ }^{165}$ Anstelle der Stadt sehen wir den Fluss, den Berg, den Regen und den Regenbogen. Das Bild ist in Klammern gesetzt, als solle die Natur vor der Stadt geschützt, gewissermaßen abgeschirmt werden.

Auch in einigen der folgenden Gedichte ist das Thema der Stadt präsent. In Ciudad Nr. 3 (S23) hören wir einen Mapuche, der in die Stadt gezogen ist und nun Schwierigkeiten hat, sich an das neue Leben dort zu gewöhnen: „Y he llegado a tu ciudad perdida / entre letreros luminosos y supermercados / que regalan televisores en color“". Im Folgenden zählt der Sprechende auf, was ihm in der Stadt fehlt:

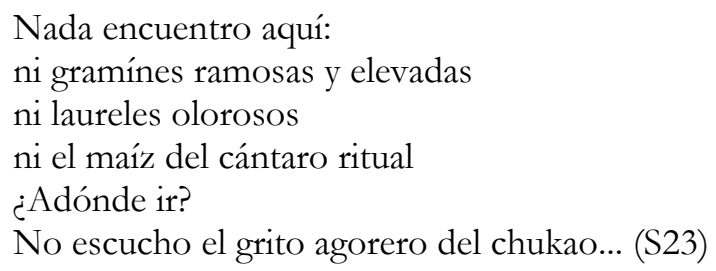

So wie die verschiedenen Entdecker und Eroberer in den Chroniken des 15. und 16. Jahrhunderts häufig davon sprachen, was sie in der Neuen Welt vermissten, was also ihrer Meinung nach im Vergleich zu ihrer Heimat fehle, zählt der Mapuche nun auf, was ihm in der Stadt fehlt: die Flora und Fauna seiner Heimat sowie die heiligen Rituale. ${ }^{166}$ Es soll ausgedrückt werden, dass die chilenische Kultur im Vergleich mit der der Mapuche durchaus als

${ }_{165}$ Nielol: Vgl. Kapitel 6, S127. 
defizitär und unterlegen empfunden werden kann, es kommt nur auf den Blickwinkel an.

Das Motiv der Stadt ist meist verbunden mit Rastlosigkeit, mit Entwurzelung, mit unruhigen Pendel-Bewegungen zwischen den beiden Polen Stadt und Land sowie zwischen den Polen Gegenwart und Vergangenheit. Denn meistens bedeutet der Aufbruch in die Stadt auch den Verlust des früheren Lebens, der früheren Gewohnheiten. Die Erfahrung eines Lebens ,dazwischen', eines Lebens, das sich nie völlig in die Stadt integrieren wird, aber auch nicht mehr zurück kann, manifestiert sich in Cuidad Nr.3. „Y vengo y voy“ (V20), „Y voy y vengo“ (V24) und „¿Adónde ir?“ (V30).

Das gleiche Thema greift das Gedicht Trasplantado auf. Der Erzähler beschreibt, wie er aus der Stadt, wo er studiert hat, zurück in sein Dorf kommt:

\section{Después, en fin, del sudoroso embate resistido a la supercivilización: regreso (regresaste tú también un día) ¡Soy letrado!, libre vengo de orgullos y exageraciones. (S26)}

Er berichtet, wie er zurückkehrt in den Schoß seiner Familie: „Tengo padre, intacto el hilo umbilical“" (S27). Er setzt sich ans Feuer, und die Mythen und Erzählungen seiner Vorfahren werden in ihm lebendig. Am Ende des Textes stellt sich alles als ein Traum heraus: „Pero los espíritus del mal irrumpen desde / la oscuridad / transformando en cenizas todos esos sueños“. Stattdessen sieht er die Hütte vor sich brennen: „(Mientras con lengua larga y lerda / la llama lame el techo de la ruka)“. Schon zweimal waren die beiden letzten Verse von Gedichten eingeklammert, und in beiden Fällen stellten sie eine Gegenwirklichkeit zu den vorangegangenen Zeilen dar. In El sueño de Lautaro offenbart das Gedichtende den vorangehenden Text als Traum, in Temuco stand am Ende die unberührte Natur der bedrohlichen Stadt gegenüber. Wie Lautaro muss der Erzähler hier aus seinem Traum erwachen und der Realität ins Gesicht sehen. Während er sich wünscht, nach seinem Studium in der Stadt innerhalb der Familie zurückerwartet zu werden und wie vorher leben zu können, haben längst - echte oder metaphorische - Flammen die Vergangenheit zerstört. Die Rückkehr ist nicht mehr möglich, er bleibt ein trasplantado, ein Verpflanzter.

Sowohl die Bewegungen des Hin und Her als auch das Erleben von Wirklichkeit und Gegenwirklichkeit bzw. Traum lassen sich verbinden mit dem Bewusstsein von Vergangenheit und Gegenwart.

166 Der chukao ist ein in Südchile beheimateter Vogel, der besonders für die Wälder zwischen Valdivia und Chiloé charakteristisch ist. 
In den folgenden Gedichten, in denen ebenfalls die Stadt im Mittelpunkt steht, vermischen sich mythische Motive, Aspekte aus der Geschichte, Träume und persönliche Erinnerungen. Die verschiedenen geschichtlichen Ereignisse, die ich betrachten werde, sind die Diktatur, die Vernichtung der Ona und die kurze Amtszeit des Königs Orelie Antoine I. von Araukanien.

In den Abschnitten 6 und 7 von La ciudad y sus calles findet sich die einzige deutliche Anspielung auf die Verbrechen der Diktatur:

Pero hasta la muerte (hoy) es otra en estas irreconocibles calles de Chile

Estas mismas calles que rememoran a Alejandro Ancao mientras su madre sueña que habita entre las araucarias y muele piñones en la piedra y bebe cosay. (S41-43)

Anhand einer konkreten Person wird an die desaparecidos unter den Mapuche erinnert. Alejandro Ancao (Mapuche) wurde am 26. September 1973 in Cunco festgenommen. Man weiß bis heute nichts Genaues über sein Schicksal und seinen Verbleib.

Die Mapuche waren eine der Bevölkerungsgruppen, die gezielt und systematisch verfolgt wurden. Dabei stand ihre ethnische Zugehörigkeit und keineswegs etwaige politische Aktivitäten im Vordergrund. Der Satz Pinochets „No hay mapuches. Somos todos chilenos“ sollte Gesetz werden und formulierte die geplante Ausrottung oder Anpassung alles Indigenen. (Gesellschaft für bedrohte Völker 1999) Unter der der Diktatur vorausgehenden sozialistischen Regierung Allendes hatten die Mapuche ihre politische und soziale Stellung im Land stärken können. Bis Ende 1972 waren ihnen etwa 700.000 Hektar ihres ursprünglich eigenen Land zurückgegeben worden. Ein im September 1972 erlassenes Gesetz sicherte den Mapuche die Rückgabe verlorener Landrechte sowie die Erweiterung der territorialen Garantien zu. Darüber hinaus wurden die Förderung sozialer und kultureller Belange und die Verbesserung des Gesundheitswesens und Unterricht in ihrer eigenen Sprache zugesagt. ${ }^{167}$

Mit dem Militärputsch änderte sich die Situation der Mapuche radikal. Die Confederación Nacional de Mapuche, in der die Mapuche organisiert waren, wurde unmittelbar nach dem Staatsstreich verboten, ihre Anführer und Mitglieder festgenommen, gefoltert, ins Exil gezwungen, getötet oder sie verschwanden spurlos wie der dirigente Alejandro Ancao. In

\footnotetext{
${ }^{167}$ Allende führte eine Politik fort, die bereits in der vorangegangenen Regierung betrieben wurde: „Los parlamentos de Ercilla en 1969 y Temuco en 1970 fueron el mecanismo para promover la participación mapuche en la generación de ese proyecto de ley, y el movimiento mapuche tenía esto muy fresco en la memoria. Se trataba entonces de una nueva ley indígena ,con` la participación de los mapuche.“ (Marimán 1994:2.4 Interpretación del conflicto)
} 
Temuco waren in den ersten Monaten nach dem Putsch 80 Prozent der Gefangenen Mapuche.

„Es gibt keine Ureinwohner, wir sind alle Chilenen.“ Deutlicher hatte [sic] Diktator Pinochet, der in Chile zwischen 1973 und 1990 die Macht hatte, es nicht ausdrücken können: Er wollte die kulturelle Eigenständigkeit der indianischen Bevölkerung Chiles allen voran die der Mapuche - im Namen des Einheitsstaates vernichten. Eine Arbeitsgruppe der Vereinten Nationen bestätigte in einem Bericht von 1978 die Konsequenzen dieser Politik: „Mit dem Tage des Putsches starteten die Großgrundbesitzer und Landbarone, das Militär und die uniformierte Polizei eine regelrechte Hetzjagd auf die Mapuche.“ (Gesellschaft für bedrohte Völker 1999)

All dies ruft Chihuailaf mit der namentlichen Nennung von Alejandro Ancao ins Gedächtnis. Zunächst sind es die Straßen, die des dirigente gedenken, dann seine Mutter, und schließlich ruft Chihuailaf allgemein zur Erinnerung auf und dazu, dass diese Erinnerung auch an nachfolgende Generationen weitergegeben werden soll: „Levantarnos, y su recuerdo sea el libro abierto / en el que hayan de mirarse nuestros hijos / con sus sonrisas desdentadas y hermosas“ (S43).

Die vorangehenden sechs Abschnitte des Textes La ciudady sus calles zeigen, dass nicht nur die chilenische Kultur und die der Mapuche in der Stadt aufeinandertreffen. Die Zeilen „China, Japón, Taiwan rezan las vitrinas [...] acordes de violínes / interpretando Yesterday“ deuten an, dass längst auch andere Kulturen Einzug gehalten haben und dazu beitragen, dass der Erzähler sich fremd fühlt: „Soy un extranjero de esta tierra“ (S40).

\subsection{Adiós, Brüder}

\section{Ayer adiós hemanos onas. Mapuche hermanos ya nos dicen adiós und Antes desaparecieron (a) nuestros hermanos onas. Hemanos mapuches para nosotros quieren lo mismo (S46-49)}

In den beiden aufeinanderfolgenden Gedichten zieht der Erzähler eine Parallele zwischen der systematischen Vernichtung des Volkes der Ona und ihrer eigenen drohenden Ausrottung. ${ }^{168}$ In beiden Fällen scheint ein und dieselbe Kraft hinter den Verbrechen gegen die Menschlichkeit zu stehen, die in beiden Titeln als eine unpersönliche dritte Person Plural auftritt. Beide Texte sind einander sehr ähnlich, manchmal bis in die exakten Formulierungen hinein.

Im ersten Text werden die Mapuche mit Schwänen verglichen, die gejagt werden: „Henos aquí compañeros, cisnes de alas extendidas / ofreciendo blanco perfecto al cazador“ (S46).

$168 \mathrm{Zu}$ den Ona vgl. Kapitel 4. 
Gemeint sind die in Südchile und Feuerland lebenden Schwarzhalsschwäne, die in der ersten Hälfte des letzten Jahrhunderts durch starke Bejagung vom Aussterben bedroht waren. Mittlerweile stehen sie unter strengem Artenschutz. Auch die Mapuche werden gejagt, ebenso wie die Feuerland-Bewohner vor 100 Jahren gejagt wurden, in beiden Fällen ist die chilenische Regierung der Jäger. Das zweite der beiden Gedichte, die den Ona gewidmet sind, beginnt analog zum vorangehenden mit einer Metapher, in der der Erzähler die Mapuche als Vögel sieht, die gejagt werden: „como pájaros que no se ocultan / y son presa fácil para los cazadores“ (S48).

Die gejagten Vögel haben in beiden Texten eine einzige, eine letzte Bitte. Einmal bittet der Erzähler um „el último aire / el respiro para el vuelo que espera“, im zweiten Text möchte er „una última oportunidad / para tomar las riendas de nuestro destino“.

In beiden Texten geht es um die Überwindung einer Distanz, um eine Rückkehr: „Lejos estamos“ aus dem ersten Text wird im zweiten zu „Estamos lejos“. Es klingen leise Drohungen an, die besagen, dass das Volk noch nicht besiegt ist: „pero crece la bandada“ und „pero -aunque no quieran- nacen hijos que llevan / nuestra sangre“. Es werden die Nachkommen beschworen, die für den Fortbestand der Mapuche sorgen sollen.

Wie schon in vorangegangenen Gedichten steht die Erinnerung an Traditionen der gegenwärtigen Situation in den Städten gegenüber: „dulzor de canelos y arrayanes alientan los pulmones“ (S46). In den Städten gibt es keine Schwäne, sondern Kanarienvögel in Käfigen: „En la ciudad canarios de verdades últimas / intentan aprehender nuestro áspero grito / en sus jaulas delicados trinan, trinan“ (S47). Und es gibt Menschen, die die Mapuche bevormunden und unterdrücken. Wieder ist von Rückkehr die Rede: „[...] ¡A aletear pequeños cisnes!“ (S46) und „[...] ha llegado la hora del regreso“ (S47). Vordergründig ist die Rückkehr aus der Stadt gemeint: ,„La cordillera!, ¿pero dónde el verdor del valle / y el nido cisnes solemnes y a punto de desaparecer?“" (S47) Gleichzeitig ist es die Rückkehr aus diesem, ihnen fremd gewordenen Land in ihre Heimat: „Sopla el viento sur, en un país extranjero, y / nos hace recordar“169 (S48).

Aber es geht auch um eine umfassende Neubesinnung, besser gesagt, um eine Rückbesinnung. Während sie von der Wirklichkeit - einer Wirklichkeit, die mit ihren Feinden aus

\footnotetext{
${ }^{169}$ In La ciudady sus calles nannte der Erzähler sich bereits extranjero. Auch Lienlaf äußert in einem
} Interview, daß er sich als Fremder fühlt. (Zerán 1990:4) 
dem Norden kommt ${ }^{170}$ - geschlagen werden (,[...] y allá / la realidad, el viento norte golpea mis mejillas“, S47), sollen sie sich eine andere Zukunft aufbauen: „Beberemos muday, de vertientes agua beberemos“ (S47). Aus den Quellen zu trinken ist ein sehr spirituelles Bild. Die Quellen sind auch die Wurzeln, die Ursprünge, zu denen die Mapuche zurückkehren sollen. Gleichzeitig wendet sich der Text gegen die christliche Spiritualität, die ihnen erst von den Spaniern und später von den Chilenen gepredigt wurde: „el viento norte golpea mis mejillas / (¿pudo alguien - quién - poner la otra?)“ (S47). Der Klammersatz legt nahe, dass dieser christliche Grundsatz gar nicht zur Anwendung hätte kommen können, da die Mapuche von vornherein auf beide Wangen geschlagen wurden.

Diese beiden fast identischen Texte rufen auf zu einem Neubeginn, dessen Grundstein jedoch die Erinnerung sein soll. Das Land, das entstehen soll, ist die Utopie eines país de la memoria, nach dem das Buch benannt ist. Trotzdem enden beide Texte mit Zweifeln und Fragen. Vor den Augen des Erzählers verschwinden das Grün des Tales sowie das Nest der Schwäne. Die Zukunft bleibt ungewiss.

\section{Sueños (S63)}

Im vierten Abschnitt des Gedichtes Sueños / Primera versión: Hijo de la noche wird der Name der historischen Person Orelie Antoine genannt. Der Text hat sieben Abschnitte, in denen verschiedene Traumbilder - manche sehr realistischer Art - aneinandergereiht sind. Der vierte Abschnitt enthält die Bilder eines guten Traumes, eines Wunschtraumes:

Ya no hay conquistadores que cuelguen sus retratos Orelie Antoine cuenta su plan a mis hermanos Ya nadie se extravía en las ciudades Juntas tu voz y mi voz elevan su registro. (S66)

Orelie Antoine I war von 1860 bis 1862 selbsternannter König des Königreiches Araukanien und Patagonien. Der aus Frankreich stammende Anwalt Orelie Antoine de Tounens (1825-1878) hatte schon als Kind den Plan, eines Tages König zu werden. Er interessierte sich sehr für Geschichte, las viel über fremde Kulturen und begann, die Mapuche, ihre Kultur sowie ihren Mut und ihre Zähigkeit zu bewundern. Schließlich ergriff die Idee von ihm Besitz, dieses Volk als ihr König gegen Chile und Argentinien ins Feld zu führen. Im Jahre 1858 reiste er mit dem festen Vorsatz nach Chile, die Araukanier in ihrem Kampf zu unterstützen. (Gil-Montero 1990:The Making of a King) Orelie Antoine integrierte sich schnell in die Gesellschaft der Mapuche, aß und kleidete sich nach ihrer Art und gewann ihr Vertrauen. Als Jurist beriet er die Mapuche bei Verhandlungen mit der Regierung und

${ }^{170}$ Der Westen und der Norden stehen in der Kosmovision der Mapuche für das Böse, der Osten 
wurde für sie eine politisch wichtige Person. Dies waren die besten Voraussetzungen für sein Vorhaben, und im Jahre 1860 gründete er das Königreich von Araukanien und Patagonien. Die Araukanier, denen ohnehin eine einende Kraft in ihrem Kampf gegen Chile und Argentinien fehlte, beugten sich gerne der kühnen und visionären Entschlusskraft des Franzosen. Zunächst konnten die Mapuche ihren König vor der Hetzjagd beschützen, die die chilenische Regierung daraufhin in Gang setzte, um den unbequemen König von Araukanien gefangenzusetzen. Doch im Januar 1862 fiel er Cornelio Saavedra in die Hände. Er wurde zunächst in Los Ángeles gefangen gehalten, wo ihm der Prozess gemacht wurde; später wurde er nach Frankreich zurückgeschickt.

In europäischen Quellen wird der ,König auf eigene Faust` meist belächelt, als Verrückter oder als Machtbesessener dargestellt, der nur darauf aus war, sich mit einem Adelstitel zu schmücken. Für die Mapuche hingegen ist er ein Mann, der für seine Träume - und für die Träume der Araukanier - kämpfte; der Mut, Entschlossenheit und Begeisterungsfähigkeit zeigte und insbesondere nicht den Stereotypen und Vorurteilen der öffentlichen Meinung folgte.

La visión positiva sobre el mapuche, su cultura y sociedad por Orelie Antoine, rompia con los estereotipos creados por la sociedad opresora; estereotipos necesarios pues justificarían el genocidio que se preparaba contra nuestro pueblo, que luego les traería generosas recompensas. Había que deshacerse del „intruso“", después de todo no podía ser „,normal“ (se convencian así mismos), un „blanco“, reivindicando los derechos de los „salvajes“ de los „barbaros“, en la mente cuadrada de los criollos constituía absolutamente una „anormalidad“, una aberración, una „locura“. (Marhikewun 1988)

Die Erwähnung des Königs von Araukanien steht im Text zwischen utopisch anmutenden Visionen: zwischen dem Wunsch nach Freiheit von jeglicher Unterdrückung und dem Wunsch nach menschlicheren, wohnlicheren Städten, in denen sich weder die Füße noch der Geist des Menschen weiterhin verirren mögen. Damit bekommt auch die Episode mit Orelie Antoine eine positive Färbung, wenngleich mit dem Beigeschmack von Vergeblichkeit und unrealistischer Bemühung.

Im Abschnitt 5 desselben Gedichtes steht in der letzten Zeile der Begriff pacificadores in Anführungszeichen. Zum einen ist dies eine Kritik an der offiziellen Geschichtsschreibung, in der bis heute der Ausdruck der ,Befriedung' verwendet wird, um sich auf die Unterwerfung der Mapuche unter den chilenischen Staat zu beziehen. Chihuailaf hat diesen Sprachgebrauch mehrfach in Interviews kritisiert und als eine Form der alltäglichen und gedankenlosen Diskriminierung entlarvt. ${ }^{171}$

und der Süden (aus dem die hermanos ona stammen) repräsentiert das Göttliche und Gute.

${ }^{171}$ Siehe Zitat Kapitel 7.1, S162. 
Zum anderen bezieht sich Chihuailaf mit der Bezeichnung „pacificación de los Chilenos“ 172 oder in „volvieron los pacificadores“ (S15) auf die Diktatur. Mit diesem Sarkasmus erreicht er, dass Menschen, die den Begriff der pacificación im Zusammenhang mit der Unterwerfung Araukaniens bedenkenlos verwenden, sich der Ungeheuerlichkeit ihrer Diktion bewusst werden.

An dieser Stelle ist nicht eindeutig von einer der beiden pacificaciones die Rede. Da der Text Sueños nicht in einer bestimmten historischen Zeit verortet ist, sondern verschiedene geschichtliche Aspekte miteinander verbindet, ist es sehr wahrscheinlich, dass beide, wenn nicht alle Arten von pacificadores, von Unterdrückern und Diktatoren gemeint sind.

\subsection{Die blaue Geschichte}

Arauco Chihuailaf N. unterstreicht in seinem Aufsatz Poesía Mapuche die Tatsache, dass sich die Lyrik der Mapuche in besonderem Maße auf die Geschichte bezieht:

Quisiéramos subrayar aquí lo que nos parece una de las singularidades de la poesía mapuche: la referencia a la historia. Historia en un sentido amplio: vivencias, raíces culturales, la evocación de los antepasados, el papel de los héroes, la referencia a la historia reciente. Sin duda esto no es una casualidad. Basta con pensar que la historia desde la llegada del conquistador ha estado cargada de embates y combates.

Naturalmente, en la producción poética que nos ocupa la historia no tiene un sentido diacrónico, puesto que es presente, pasado y futuro a la vez. Es la memoria histórica, pero al mismo tiempo más que eso. Es reconocerse en una dimensión colectiva: los antepasados, las luchas centenarias, la casa común: la tierra. Es decir, en la poesía se reencuentran los abuelos de nuestros abuelos, los hijos de hoy y aquéllos que vendrán. (Chihuailaf N. 1998: La referencia a la historia)

Ebenso wie Elicura Chihuailaf legt auch Arauco Chihuailaf großen Wert darauf, dass die Geschichte eine besondere Rolle in der Dichtung seines Volkes spielt. Die identitätsstiftende Funktion der Geschichte steht bei beiden im Vordergrund. Wie an Elicura Chihuailafs Text deutlich wird, ist häufig ein klarer Kontrast zur „offiziellen“ Geschichtsschreibung beabsichtigt, der in der Ausführung unmissverständlich zutage tritt. In dieser Funktion ist zum einen die bewusste Vermischung von überindividueller Historie und individuellen - oder auch kollektiven - Träumen zu nennen. ${ }^{173}$ Dabei stellen Träume zwar eine Gegenwirklichkeit im Sinne des europäisch-modernen Verständnisses einer Trennung von Wirklichkeit und Traum dar („Lautraru, lonko: abre los ojos / y ¡deja de soñar!“, S15; oder

\footnotetext{
172 „Todas las masacres de los años veinte, la entrada del Estado chileno y, antes, la llamada eufemísticamente ,pacificación de la araucanía‘ están vivas en nuestra memoria. Imagínate las paradojas, cuando en 1973 se produce el golpe, yo digo la ,pacificación de los chilenos', como un elemento revelador de lo que fue la pacificación de la araucanía." (Chihuailaf in González Cangas 1999:77f.)

173 „La pluma de los poetas viene a recordarnos que el universo mapuche sigue allí: sus hombres y sus luchas, su memoria y sus sueños.“ (Chihuailaf N. 1998: La textualidad)
} 
„Pero los espíritus del mal irrumpen desde / la oscuridad / transformando en ceniza todos estos sueños“, S27). Gleichzeitig wird jedoch diese Trennung in Frage gestellt, wenn der Traum von Lautaro aus unserer Sicht kein Traum ist, sondern ein Blick in die zukünftige Wirklichkeit.

Chihuailaf lässt Vergangenheit und Gegenwart auch lexikalisch verschwimmen. Er verwendet den eindeutig belegte historische Begriffe im aktuellen Zusammenhang: „pacificación (de los Chilenos)“ (González Cangas 1999:78) oder „colonialismo nuevo“ (S36).

Es entspricht der Tradition der Mapuche, die Vergangenheit durch Zuhören, Verstehen und Träumen in sich aufzunehmen. ${ }^{174}$ Diese Wege zur Vergangenheit beschreitet auch Elicura Chihuailaf in seinen Texten. Seine Geschichte ist zum Singen, zum Zuhören, und bildet an vielen Stellen die Logik der Träume nach. Dabei verfolgt Chihuailaf ein klares Ziel: „EN EL PAÍS DE LA MEMORIA - libro blanco que toma conciencia de la historia y que quiere ser el primer grito de un pueblo al que no dejan nacer“" (S77).

Um die Notwendigkeit für diesen Schrei zu verdeutlichen, zitiert er in seinem Nachwort Pablo Neruda: „La Araucana está bien, huele bien. Los araucanos están mal, huelen mal. Huelen a raza vencida. Y los usurpadores están ansiosos de olvidar o de olvidarse.“" ${ }^{\text {175 }}$ (S77) Die Besetzer, von deren schlechtem Gedächtnis hier die Rede ist, sind nicht die Spanier vergangener Zeiten, sondern seine chilenischen Zeitgenossen, die vergessen wollen, dass die Mapuche - biologisch und kulturell - ihre eigenen Vorfahren und vor allem die rechtmäßigen Besitzer eines Großteils „,ihres“ Landes sind. Was zwar Neruda nicht mehr erlebt hat, Chihuailaf aber sicher ebenfalls meint, wenn er Neruda zitiert, sind die Verbrechen, die von Chilenen an Mapuche während der Militärdiktatur verübt wurden und an die sich niemand erinnern will.

Im letzten Abschnitt seines Nachwortes spricht sich Chihuailaf noch einmal ausdrücklich für den Gebrauch der Schrift als Werkzeug für die Tradierung von Kultur und Geschichte der Mapuche aus:

Nacimos mapuche, moriremos siéndolo y la escritura, hermanos, es una de las más grandes maneras de dignificarnos, de guardar y recuperar (aunque para otros tantos todavía resulte extraño) para y por nosotros mismos el alma de nuestro pueblo. (S77)

${ }^{174}$ „Escuchar y comprender el lenguaje del alma, el lenguaje del corazón, es la metáfora del silencio; ahí, y en el soñar, nos están mirando las raíces azules de nuestros antepasados.“ (Valente 1989:1)

${ }^{175}$ Es ist mir nicht gelungen, die Herkunft des Zitates zu ermitteln. 
In diesem Sinne versteht Chihuailaf sein eigenes Buch als Teil dieser Arbeit. Er möchte mit seinen Texten sein eigenes Volk und dessen Geschichte in die Erinnerung rufeninsbesondere in die Erinnerung der Sieger - und schreibt auf diese Weise Geschichte. 


\title{
8. TOMÁS HARRIS: CIPANGO
}

Der Autor Tomás Harris (*1956) sprengt in gewisser Hinsicht den Rahmen, den ich für diese Arbeit abgesteckt habe. Er ist weder im Süden Chiles geboren noch aufgewachsen, sondern ist ein zugezogener sureño. Harris stammt aus La Serena, im sogenannten ,Kleinen Norden`Chiles, ca. $500 \mathrm{~km}$ nördlich von Santiago. „Una ciudad colonial, gris y llena de campanarios“, erinnert er sich. 1969 zog er nach Concepción, der zweitgrößten Stadt Chiles, wo er Spanisch für das Lehramt studierte. Man kann sicherlich die Frage stellen, ob seine Dichtung als repräsentativ für Südchile angenommen werden kann, da seine Verbundenheit zur Region biographisch eine andere ist als die der bisher untersuchten Autoren. Andererseits hat Harris 21 Jahre in Concepción gelebt, ${ }^{176}$ so dass man von einer bewussten Entscheidung für die Wahl-Heimat sprechen kann. Die Stadt in der achten Region Chiles inspirierte ihn zu den meisten seiner Texte:

Concepción es una ciudad pequeña, con un millón de habitantes, a la que considero una verdadera metáfora de la ciudad latinoamericana. Donde la lluvia es una presencia constante, que al mojar la calle duplica las cosas y convierte todo en reflejos, haciéndote creer que tienes dobles. (Guerrero 1995)

\subsection{Der Chronist von Concepción}

\author{
la mente se nos ha cansado, \\ emblanquecida, \\ los recuerdos se nos desvanecen, \\ es necesario anotarlo todo- \\ Tomás Hamis
}

In seinem Gedichtband Cipango fasst Tomás Harris die drei schon früher erschienenen Gedichtzyklen Zonas de peligro, Diario de navegación und El último viaje zusammen, fügt ihnen die beiden Teile La forma de los muros sowie Cipango hinzu und benennt das Buch nach dem letztgenannten Abschnitt. Diario de navegación, El último viaje und Cipango waren bereits von Beginn an als Trilogie konzipiert, aber auch die Ergänzung um zwei weitere Teile zu dem vorliegenden über 200 Seiten umfassenden Zyklus ist inhaltlich motiviert und lässt ein organisches Text-Ganzes entstehen. Die Bilder, Themen und Motive wiederholen sich und bilden ein semantisches Netz, das das Buch vom ersten bis zum letzten Text durchzieht und konstituiert. Die Art und Weise, wie die einzelnen Motive sich zueinander und zu

\footnotetext{
176 Seit 1990 lebt Harris in Santiago.
} 
ihrem jeweiligen historischen Kontext verhalten, soll in diesem Kapitel untersucht werden. Es erschließt sich recht schnell, dass die dominanten Motive im Wesentlichen auf zwei verschiedenen Ebenen begegnen, die sich als in Raum und Zeit unterschiedliche Szenarien darstellen. Zum einen handelt es sich um die Milieuschilderung einer Straße namens Orompello. Orompello ist eine reale Straße in Concepción, und wir bekommen sie aus der Perspektive eines Erzählers aus den 80er Jahren des 20. Jahrhunderts gezeigt - aus der Gegenwart des Autors also. Zum anderen blickt der Text 500 Jahre zurück in die Karibik: Zeit und Ort der Entdeckung Amerikas durch Cristóbal Colón. Die Verteilung des Geschehens auf zwei zeitliche Ebenen ist prinzipiell ein ähnliches Verfahren wie das in den Texten von Riveros oder Muñoz, die ebenfalls durch die Vergangenheit auf die Gegenwart deuten - oder über die Gegenwart auf die Vergangenheit. Bei Harris verstricken sich die Ebenen jedoch auf eine sehr viel komplexere Weise, wie zu zeigen sein wird.

In den ersten beiden Teilen überwiegt zunächst die erstgenannte Kulisse. Die Straße Orompello, wie Harris sie beschreibt, wird nachts lebendig, hier findet man Bars und Prostituierte, ein bisschen Glamour und viel Elend. Als Synonym für das Nachtleben der Stadt ist Orompello in fast jedem einzelnen Gedicht des Zyklus' präsent. Heute befinden sich in Orompello noch ein paar Kneipen, ansonsten ist vom früheren Straßenbild nicht mehr viel vorhanden. Harris nennt sowohl die Straße als auch die Stadt häufig beim Namen und beschreibt das Leben in Orompello, wie er es in den 80er Jahren gesehen und erlebt hat. Die Straße fand bereits vor Harris eine recht prominente Erwähnung in der chilenischen Dichtung. Gonzalo Rojas veröffentlichte 1964 in Contra la muerte ein Gedicht, benannt nach der Straße, in der er aufwuchs: „Volví / a los peñascos sucios de Orompello en castigo, después de haberle dado / toda la vuelta al mundo.“177 (Rojas 1993:30)

Hilda May erklärt in ihrer Untersuchung über die Dichtung Rojas’:

¿Qué es Orompello? Apenas el nombre de una calle de Concepción que a su vez recuerda otro nombre: el de una heroína registrada en La Araucana de Ercilla. Calle residencial y apacible hasta un límite, y más allá de él noctámbula y lujuriosa desde los primeros tiempos de la metrópolis. (May 1991:59)

Harris beschreibt die Straße ebenso wie die ganze Stadt mit einer erbarmungslosen und schamlosen Direktheit. Schmutz, Einsamkeit und fehlende Kommunikation beherrschen die Szenen, ebenso wie die auffällige Körper-Metaphorik. Meistens ist es eine sexuelle Körperlichkeit, die sich im Rotlichtbezirk Orompello abspielt. So ermöglicht Harris dem Leser und der Leserin zB voyeuristische Blicke in die Zimmer der Stundenhotels. An

${ }^{177}$ Der Text handelt in trostlosen Bildern von der unmöglichen Rückkehr zu einem Ort der Kindheit. 
anderen Stellen ist - manchmal konkret, manchmal metaphorisch - die Rede von körpereigenen Substanzen wie Blut oder Sperma. Auch die Stadt selbst wird als ein lebendiger Körper dargestellt („había ciudades hechas de carne / había ciudades enteras orgánicas latientes“, S67; „dejó atrás las últimas mediaguas como hematomas en el barro“, S160).

Für Harris ist Orompello der Ort, an dem die Stadt kulminiert, der die Stadt für ihn auszumachen scheint, der metonymisch für Concepción steht („Orompello es un puro símbolo echado sobre la / ciudad“, S34). Concepción wiederum steht bei Harris stellvertretend für die „Städte des Südens“ („Estas ciudades del Sur...“, S72), wobei ,Süden“ keine ausschließlich geographische Angabe ist. „El prefijo ,sud“ precede a la determinación espacial. Se está ,aquí, o más bien ,aquí abajo،““ (Giordano 1994:887) So zählen zu Harris’ „ciudades del Sur“ auch eine Reihe anderer Städte. Die Großstädte, die Harris beschreibt, ähneln sich, wenn sich der Erzähler auch zugleich in Theben, in New York oder in Algier zu befinden scheint oder Concepción, Cipango` oder ,Cathay' nennt:

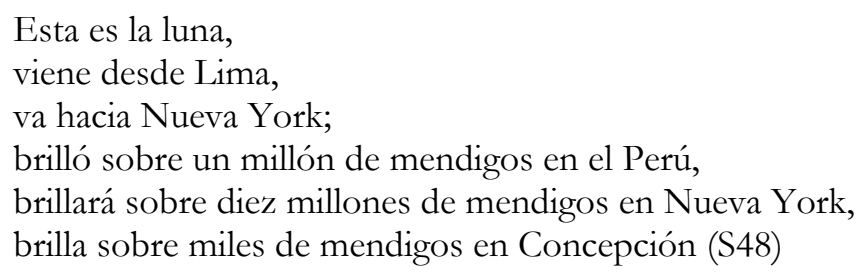

Zum Teil tauscht Harris die Namen verschiedener Städte gegeneinander aus, als handele es sich nur um eine einzige Stadt, eine Art Urbild der Stadt, deren Name keine Rolle spielt; zum Teil überbieten sich die Städte mit dem, was sie als „ciudad del sur“ ausmacht wie in der zitierten Klimax mit ihrer Armut. Orompello, die „ciudades del sur“ und die historische Gegenwart Harris' sind aber nicht nur Kulisse für Not und Elend in der modernen Stadt, sondern auch für Gewalt und Repression der Diktatur.

Das zweite dominante Thema tritt hauptsächlich in den als Trilogie geplanten Teilen Diario de navegación, El último viaje und Cipango in Erscheinung. Schon die Titel beziehen sich auf die vier Fahrten des Cristóbal Colón nach Amerika, und entsprechend werden die Entdeckungs-Reisen in den Texten immer wieder aufgegriffen. Dabei wird wörtlich aus dem Bordbuch des Colón zitiert, ${ }^{178}$ an anderen Stellen handelt es sich um Anspielungen oder Motive wie die Suche nach Gold oder das Aufeinandertreffen zweier Kulturen, in denen die historische Dimension des Textes Ausdruck findet.

Die Verbindung von historischen Quellen mit ausführlichen Milieuschilderungen trug Harris von Seiten der chilenische Literaturwissenschaftlerin Soledad Bianchi die Bezeichnung „cronista urbano de Concepción“ ein. (Bianchi 1990c:1) Im Werk des Chronisten 
Harris finden sich allerdings keine Daten, keine Übersicht von Namen und Ereignissen, nicht einmal die chronologische Anordnung einer Erzählung. Vielmehr sind es düstere Visionen, die sich rhythmisch wiederholen, alptraumhafte Bilder, die eine Endzeitstimmung evozieren.

Wie schon erwähnt, werden die beiden historischen Kontexte, die die Szenarien des Buches bilden, durch die parallele Motivik miteinander verbunden. Die Bilder verschränken sich miteinander, verschmelzen, werden aus den Zusammenhängen gelöst und $\mathrm{zu}$ anderen, häufig sich wiederholenden Bildkomplexen und Symbolen neu zusammengesetzt. Durch die zwei Settings ${ }^{179}$, die denkbar unterschiedlich sind, sich aber in weiten Teilen in ihrer Darstellung überlagern, entsteht der Eindruck zweier Parallel-Welten, die zwar jeweils eine eigene Einheit bilden, aber an vielen Stellen nur durch eine so dünne Wand voneinander getrennt sind, dass beide ineinander übergehen. Der Erzähler kann in beide Welten hineinsehen und wechselt den Schauplatz ohne Ankündigung bisweilen mitten im Satz. Durch dieses Überblenden scheinen kausale Zusammenhänge zwischen den beiden Parallel-Welten zu entstehen, und je weiter die Erzählung fortschreitet, umso enger verbinden sich beide miteinander. ${ }^{180}$

Insgesamt möchte ich fünf Motive oder Themen hervorheben, deren Dominanz auf beiden Bedeutungsebenen im Text mit Hilfe der Analysen zu zeigen sein wird: Flucht in die Fiktion, repressive Machtausübung, Suche nach Gold/Glück, visuelle Wahrnehmung und unterdrückte Sexualität.

In Analysen einzelner Textabschnitte soll die Komplexität des Gesamtextes mit seinen Bezügen und Querverweisen aufgezeigt werden; ein Verfahren, das zugleich Aufschluss gibt über Harris' Umgang mit den dargestellten geschichtlichen Ereignissen - insbesondere mit der Gegenwart der Diktatur auf der einen und und der Entdeckung Amerikas ${ }^{181}$ auf der anderen Seite.

${ }^{178}$ Es ist nur noch das Diario de a bordo der ersten Reise erhalten. Außerdem gibt es Briefe, in denen Colón seine Reisen schildert. (Colón 1982)

${ }^{179}$ Der Begriff des setting weist bereits auf den Komplex der Film- und Theatermetaphorik voraus, der in Kapitel 4.5 herausgearbeitet wird.

${ }_{180}$ Wenn ich im Folgenden die Formulierung Parallel-Welt oder Parallel-Text verwende, beziehe ich mich auf dieses Phänomen.

181 Der Begriff der ,Entdeckung' ist zurecht wegen der ihm innewohnenden eurozentrischen Perspektive umstritten, soll hier aber verdeutlichen, dass es sich - basierend auf dem Diario de a bordo - um die eurozentrische Sicht von Colón handelt. 


\subsection{Cipango}

Als Ausgangspunkt der Analysen werde ich jeweils Texte aus den Abschnitten Diario de navegación, El último viaje und Cipango aus dem Gedichtband Cipango untersuchen. ${ }^{182} \mathrm{Um}$ aber die Texte und ihre Verortung innerhalb des Gesamttextes verstehen zu können, ziehe ich in einem weiteren Schritt auch die ersten beiden Abschnitte hinzu. In den drei als Trilogie konzipierten Teilen des Buches spielt der geschichtliche Stoff eine größere Rolle, tritt offener zutage und ist schon durch die Titel programmatisch. Diario de Navegación spielt auf das Bordbuch der ersten Reise des Colón an, das der Dominikaner Bartolomé de las Casas unter dem Titel Diario de a bordo veröffentlichte. ${ }^{183}$ Colón hat das Bordbuch hauptsächlich für das spanische Königshaus verfasst. Es sollte Zeugnis darüber ablegen, wie gut seine Geldgeber in ihn und in sein Unterfangen investiert hatten. Seine Reise sollte als lohnendes Geschäft für Spanien aus seinen Aufzeichnungen hervorgehen und ihm somit für weitere Fahrten den Weg ebnen. Deshalb werden die entdeckten Landstriche von Colón in erster Linie als reich an Bodenschätzen (insbesondere Goldvorkommen), an Gewürzen und edlen Hölzern beschrieben und ihre Einwohner als friedliebend, unterwürfig und geradezu begierig darauf, missioniert zu werden. Gilberto Triviños äußert sich folgendermaßen über Sinn und Zweck der Schriften des Colón: „....mostrar a los Reyes que su emisor ha encontrado las tierras y los hombres mejores del mundo para ser conquistados y colonizados“. Besonders die Beschreibung der ersten Reise arbeitet seiner Meinung nach mit der Rhetorik der alaban₹a. (Triviños 1985:59f.)

Aus heutiger Sicht sind insbesondere die Irrtümer und Fehlinterpretationen des Colón aufschlussreich, da sie als paradigmatisch für die Wahrnehmung des Fremden und für die Asymmetrie in der Darstellung der „Begegnung“ zweier Kulturen gelten können. ${ }^{184}$

El último viaje muss ebenfalls auf die Reisen des Colón bezogen werden, gleichzeitig ist es

\footnotetext{
${ }_{182}$ Im Folgenden werde ich die drei Teile kurz Diario, Viaje und Cipango nennen.

${ }^{183}$ Nachdem Colón von seiner ersten Reise zurückkehrte, lieferte er sein Bordbuch bei Hofe ab, bat jedoch um Rückgabe des Originals nach Abschrift. Diese Abschrift ging unter Geheimhaltung vor sich, die Arbeit wurde auf zwei Schreiber aus verschiedenen Regionen Spaniens verteilt, damit niemand den gesamten Text zu Gesicht bekäme. Sechzig Jahre später befanden sich Original sowie Abschrift der ersten wie auch der folgenden Reisen wieder in den Händen der Nachfahren Colóns, die jedoch kein Interesse daran hatten, die Zeugnisse zu veröffentlichen. Anders Bartolomé de las Casas, der enge Beziehungen zu den Nachkommen Colóns pflegte und zwischen 1544 und 1552 häufig Zugang zum Familienarchiv mit Colóns Schriften hatte. Die Spur der Aufzeichnung verliert sich. Erst 1786 fanden sich Abschriften der ersten und der dritten Reise, angefertigt von Fray Bartolomé de las Casas. Jedoch weiß man bis heute nicht, wie originalgetreu dieser Text ist, da Las Casas Veränderungen vornahm. Neben den scheinbar originalen Abschnitten, in denen Colón in der 1. Person berichtet, gibt es viele Stellen, an denen Las Casas die Ereignisse kommentiert. Hier lesen wir von Colón in der 3. Person. (Strepponi 1998)

${ }^{184}$ Mit diesem Thema beschäftigen sich Todorov 1982 und Greenblatt 1991.
} 
eine Metapher für den Tod und den Verfall, der die Bilder und Stimmung der Texte dieses Abschnittes beherrscht. Cipango schließlich ist der mittelalterliche Name für Japan, bzw. für eine japanische Insel ${ }^{185}$ und bezeichnet hier das Land, in dem Colón angelandet zu sein glaubte. Der Titel steht somit für einen gewaltigen Irrtum, dessen Richtigstellung Colón nicht mehr erleben sollte. Andererseits ist es der Name des Traumes, der ihm überhaupt erst die Kraft gab, seine Reise anzugehen. Als solcher steht er für Hoffnungen und Wünsche als die Triebfedern für das historische Unternehmen der Entdeckung Amerikas. Als Name eines fernen Landes, das außer Marco Polo noch kein Europäer zu Gesicht bekommen hatte oder von dem zumindest kein anderer bisher wiedergekehrt war, hatte schon der Klang Cipango visionäre Kraft. Und Colón scheint im Bann dieser Kraft zu stehen:

creo que [...] es la isla de Çipango de que se cuentan cosas maravillosas. (Colón 1982:44) [...] por las señas que los indios le daban de la grandeza y del oro y perlas d'ella pensaba que era ella, conviene a saber: Çipango (Colón 1982:45)

[...] entre los lugares que nombravan donde se cogía el oro, dixeron de Çipango, al cual ellos llaman Çibao, y allí affirman que ay gran cantidad de oro [...] (Colón 1982:95)

[...] concluye que Çipango estaba en aquella isla y que ay mucho oro y espeçería y almáçiga y ruibarbo (Colón 1982:107)

Esta isla es Tharsis, es Cethia, es Ophir y Ophaz e Çipanga, y nos le havemos llamado Española. (Colón 1982:286)

„Entramos en las urbes del Sur“ (S67) beginnt das erste Gedicht von Diario. Die Zeile verbindet bereits das Thema der Stadt aus den ersten beiden Teilen mit dem Motiv des Eindringens, Entdeckens und Eroberns, das von nun an im Text dominant sein wird. Die Städte des Südens werden betreten und im Folgenden beschrieben. Dabei ist die Erzählperspektive meistens die desjenigen, der unbekannte Orte betritt, der staunt, sie aus seiner Sicht beschreibt, sie besetzt, in Besitz nimmt, schändet und zerstört. In Diario und in vielen Texten von Viaje ist der Erzähler einer von Colóns Leuten, der seinen Admiral direkt anspricht („Almirante"), in Viaje spricht in einigen Texten die Figur des Colón selbst, zu erkennen an der Anrede „Vuesas Altezas“, mit der sich auch der historische Colón im Bordbuch an seine ihm wichtigsten Leser, nämlich an den König und die Königin von Spanien, wendet.

Bereits vom ersten Text an ist die Suche nach Gold ein immer wiederkehrendes Thema, das nur leicht abgewandelt auch in der Kulisse von Orompello zentral ist. Die Suche nach Gold ist hier die Suche nach Geld, Glück und Liebe (S151: „pero oro no había, [...] pero amor no había“). Dem Betrug mit nur vorgegebenen oder erhofften Goldvorkommen,

${ }_{185}$ Marco Polo erzählt in seinen sagenhaften Reiseberichten von einer Insel namens Cipango, Toscanelli hat diese Berichte aufgegriffen, Berechnungen angestellt und schließlich Karten nach 
bzw. mit Glasperlen als billiger Tauschware entspricht in Orompello das Vorgaukeln von Reichtum, falschem Gold, falschem Glanz, falschen Gefühlen, Flitter, Tand und Künstlichkeit. 186

In Diario und Viaje sind von insgesamt 57 Gedichttiteln 43 reale oder fiktive geographische Angaben. Die Namen sind meistens zweiteilig: Sie bestehen aus einer topographischen Bezeichnung, in den meisten Fällen Mar, und aus einem Genitivattribut, das der Landschaft Gefühle oder emotional besetzte Symbole zuordnet (zB „,de los besos rojos“, „, del dolorido sentir“, „de la ceniza“) und mit dem die Landschaft metaphorischen Charakter bekommt. Harris navigiert vom Meer der Verzweiflung durch die Meere der Spiegelungen, der Schuld und der Notwendigkeit ins Meer der roten Küsse, um nur einige wenige zu nennen. Darüber hinaus begegnen die Namen von Städten, Inseln, einer Meeresenge, eines Sees, einer Bucht und zweier Nachtclubs (Cotton Club, Boite Tropicana). An den Titeln wird eine der Verfahrensweisen deutlich, mit deren Hilfe Harris verschiedene Ebenen in seinen Texten miteinander verbindet. Auf dem Hintergrund der Entdeckungs-Fahrt des Colón wird durch die geographischen Bezeichnungen der Eindruck einer Route mit einzelnen Stationen erweckt, die sich in der Tat aus sehr viel Meer, einigen Inseln und der Suche nach Städten zusammensetzte.

Weiterhin sind die Namen als Anspielung auf die zentrale Rolle zu verstehen, die die Namensgebung und Taufe der vorgefundenen Topographien auf den Reisen des Colón (und letztlich im gesamten Kontext der ersten Phase der Conquista) spielte. Ob die Landstriche und Inseln, an denen er anlandete, bereits Namen hatten oder nicht, war bedeutungslos; alles wurde neu benannt, oft mit einem Hinweis im Bordbuch darauf, wie der betreffende Ort ursprünglich geheißen habe. Meist gereichten die Namen dem spanischen Königshaus zu Ehren oder entsprangen dem religiösen Kontext. Zusammen mit dem Aufstellen eines Kreuzes handelte es sich bei der Benennung um einen rituellen Akt der Inbesitzname, um eine symbolische Aneignung. ${ }^{187}$

Die letzten Texte von Viaje greifen Details aus dem Leben des Colón auf und skizzieren den Seefahrer, der desillusioniert auf ein Leben voller Täuschungen, Lügen und Irrtümer zurückblickt.

Marco Polos Vorgaben angefertigt. Auf diese Land- und Seekarten gründete sich Colóns Plan, den fernen Osten über die Westroute zu erreichen.

186 Auffällig ist, dass das Gold buchstäblich in Orompello zu finden ist.

${ }^{187}$ Siehe dazu Todorov: “Comme Adam au milieu de l'Eden, Colon se passionne pour le choix des noms du monde vierge qu'il a sous les yeux. [...] Colon sait donc parfaitement que ces îles ont déjà des noms, naturels en quelque sorte [...] la nomination, de plus, équivaut à une prise de possession.“ (Todorov 1982:33f.) 
Der abschließende Teil schließlich, Cipango, enthält kaum mehr Anspielungen auf Colón. Nach seinen ernüchternden Erkenntnissen, der Zerstörung seiner Hoffnungen und den Bildern von Tod und Ende beginnt hier ein neuer Traum, eine neue Hoffnung, bis hin zum letzten Text, der Poiesis de la vida mejor.

Die drei Teile erinnern an die Vorstellung einer zyklischen Zeit. (Barthold 1981) Dieses mythische oder religiöse Konzept legt der Abfolge der Zeit oder der Geschichte ein Schema zugrunde, das sich als Dreisprung ausdrücken lässt: Entdeckung - Verfall Neubeginn/Utopie (auch: Geburt - Tod - Wiedergeburt oder Paradies - Sünde Erlösung). Während das Diario die Entdeckung darstellt und (wenn auch meist in pervertierter Form) auf die Vorstellung eines Paradieses oder eines goldenen Zeitalters anspielt, sind die Schwerpunkte der Viaje Tod und Verfall. In Cipango kündigt sich ein möglicher Neubeginn an, utopische Ideen gewinnen an Bedeutung. Die Topoi werden angedeutet, zum Teil parodiert oder in Frage gestellt, bleiben aber als strukturgebende Elemente der geplanten Trilogie zu erkennen.

Trotz der motivischen Homogenität und dem inhaltlichen Zusammenhang der drei Teile ist die Erzählperspektive keineswegs einheitlich. Klar erkennbar sind die Stimmen Colóns (als yo, das seine Worte an Vuesas Altezas richtet) und seiner Leute (nosotros, die über ihre Erlebnisse berichten und den Almirante ansprechen). Im Concepción der 80er Jahre gibt es ein weiteres yo sowie ein nosotros, das als kollektive Stimme verstanden werden kann. ${ }^{188}$ Andere Stimmen können nicht klar zugeordnet werden, überdies wechseln Zeit, Ort und Perspektive abrupt und häufig.

Harris erzählt in seinem Buch die Geschichte der Entdeckung und Eroberung Amerikas. Er erzählt von der Figur des Colón, sowohl von der historischen als auch von der fiktiven. Schließlich erzählt er von der Gegenwart der Repression in der Diktatur. ${ }^{189}$ Für alle Erzählungen bildet die Stadt Concepción die Kulisse.

\footnotetext{
188 Jaime Giordano in seiner Interpretation des Textes La calle última: „No es un ,nosotros‘ retórico. Se habla, no desde la singularidad del hablante, sino de su condición colectiva." (Giordano 1994:886)

189 Ich verwende den Begriff des ,Erzählens', weil zum einen die Länge des Zyklus' und die dadurch bedingt - wenig lyrisch anmutende, fast epische Ausführlichkeit, mit der einzelne Begebenheiten oder Bilder immer wieder thematisiert werden, dazu einlädt. Zum anderen sind für eine angemessene Analyse, insbesondere der Erzählsituationen und der Perspektiven, Begriffe aus der Erzählanalyse unerlässlich. Ich werde im Folgenden für die entsprechenden Betrachtungen die Terminologie von Stanzel 1989 verwenden.
} 


\subsection{Das Bordbuch}

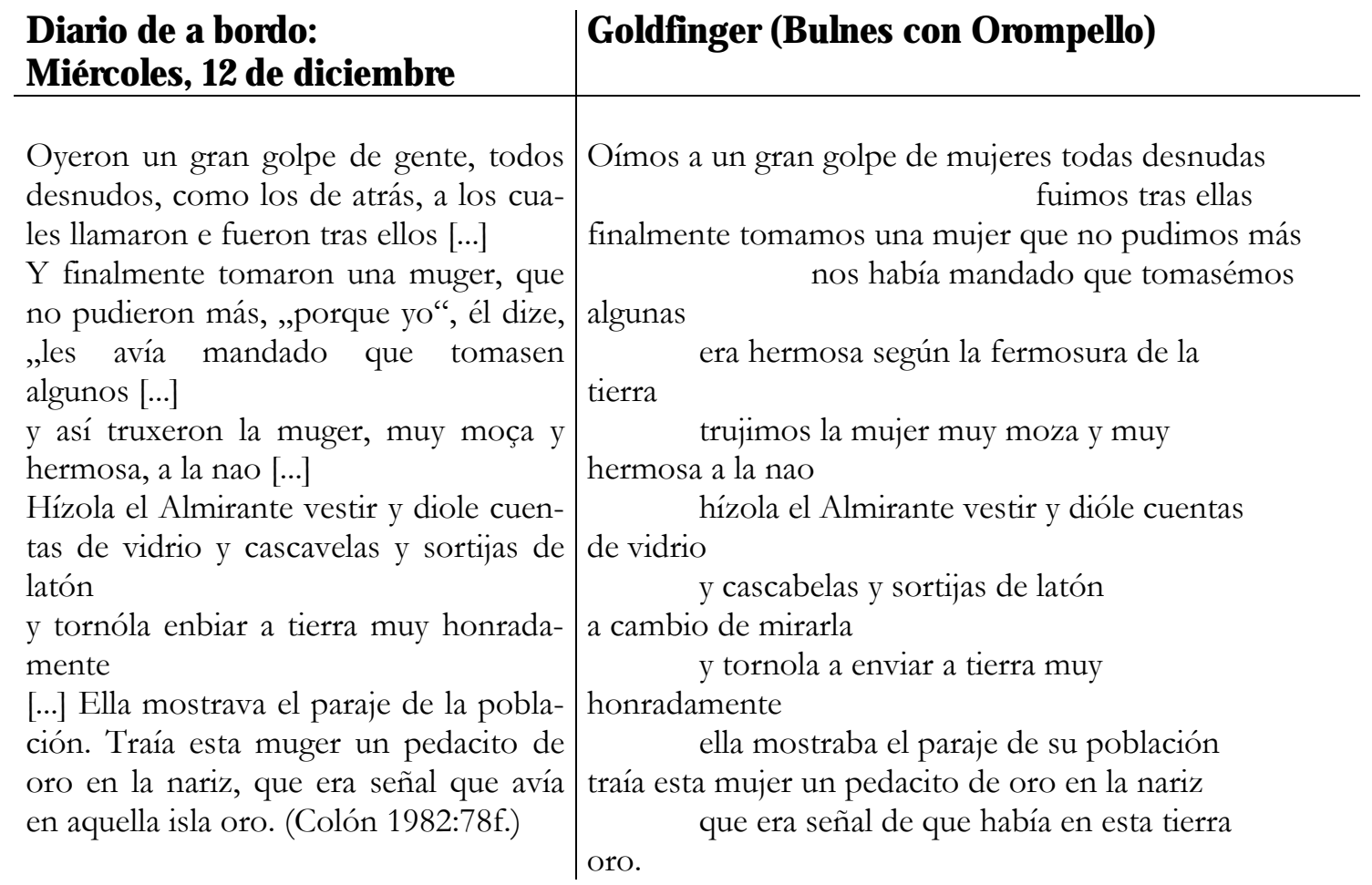

Ich beginne die Analysen mit einem Text, der zunächst sehr offensichtlich den historischen Kontext der Conquista evoziert. Er zitiert fast wörtlich einen Ausschnitt aus Colóns Eintragung vom 12. Dezember 1492 in sein Bordbuch. Aus dem fortlaufenden historischen Text sind freie Verse geworden, die als Lang- und Kurzverse angeordnet sind; die Rechtschreibung wurde nur zum Teil angepasst. Auch inhaltlich hat Harris einige Änderungen vorgenommen. Drei Passagen wurden ausgelassen (in der Gegenüberstellung erkenntlich an den Auslassungsklammern im Originaltext). An dreien dieser Stellen ist von „indios“ die Rede. Durch Streichen dieser Passagen wird der Text allgemeiner, es muss sich nicht mehr um Indios handeln, über die hier verfügt wird.

Eine andere Modifikation des Textes liegt in der Perspektivverschiebung. Aus der unpersönlichen Episode, in der alle Beteiligten in der dritten Person erscheinen, (also einer auktorialen Erzählsituation) wird eine Geschichte, die Spanier aus ihrer Sicht berichten (eine personale Erzählsituation). Weiterhin wird sehr viel stärker hervorgehoben, dass es sich bei der Gefangenen um eine Frau handelt. Die Männer des Colón machen in Harris’ Text ausdrücklich Jagd auf Frauen. Die Schönheit derjenigen, die sie dann aufgreifen, wird ausführlicher beschrieben als im Ursprungstext und mit der Erde verglichen. Schließlich wird aus den freigebigen Geschenken des Almirante ein Tauschhandel: Er bezahlt die Frau dafür, dass er sie betrachten darf. 
Zunächst erscheint der lyrische Text als ein rein historischer (unabhängig von der Frage, ob die dargestellten Ereignisse authentisch oder fiktiv sind). Eine Gruppe nackter Frauen, der Befehl, einige davon zu fangen, die Erwähnung des Almirante, die Geschenke, die er der Gefangenen macht und die vermeintlichen Hinweise auf Goldvorkommen situieren die Episode auf inhaltlicher Ebene ebenso in der Vergangenheit wie die Sprache und die Orthographie dies auf der formalen Ebene tun. Auch ohne die Kenntnis vom Reisetagebuch des Colón zu haben, würde man die Szene vermutlich als historisch einordnen.

Erst mit Rücksicht auf den Kontext des gesamten Zyklus' lassen sich Entsprechungen zur modernen Parallel-Welt aufzeigen. Sowohl Entsprechungen, die auch im Originaltext von Las Casas zu finden sind, - billiger Flitter, glitzernde Pfennigware, die einen Wert vortäuschen soll, den sie nicht besitzt - als auch Parallelen, die Harris erst durch die Manipulation des Textes erreicht. Wenn Colón nämlich die Frau dafür bezahlt, dass er sie ansehen darf, hat er ein Szenario auf dem Schiff geschaffen, das in der Umgebung von Orompello etwa als ,Peep-Show` bezeichnet werden könnte. ${ }^{190}$

Die Parallelisierung der beiden Figuren der india und der puta begegnet häufiger im Text.191 Durch die analoge Verwendung beider Figuren und die Engführung der Szenen, in denen sie auftreten, scheint die Stelle nahelegen zu wollen, dass Colón und seine Leute die indias durch ihr Verhalten, durch Gewalt und durch Geschenke zu Prostituierten gemacht haben - zu Prostituierten, wie sie 500 Jahre später in Orompello arbeiten.

Der Titel besteht aus dem Filmtitel Goldfinger und der Ortsangabe ,Orompello Ecke Bulnes‘. Im Agenten-Film Goldfinger versucht der Gegenspieler von James Bond, ein weltweites Gold-Monopol aufzubauen, indem er soviel Gold wie möglich in seinen Besitz bringen und das übrige zerstören will. Als eine seiner schönen, jungen Gespielinnen seine Machenschaften aufzudecken droht, bringt er sie um, indem er sie nackt vergolden lässt, also mit einer dünnen Schicht Gold überzieht. Die nackte Frau aus dem Gedicht wird angezogen und mit Flitter beschenkt, um ihr und ihrer Leute Vertrauen zu gewinnen und letzendlich, um sich das Gold anzueignen, auf das ihr Nasenschmuck hindeutet. Goldfinger wird in der Überschrift an einer Ecke der Straße Orompello situiert. Möglicherweise handelt es sich um eine Kneipe, die nach dem Film benannt wurde. Es ist auch denkbar, dass die Ortsangabe verdeutlichen soll, dass etwas der Handlung im Film

\footnotetext{
${ }^{190}$ Ich möchte auf den Gedichtband Escenas de peep-show von Federico Schopf hinweisen, der in der Eindringlichkeit und Schamlosigkeit seiner Bilder an Harris' Orompello erinnert.

${ }^{191}$ S111: „las indias y las putas nos lavaban las heridas abiertas / en el alma“", S127:“y las indias y las putas / les orlamos el pecho y el cuello de cuentas / verdes“ oder S157: „chiquillos colgados de las
} 
Vergleichbares an jeder beliebigen Ecke Concepcións geschehen kann. Dafür spricht die folgende Deutung des Textes.

Der Gedichttitel mit seiner exponierten Stellung ist das Gegengewicht zum historischen Inhalt, aber der Titel Goldfinger bildet nicht nur die Brücke zur Populärkultur der 60er Jahre, sondern auch zur politischen Situation Chiles der 80er Jahre, indem er auf einen der ersten Texte des Buches, Orompello III, verweist, in dem schon einmal auf den Film angespielt wurde:

Como todo transcurría en Orompello estábamos protegidos

por la ficción; como en Goldfinger la habían pintado

de dorado, toda entera.

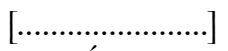

FERÓZ ACTO DE SODOMÍA - dirá en los diariospero juro que toda ella estaba dorada,

a brocha gorda (S37)

Dieser Text ist in der Gegenwart des Erzählers situiert, in den Zonas de peligro, wie der erste Abschnitt überschrieben ist. Die Fiktion soll die Menschen vor Gefahren beschützen, so wie die verschiedenen Versionen desselben Geschehens vor der Wahrheit schützen sollen: der Zeitungsbericht über ein Sexualdelikt oder die Geschichte über eine vergoldete Frau. Wir erfahren nicht, was tatsächlich mit der Frau geschehen ist, nur dass sie auf den unbebauten Halden im Südosten der Stadt gefunden wurde, a la hora de la amenaza, zur Stunde der Bedrohung. Besonders diese letzte Zeile des Textes evoziert eine allgemeinere Bedrohung als die durch einen Sexualstraftäter. Im Zusammenhang mit der falschen Berichterstattung der Zeitungen lässt die beschriebene Atmosphäre an die Zustände während der Diktatur denken, an einen politischen Mord und seine Vertuschung durch die Medien.

Der Filmtitel hat in Orompello III die Funktion, die Flucht in die Fiktion - oder die Lüge als Rettung vor der Wirklichkeit einzuführen. Im Text Goldfinger wird diese Bedeutungsebene wieder aufgegriffen, zusätzlich wird aber das Motiv des Goldes dominant gesetzt, indem der Titel in den Kontext der geradezu besessenen Suche Colóns nach Gold gesetzt wird.

Im Text Cipango (Poe) (S104) ist noch einmal von Goldfinger die Rede: „oro no había, /decían que esta era la tierra del Can, / de Goldfinger“. Hier wird die fiktive Figur mit dem sagenhaften Herrscher von Cipango, dem Khan, verglichen. Es verbinden sich das Motiv des (erhofften) Goldes mit dem der Macht, das im Folgenden im Mittelpunkt stehen wird. 
Eine andere ebenfalls fast wörtliche Übernahme aus dem Bordbuch führt ein weiteres wichtiges Motiv ein: I have the power (S93) beschreibt, wie Colón und seine Leute mit den Menschen umgehen, die sie antreffen, wie sie ihre Macht über sie ausüben und über sie verfügen. ${ }^{192}$

Auch an anderen Stellen ist von Macht, also von poder die Rede: „los ojos refulgían desde algún centro de Poder“ (S105), „[...] las interdicciones del Poder absoluto“ (S107), „rumiando para nosotros solos todo el Poder deste / mundo virgen“ (S109). Auffällig ist die konsequente Großschreibung des Wortes, die dem Motiv umso mehr Gewicht verleiht. Die erstgenannte Stelle ist eben dieselbe, an der Goldfinger mit dem Khan gleichgesetzt wird. Goldfinger erscheint als geheimnisvoller Tyrann, der die Menschen - zusammengetrieben wie Vieh - unterdrückt (S106). Die „Verbote der absoluten Macht“ im Text Tebas beziehen sich darauf, dass in der griechischen Mythologie der König Kreon bei Todesstrafe verboten hatte, den Leichnam des Polyneikes zu begraben. Harris lässt hier Polyneikes Schwester Antigone sprechen, die dem Verbot zuwiderhandelt und im Text ihren toten Bruder anredet (S107, V1-8). Im dritten Beispiel für die Verwendung des Begriffs Poder wird der alternde Colón angesprochen, so dass „,mundo virgen“ eine Paraphrasierung der Neuen Welt und die gemeinte Macht diejenige über Amerika ist. Die Formulierung „virgen“ ist zwar nicht ungewöhnlich, trotzdem besitzt das Lexem neben der Bedeutung, die es im Zusammenhang mit der Entdeckung von Land hat, auch das Sem [sexuell unberührt]. Durch den unmittelbaren Kontext des Textes Tebas wird dieses Sem zwar nicht aktualisiert, aber umso mehr im Zusammenhang mit der Feststellung, dass bisher meist Frauen als die Opfer von Gewalt und Macht beschrieben wurden (Colón lässt eine Frau fangen, die als Sexualobjekt betrachtet wird; eine Frau wird ermordet aufgefunden - zur Vertuschung dient eine Sexualstraftat; Goldfinger lässt im Film eine Frau umbringen, mit der nicht nur er, sondern auch James Bond vorher sexuellen Kontakt hatte). Auf die Bedeutung der Sexualität in Harris' Text werde ich in den folgenden Abschnitten zurückkommen, hier sei lediglich auf die enge Verknüpfung der einzelnen Themen untereinander hingewiesen, die mit jeder weiteren Stelle, die man hinzuzieht, umso unlösbarer wird.

\footnotetext{
${ }^{192} \mathrm{Im}$ Originaltext von Colón handelt es sich um zwei unterschiedliche Stellen, die Harris hier montiert. (Colón 1982:52, 56)
} 


\subsection{Wahmehmung und Täuschung}

Nosotros cerramos los ojos, pero como siempre las imágenes atravesaban los párpados Tomás Hamis

Der Zyklus Cipango tritt uns in seiner Gesamtheit als eine Bilderwelt entgegen. Visuelle Eindrücke, Stilleben und Metaphern aus Film und Theater beherrschen den Text, und Bilder sind es auch, die das Ich unaufhörlich verfolgen. Weder mit geschlossenen noch mit verbundenen und nicht einmal mit zugenähten Augen ist es - und mit ihm Leserin und Leser - vor ihnen sicher: „Me cosieron la boca y los ojos [...] (la intensidad del color filtraba la venda) / el pasillo se hacía verde azul dorado tras la venda / todo iba siendo brillo y color y ardor“ (S85f.).

Es findet sich kaum ein Text, der nicht die visuelle Wahrnehmung in irgendeiner Weise thematisieren würde. Lexeme wie „ojo“ (V1), „luz“ (V7), „verde azul dorado“ (V38), „,color“ (V39), „brillo“ (V39), „,rojo“ (V48) im Text Mar del dolorido sentir (S85) oder „flash“ (V14), „encandilado“ (V28), „película“ (V34), „reflejo“ (V37) in Mar de los incomprensibles luces (S87) bilden die Isotopie \pm visuelles Wabrnehmen, die im gesamten Text dominant ist. Besonders häufig begegnen verschiedenste Arten von Lichtwahrnehmung: seltener natürliches Licht „,sol“ (S90), ,alba“ (S81), ,estrella“ (S96), dafür umso häufiger künstliches Licht („semáforos“ (S68), „farol rojo“ (S69) „luz neón“ (S71), „el sol de cuarenta wattios“ (S73), „,faro“ (S73), ,reflectores“ (S75), „luz roja“ (S77), ,fulgor de cine“ (S91), „fuegos artificiales“ (S126)) und Lichteffekte („,espejismo“ (S71), ,reflejo“ (S82), „,efectos especiales“ (S84), „,halo de luz“ (S85), „brillo“ (S86), „flash“ (S87)).

Eng damit verwandt ist die ebenfalls wichtige Isotopie des aktiveren \pm Sehen. Hierzu gehören „ojos“ (S77), das Motiv der verbundenen Augen (S85f.) und implizit jeder optische Reiz, der potenziell gesehen werden kann.

Auffällig sind die sinnlich-subjektiven Beschreibungen eines Ortes oder einer Szene. Wir sehen optische Eindrücke, besonders Farben und Licht, mit den Augen des Erzählers und beeinflusst durch seinen körperlichen und mentalen Zustand. („Estaba encandilado, me dañaba la luz los ojos“, S87; „El pasillo se hacía verde azúl dorado tras la venda“, S86.)

Etwas Ähnliches geschieht im Text Mar de las incomprensibles luces. Der Text beginnt, indem das Ich seinen eigenen Zustand beschreibt: „Aparecí en la calle Pedro León Gallo, / quebrado, descompuesto, borracho [...]“. Sechs Verse später folgen seine visuellen Wahrnehmungen: 
[...] Abrí los ojos: el mundo estaba en

descomposición [...]

$[\ldots \ldots \ldots . . . . . . . . . . . . . .$.

[...] el mundo me volvía a

flash, un poste, una vitrina, un reflejo

un maniquí. [...] (S87)

Es lässt sich an dieser Stelle nicht mit Sicherheit sagen, ob die Umgebung gleichgeblieben ist oder sich dem Ich tatsächlich ein ungewohnter Anblick bietet. Hier wird sehr deutlich, wie der eigene Zustand und seine Sicht auf die Welt um ihn herum miteinander zusammenhängen.

Im Text Mar del silencio ist sich das Ich seiner Wahrnehmung noch viel weniger sicher. Es beschreibt die nächtlichen Straßen sehr vage. Innerhalb weniger Zeilen setzt es zweimal „,no sé bien“ und zweimal „creo“ zwischen seine Beobachtungen und fügt an „creo todo lo que veo, creo cuerpos“ (S116f.). Der Gesichtssinn ist immer noch der, der die entscheidenden Informationen liefert, dennoch hat eine Desillusionierung, die Zerstörung von Illusionen stattgefunden. Während zu Beginn des Diario die imaginación die Städte des Südens zu charakterisieren schien („Estas ciudades del Sur enfervorizan y pervierten / la imaginación“, S72), soll sie jetzt aufgegeben worden sein. Am Anfang des Textes steht die Feststellung ,También tuvimos que enterrar la imaginación / para no continuar deslumbrándonos“ und er schließt „en esta ciudad que brillaba como el mar, / pero que era el baldí0“"193. Die Gefahr der Täuschung durch das, was wir sehen, und gleichzeitig die Konsequenz daraus, nämlich die Absage an die Vorstellungskraft, umrahmen diesen Text. Die äußeren Umstände werden etwa in der Mitte des Textes deutlich:

Otra vez el Estado de Sitio y el silencio y otro silencio.

Nada.

O lluvia.

Lo mismo. (S116)

Die verlassenen Straßen und die Stille sind bedingt durch den estado de sitio, den Ausnahmezustand oder Belagerungszustand während der Diktatur. Wenn Harris den Terminus mit Majuskel schreibt, spielt er mit Estado, dem Staat. Es verschmelzen in dem Ausdruck der Belagerungszustand und der Belagerungsstaat oder Ausnahmestaat.

Die Stadt hat sich so sehr verändert, dass der Sprecher sich nicht mehr zurechtfindet:

afuera hay una plaza

la Plaza Isabel La Católica, creo

\footnotetext{
${ }^{193}$ Bei dem Wort „baldío“ darf man sicherlich an The Waste Land (La tierra baldía) denken. Die Bedrohlichkeit der modernen Stadt sowie die peepshow-artigen Blicke, die Harris uns auf Menschen gewährt, legen die Assoziation nahe, zumal der Begriff sich im Text häufig wiederholt.
} 
más allá un cerro todo poblado miserable,

el Cerro La Cruz, creo (S116)

Er ist sich der verschiedenen Örtlichkeiten nicht mehr sicher. Dazu tragen auch Lichtreflexe und Blendungen bei: „un reflejo sobre la ventana, / esos resplandores que no son nada y nos deslumbran / los días de lluvia“ (S117). Besonderes Gewicht bekommt aber die Rede vom estado de sitio. Nur an wenigen Stellen im ganzen Text wird so explizit von der Diktatur gesprochen. Zum ersten Mal am Ende des ersten Abschnittes im Text Zonas de peligro (final), wo „los / muertos de mil novecientos setenta y tres“ genannt werden. Die Texte sind noch durch andere Hinweise miteinander verbunden, so sprechen beide vom Cerro de la Cruz und schließlich enden beide mit dem Wort „baldío“, das den Zustand der Stadt beschreibt.

Die Stille in den Straßen gehört zu den Repressionen der Diktatur. Ausgangssperre und Versammlungsverbot verändern den Alltag und das Stadtbild. Andererseits sind die Vorstellungen von Ruhe ebenso wie der Glanz der Stadt oder das Leuchten des Meeres in En aquella mar fecha sangre (S124) nur ein Trugbild. ${ }^{194}$ In allen Fällen soll über die Gewalttätigkeiten (der Diktatur, der Stadt, des Ozeans) hinweggetäuscht werden.

Vor dem Hintergrund der Diktatur muss auch das einleitende Zitat, in dem dem Ich die Augen verbunden werden, sehr viel konkreter verstanden werden: „Me cosieron la boca y los ojos“ (S85). Zum einen geht es hierbei um Zensur, Selbstzensur und darum, die Augen vor etwas zu verschließen. Zum anderen erinnert die Szene aber an Festnahmen, Gefangenschaft und Folter, wie sie unter der Diktatur üblich waren. Dafür sprechen auch die Verse 17-19 desselben Textes (Mar del dolorido sentir):

por la radio tocaban un corrido

perros ladraban

la música se me emplasta en los oídos (S85)

Musik als zermürbendes Instrument der systematischen Folter ist nicht ungewöhnlich, und scharfe Hunde gehören zum Szenario eines Gefangenenlagers. Bei dem Begriff „dolorido sentir" im Titel handelt es sich um ein Zitat von Garcilaso de la Vega: "No me podrán quitar el dolorido / sentir si ya del todo / primero no me quitan el sentido.” ${ }^{95}$ Auch in Harris’ Text scheint es auf „quitar el sentido“ hinauszulaufen, denn die Menschen werden systematisch ihrer Sinneswahrnehmung und ihrer Vernunft beraubt.

Die Thematik des Internierungslagers wird gestützt durch Verse aus den ersten beiden Abschnitten. Zonas de peligro (S29) endet mit der Neonlichtschrift „CAMPOS DE EXTER-

194 „En aquella mar fecha sangre“ ist ein Zitat aus einem Brief Colóns über seine vierte Reise vom 7. Juli 1503, in dem er einen Sturm beschreibt, in dem beinahe seine gesamte Mannschaft das Leben verloren hätte. (Colón 1982:296) 
MINIO“ und die ersten beiden Texte aus dem Abschnitt La forma de los muros erwähnen das Konzentrationslager Treblinka: „es una barraca como las de Treblinka“ (S55) und „[e]ra Treblinka el lugar de la comedia y no / estábamos en Treblinka“ (S56). Noch deutlicher wird das Geschehen durch die Verse 22-25:

el corrido comienza a arderme en los oídos los hombres sacan las pistolas a mí me trataron como a todo prisionero de guerra olvidando los tratados y la piedad (S85)

Wahrnehmung ist im Text fast immer sehr eng mit Täuschung und Irrtum verbunden.

Una indagación sobre esta pervertida manera de ver las cosas:

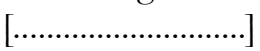

pero no sabemos a ciencia cierta si el tropel de

caballos

amarillos

era parte de los pervertidos mecanismos del sueño o un dato efectivo de lo real. (73f.)

Diese Vermischung von Wirklichkeit und Traum oder Täuschung findet in beiden Welten statt. Colón und seine Leute irren sich aufgrund falsch gezeichneter Karten („mapas figuraciones falsedades fantasma- / gorías“, S69; „en las cartas alucinantes destas ciudades“, S107); aufgrund dessen, was sie vorzufinden erhoffen („¿Oro, no había oro?“, S69) und aufgrund ihrer eurozentrischen Wahrnehmung. Dabei sind sowohl die auf Wunschdenken beruhende Täuschung wie auch das aus der Desillusion, aus der Ent-Täuschung entstehende Gegenbild Verzerrungen der Wirklichkeit.

Las promesas de Colón habían sido un falso señuelo. Las esperanzas del oro cosechable como fruta madura se reducían al aleatorio futuro de unas minas que requerían trabajo y privaciones. El suave clima y la perfumada templanza de los aires cobraron en vidas de cristianos su pestífero engaño. [...] La beata imagen de la edad de oro rediviva se transmutó, al conjuro del desengaño, en edad de hierro que dominaba la creciente convicción de que esos desnudos hijos del Océano formaban parte del vasto imperio de la barbarie, el señorío, confesado o no, del Príncipe de las Tinieblas. (O’Gorman 1958:44)

Die Menschen in der modernen Parallelwelt erliegen Irrtümern, weil ihre Phantasie lebhaft bis krankhaft ist: „estas urbes del Sur / te acaloran, te enferman la imaginación“ (S76). An anderen Stellen scheint das Verkennen der Wirklichkeit einer fremden Absicht zu folgen: Menschen werden vorsätzlich getäuscht. Irrtum entsteht aus Fälschung und Betrug: „oro falso“ (S107); „mar [...] engañoso“ (S104) oder sogar aus einer Falle: „,[...] una trampa pobre / que se abre a nuestros sentidos“ (S108f.). Hierzu gehören alle Täuschungen und Lügen, die die Militärregierung und die von ihr gesteuerte Presse verbreiten lässt (so wie beispielhaft der irreführende Bericht über ein angebliches Sexualdelikt).

Die Verwechslung von Wirklichkeit und Anschein funktioniert aber auch in der entgegen-

195 Vers 349/350 der Egloga I (Vega 1964:79). 
gesetzten Richtung. Wirklichkeiten werden - vermutlich aus Gewohnheit - als Abbilder wahrgenommen: „todas las mujeres estaban / dibujadas a lápiz, fotos pornográficas“ (S89); „y los cuerpos en los baños eran planos sin volumen, / aunque la luz daba la ilusión de volumen“ (S89); „ese Mundo se poblaba de efectos especiales, / de espías, / siempre tanta ráfaga $[\ldots]^{“}(\mathrm{~S} 220)$.

Wahrnehmung, und ganz besonders die irregeleitete Wahrnehmung, ist einer der wichtigsten Berührungspunkte beider Welten, einer der deutlichsten Übergänge von der einen in die andere. In beiden Fällen spielt die Verführung durch Visionen oder Illusionen eine Rolle. Colón wurde geleitet durch seine Visionen und die Prophezeihungen anderer. Im Text Discurso de Marco frente al Can wird auf eine Stelle aus dem Buch Jesaja angespielt, die als Prophezeihung verstanden wurde und die Colón selbst in seinen Schriften als Bürgtext heranzieht:196 „llanamente se cumplió lo que dijo Isaías“ (S226). Es sind ebenfalls diese Visionen und Erwartungen, die ihn die Wahrheit nicht erkennen lassen, nämlich dass es die erhofften Goldvorkommen nicht gibt und dass er nicht in Ostasien angelandet ist. Die Visionen des Concepción der 80er Jahre entstehen im Kino und im Fernsehen, in pornographischen Zeitschriften und in der Werbung. Und auch sie verstellen den Blick auf die Wirklichkeit.

Schließlich geht Harris so weit anzudeuten, dass unsere eigenen Wahrnehmungen in ihrer Naivität dem mittelalterlichen Blick von Colón und seinen Leuten in nichts nachstehen. Er vergleicht unsere Perspektive mit einer, die bildlich gesprochen den Fluchtpunkt noch nicht kennt, die wir also für einfältig und unaufgeklärt halten.

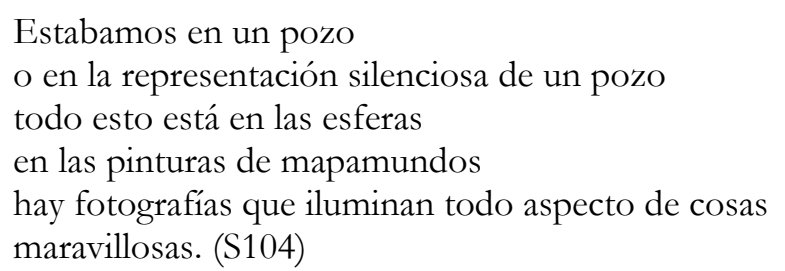

Unten im Brunnen sitzend, sehen wir nur den kleinen Ausschnitt der Welt, der direkt über uns liegt. Und doch glauben wir den Landkarten, die wir aus unserer Brunnen-Perspektive heraus zeichnen, ebenso bedingungslos oder hoffnungsvoll wie Colón das tat. Mit Hilfe

\footnotetext{
${ }^{196}$ Jesaja 60.9: „Die Inseln harren auf mich und die Tarsisschiffe vor allem, daß sie deine Söhne von ferne herbringen samt ihrem Silber und Gold für den Namen ihres Herrn, deines Gottes [...]“ und Jesaja 65.17: „Denn siehe, ich will einen neuen Himmel und eine neue Erde schaffen, daß man der vorigen nicht mehr gedenken und sie nicht mehr zu Herzen nehmen wird." Unter anderem diese Stellen führte Colón an, um seinen Plan und die Besessenheit, mit der er ihn verfolgte, zu rechtfertigen.
} 
unserer Fototechnik glauben wir, jede Art von Wunder festhalten und ausleuchten zu können. Der Brunnen ist aber nichts anderes als Platos Höhle, was wir sehen, sind nur die verzerrten Schatten der Wirklichkeit.

In demselben erkenntnistheoretischen Zusammenhang ist eine Stelle aus Mar de la necesidad bedeutsam:

una lacerada procesión como ésta en pleno Siglo de las Luces o de oro

o da lo mismo. (S76)

Die beiden Kulturepochen, el Siglo de las Luces und el Siglo de Oro, die in etwa der deutschen Aufklärung und dem deutschen Barock entsprechen, werden hier als austauschbar dargestellt. Obwohl sie historisch unterschiedliche Prinzipien vertreten und das Siglo de las Luces kulturell, gesellschaftlich und politisch eine Gegenreaktion auf das Siglo de Oro darstellt, scheint es dem Erzähler gleichgültig, ob es sich um das eine oder um das andere handelt: „da lo mismo“.

Als bislang einziger expliziter Hinweis auf eine Epoche - von dem Versuch einer historischen Einordnung zu sprechen, wäre wohl zuviel gesagt - erscheint diese Stelle zunächst sehr unvermittelt. Doch auf anderer Ebene sind die beiden Angaben fest in den Kontext eingebettet. Die beiden Epochen werden im Spanischen metaphorisch als ,Zeitalter des Goldes ${ }^{\varsigma}$ und ,des Lichtes` bezeichnet. Damit können sie jeweils einem der Hauptmotive des Textes zugeordnet werden. Als historische oder kunst- und kulturgeschichtliche Bezeichnungen verhalten sie sich antagonistisch zueinander. Während das Stereotyp des Barockmenschen als religiös motiviert dargestellt wird, kreist in der Aufklärung alles um den Menschen selbst als Ziel und Zweck der Erkenntnis von der Welt und des Handelns. Wollte man diese Weltanschauungen auf die beiden Parallelwelten des Textes übertragen, so müsste man die Entdeckung Amerikas in das goldene und Concepción in das aufgeklärte Zeitalter verlegen. Bis zu einem gewissen Grad lässt sich dieser Vergleich durchhalten. Colóns - vorgeschobene oder wahrhaftige - Religiosität, seine Dienste im Namen Gottes und im Namen der spanischen Krone, seine Suche nach Gold stehen der Nüchternheit von Neonlichtern und 40-Watt-Birnen gegenüber und einer Gottlosigkeit, die immer wieder durch den Begriff der Leere ausgedrückt wird („la que conduce al vacío“, S118; „los ojos buscan puntos de fuga en el vacío“, S77; „amanecía en Concepción“, S86; „anochecía en Cipango“, S107). An anderen Stellen dagegen verschmelzen die beiden Prinzipien, bzw. die Kulissen miteinander, bedingen einander oder werden austauschbar, so wie an der oben erwähnten Stelle, an der es egal ist, ob es sich um eine Prozession der einen oder der anderen Zeit handelt. 
Ein Sonderfall der Bilder im Text sind die Trugbilder. Täuschungen und Illusionen spielen in beiden Welten eine große Rolle. Triviños bemerkt über die Illusionen Colóns:

El objeto anhelado cambia de lugar constantemente, sin producir la destrucción de la creencia en el mito. La desilusión producida por un lugar se sustituye por la ilusión de descubrir lo deseado en otro lugar que está más allá [...] Los relatos colombinos así simularizados fundan la percepción del nuevo mundo como lugar donde los sueños, ficciones y mitos europeos pueden convertirse en realidad [...] (Triviños 1985:64)

Triviños beschreibt die europäische Sichtweise auf Amerika als Ort der Wünsche und Sehnsüchte, als Projektionsfläche für alle Träume, die sich in der alten Welt nicht mehr träumen lassen. Im Folgenden entwickelt er, wie diese Perspektive Stück für Stück zur amerikanischen Perspektive wird. Der Name, der Blick auf das eigene Land, sogar die Selbstwahrnehmung wird dem zunächst „Entdeckten“ und später Kolonisierten aufgezwungen, er wird zum ens ab alio. (Triviños 1985:52)

Anhand einiger Texte habe ich gezeigt, dass der Mensch bei Harris als Augentier dargestellt wird, als Wesen, das seine Welt durch Blicke und Bilder erfährt. Ob sich das Ich seiner Wahrnehmungen sicher ist oder nicht, lässt Rückschlüsse auf seinen individuellen Zustand zu, sagt aber auch etwas über seinen historisch-kulturellen Hintergrund aus. Colón fühlt sich auch dann noch im Recht, wenn er einer gewaltigen Täuschung erliegt. Das moderne Ich in der prekären geschichtlichen Situation einer Diktatur hingegen ist sich selbst seiner vertrauten Umgebung nicht mehr sicher.

Aus dem gewaltigen Irrtum, als der sich die Entdeckung des Colón herausstellen wird und der Gier, die ihn an seiner Wunschvostellung festhalten lässt, entwickelt der Text über die Zeit hinweg die bewusste Täuschung und Irreführung des späten 20. Jahrhunderts. Im Kino, in Hochglanzmagazinen und in der Werbung werden wir über unsere Instinkte und unsere Wahrnehmung manipuliert, weil wir - wie Colón - sehen, was wir sehen wollen. Aus dem fälschlich vermuteten und herbeigesehnten Gold wird das nachgemachte und gefälschte.

Durch die immerwährende Parallelisierung der zeitlichen Ebenen mit semantischen und lexikalischen Mitteln scheint der Grundstein für die modernen Täuschungen bereits von Colón gelegt worden zu sein. Seine in Macht- und Geldgier begründete Selbsttäuschung schreibt sich durch die Geschichte fort bis zur pervertierten Phantasie der Gegenwart.

Eine andere Parallele zieht Harris zwischen der unaufgeklärten Perspektive des Mittelalters und der Sichtweise seiner Zeitgenossen. Unsere Erkenntnis wird ebenso beschränkt dargestellt und unser Blick ebenso verstellt wie der des Colón - es sind dieselben Vexierbilder, die uns täuschen. 


\title{
8.5 Inszenienung der Geschichte: Flucht in die Fiktion
}

\begin{abstract}
(el escenario que representa la ciudad queda completamente vacío y las luces se apagan lentas, lumínicos, semáforos, ventanas, a la manera de un disolvimiento cinematográfico)
\end{abstract}

Tomás Harris

Dem Themenkomplex ,Visuelle Wahrnehmung - Vision - Illusion` verwandt ist die Motivik von Theater, Fotografie und Film, die bei Harris sehr präsent ist. Der Literaturkritiker Javier Campos charakterisiert die Dichtung Harris’ folgendermaßen:

Tomás Harris pertenece, a partir de los 80, a una línea o tendencia [...] dentro de la poesía chilena cuya significación más notoria creo no radica tanto en las influencias de „lecturas literarias" propiamente tales sino más bien en la „lectura de lo visual“. Una poesía que se va construyendo más que nunca con la lectura de la „cultura de la imagen“ que algunos poetas chilenos a partir de la década mencionada vienen haciendo cada vez más del cine, los medios visuales de alcance masivo, la fotografía, la pintura, la publicidad comercial nacional o transnacional así como la nueva y alta tecnología que reinventa la belleza en híbridas, nuevas y sofísticadas imágenes. (Campos 1995:88)

Im Text Alguien que sueña, Madame (1986) und in Harris' neuester Veröffentlichung Crónicas maravillosas (1997) ist sein Interesse am Kino augenfälliger, da es sich in einer expliziten Intertextualität mit dem Medium Film niederschlägt. Man liest Filmtitel, Namen von Figuren, Schauspielern und Regisseuren. Aber auch in Cipango ist der Einfluss des Kinos deutlich, er drückt sich hier allerdings im weniger auffälligen Gebrauch von filmischen Wendungen und Metaphern aus, die zum Teil bereits in die Alltagssprache eingegangen sind: „Todo transcurre en una película mexicana“ (S85); „En otra película el mundo era una esfera en / blanco y negro despoblado por fantasmas“ (S88); „pudimos ser papel lustre / fotografías viejas de una raza ya extinta sin más huella / que las fotos obscenas de tiempo“ (S114). An den drei Texten Mar de la culpa, Mar de la Necesidad und Las islas de arena (das dritte, fünfte und sechste Gedicht des Diario) lässt sich Harris' Umgang mit den Medien Film und Theater gut zeigen.

Mar de la culpa ist beinahe ausschließlich aus Parallelismen mit antithetischem Inhalt aufgebaut. Die ersten beiden Sätze beginnen mit „En el amplio horizonte había“ und während der erste mit einer Aufzählung von Requisiten fortfährt, die einer modernen urbanen Umgebung zugeordnet werden können (,bolsas de polietileno negras / maniquíes soñados, putas, flechas, ráfagas' ${ }^{`}$, nennt der zweite Dinge mit einer symbolisch-spirituellen Bedeutung („emblemas, fetiches, ritos / imcomprensibles, altares y espejismos“). Auch im Weiteren bietet der Text häufig mindestens zwei Antworten, also mehrere Möglichkeiten oder Interpretationen an. Was wie ein im Regen gespiegeltes Neonlicht aussieht, könnte auch Gold sein: 
por estas noches, la lluvia borronea algo como luz neón,

pero pueden ser peces de colores,

oro,

hembras fantasmales. (S71)

Die Ambiguität bleibt bestehen. Es gibt zwei nicht miteinander zu vereinbarende Leitsprüche, die den Menschen mit auf den Weg gegeben wurden: "Vayan y busquen el amor" und "Todo en sueños les será concedido. "Im selben Text ist davon die Rede, dass der Erzähler mit einer Frau intim ist, wobei sie einmal als Priesterin und dann als Prostituierte bezeichnet wird:

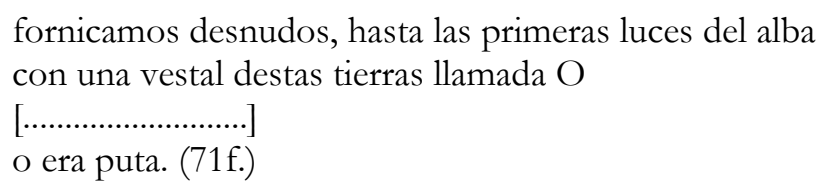

Die Konnotation mit der Histoire d'O unterstreicht zum einen die erotische Komponente. ${ }^{197}$ $\mathrm{Da}$ es in der Histoire um sadomasochistische Praktiken geht, sind aber die Aspekte der psychologischen sowie physischen Machtausübung inbegriffen. Ebenso lässt sich das $O$ aber auch als Abkürzung für Orompello lesen oder als großgeschriebenes oder, das eben gerade die Ambiguität des gesamten Textes hervorhebt. In diesem Zusammenhang deuten sich an mindestens zwei Stellen die Isotopien [Sünde/Promiskuität] und [Religion] an (,putas“, „maniquíes soñados“, „O era magra, pero sexual“, „O era puta“, „,pervierten la imaginación“"vs. „altares“, „una vestal"), die miteinander konkurrieren.

Auch die Wirkung der Städte des Südens auf die Vorstellungskraft der Menschen wird ambivalent beurteilt. Sie wird von ihnen sowohl entzündet als auch pervertiert: ,pero estas ciudades del sur acaloran y enferman la imaginación“..198

Fast genau in der Mitte des Textes wird die Beschreibung eines frühen Morgens durch eine offensichtliche Anspielung auf die fehlende Qualität der folgenden Szene unterbrochen: (,Todo lo que sigue es serie B [... $]^{“}$ ). Diese Klammer ist nach Art einer Regieanweisung eingefügt, unmittelbar hinter ihr nimmt der Text den erwähnten Morgen wieder auf. Dadurch wird der Effekt erzielt, dass der Inhalt des Kommentars sich direkt auf die der Klammer folgenden Zeilen bezieht, dass also das, was erzählt wird, mit einem billig produzierten Film verglichen wird. Folgende Dinge werden der serie B zugeordnet:

${ }^{197}$ Vermutlich bezieht sich Harris eher auf den Film (1975) als auf das Buch, das 1954 unter dem Pseudonym Pauline Réage veröffentlicht wurde. Sowohl Buch als auch Film sorgten bei ihrem Erscheinen für Aufsehen.

${ }^{198}$ Im letzten Teil Cipango ist ein Text noch einmal ähnlich aufgebaut: In Teoría de la percepción streiten sich verschiedene Stimmen darum, ob Ratten oder Frauen vom Meer an den Strand gespült werden und ob sie in den Wellen einen Toten, einen Mast, einen gelben Hund oder eine halbverhungerte Hündin erkennen können. (S193f.) Der Titel weist auf die Problematik der Wahrnehmung hin, die Streitfragen werden nicht geklärt. 


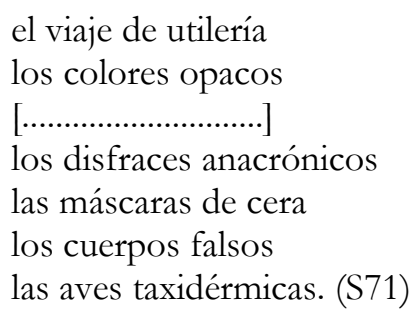

Der Film, von dem hier die Rede ist, wirkt unecht, unglaubwürdig: „-no se vaya a creer-“. Eben jener Ausruf der Ungläubigkeit ist der eigentliche Kern dieses B-Movie, das vom lyrischen Ich hier konstruiert wird. Er deutet seine eigene Wirklichkeit - an die er nicht glauben kann oder will - in einen schlechten Film um. Hier wird durchgeführt, was im Text Orompello III bereits beschrieben ist: „[...] estabamos / protegidos / por la ficción; [...]“. Diese Gegenüberstellung von Wirklichkeit und Fiktion lässt sich auch auf die anderen Ambiguitäten des Textes beziehen. Der weite Horizont des ersten Verses, (der mit der Prärie und den Büffeln am Anfang von Mar de la necesidad korrespondiert, S75), ist die Fiktion, die der Wirklichkeit aus Plastik gegenübersteht. Wo die Phantasie Gold ersinnt, gibt es den Schein von Neonlicht, und die Priesterin ist in der Wirklichkeit von Orompello eine Prostituierte. Der Text Las islas de arena (S77) greift die Vorstellung von der Welt als schlechtem Film wieder auf: „Este mundo es serie B“.

Im Text Mar de la necesidad wird das Thema fortgesetzt, indem der „éxodo de las putas de Orompello“ (S75) als filmische Inszenierung dargestellt wird. ${ }^{199}$ Das Gedicht beschreibt den Auszug der Prostituierten so, als würde es sich nicht um tatsächliches Geschehen, sondern um ein dargestelltes, nachgestelltes Ereignis handeln:

el desierto rojo de la calle se había superpoblado

a lo Cecil B. de Mille

46 papeles príncipales 82 menores

más de doscientas intervenciones habladas

algunas escenas eran soberbias (S75)

Cecil B. de Mille hat seit 1914 an über 80 Filmen gearbeitet, meistens als Regisseur. Sein wohl bekanntester Film ist das 1957 gedrehte Monumentalwerk „Die zehn Gebote“, auf dessen Massenszenen Harris hier anspielt. Eine inhaltliche Parallele deutet sich in der Formulierung „éxodo“ an, die die Prostituierten mit dem Volk Israel vergleicht, dessen Auszug von de Mille filmisch umgesetzt wurde. Diese Parallelisierung von Prostituierten und dem biblischen Volk greift die Ambiguität von [Sünde/Promiskuität] und [Religion] als einander überlagernde Deutungsmöglichkeiten wieder auf.

\footnotetext{
${ }^{199}$ Die Prostitution ist in Chile während der Diktatur nie offiziell verboten gewesen. Allerdings hat es gewaltsame Übergriffe auf Prostituierte von Seiten des Militärs gegeben. Der „éxodo“ bezieht sich vermutlich auf die nächtliche Ausgangssperre, die ihnen die Arbeit fast unmöglich machte.
} 
Mar de la necesidad wird sehr viel deutlicher mit der Wirklichkeit, die durch die Fiktionalisierung verschleiert werden soll:

pero rodeaban Orompello guardias armados

y alambradas de púa para resguardar el éxodo

sobrevolaban helicópteros

aves taxidérmicas. ( $\mathrm{S} 75 \mathrm{f}$.)

Bewaffnete Polizei, Stacheldraht und kreisende Hubschrauber bilden eine Isotopie mit „los / muertos de mil novecientos setenta y tres“ (S50) und „Estado de Sitio“ (S116). Es ist die repressive Willkür der Diktaturregierung, die die Wirklichkeit bestimmt und die auch für die Vertreibung der Prostituierten verantwortlich ist. Derartige Aktionen fanden mit der bigotten Begründung statt, das Land von Sünde und Unrecht säubern zu wollen. Auf der Grundlage angeblicher christlicher Ideen wollten die Machthabenden so sich und die Diktatur rechtfertigen. ${ }^{200}$ Durch den impliziten Vergleich mit dem biblischen Exodus weist Harris den Machthabern die Rolle des grausamen ägyptischen Königs und den Prostituierten die des unschuldig unterdrückten Volkes zu.

Eine weitere Doppeldeutigkeit entsteht mit dem filmischen Effekt einer Überblendung. Inmitten der Beschreibung vom Auszug der Prostituierten durch die Straßen der Stadt, am Fluss und am Friedhof vorbei finden sich folgende Verse:

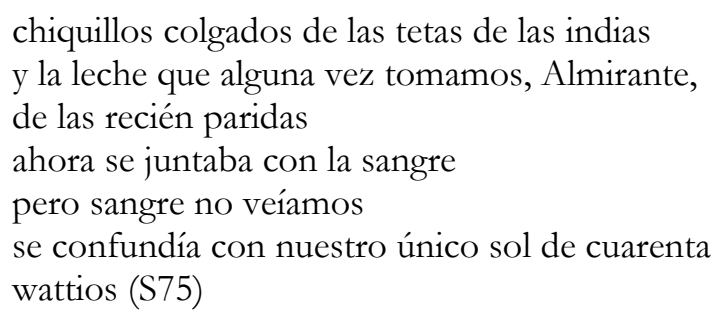

Durch die Anrede Almirante schiebt sich eine Szene der Eroberung des Kontinents in die Darstellung. In beiden Fällen sind Frauen die Opfer, in beiden Fällen liegt eine spezielle Art der sexuellen Unterdrückung vor. Die Parallelisierung der Begriffe „india“ und „puta“ wurde bereits angesprochen, ${ }^{201}$ hier wird deutlich, wie Harris dadurch gleichzeitig das männliche Verhalten den Frauen gegenüber in unterschiedlichen Epochen vergleicht (hierauf wird im nächsten Abschnitt noch zurückzukommen sein). Ebenso wird die Gewalt in beiden Situationen parallelisiert: Das Blut, das floss, wurde von den Urhebern der Gewalt damals nicht gesehen, ebenso wie bei der Darstellung der fiktionalisierten aktuellen Gewalt auf der Bühne kein Blut fließen wird.

${ }^{200}$ Vgl. Tomás Moulian: „[...] nos conduce al corazón de una paradoja y de una tensión que erosionó la relación entre uno de los dispositivos de justificación, el discurso católico, y la práctica del autoritarismo chileno" und seine anschließenden Ausführungen zum erklärten „gobierno cristiano“ der Diktatur. (Moulian 1997:178-180)

${ }^{201}$ Kapitel 8.3, S190. 
Der folgende Text Las islas de arena schließt mit der ersten Zeile „Ante nosotros, las ciudades eran el teatro del dolor" direkt an die vorangegangene Filmmetaphorik an. Wieder handelt es sich um eine Situation, die jedoch aus verschiedenen Gründen als nicht-real empfunden wird: ,die Städte waren Theater`. Das ,Theater des Schmerzes`, bzw. die Stadt wird auf eine sehr naive Weise dargestellt. Der Erzähler nimmt die Haltung eines Fremden ein, der aus seiner Distanz heraus staunend versucht, das Gesehene im Concepción der 80er Jahre in Worte zu übersetzen:

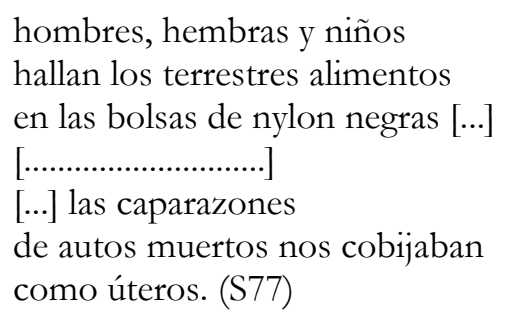

Er beschreibt Menschen, die ihre Lebensmittel in schwarzen Plastiktüten tragen. Er erwähnt starre Blicke der Leute, die ins Leere fliehen und schildert, wie die panzerartigen Hüllen von Autos den Menschen Unterschlupf gewähren. Wenn er auch im Zusammenhang mit den Autos von der dritten Person Plural in die erste wechselt, so beschreibt er Dinge wie die Autos doch, als kennte er sie nicht aus eigener Erfahrung, sondern versuche lediglich, etwas Unbekanntes möglichst nachvollziehbar darzustellen. Damit ist seine Erzählhaltung mit der der Spanier vergleichbar, die in die Neue Welt kamen und das Gesehene und Bestaunte in ihren Chroniken wiedergeben.

Es folgt eine ähnliche Klammer wie im Text Mar de la culpa:

[...] (Este mundo es Serie B.

Estas palmeras de acrílico no corresponden a ninguna clase real. El sonido del mar se consigue agitándo enormes sábanas de polietileno. Poca cosa corresponde a su modelo original. De otra manera no sería posible reproducir tanta maravilla, chancro, barro orgánico, orquídea, luz, entrevisión) (S77)

Wieder wird ein Geschehnis als nachgestellte Szene eines schlechten Filmes beschrieben. Nichts wirkt echt, das Geräusch des Meeres kommt nicht einmal vom Band, sondern muss mit dem Rascheln von Plastikfolie erzeugt werden, die Palmen sind aus Kunststoff.

Dann setzt die Handlung innerhalb der Kulisse ein. Wir betreten eine Welt, die eine Mischung aus dem modernen Concepción (dunkle Stadtteile mit ihren authentischen Namen: La Libertad, El Cerro la Cruz, La Plaza Isabel la Católica) und einer feindlichen Natur darstellt, durch die man sich mit Gewalt - einer Mensch und Natur verachtenden Gewalt einen Weg schlagen muss: „Nos abríamos camino machete en mano, / tajando culos, / 
destasando tetas, / talando araucarias“ (S77). ${ }^{202}$ Die letzten zwei Verse situieren das Geschehene wieder in der Stadt („Lo narrado transcurre en una ciudad / al Sur del Mundo“).

Es finden sich noch weitere Stellen, an denen das Geschehen ins Kino oder ins Theater verlegt wird: „Todo transcurría en el teatro o en el cine. / Todo transcurría en la calle o en un sueño.“ (S84) oder „en las pantallas de los muros / en los teatros de los baldíos“ (S144). An anderen Stellen werden Metaphern aus dem Film benutzt: „la imagen, intermitente, era ya un / close-up“ (S58), „la voz en el off“ (S58), „el escenario que representa la ciudad queda / completamente vacío y las luces se apagan lentas, / lumínicos, semáforos, ventanas, a la manera de un / disolvimiento cinematográfico“ (S103). Durch die Einflechtung solch expliziter oder scheinbarer Unwirklichkeit wird das Geschehen distanziert und fiktionalisiert. ,Film‘ steht ähnlich wie ,Märchen` für etwas Nicht-Wirkliches. ${ }^{203}$

Zum einen ist Harris' Umgang mit dem Medium Film Ausdruck des modernen Lebens mit den entsprechenden visuellen Reizen. Zum anderen bewirken gerade die Anleihen an Film und Theater sowie die Verschachtelung verschiedener Formen und Stufen der Darstellung eine Fiktionalisierung des Textinhaltes. Dadurch, dass offenbar Wirkliches als Szene eines Filmes dargestellt wird und zugleich Figuren oder Szenen aus einem Film in die Wirklichkeit eingreifen (Goldfinger, „película mexicana“), verschwimmen die Grenzen. Die Fiktionalisierung dient dem Umgang mit der Wirklichkeit. Es ist deutlich geworden, wie das lyrische Ich die Realität zu Fiktion umdeutet, um der Wirklichkeit zu entfliehen.

Das als real Dargestellte steht im Text dem als fiktional Dargestellten gegenüber, und es bilden sich zwei große Deutungsebenen, die zu verschiedenen semantischen Ambiguitäten führen, wie der Bezeichnung ein und derselben Frau als vestal und als puta oder der Doppeldeutigkeit einer Situation als Szene der Conquista und der Diktatur.

\subsection{Die Figur des Cristóbal Colón}

Bedeutung und Leistung von Cristóbal Colón werden heute sehr unterschiedlich gewertet. Sein Name ist zum Synonym für die Inbesitznahme Amerikas durch die Europäer geworden. Das bedeutet einerseits, dass seine Entschlossenheit, sein Mut und die Zähigkeit, mit der er über viele Jahre hinweg seine Reisepläne verfolgte, gelobt und gefeiert

\footnotetext{
202 Araukarien gibt es zwar auch in Südbrasilien, Argentinien und Südostasien, aber hier ist in erster Linie an die Region Südchiles der Araucanía zu denken, die nach dem Nadelbaum benannt wurde. Das Holz der Araukarien ist sehr begehrt, der Baumbestand ist bereits stark zurückgegangen.
} 
werden. Andererseits wird er verantwortlich gemacht für den Genozid, der sich an die Eroberung des Kontinents anschloss. Für viele repräsentiert er die Habgier, den Eurozentrismus und das Sendungsbewusstsein, mit denen die Europäer den Kontinent in Besitz nahmen.

Der historische Colón wird 1451 als Cristoforo Colombo, Sohn eines Wollwebers, in Genua geboren. Auf Handelsreisen zur See im Auftrag seines Vaters erlangt er Kenntnisse als Seefahrer. Nach einem Kampf gegen Korsaren, einem Schiffbruch und einer anschließenden Reise nach Irland beschließt Colón, nach Portugal überzusiedeln, wo er 1479 in den Adel einheiratet. Die Idee, den Westweg nach Indien zu finden, geht vermutlich auf die sagenhaften Reiseberichte des Venezianers Marco Polo aus der zweiten Hälfte des 13. Jahrhunderts zurück, die ihn faszinierten. Insbesondere dessen Einschätzung, dass das Goldland Cipango, das Marco Polo seinen Angaben nach erreicht hatte, viel weiter vom chinesischen Festland entfernt sei als dies der Fall ist, ließ Colón hoffen, auf seinem Weg zum Festland auf Cipango Station machen zu können. Bestärkt wurde Colón durch die Texte Historia Rerum Ubique Questarum von Papst Pius II und die Imago Mundi des Kardinals Pierre D'Ailly, in der ebenfalls von einer Westroute die Rede ist. (Gewecke 1981:313f.) Sein wichtigster Gewährsmann war vermutlich der florentinische Kosmograph, Arzt und Humanist Paolo del Pozzo Toscanelli, dessen 1474 entwickelte Weltkarte Aufsehen erregte. Colón erhielt Kenntnis von einem Brief und einer Karte, die der Wissenschaftler 1474 für einen Kanonikus am portugiesischen Hof anfertigte. Dort drückt Toscanelli seine Überzeugung aus, dass ein Seeweg in Richung Westen befahrbar sei und fügt eine genaue Wegbeschreibung bei. Toscanelli hatte allerdings die Entfernung zwischen den kanarischen Inseln und Cipango (Japan) mit 3000 Seemeilen und von dort bis zum chinesischen Festland mit weiteren 2000 Seemeilen als viel zu kurz berechnet. ${ }^{204}$ Colón schenkte diesen vielversprechenden Zahlen jedoch nicht nur gern Glauben, sondern verkürzte die Entfernung bis Cipango durch eigene fehlerhafte Berechnungen um weitere 600 Meilen und wähnte die Insel nun in etwa auf der geographischen Länge, auf der sich tatsächlich die karibischen Inseln befinden. ${ }^{205}$

\footnotetext{
${ }^{203} \mathrm{ZB}$ die umgangssprachlichen Ausdrücke ,... de película‘ für Traum-... oder ,pasarse una película für träumen.

${ }^{204}$ Die tatsächliche Distanz zwischen den Kanaren und Japan beträgt über zehntausend Seemeilen.

205 Diese Verringerung der Strecke resultiert daraus, dass Colón - Ptolemäus' Berechnungen folgend - von einem Erdumfang von $28.000 \mathrm{~km}$ gegenüber tatsächlichen $40.024 \mathrm{~km}$ ausging. Ein weiterer Fehler unterlief ihm bei der Berechnung der Distanz zwischen Portugal und Asien. Er folgte dabei den Angaben des arabischen Kosmographen El Fargani, die zwar korrekt waren,
} 
Seine Überzeugung und Entschluss standen somit fest, indes sollte es noch über acht Jahre dauern, bis ihm die Mittel zu seinem Vorhaben gewährt werden sollten. 1484 wurde sein Gesuch am portugiesischen Hof abgelehnt, zwei Jahre später sprach er vor der Königen Isabella von Kastilien zum erstenmal vor. Zunächst wurde er jedoch hingehalten, insbesondere die Reconquista ließ kaum die Planung und Durchführung anderer Unternehmen zur selben Zeit zu. 1488 wandte er sich nochmals an den König von Portugal, der ihm Hoffnung machte, kurzfristig aber entschied, lieber die Erschließung des Seeweges nach Indien über die Ostroute weiter voranzutreiben.

Die Zeit, bis seine Reise schließlich 1492 von der spanischen Krone bewilligt wurde, war für Colón materiell zermürbend und psychisch äußerst belastend, da jedem neuen Hoffnungsschimmer schnell eine Enttäuschung folgte. Als seinen unermüdlichen Bemühungen endlich Erfolg beschieden war, handelte er zunächst den Admiralstitel, das Amt des Vizekönigs und Gouverneurs für sich in allen von ihm zu entdeckenden Ländern aus. Außerdem wurde ihm ein Zehntel von allen Gewinnen aus den neuen Ländern zugesichert. ${ }^{206}$ 1499 auf seiner dritten Reise wird Colón seines Amtes in der Neuen Welt enthoben und als Gefangener nach Spanien zurückgeschickt. Dort wurde er zwar begnadigt, kam allerdings nicht wieder in Besitz seiner Privilegien. Er starb nach einer vierten Reise nach Amerika (1502) im Jahre 1506 recht wohlhabend, aber doch gekränkt und enttäuscht darüber, dass ihm nicht die gewünschte Anerkennung entgegengebracht worden war.

Dies sind - knapp gefasst - die bekanntesten Fakten über das Leben des historischen Colón. In den letzten drei Teilen von Cipango (die zusammen immerhin 175 von 215 Seiten ausmachen) ist Colón ständig präsent. Dabei finden sich ebenso Züge des authentischen Colón (soweit er aus Quellen rekonstruierbar ist), der über das Meer nach Westen reiste, dabei Tagebuch führte, und nie erfahren sollte, wo er gelandet war, als auch die Spuren fiktiver Figuren, die sich ebenfalls Colón nennen, aber nur bestimmte, manchmal auch nur vermeintliche Charakteristika des historischen Colóns repräsentieren. So stellt Harris dem Diario de navegación ein Motto voran, das dem Roman El arpa y la sombra von Alejo Carpentier entnommen ist und die Colón-Thematik einleitet:

[...] desplegué, una vez más, mi Retablo de Maravillas, mi aleluya de geografías deslumbrantes, pero, al oficiar de anunciador de portentos posibles, desarrollé una nueva idea, madurada por lecturas recientes, que pareció agradar en mucho a mi oyente. (Carpentier 1983:285)

allerdings bezogen sie sich auf arabische Meilen, während Colón die - wesentlich kürzeren italienischen Meilen zugrunde legte. (Madariaga 1992:122ff.)

$206 \mathrm{Zu}$ den historischen Details vgl. Bitterli 1992:45-57. 
Mit diesem Satz kommentiert Carpentiers Colón in einer Rückschau am Ende seines Lebens die redegewandten Versuche, Geldgeber für sein abenteuerliches Vorhaben zu gewinnen. Der Ich-Erzähler Colón stellt sich als Taschenspieler, als Lügner, als Schwindler dar; als jemand, dem jeder Ausspruch von prominenter Seite recht ist, der seine gauklerischen Berechnungen von Entfernungen zu untermauern scheint, um so einen finanzkräftigen Fürsten in dieses zweifelhafte Unternehmen zu locken. Das Motto ist somit ein entlarvender Satz aus dem Munde einer wenig rühmlichen Colón-Figur. ${ }^{207}$

Es ist bezeichnend, dass Harris das Colón-Thema mit diesem Motto einführt. Zum einen handelt es sich um ein Zitat aus einem fiktionalen Text (anders also als die Zitate aus dem Bordbuch), zum anderen stellt es Colón negativ, nämlich als Blender und Lügner dar.

In Diario wird Colón nur sehr indirekt beschrieben: durch die ihm in den Mund gelegten Worte (zitiert oder angelehnt an Passagen aus dem Bordbuch oder an Briefe an das spanische Königshaus), durch die an ihn gerichteten Anreden (häufig wird er mit seinem militärischen Rang Almirante angesprochen, meistens eindeutig von den Männern, die zu seiner Mannschaft gehören) und manchmal durch eine Handlung, als deren Akteur er auftritt.

Der Viaje wird ebenfalls ein Motto vorangestellt, das von Colón handelt, ein Zitat von Wladimir Majakowski: „Acabarás tus días, / Cristóbal, / acabarás tu vida de perro.“ Auch hier wird das Leben des Colón keineswegs als des strahlenden Helden und ruhmreicher Entdeckers dargestellt, sondern als das eines Hundes, dessen Ende bevorsteht. Das Thema des Todes, das der Titel El último viaje bereits ankündigt, nehmen insbesondere die Texte in der zweiten Hälfte des Abschnitts auf.208

Die ersten beiden Texte des Abschnittes spielen auf den vermutlich schlimmsten Sturm an, den Colón während seiner Reisen erlebte. Océano de las tempestades (S123) übernimmt wörtlich die betreffende Stelle aus dem Bordbuch (Colón 1982:296), und En aquella mar fecha sangre (S124) nimmt noch einmal Bezug darauf, wobei diesmal Concepción zum blutigen Meer und Colón zum Gescheiterten wird:

nuestra tripulación de sombras

había perdido los fetiches en la huida,

${ }^{207}$ Frauke Gewecke über die Figur des Colón bei Carpentier: „,...doch vor dem Leser entsteht ein Bild, das trotz der extremen Überzeichnung der Persönlichkeitsstruktur des Colón näherkommt als jede bisher erschienene, mit dem Anspruch auf „Historizität‘ verfaßte Biographie.“ (Gewecke 1981:328)

${ }^{208}$ Bei Eduardo Galeano ist der Abschnitt über Colóns Tod El quinto viaje überschrieben. (Galeano 171989:63) 
habíamos olvidado las palabras mágicas en el miedo:

-Silencio, amor, pez?-

la visión se había vuelto un torbellino pálido,

un trombón de cuerpos y soledad. (S125)

Die Träume und der Zauber sind verlorengegangen inmitten der Flucht und der Angst. Die letzten beiden Verse kündigen den Colón an, der im gesamten Abschnitt begegnen wird: eine einsame Figur ohne Vision auf der Suche nach Körperlichkeit.

In El estrecho de la culpa (S159) muss die Figur des Colón mit dem „campesino medieval“ assoziiert werden: „iba así como un campesino medieval mirando los surcos de la / tierra, / pero tierra no había“. Colón wird normalerweise nicht nur seiner Lebensdaten sondern auch seiner Weltanschauung wegen als Renaissance-Mensch betrachtet, der die mittelalterlichen Vorstellungen hinter sich gelassen hat. Hier scheint er einen Rückschritt gemacht zu haben. Seine Situation wird als bedauernswert geschildert. Er ist verlassen worden von seinen ehemaligen Frauen ebenso wie von seiner „tripulación de sombras“ und denkt unablässig an „la carta de los cuerpos“. Hier begegnet eine stilistische Besonderheit, auf die im Zusammenhang mit den Gedichttiteln schon hingewiesen wurde. Die Begriffe sind zweiteilig: Ein Teil verweist konkret verstanden auf die Person des historischen Colón (hier: Mannschaft und Seekarten). Der jeweils andere Teil der Nominalkonstruktion (Schatten und Körper) metaphorisiert den Ausdruck. Nun sind es nicht mehr die Karten von Meeren und Ländern, die ihn beschäftigen, sondern die von Körpern, was die Isotopie der Sexualität in diesem Text aktualisiert. Auf dieselbe Bedeutungsebene gehören die „amores imaginarios" des Colón.

„Atrás quedaba el mundo conocido“ fügt sich leicht in den Kontext der historischen Figur, der der Welt eine neue Topographie gab - anders die parallel gebaute folgende Zeile „atrás los desteñidos avisos luminosos de las calles del centro“. Hier lässt sich die Technik der parallelen Syntax wiedererkennen, in der sich die Parallelität oder die unterstellte Parallelität der beiden Welten spiegelt.

Auf seinem Weg aus der Stadt begegnen dem Mann die Vergänglichkeit und der Tod. Es werden Dinge aus seinem Leben beschrieben, die schon lange zurückliegen, Dinge, die sich geändert haben, und nichts scheint sich für ihn zum besseren gewandt zu haben, alles klingt nach Verlust und Versagen. Auf seinem Weg liegt ein Toter, bedeckt mit alten vergilbten Zeitungsblättern. (Alte Zeitungen sind als Symbol der Vergänglichkeit zu verstehen, werden Zeitungen doch ausschließlich um ihrer Aktualität willen gelesen.) Durch den toten Körper wird außerdem die Ebene von Gewalt und Repression wieder aufgegriffen.

Die Verbindung der Themen Sexualität/Körperlichkeit einerseits und 
Gewalt/Machtausübung andererseits ist auch in den folgenden Texten eng mit der Figur des Colón verbunden.

Mar de los cangrejos (S165) greift sehr viel unzweideutiger Details aus dem Leben des historischen Colón auf. Das Gedicht ist in der zweiten Person geschrieben, der gesamte Text ist eine Anrede. Zwar ergibt sich aus dem Zusammenhang, dass, wie schon häufiger im Diario, Colón der Angesprochene ist, diesmal sind es aber nicht seine Zeitgenossen, die das Wort an ihn richten, sondern ein auktorialer, allwissender Erzähler. Er kann in das Innere Colóns blicken, berichten, was in ihm vorgeht und vorhersagen, was mit ihm geschehen wird. Insbesondere prophezeit er Folgendes:

te quedarás sin santos en la corte, y eso, en este mundo despiadado, significa el infierno y la muerte. (S165)

Colón läuft einsam und traurig durch den Regen und empfindet trotz sexueller Stimulation durch eine Straßenverkäuferin kein Begehren: ,pero la tenías magra“. Wie bereits in El estrecho de la culpa verbinden sich die trostlose Stimmung (Regen, Einsamkeit) mit dem Gefühl, im Leben gescheitert zu sein und dem sexuellen Unvermögen. Im Weiteren wird Colón vorausgesagt, dass er sich an nichts mehr werde erinnern können als an die verschiedenen Namen für Gold in den verschiedenen Gegenden, an denen er landete:

nada más te ibas recordando los nombres del oro,

tuob,

en la parte occidental de La Española;

canoa,

en la primera parte de la isla;

nosay,

en El Salvador y otras islas. (S165)

Ihm war ebenso wenig Erfolg beschieden wie den Alchemisten seiner Zeit, die Gold herstellen wollten: „tomando polvo de azufre y disolviéndolo con amoníaco y arsénico“. Doch mehr als die Namen ist ihm tatsächlich nicht vom Traum vom Gold geblieben: „entre las manos, ahora, el oro se te hacía / sangre, / esperma, / lágrimas“.

Die männliche Sexualität, wie sie in diesem Text beschrieben wird, steht im Gegensatz zu anderen Stellen, insbesondere im Text Mar de los besos rojos (S79):

machete en mano,

verga en mano, por el Poniente del Mundo (S79)

Diese Stelle, in der das Geschlechtsteil in der Hand mit einer Machete verglichen wird, mit der sich die Spanier den Weg durch den amerikanischen Urwald schlagen, greift wiederum 
zurück auf eine Stelle im vorangehenden Text Las islas de la arena (S77), auf die ich bereits in einem anderen Zusammenhang eingegangen bin: „Nos abríamos camino machete en mano, / tajando culos, / destasando tetas, / talando araucarias“ (S77). Hier war das männliche Glied noch eine Waffe, die die Eroberer zu führen verstanden; sie übten Gewalt damit aus, und sie gab ihnen Macht über die Menschen, bzw. die Frauen. ${ }^{209}$

Das folgende Gedicht Babia de la sequedad (S167) ist ebenfalls direkt an Colón gerichtet. Diesmal wird er in der ersten Zeile sogar ausdrücklich als Adressat benannt: „He aquí tu herencia, Almirante“. Der Doppelpunkt lässt uns die folgende Aufzählung als das Erbe des Colón verstehen, als Dinge oder Zustände, die ihm gewissermaßen zugeschrieben werden: vastos ejércitos de oligofrénicos y desalmados, verdes como la carne que transita por la muerte, sucios y perdidos [...] putas, enfermos y corroídos del cerebro. (S167)

Vor unseren Augen formieren sich die Geldbesessenen, Seelenlosen, die Geilen, Prostitutierten, Kranken und Wahnsinnigen zu einem Szenario, das der Erzähler mit einer mittelalterlichen Bußprozession vergleicht (,esta lacerada procesión de penitentes / como si todo esto fuera en pleno siglo XIV“). Der Text ist gespickt mit religiösen Begriffen („la cruz“, „el camposanto“, „la procesión de penitentes“, „los sambenitos“, „la ceniza“). In diesem Kontext kann das Verhalten der Menschen, das als habgierig, wollüstig, gewalttätig und krankhaft beschrieben wird („oligofrénicos“, „desalmados“, „,verdes“, „,sucios y perdidos“), nicht nur unmoralisch genannt werden, sondern wird zur Sünde im religiösen Sinn.

Die Prozession, die der Erzähler beschreibt, besteht nicht nur aus moralisch zweifelhaften Figuren, sondern auch aus Unglücklichen, die sich der Schwere ihrer Vergehen aus christlicher Sicht durchaus bewusst zu sein scheinen (Büßerhemd, Bußgang und Asche sind Zeichen der Reue und der Buße). Das Erbe des Colón besteht demnach nicht nur darin, die Menschen durch seine eigene Habgier nach Gold verdorben und krank gemacht zu haben, ${ }^{210}$ sondern außerdem darin, ihnen das Bewusstsein für ihre Verdorbenheit gleich mitgeliefert zu haben. Denn auch die Religiosität, die die Conquista mit sich brachte und die im Text mit Buße, mit Schuld und mit Scham in Verbindung gebracht wird, wird hier als Vermächtnis des Entdeckers dargestellt. Die Asche als Zeichen für den religiösen Akt der Buße bedeckt schließlich die ganze Stadt:

${ }^{209}$ Der Urwald, durch den man sich mit Macheten schlagen musste, heißt auf Spanisch ,selva virgen ${ }^{6}$, also ,jungfräulicher Wald' (vgl. auch Kapitel 8.3, S192f.).

${ }^{210}$ Zunächst geschah es zufällig, später vorsätzlich, dass die Völker Amerikas von den Spaniern mit der Grippe oder den Masern angesteckt wurden, die aufgrund fehlender Antikörper eine verheerende Wirkung hatten und ganze Stämme ausrotteten. 
ceniza empozada en cada estante,

libro,

rincón,

ceniza que nos enceniza las sábanas,

el mismo amor,

y se te pega al cuerpo;“ (167f.)

Religiöse Vorstellungen machen Körperlichkeit und Sexualität zur Sünde und verändern den Umgang damit. Der Titel Babia de la sequedad kann als die Folge davon, also als das „Austrocknen“, das Versiegen der Sexualität aufgrund von Unterdrückung und Verdrängung verstanden werden. Ähnliches gilt für die Überschrift des folgenden Textes Mar del frío (S169). Wir bringen sexuelle Handlungen mit Feuchtigkeit und Wärme in Verbindung, Trockenheit und Kälte deuten hingegen auf Frigidität hin.

Había tumbas tapizadas de felpa roja,

había lápidas fluorescentes,

había cráneos tremendos como mundos,

había espejismos y fuegos fatuos entre los mausoleos,

había mausoleos de hielo como mármol,

inscripciones había“" (S169)

In der Beschreibung entsteht ein Friedhof mit pompösen Grabstätten, prunkvoll geschmückt mit samtbezogenen Steinen und Marmorplatten mit Inschriften und „premoniciones indescifrables“, also mit Warnungen, die nicht entziffert werden konnten, und schließlich mit Botschaften von den Lebenden an die Toten, die unbeantwortet bleiben. Allerdings ist nur von weiblichen Toten die Rede: pero con las muertas es pobre industria. Es wird die sexuelle Annäherung von Seiten der Lebenden beschrieben und die Reglosigkeit und das Schweigen der toten Frauen.

se te enfría el bajo vientre y la mente,

se te queda pegado al cerebro el amor como culpa

y no responden (S169)

Die Frauen sind also nicht tot, es ist ihre Lust, ihr Begehren, das aufgrund der Schuldgefühle, die ihnen eingeredet werden, erstorben ist. Die Frigidität der Frauen wird mit der bereits erläuterten Episode in Verbindung gebracht, in der Colón eine Eingeborene gefangen nimmt:

fue ahí cuando travestimos al silencio, cuando vestimos al silencio de hembra, cuando le colgamos cuentas verdes de las tetas y el vientre (S169)

Damit wird der Umgang mit Sexualität in beiden Zeitebenen miteinander in Verbindung gebracht und zugleich die männlich dominierte Sexualität in Frage gestellt. Der Umgang 
mit der Frau - ihr die Mitsprache zu verbieten und sie mit Geschenken zu überhäufen ${ }^{211}$ lässt an die männliche Machtausübung denken, wie sie im Bild „machete en mano, / verga en mano“ (S79) Ausdruck findet. Die Verknüpfung von Liebe und Gewalt wurde bereits an anderen Stellen thematisiert, zB in Orompello II:

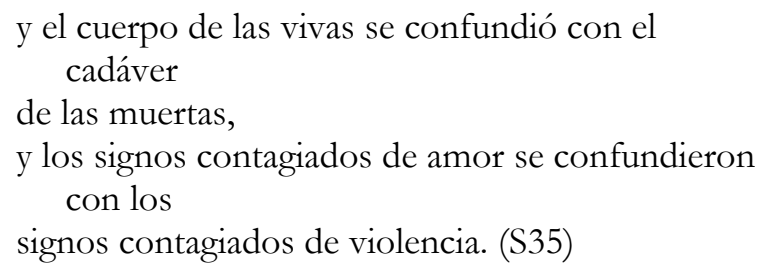

In diesem Textbeispiel vermischen sich lebendige und tote Frauenkörper, ähnlich wie der Friedhof sich belebt, hier jedoch verbinden sich parallel dazu Liebe und Gewalt.

In Los sentidos de la limosna (S173) spricht die Figur des Colón eine lange Bitte, eine Art Bittgebet an der Pforte des Franziskanerklosters „La Rábida“ und gleichzeitig in Concepción. Möglicherweise handelt es sich auch um zwei Figuren, aber allein Colón ist zu identifizieren aufgrund von Namen und Ereignissen, die sich in seine Biographie einordnen lassen. Zunächst ist das Kloster „La Rábida“ zu nennen, mit dessen Mönchen Colón vor Beginn seiner ersten Reise Kontakt pflegte. Dort fand er Zuflucht in Zeiten, als es wenig Hoffnung für ihn gab, seinen Traum von der Reise nach Westen jemals erfüllen zu können. (Gewecke 1981:319f.) Ein eindeutiger Hinweis auf die Figur des historischen Colón ist auch die Nennung derer, in deren Namen er seine Bitte vorbringt: Ptolomeus, Gott und Toscanelli, „a través de su idea del Mundo / que sería mi idea del Mundo“. Die drei Genannten waren von äußerster Wichtigkeit für den Entschluss Colóns, die Reise nach Westen anzutreten und zugleich diejenigen, auf die er seine geographischen Berechnungen stützte.

Die zweite bittende Figur befindet sich in den 80er Jahren in Concepción. Die beiden Figuren sprechen für zwei Welten, die parallelisiert werden: „,nosotros, los peor nacidos, / nosotros, los grandísimos hijos de la Madonna“. Der Effekt, der - einmal mehr - durch die Verschmelzung zweier Zeiten und Orte erzielt wird, wird selbst im Text beschrieben:

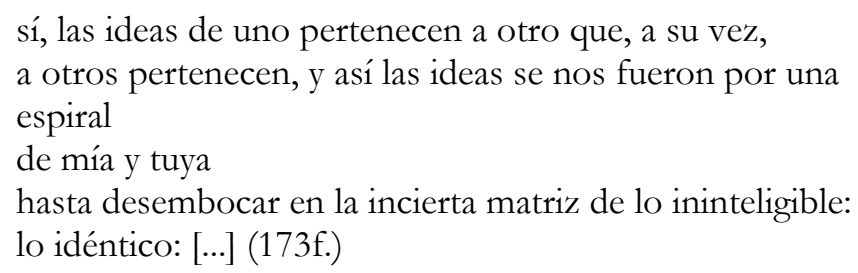

${ }^{211}$ In diesem Zusammenhang wird eine Nebenbebedeutung der Farbe der Perlen aktualisiert, da „verde“ auch „geil" und ,lüstern“ bedeuten kann. 
Für einen Moment sind die beiden Bittenden zu einer Figur geworden und beide bitten oder beten - für das Unternehmen, die Welt zu erweitern, den Erdball auszudehnen. Es ist Colóns Wunsch, weiße Flächen von der Landkarte zu tilgen und für seine Landsleute, „,nosotros, los grandísimos hijos de la Madonna“, zugänglich zu machen und dabei gottgefällig zu handeln: ,por eso ensanchamos el Mundo hasta esta esfera de / sangre de cordero“ ${ }^{212}$. Darübergeblendet ist das Ergebnis: „ensanchamos el mundo hasta / esta caca áurea / del 80, / ahora“. Diese Stimme spricht für ein anderes Wir: „,nosotros, los peor nacidos“. Aus dem Lammblut wird „,esmalte sintético“, nur eine Vortäuschung von Erlösung. Das Motiv der Täuschung, des Falschen, dominiert die letzten Zeilen des Textes, und mit den täuschenden Spezialeffekten werden aus den sieben Schöpfungstagen sieben Tage der Zerstörung:213

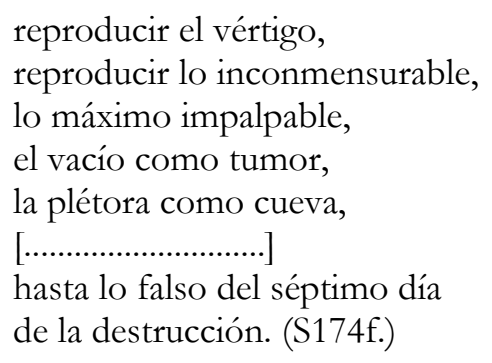

Mit dem Falschen, das zur endgültigen Zerstörung führt, könnten stellvertretend und symbolisch Colóns falsche Frömmigkeit gemeint sein, seine Lügen und Täuschungen, wie sie in dem Motto von Carpentier formuliert sind. Der Wunsch nach Erweiterung der Welt wird durch die Stimme aus den 80er Jahren jedenfalls verhöhnt und ad absurdum geführt.

Die Figur des Colón, die uns das gesamte Gedicht präsentiert, integriert verschiedene Ebenen, die der Text aufweist. Er verbindet die historische Zeit der Conquista mit der Gegenwart des Erzählers. Zum einen erhält die Figur eine gewisse Historizität durch die vermeintlich realistische Beschreibung seiner Situation. Der glücklose Goldsucher ist gesellschaftlich zur persona non grata im eigenen Land geworden und am Hof in Ungnade gefallen. Er lebt unzufrieden und unbeachtet, verlassen und gescheitert. Als solcher streift er durch die Straßen von Concepción.

\footnotetext{
${ }^{212}$ Das Lamm und sein Blut als Sinnbilder für Christus und sein Leiden symbolisieren die Erlösung der Welt. Das lässt an den Namen denken, den Colón sich selbst gab: Cristóforo, der ChristusTräger oder -Bringer. Er wollte Christus und seine Kirche in andere Länder bringen und so die Welt erlösen. Dies ist zumindest eines der wirklichen oder vorgeschobenen Motive für die Reisen des Colón.

${ }^{213}$ Die Zahl sieben spielt auch an anderen Stellen des Buches eine Rolle, zB „,y las casas siete casas con puertas de oro / y las putas siete putas vestidas con ropas blancas“ (S34); „húmedos de las 7 formas del deseo“ (S172); „¿Por qué el 7? / [..................] / recordé los 7 pecados capitales, / recordé las 7 virtudes teologales, / recordé las 7 maravillas deste Mundo“ (S222).
} 
In Mar del frío und Babia de la sequedad geht das Thema weit über die Person und Biographie Colóns hinaus. Er steht für die gesamte Conquista und alles, was in den 500 Jahren nach der Entdeckung folgte, wird als sein Erbe bezeichnet, er wird verantwortlich gemacht. Colón wird angeklagt, stellvertretend für die Spanier oder die Europäer, stellvertretend für alle Eroberer oder Entdecker oder Männer (je nach Interpretationsebene). Er wird angeklagt, dem Kontinent eine Macht und eine Religion aufgezwungen und dabei Lust und Begehren ausgelöscht zu haben. Es scheint, als wären die Bedingungen, in denen die Menschen heute in Concepción leben, auf Colón zurückzuführen.

\subsection{Verflechtungen der Geschichte}

Es ist deutlich geworden, dass es sich bei den einzelnen Motiven nicht nur um ein Nebeneinander von einzelnen thematischen Komplexen handelt, sondern dass sie sich auf zwei einander überlagernden Ebenen des Textes bewegen, die verschiedene Deutungsmuster des gleichen Sachverhalts darstellen. Wörter, Sätze, Szenen oder ganze Gedichte können häufig beiden Ebenen zugleich zugeordnet sein und somit unterschiedlich interpretiert werden. Ich habe gezeigt, wie die fünf Themenkreise, die ich in den Mittelpunkt der Analyse gestellt habe, sich zum einen in den beiden Szenarien jeweils unterschiedlich konkretisieren und wie sie zum anderen miteinander Verbindungen eingehen. Die Flucht in die Fiktion hilft, die politisch-gesellschaftliche Realität zu verdrängen, die Suche nach Gold paart sich mit dem Griff nach der Macht, die ausgeprägte Rolle der sinnlichen Wahrnehmung macht die Menschen offen für Fiktionen, ein repressives System unterdrückt auch die Sexualität, um nur einige der möglichen Kombinationen zu nennen.

Das Buch ist ein Vexierspiel, ein Spiegellabyrinth, in dem man Abbildungen sieht und nie weiß, ob es sich um eine einfache sprachliche, bzw. literarische Abbildung der Wirklichkeit handelt, um die Abbildung einer Abbildung oder um die Verzerrung einer Abbildung einer Abbildung. Ich habe Textstellen gezeigt, die sich eng an den Originaltexten von Colón orientieren. Allerdings sind die Texte aus dem Bordbuch sowohl durch Colóns Wahrnehmung als auch durch seine Intentionen beim Schreiben nur noch verzerrte Spiegelbilder der tatsächlichen Ereignisse. Und selbstverständlich ist das Bordbuch bereits eine von Las Casas redigierte und kommentierte Bearbeitung von Colóns Originaltexten.

Die auffällig häufige Erwähnung von Sinneswahrnehmungen beschreibt den Versuch des Menschen, seine Umwelt im eigenen Geist abzubilden und wiedererkennbar zu machen (so wie das optische Bild auf der Netzhaut gespiegelt wird). Doch dies wird als schwieriges 
Unterfangen beschrieben, da schon die (urbane) Umwelt voll ist von Spiegelungen und Täuschungen.

Im selben Zusammenhang wird der Versuch thematisiert, vergangenes wie gegenwärtiges Geschehen zu fiktionalisieren, also als fiktional darzustellen, um sich selbst davon distanzieren zu können. Auch hier entstehen Wechselwirkungen zwischen der inszenierten Wirklichkeit, der erinnerten Wirklichkeit und einer (vermeintlich) unverfälschten Wirklichkeit.

Das Wahrnehmen und Darstellen von historischen Ereignissen ist im Text der Willkür des Erzählers, aber auch dem Einfluss verschiedener äußerer Umstände ausgeliefert (optische Täuschungen, Lügen, Zensur). Man kann sich keiner Aussage, noch weniger aber der eigenen Wahrnehmungen sicher sein. Mit einer Mischung aus epischer Dichtung, surrealistischen Bildern und fast gebetsartigen Wiederholungen, Quellentexten, Werbeslogans und nachgestellten Szenen wird die Vergangenheit zu einem Teil der Gegenwart.

Colón erscheint in der Straße Orompello. Andere Figuren aus einer Epoche finden ihre Entsprechung in der jeweils anderen Zeit. Das Gold und die Frage nach seiner Authentizität spielt in beiden Szenarien eine Rolle. Moderne Sprache und das Spanisch des sechzehnten Jahrhunderts wechseln einander ab. Gewalt, Sexualität, Verzweiflung und Elend werden in beiden Welten mit den gleichen Worten und Bildern beschrieben. Oftmals steht nur zwischen den Zeilen, dass die Gegenwart in Orompello von Repression und Gewaltausübung durch das Militärregime geprägt ist. Durch immer neue Indizien wird dies aber zu einem der wichtigsten Themenkreise des Textes, der sich wiederum mit den anderen verbindet.

Dadurch, dass die verschiedenen Motive nicht nur auf den beiden Ebenen zweier historischer Zeiten wiederkehren, sondern oft in verschiedenen Kombinationen mit den anderen Motiven, werden historische Zeiten, historische Geschehnisse und ihre Folgen in der Gegenwart unlösbar miteinander verknüpft. Insbesondere die aktuellen Zustände wie Machtmissbrauch, verdrängte oder aber gewalttätige Sexualität, Leere der christlichen Traditionen sowie allgegenwärtige Täuschung und Künstlichkeit sind auf diese Weise dem Text nach bereits in der Conquista angelegt. 


\section{Trujillo Über Mansilla Über Trujillo: GEGENWARTSGESCHICHTE}

Im letzten Analysekapitel dieser Arbeit behandele ich einen Sonderfall, nämlich das Zusammentreffen von Poesie und Reflexion über Poesie anhand der beiden Dichter Sergio Mansilla und Carlos Alberto Trujillo. Eine außergewöhnliche Konstellation ergibt sich dadurch, dass beide Autoren nicht nur selbst Lyriker sind, sondern gleichzeitig Literaturwissenschaftler und -kritiker und sich eingehend mit der Lyrik des jeweils anderen beschäftigt haben. Insbesondere werde ich mich mit ihren Dissertationen befassen, in denen beide die neuere südchilenische Lyrik in den Blick nehmen.

Carlos Alberto Trujillo hat 1993 in Pennsylvania seine Dissertation Por la décima region: Poesía del sur de Chile (1973-1993) eingereicht. Drei Jahre später hat Sergio Mansilla Torres an der Universität von Washington, Seattle, seine Dissertation Poesía del sur de Chile 1975-1995. El paraíso vedado o el deseo de un lenguaje y de una bistoria verteidigt. Nicht nur das Thema und der Zeitraum, die die beiden Arbeiten untersuchen, stimmen beinahe exakt überein, auch ihre geographischen „Einzugsgebiete“ sind fast deckungsgleich. Beide legen als Schwerpunkt ihrer Untersuchungen die zehnte Region Chiles fest. ${ }^{214}$ Somit haben beide Dichter - selbst weit entfernt von ihrer Heimat - denselben Schwerpunkt für ihre Dissertationen gewählt.

Trujillo, der Ältere von beiden, wird 1950 in Castro auf Chiloé geboren. Er studiert von 1969 bis 1973 in Temuco Spanisch auf Lehramt und gründet 1974 in Castro die literarische Gruppe Aumen. 1977 erscheint seine erste Veröffentlichung Las musas desvaídas. Es folgen Escrito sobre un balancin (1979), Los territorios (1982) und Los que no vemos debajo del agua (1986). 1992 publiziert er die Anthologie Mis límites. Antología de poesía (1974-1983). Insbesondere durch seine unermüdliche Arbeit als Initiator und Organisator von kulturellen und literarischen Veranstaltungen sowie als Herausgeber von Anthologien und der Zeitschrift der Gruppe Aumen ist Trujillo zu einer der wichtigsten Figuren in der literarischen Landschaft Südchiles geworden. Iván Carrasco bezeichnet ihn als „el fundador de la poesía contemporánea de Chiloé“. (Carrasco 1989c:149) Drei der wichtigsten Vertreter, die aus seiner

\footnotetext{
${ }^{214}$ Die einzige Ausnahme bei Mansilla ist Elicura Chihuailaf, der aus der neunten Region stammt. Ansonsten untersucht Mansilla die Dichtung von Jorge Torres, Carlos Trujillo, Clemente Riedemann, David Miralles und Rosabetty Muñoz. Trujillo behandelt Texte von Mario Contreras Vega, Sergio Mansilla Torres und Rosabetty Muñoz.
} 
Literatur-Werkstatt Aumen hervorgingen, sind Rosabetty Muñoz, Mario Contreras Vega und Sergio Mansilla. Ausschließlich deren Texte sind es auch, die Trujillo in seiner Dissertation vorstellt und untersucht.

Mansilla wird 1958 in Achao, ebenfalls auf Chiloé, geboren, wo er früh zu der Gruppe Aumen stößt. 1976 geht er nach Valdivia, um an der Universidad Austral Spanisch und Philosophie zu studieren. Anfang der 90er Jahre ist er für einige Jahre an der Universität von Seattle und unterrichtet seit seiner Rückkehr nach Chile Literatur an der Universidad de Los Lagos in Osorno. 1986 veröffentlicht er seinen ersten Gedichtband Noche de agua. 1991 erscheint El soly los acorralados danzantes und drei Jahre später (1994) De la buella sin pie.

Dieses Kapitel wird im Gegensatz zu den vorhergehenden weniger Analysen der Dichtung beinhalten, als vielmehr Betrachtung und Gegenüberstellung der bereits vorliegenden Analysen des einen Dichters über den anderen, um herauszustellen, worauf sie jeweils fokussieren und um zu zeigen, inwieweit der jeweils andere als Spiegel oder Projektionsfläche der eigenen Produktion betrachtet werden kann.

\subsection{Trujillo über Mansilla}

Trujillos Dissertation ist in ihrer Konzeption eine sehr allgemein gehaltene Untersuchung der von ihm so genannten 78 er Generation von Chiloé. In der Einleitung bestimmt er das Ziel der Arbeit:

[...] dar a conocer la existencia del movimiento poético desarrollado en la Décima Región y particularmente en Chiloé a partir de 1973, demostrar su validez e importancia como conjunto, las características que los particularizan en el contexto de la poesía chilena del mismo período y sus aportes a la tradición poética del país a través de la obra de tres de sus más destacados representantes. (Trujillo 1993b:Introducción)

Wie schon erwähnt, stellt er die südchilenische Dichtung am Beispiel von nur drei Personen vor: Rosabetty Muñoz, Mario Contreras und Sergio Mansilla. Im folgenden Zitat aus der Einleitung der Arbeit streicht er zwei Aspekte heraus, die die besonderen äußeren Umstände der südchilenischen Dichtung nach 1973 betreffen:

Este estudio surge de la necesidad de llenar en parte el gran vacío histórico-crítico que existe en relación a la literatura chilena escrita después del golpe de estado y, en especial, a la de los narradores y poetas que comenzaron a publicar y/o a escribir alrededor de esa fecha. Los poetas a quienes dedico estas páginas se encuentran en una zona aun más subterránea en cuanto a falta de estudios sobre sus obras debido al hecho de haber nacido y permanecido viviendo en el lejano sur de Chile; país en el que vivir en provincia es sentir permanentemente y de diversas maneras el peso de la marginalidad. (Trujillo 1993b:Introducción)

Zum einen weist er hier auf die Bedeutung des Staatsstreiches und seiner Folgen für die literarische Aktivität im gesamten Land hin, zum anderen gibt er die geographische und 
politische Randständigkeit der Schriftstellerinnen und Schriftsteller im Süden Chiles zu bedenken. Beide Aspekte werden seine Untersuchung in gewissem Maße leiten, beides wird er immer wieder als prägende Faktoren hervorheben:

La poesía de Contreras, Mansilla y Muñoz, escrita en las últimas décadas en medio de una específica circunstancia histórica (Chile en las dos últimas décadas) y política (dictadura de Pinochet) y en un medio geográfico de características muy particulares (Chiloé, sur de Chile) [...]. (Trujillo 1993b:Kap.3)

Im ersten Kapitel behandelt Trujillo die chilenische Dichtung vor 1973, um den anschließenden Zeitraum, dem sein eigentliches Interesse gilt, vorzubereiten. Es folgen vier Kapitel, die die Texte von Muñoz, Contreras und Mansilla unter verschiedenen Fragestellungen untersuchen. Den Abschluss bilden Interviews mit der Autorin und den beiden Autoren.

Im Rahmen dieser Arbeit stellt sich die Frage, inwieweit und auf welche Weise Trujillo die Historizität, bzw. die Umsetzung von Geschichte in der Dichtung, die zunächst keinen zentralen Punkt in der Konzeption der Arbeit darstellt, innerhalb seiner Untersuchung thematisiert. In den ersten beiden Textanalysekapiteln findet Geschichtsbetrachtung in der Tat nur sehr am Rande Erwähnung. Es fällt auf, dass der eigentliche Schwerpunkt immer wieder auf der eigenen Gegenwart und Zukunft liegt (und somit gleichzeitig auf der der Autorinnen und Autoren). So ruft Trujillo zum einen häufig die jeweils kontingenten Umstände der Entstehungskontexte ins Gedächtnis; zum anderen interessieren ihn die intendierte sowie die tatsächlich erzielte Wirkung der Gedichte auf Leserinnen und Leser. Ich werde mich im Folgenden hauptsächlich auf das dritte und vierte Kapitel (Imagen de la voz. lírica und Concepto y función de la poesía) beschränken, in denen die Darstellung der Geschichte an einigen Stellen deutlich angesprochen wird.

Zunächst untersucht Trujillo die verschiedenen Stimmen, die in den Gedichten zu Wort kommen, die verschiedenen Perspektiven, aus denen der Autor oder die Autorin die Welt beschreibt. Am Beispiel des Gedichtes Cauquil von Mansilla arbeitet Trujillo ein lyrisches Ich heraus, das ganz in seiner sozialen und historischen Bedingtheit verhaftet ist: im bäuerlichen Leben auf Chiloé zur Zeit der Diktatur. Carrasco beschreibt das lyrische Ich als Stimme „que habla desde la pobreza, reduciendo su estilo, su lenguaje, su retórica, su proyecto de escritura no por carencia o incapacidad, sino por compromiso voluntario y lúcido con esa forma de vida." (Carrasco 1986:12) Auch hier ist die unmittelbare Gegenwart die Form, in der uns die Geschichte entgegentritt. 
Aber gerade bei Mansilla bemerkt Trujillo ebenfalls die Stimme eines Dichters, der weiterblicken kann, der zuversichtlich in die Zukunft schaut und die Macht der Sprache und der Dichtung beschwört:

Y estos Poemas son los que deambulan por los montes, los verdaderos prófugos de las verdaderas prisiones; estos que un día sembró bajo la tierra para el futuro. (Mansilla 1991:68)

Trujillo unterstreicht die konstruktive, in die Zukunft gerichtete Kraft dieser Verse über Gedichte (deren Majuskel ihre Bedeutung noch betont): „tiene confianza en los tiempos futuros que él (con sus versos prófugos, perseguidos y negados por el sistema igual) está ayudando a construir“،. (Trujillo 1993b:Kap.3.1.1)

Fast im Vorübergehen erwähnt Trujillo, dass unter den Stimmen, die Mansilla in seinen Texten vernehmlich macht, auch die von Alonso de Ercilla ist: „pero sí pueden encontrarse otros que encarnan a seres históricos como en el poema en que la voz que se oye es la de Alonso de Ercilla“. (Trujillo 1993b:Kap.3.1.4)

Ein wenig mehr Augenmerk legt Trujillo hingegen auf Mansillas Text Muerte de Hector, obgleich er ihn als Beispiel für eine Technik bezeichnet, die Mansilla nur selten verwende. Zunächst zeigt Trujillo anhand eines Gedichtes von Contreras Vega, wie historische Daten und Begebenheiten stellvertretend für die eigene Gegenwart stehen können. Im Text Despedida, mit dem das Buch Palabras para los días venideros endet, spricht Contreras Vega zu seinem Gegenüber von einer Laute und von der heiligen Musik auf den Feldern bei Florenz. Über all dem liegt die Gefahr, verschwiegen zu werden und in Vergessenheit zu geraten: „Nadie queda que sepa tu historia y la cuente.“ (Contreras Vega 1984:87) Trujillo interpretiert die Elemente folgendermaßen: Das Du wird zum lyrischen Ich, die Laute und die Musik werden zur Dichtung des Ich und seiner Zeitgenossen, und die Landschaft bei Florenz wird die heimatliche Landschaft Chiloés. Die Bedrohung durch Schweigen und Vergessen entspricht der Repression und Zensur von Seiten der Militärregierung.

An dieses Beispiel für das symbolische Mit-Meinen einer anderen Realität hinter der offensichtlich thematisierten Wirklichkeit knüpft Trujillo mit einem Text von Mansilla an:

No es común el uso de esta técnica en Mansilla aunque sí ofrece un buen ejemplo de ella en el poema „Muerte de Héctor“, en que tras un juego de intertextualidades oculta el verdadero sentido y objetivo del poema donde la muerte de Héctor y el dolor contenido de Príamo se hiperbolizan al representar a todos los Héctores y Príamos que con otros nombres habitan en la historia chilena de los últimos años. (Trujillo 1993b:Kap.3.2.1) 
Trujillos Kommentar zu Muerte de Héctor beschränkt sich auf diesen einen Satz. Ich werde etwas genauer auf das Gedicht eingehen.

No deberías guardar tus lágrimas, oh Príamo, para otra ocasión que puede no llegar: estamos en el tiempo preciso de la muerte de Héctor, el más valiente mortal de Troya.

Deberías reconocerle entre los cadáveres que entierras en las noches sin luna y llorar, llorar de rabia contra el viento, contra las rocas, infinitivamente.

$[$.................................

Derrama tus lágrimas, oh Príamo

No detengas tu dolor sobre esta hoguera de casas que arden en las calles de Troya. (Mansilla 1986:58)

Das Gedicht steht auf der ersten und offensichtlichen Bedeutungsebene im Kontext des Trojanischen Krieges, also mit einem Fuß auf historischem Boden, mit dem anderen in der Welt der griechischen Mythologie. Er greift die Situation auf, in der Hektor von Achilles getötet und der Leichnam geschändet wird, und fordert den Vater Priamos zur Trauer um seinen Sohn auf. Eine Reihe direkter und indirekter Befehle richten sich an den Vater: „,no deberías“, „deberías“, „deberías“, „deja“, „cuida“, „debes“, „derrama“, „,no detengas“. Er soll im Fieber der Schlacht nicht vergessen zu trauern, sondern den Schmerz, die Tränen, aber auch den Zorn zulassen: „llorar de rabia contra el viento, / contra las rocas, infinitamente“.

Auf der verborgeneren Ebene spricht Mansilla seine Mitmenschen an, die mit ihm unter der Herrschaft der Diktatur leiden. Viele von ihnen haben zum Zeitpunkt, da er den Text schreibt (1982), bereits jemanden aus ihrer Familie oder ihrem Bekanntenkreis verloren. Sie sollen angesichts so vielen Leides nicht abstumpfen, nicht verlernen zu trauern, sondern Wut und Schmerz am Leben erhalten. Hektors Leiche wird der Sage nach geschändet, indem Achilles ihm die Haut abziehen und den blutigen Leib um die Stadt schleifen lässt. Solche Unmenschlichkeit erreicht die Dimension der Folter, die zu den Maßnahmen der chilenischen Diktatur gehörte. Es entsteht eine Parallele der Brutalität und der Grausamkeit.

An einer anderen Stelle seiner Dissertation bespricht Trujillo ein Gedicht von Contreras Vega, den dieser einem Mann namens Santana gewidmet hat, und erklärt:

Héctor Santana, dirigente comunista de Quellín, asesinado en la comisaría de carabineros de ese pueblo cuando fue a entregarse a la autoridad militar para que liberaran a su esposa, pocos días después del golpe de estado. (Trujillo 1993b:Kap.4.5) 
Es verwundert, dass Trujillo diese Information nicht in Zusammenhang mit dem Gedicht von Mansilla gebracht hat. Quellín ist eine der Inseln des Archipels um Calbuco, einer Chiloé benachbarten Inselgruppe. Aufgrund der geographischen Nähe muss vorausgesetzt werden, dass der Vorfall auch Mansilla bekannt war. Somit liegt es nahe, dass er bei seinem Text Muerte de Héctor an den Dirigente gleichen Vornamens gedacht hat, ihn zumindest mitgemeint hat.

Im Gedicht Contreras' heißt es über Santana:

Aunque hoy vosotros no sepáis quien fue Santana o el mismo espíritu no sepa de Santana porque no tienen cruces nuestros pequeños héroes porque no hay cronistas que escriban esta historia. (Contreras Vega 1984:23)

Das Kreuz, das Mansilla mit seinem Gedicht Muerte de Héctor für Santana aufstellt, ist nur für Eingeweihte sichtbar, trotzdem entspringt es ebenfalls dem Bemühen, die Geschichte (esta historia) nicht in Vergessenheit geraten zu lassen.

Selbst in diesem Text gibt es noch einen zuversichtlichen Blick in die Zukunft: ,pero cuida el futuro, Príamo: / los dioses protegen los grandes espíritus / aun en la desgracia y en la muerte.“ (Mansilla 1986:58)

Trujillo hat Muerte de Héctor zwar in nur einem Satz abgehandelt, hat aber doch die Doppelung der Deutungsebenen und die verbergende und tarnende Funktion der geschichtlichen Darstellung betont.

Noch ein weiteres Mal sind es Stimmen der Erinnerung, die Trujillo in den Texten aufdeckt. So vergleicht er den Stil Muñoz', Mansillas, und Contreras' mit der Dichtung Ernesto Cardenals:

El estilo narrativo o seminarrativo (tercera persona, enunciación) encuentra un terreno fértil en la obra de estos poetas que como Ernesto Cardenal quieren dar cuenta de la historia que les tocó vivir, ser cronistas de su tiempo. (Trujillo 1993b:Kap.3.4)

Trujillo spricht ausdrücklich von „la influencia del nicaragüense en gran parte de los poetas chilenos del período“. Wie ich bereits an mehreren Beispielen gezeigt habe, kann dieser Vergleich sich nicht nur auf den Stil beziehen, sondern muss auf die inhaltliche Beschäftigung mit der Geschichte, die die Dichter zu „cronistas“ machen, ausgedehnt werden. Trujillo spricht diese inhaltlichen Ebene nicht an. ${ }^{215}$

Bisher ist das Thema der Geschichte bei Trujillo lediglich an einigen Stellen angeklungen. Im Verlaufe seiner Arbeit wird aber die Gegenwart, also die unmittelbar erlebte Geschichte, zu einem Grundmotiv: 
En la casi decena de libros de los tres poetas estudiados vemos una poesía fuertemente comprometida con la contingencia histórica de su medio, con los sufrimientos y esperanzas de su pueblo... (Trujillo 1993b:Kap.4)

Diese Beobachtung Trujillos ergibt sich aus den Funktionen, die er in der ihm vorliegenden Dichtung sieht. Im Wesentlichen seien es drei Aufgaben, die die Dichtung von Muñoz, Mansilla und Contreras übernehme: für diejenigen zu sprechen, die nicht sprechen können („,voz de los que no tienen voz“); die Wirklichkeit zu demaskieren („una función desenmascaradora“); und Anklage gegen die politischen Verhältnisse zu erheben (,instrumento de denuncia“). (Trujillo 1993b:Kap.4) Diese Aufträge, die die Dichtung habe, hingen unmittelbar mit der historischen und politischen Gegenwart der Dichterinnen und Dichter zusammen. Als Beispiel für eine indirekte Bezugnahme auf die Gegenwart als nennt Trujillo die in den Texten häufig spürbare Angst:

El temor aparece como una sensación omnipresente que llega desde todos lados y no es ajena a nada ni a nadie. Es un temor que si no detiene, al menos, transforma el curso de la existencia con su persistente presión sobre todo lo que hay en el mundo poetizado. (Trujillo 1993b:Kap.4)

Sehr deutlich wird Mansilla in dem Text Los ojos callando, den Trujillo im Folgenden heranzieht:

Quedaron manchas de sangre

y una cuchara gastándose de soledad.

Los ojos del muerto

filmaron el último video

y lloraron en la escena final... (Mansilla 1991:109)

Hier verschmelzen die Funktionen miteinander, die Trujillo der Dichtung zuschreibt. Der letzte Film, den der Sterbende mit seinen Augen aufzeichnet, steht für den nicht mehr existierenden Augenzeugen, also für den Wunsch oder den Versuch, die Wahrheit aufzudecken - in diesem Fall ein gescheiterter Versuch. Gleichzeitig leiht Mansilla jemandem, der nicht mehr selbst sprechen kann, seine Stimme für die Anklage.

Trujillo nennt sieben weitere Gedichte aus dem Buch El sol y los acorralados danzantes, „[que hacen] referencia y [son] claramente una denuncia de algunos hechos puntuales de la historia cercana de su país.“ (Trujillo 1993b:Kap.4.2)

Neben den Gedichten, die die Zustände im Land an sich anprangern, gibt es andere, die die Desinformation über eben jene Zustände beklagen: „Igualmente esta poesía denuncia la manipulación de las informaciones que se hace en los medios oficiales de comunicación“. Als Beispiel führt er Mansilla mit seinem Text Espejos an:

${ }^{215}$ Es ist festzustellen, dass trotz der erwähnten narrativen Merkmale keine Anklänge an epische Versdichtung zu erkennen sind wie es bei allen anderen bisher untersuchten Texten der Fall ist. 
Los espejos han perdido toda exactitud;

no reflejan más que formas

disparatadas, locas imágenes en un fondo

de sueño

$[$................................

cada uno con sus pecados públicos

disfrazados de curiosos y vulgares pretextos. (Mansilla 1986:61)

Mansilla beklagt die Verlogenheit nicht nur der offiziellen Stellen, der Massenmedien und der Stellungnahmen der Regierung, sondern auch die Unehrlichkeit der Einzelnen untereinander. Aus Angst oder Unsicherheit sagt niemand mehr, was er denkt; irgendwann wissen die Menschen selbst nicht mehr, was sie wirklich denken.

Trujillo findet in anderen Texten Mansillas ähnliche Anklagen angesichts der Gegenwart und der aktuellen Lebensumstände:

En otro poema del mismo autor se denuncia el grado de enajenación a que ha llegado ese país donde realidad, horror, ficción y maravilla se han transformado en conceptos tan parecidos. [...] Es también denuncia de la fuerte agresión económica que llega desde afuera a saquear los recursos naturales del archipiélago, a empobrecer la tierra, los ríos, los mares; a despojar de sus derechos a los habitantes de esa zona y a exponerlos a una forma de explotación y de pobreza que ellos desconocen; [...] (Trujillo 1993b:Kap.4.2)

An anderer Stelle nimmt Trujillo zwar expliziter, aber kaum ausführlicher Bezug auf das Thema der Geschichte in den lyrischen Texten. Die folgenden Sätze klingen wie ein Programm, das allerdings von Trujillo nicht eingelöst wird, weil er es weder illustriert noch erklärt:

La poesía como historización del mundo chilote, tanto de la vida individual como de los hechos que han afectado a toda la comunidad. Historización hecha en el medio mismo de esa historia, por hombres y mujeres que forman parte de ella. (Trujillo 1993b:Kap.4.5; Hervorhebung von Trujillo)

Die Dichtung historisiert die Welt der Chiloten, sie macht sozusagen aus Alltag Geschichte - im Moment der Geschichte selbst und durch die Personen, die gleichzeitig Subjekte und Objekte dieser Geschichte sind. Einerseits geschieht die Geschichte ihnen gerade erst, ${ }^{216}$ andererseits machen sie die Ereignisse durch ihre Reflexion und durch das Niederschreiben zur Geschichte. Trujillo nennt die Dichtung der Autoren und der Autorin, die er untersucht „una maravillosa memoria colectiva“ (Trujillo 1993b:Kap.4.5), weil diese Dichtung detalliert das Leben der Menschen auf Chiloé aufzeichnet: „[V]a enumerando detalle a detalle hechos, mitos, costumbres, dolores, personajes, en fin, toda la vida de ese territorio llamado Chiloé desde su mismo mítico origen“. In diesem Punkt hält er die neuere Dichtung Chiloés für durchaus vergleichbar mit der Dichtung „de algunos cronistas de Indias“. (Trujillo 1993b:Kap.4.5)

${ }^{216}$ Vgl. res gestae und die Erzählung davon (Kapitel 2.2.1, S12, Fußnote 7). 
An der Stelle, an der die Darstellung von Geschichte scheinbar explizit zum Untersuchungsgegenstand wird, nennt Trujillo zwar historische Personen, die sich in Mansillas Texten wiederfinden, versäumt es allerdings, ihre Funktionen zu beleuchten:

Los personajes y hechos aludidos abarcan los más diversos campos, formando un amplio espectro y configurando la imagen de un mundo completo en el que las figuras importantes conviven con los seres comunes. Así nos enteramos de la llegada de Ercilla a Chiloé el 28 de febrero de 1558, que pone a la isla en la poesía y en la historia escritas en castellano. [...] También en las primeras páginas nos enteramos de la existencia del legendario cacique Antonio Huenteo, máxima autoridad del pueblo huilliche de Chiloé durante algunas décadas del presente siglo. (Trujillo 1993b:Kap.4.5)

Trujillo will die zahlreichen historischen Situationen lediglich - etwas pauschalisierend - als Parallelen zur Gegenwart verstanden wissen, ohne sie im Einzelnen zu untersuchen. Insgesamt entsteht der Eindruck, dass das Thema der Geschichte für Trujillo nicht von allzu großem Interesse ist. Dennoch kann er nicht umhin, es immer wieder anzusprechen. In seiner conclusión fällt nochmals der Begriff der „historización del mundo chilote“ als eines der Merkmale der Dichtung der 78er-Generation von Chiloé. Aus den Beispielen, die Trujillo anführt, kann geschlossen werden, dass die historización, die er meint, im Wesentlichen gegenwartsbezogen ist. Die Dichterinnen und Dichter legen Zeugnis über die Gegenwart ab, die sie erleben, und schreiben ihre eigene Gegenwart in die Chronik ein: „El poeta entonces se vio forzado a ser cronista de su tiempo“. (Trujillo 1993b:Conclusión)

\subsection{Mansilla über Trujillo: „Carlos Trujillo: El sueño de otra historia“}

„Su poesía [...] está indeleblemente ligada a la contingencia histórica chilena de los años 70 y 80 , aunque en su superficie textual hallemos pocas referencias a la exterioridad política del momento“. (Mansilla 1996c:35) So fasst Mansilla in einem Satz die Rolle der Geschichte in der Dichtung Trujillos zusammen.

Mansilla hebt in seiner Dissertation wie auch in dem Aufsatz Carlos Trujillo: El sueño de otra bistoria (Mansilla 1996c) die Bedeutung des Gegensatzpaares pasado und presente innerhalb der südchilenischen Dichtung immer wieder hervor: „la oposición fundante ,pasado“ v/s ,presente como ejes articuladores de la representación de una temporalidad histórica“. (Mansilla 1996c:35) Eben jene Reduzierung des gesamten Zeitstrahls auf zwei bestimmte Punkte, die als einander entgegengesetzt empfunden würden, führe zu einer besonderen Vorstellung und Darstellung von Geschichte. Gegenwart und Vergangenheit würden zum Symbol für zwei Welten, die nichts mehr gemein haben, obwohl sie nur durch den Verlauf der Zeit getrennt seien. 
Die Opposition ist sehr umfassend und prägt Mansilla zufolge das Erleben, das Selbstverständnis sowie das Werk einer ganzen Generation von Dichterinnen und Dichtern, „aunque en su superficie textual hallemos pocas referencias directas a la exterioridad política del momento.“ (Mansilla 1996c:35) Dieses stark vereinfachte Modell einer eigenen polarisierten Geschichte bringt zwangsläufig eine moralische Bewertung der beiden Bereiche mit sich, die auf einer ideologischen Verortung fußt. Dazu gehört zum einen die positiv besetzte Vorstellung von einem verlorenen Paradies, das zusammen mit der Vergangenheit unwiederbringlich verschwand. Zum anderen erkennt Mansilla in der dargestellten Gegenwart im Wesentlichen die in der Vergangenheit gescheiterten Hoffnungen für eine bessere Zukunft. Insbesondere Trujillos Dichtung sieht er als Ausdruck dieser unglücklichschicksalhaften Verstrickung der Zeiten:

Y la poesía de Trujillo no es la exepción. Al contrario, su escritura evidencia una aguda historización por la persistente reflexión metapoética reiterada que problematiza la poesía por ser, justamente, parte de este presente doloroso que vino a surgir como resultado del fracaso de las expectativas de futuro en el pasado. (Mansilla 1996c:35)

Es mag erstaunen, dass ausgerechnet in der metapoetischen Reflexion der Schlüssel zur Geschichts- und Gegenwartskritik Trujillos liegen soll, ist doch die selbstbezügliche Dichtung in der Literaturgeschichte häufig diejenige gewesen, mit der sich der Dichter von der Kontingenz der eigenen Geschichte abgrenzt und sich von der Gegenwart als konkretem historischen Moment zurückzieht. ${ }^{217}$ Mansilla erkennt hier jedoch die metapoetische Reflexion in Trujillos Texten als Instrument, das dazu dienen soll, den Gegensatz zwischen einer Vergangenheit, in der es noch Hoffnung gab, und einer Gegenwart, die das Scheitern dieser Hoffnungen verkörpert, darzustellen. Denn selbst die Dichtung, die von der Dichtung handelt, ist noch Bestandteil ihrer Zeit, in diesem Fall eines „presente doloroso“.

In dem auf den ersten Blick völlig zeitlosen Text Territorio de las palabras feiere Trujillo zunächst die Entstehung von Wort und Dichtung:

Cuando nació la idea

la palabra esperaba su momento

esperaba el hilo conductor

oculto entre las rocas y las cuevas

Cuando vivió la idea y fue palabra

el territorio se vistió de fiesta.

Mansilla kommentiert:

[...] la poesía se representa a sí misma como un lenguaje precario y siempre amenazado por el silencio, la ausencia, la desaparición. Y, dadas estas condiciones, la poesía no puede sino verse obligada a reafirmarse constantemente, proclamando y celebrando el poder funda-

${ }^{217}$ Zum Thema der metapoetischen Dichtung in Chile und ihrem politischen Anspruch vgl. Karl 1996. 
cional de la palabra porque se trata de un poder puesto en tela de juicio. (Mansilla 1996:Kap.4)

Und er geht noch weiter, indem er die beschriebene Bedrohung der Dichtung als Zeichen für die Bedrohung der Gegenwart selbst interpretiert:

[...] la precariedad de los proferimientos poéticos — la mudez ad portas - reproduce la precariedad misma de la historia en la que los cuerpos están permanentemente amenazados por la desaparición. [...] La poesía, entonces, se vuelve escritura poderosa precisamente porque se constituye como discurso alegórico de estas situaciones, de modo que el sentido de la negación, de los recortes, de las zonas obliteradas, se vuelve acto político que denuncia y atestigua una historia de inquietantes coerciones. (Mansilla 1996:Kap.4)

Die hier genannten Auslassungen, die verschwiegenen Dinge, die sozusagen Löcher in der Dichtung hinterlassen und gerade deshalb die Aufmerksamkeit der Leserin und des Lesers erregen, weil sie nicht ausgesprochen werden - obwohl doch jeder um sie weiß - werden in der chilenischen Literaturkritik das no-dicho genannt. ${ }^{218}$

Aber auch ohne ein metapoetisches Moment erkennt Mansilla in Trujillos Texten Aussagen über die Gegenwart, ohne dass direkte Anspielungen zu finden wären:

[El texto] carece por completo de referencias a la contingencia de la historia del momento; salvo por el hecho de que este testimonio íntimo cabe verlo como signo político de un discurso que se rehusa a entrar en la lógica de la „guerra interna“ de la dictadura, rescatando, en cambio, los espacios personales de la memoria no mancillada por el envilecimiento general que provocan las situaciones de dictadura y opresión extremas. (Mansilla 1996c:36)

Mansilla erkennt den Text als Reaktion auf die repressive Politik und gleichzeitig als Ausdruck der psychischen Last, die auf den Menschen liegt. Er merkt zwar an, dass Trujillo keinerlei direkte Anspielungen auf die Geschichte, bzw. die Gegenwart verwende, sieht allerdings eine umso größere Historizität in der Eigenschaft der Texte als

registro de los deseos y sueños ocurridos en la cotidianidad vivida, los que, vistos desde el presente de la escritura, exhiben su fracaso, su pura fantasmagoría, sus expectativas frustradas que han dado paso a la caída „en el vacío del silencio“. (Mansilla 1996c:36f.)

Er versteht das Aussparen von Gegenwart in den Texten Trujillos als dessen einzige Möglichkeit, die Gegenwart zu ertragen und interpretiert so das nicht Gesagte als innigsten Ausdruck für eine Wirklichkeit, die man gerne verdrängen möchte: ,sólo el sueño, el deseo de otra historia y el jugar a vivirla, hacen posible soportar el insoportable e inevitable peso de una historia no deseada.“ (Mansilla 1996c:37) Dabei vergleicht Mansilla die Bilder, die in

218 Ausführlich äußert sich hierzu Raúl Zurita in Literatura, Lenguaje y Sociedad 1973-1983. Im Kapitel II, „La aparición de lo ,no dicho“ “, beschreibt Zurita, wie Zensur und Repression dazu führen, dass in der Literatur viele Dinge - wenn überhaupt - nur noch sehr indirekt ausgesprochen werden: ,apelando a la vía de la negación, de la afirmación parcial o de la simple omisión“. (Zurita 1988:23) 
den Texten heraufbeschworen werden, mit Jugenderinnerungen des Autors, in die er sich gewissermaßen vor der Gegenwart flüchtet:

El paisaje evocado aparece como un sitio aún incontaminado por el efecto destructivo de una historia que pisoteó las expectativas de futuro de la infancia y primera juventud; espacio que, por lo mismo, nutre con su naturaleza la fantasía que hará más soportable y vivible el exilio interior del sujeto de su historia y de su lenguaje deseados. (Mansilla 1996c:39)

Der Rückzug in Vergangenheit und Träume wird zum Ausdruck für die unzureichende Realität. Umgekehrt beschreibt Mansilla die Gegenwart des Dichters als „un ámbito de existencia radicalmente precario, que delata fracturas, derrotas, incumplimientos de expectativas otrora anunciadas (o prometidas) con entusiasmo“. Vergangenheit und Gegenwart würden auf diese Weise untrennbar. Die Gegenwart sei die Summe der gescheiterten Träume der Vergangenheit, und die Vergangenheit die kindliche Unschuld, die von einer anderen Zukunft träume. (Mansilla 1996c:39)

Diese spezielle Form der Historisierung der Literatur erklärt Mansilla als bruchstückhafte Repräsentation einer Krisenzeit, die sich vollständig auf die binäre Opposition von früher und heute stützt. Durch die angenommene kausale Verknüpfung, die eine schicksalhafte Verkettung von Versagen in der Vergangenheit und Leiden in der Gegenwart impliziert, kommt eine moralische Komponente hinzu:

Trujillo „explica“ la caída por la pérdida de la fe en los mensajes ancestrales del universo y de la capacidad para descifrar a tiempo y adecuadamente los ominosos signos de la catástrofe. (Mansilla 1996c:41)

In dieser Vorstellung von Weissagungen, die nur beizeiten hätten richtig gedeutet werden müssen, klingt eine mythische Dimension an. ${ }^{219}$ Diese sieht Mansilla fortgesetzt in dem Bild der Vergangenheit, das Trujillo als Gegenbild zur Gegenwart skizziert:

[...] da paso a una representación compleja (y contradictoria) del presente, porque dicho pasado perdido no fue necesariamente una materialidad histórica efectivamente acontecida (dimensión mítica de la memoria), o bien porque se trata de algo que efectivamente aconteció pero de una manera distinta a los hechos registrados y/o registrables por la prensa, las crónicas o el discurso histórico convencional (dimensión histórica de la memoria). (Mansilla 1996c:43)

Trujillos Texte spiegeln Mansilla zufolge „un vivir que se sitúa en los espacios íntimos de la memoria y/o de la percepción de las cosas“ (Mansilla 1996c:44), also eine sehr individuelle und persönliche Geschichte. Aber Mansilla beharrt gleichzeitig auf einer politischen Dimension. Er nennt die Geschichte, die er in Trujillos Texten vorfindet, ein „cuadro poético testimonial““. Schon der Begriff von Testimonio-Dichtung besitzt eine eindeutig politische Komponente (vgl. Kapitel 3.3, S41f. und Kapitel 4.5, S85), aber Mansilla macht noch 
deutlicher, worauf er hinaus will. In der Dichtung manifestiert sich seiner Meinung nach „lo ,otro“ del gran relato de la política dictatorial del estado [sic]“ (Mansilla 1996c:44), die Gegendarstellung zur offiziellen Geschichte. Das zeigt sich am deutlichsten in der bereits erwähnten Opposition zwischen einem hoffnungsvollen, aber verlorenen Gestern und einem schmerzlichen Heute: „La tarea de la poesía será, entonces, reconstituir en el discurso ese estado originario anudando los vestigios de un tiempo perdido“. (Mansilla 1996:Kap.3), die die Klage über eine defizitäre Gegenwart beinhaltet: „La memoria poética del origen funciona, en consecuencia, como estrategia para atestiguar y recomponer un presente aquejado de graves carencias.“ (Mansilla 1996c:43)

Zusammenfassend findet Mansilla eine Reihe Geschichte konstituierender sowie Geschichte problematisierender Funktionen in der Dichtung Trujillos. Auf den ersten Blick erschafft Trujillo eine Welt, von der Geschichte und Politik ausgeschlossen bleiben; in der nur das Individuelle seinen Platz hat, der Alltag des Einzelnen, das Menschliche und die Dichtung selbst. Das entspricht sicherlich der Sehnsucht nach einer anderen Realität ${ }^{220}$, zugleich zieht das bewusste Ausblenden des Offensichtlichen und Allgegenwärtigen, nämlich der politischen Situation, Fragen nach eben jenem Nicht-Gesagten nach sich und rückt es so in den Mittelpunkt, ohne dass man es direkt nachweisen könnte. Des Weiteren verklärt Trujillo mit seinen Texten ganz bewusst die Vergangenheit als verlorenes Paradies, um einerseits den Kontrast zur Gegenwart umso deutlicher zu machen und andererseits die Frage nach möglichen Fehlern, nach Schuld oder Verantwortung in der Vergangenheit aufzuwerfen. Der letzte Aspekt weist gleichzeitig in die Zukunft, denn auf diese Weise versucht Trujillo, nicht nur zu erklären, was geschehen ist, sondern auch daraus zu lernen oder zu lehren.

Trujillos Gedichte bilden einen Gegentext zur offiziellen Geschichtsschreibung - ebensosehr mit der ,Geschichte der kleinen Leute, wie die Alltagsszenen sie darstellen, wie auch mit der verborgenen Anklage, die sich im Schweigen und Auslassen verbirgt - und offenbart. Schließlich stellt Mansilla die Frage, inwieweit die Dichtung, die in Frage stellt, demaskiert, im Schweigen anklagt und im Aussprechen verschweigt, in der Lage sein kann, eine neue Geschichte aufzubauen. Er sieht zwar die Schwierigkeiten, kommt aber zu folgendem Ergebnis und hoffnungsvollem Ausblick:

${ }^{219}$ Ich erinnere an die Prophezeihungen bei Muñoz, die ebenfalls der bedrückenden Gegenwart gegenübergestellt werden (Kapitel 5.5, S110f.).

${ }^{220}$ Das Kapitel seiner Dissertation, in dem sich Mansilla mit Trujillos Texten befasst, hat er Carlos Trujillo: La vida es sueño de otra historia genannt. Ein Aufsatz Carlos Trujillo: El sueño de otra historia erschien kurze Zeit später. (Mansilla 1996c) 
[...] podríamos decir que sí es posible construir una nueva historia reconociendo el „engaño“ y la „máscara“, si los leemos como expresión de una nueva concepción de la temporalidad: la historia, cuyas bases se están construyendo ahora, no podrá hacerse sino con la conciencia de que no hay fundamentos inamovibles de alcances globales, que la simulación se ha vuelto estrategia para bosquejar „el nuevo calendario“ de los días, que la presencia se constituye por su ausencia y viceversa. (Mansilla 1996c:53)

Damit spricht er der Dichtung große kreative Kraft zu und endet seinen Abschnitt über Trujillo zwar sicher nicht mit einem Happy End, aber gewissermaßen mit der Zuversicht in die Zukunft.

\subsection{Visionäre der Gegenwart}

Den Dichterinnen und Dichtern in Südchile wird manchmal vorgeworfen, dass sie sich immer nur in ihren eigenen Zirkeln bewegen. So sind die Urheber von Kritiken, Rezensionen oder Klappentexten meist selbst wieder südchilenische Dichterinnen oder Dichter, und die Kritiker und Literaturwissenschaftler, stehen den talleres selbst nahe, in denen die Dichtung entsteht, mit der sie sich beschäftigen. Ich denke, die Kritik sollte sich nicht gegen die südchilenischen Dichter und Kritiker richten, sondern vielmehr gegen andere, die es versäumen, sich mit diesen lyrischen Texten zu befassen.

Anhand der Textbeispiele von Trujillo und Mansilla wird deutlich, dass die beiden Dichter sowohl in ihrer Dichtung als auch in kritischen Arbeiten über die Dichtung anderer immer wieder versuchen, ihre eigene Gegenwart zu verstehen und zu bewältigen, das Unsagbare in Form der Lyrik sagbar zu machen. ${ }^{221}$

Mansilla und Trujillo thematisieren Geschichte, ohne Geschichten zu erzählen. Im Gegensatz zu allen bisher untersuchten Texten finden sich hier keine epischen Elemente; die einzelnen Texte sind zwar formal, nicht jedoch inhaltlich zu einem Zyklus, also zu einer in sich geschlossenen Struktur verbunden. Vielleicht ist die Geschichte, die thematisiert wird noch zu nah, zu unmittelbar, um erzählt zu werden. Denn es handelt sich ausschließlich um die Gegenwart der Diktaturerfahrung im weitesten Sinne.

Eine Besonderheit der Texte Mansillas besteht darin, dass sie die Gegenwart nicht nur betrachten, sondern dabei in die Zukunft blicken, dass sie thematisieren, wie die Menschen mit den Zuständen umgehen und fragen, wie es weitergeht. Gerade durch den Aspekt der

221 Mansilla und Trujillo kennen sich persönlich, sie kennen die Lebensumstände und den Werdegang des andern. Das ermöglicht ihnen, auch Verborgenes zu erkennen, Dinge, die vielleicht dem anderen gar nicht bewusst waren. Das birgt andererseits die Gefahr, Vorstellungen, Ängste, und Absichten in den Text des anderen hineinzuprojizieren, die entweder gar nicht existieren oder aber vielmehr in der eigenen Dichtung zu suchen wären. 
Konsequenzen und eventueller Handlungsmöglichkeiten erlangen die Texte eine politische Dimension, die über die der anderen - meist ausschließlich anklagenden Texte hinausgeht.

Bei Trujillo fällt der Kontrast zwischen scheinbarer Zeitlosigkeit der Texte und ihrem Verhaftetsein in der Gegenwart, wie Mansilla sie herausarbeitet, auf. Daher ist es aufschlussreich, die Gedichte im Zusammenhang mit Mansillas Interpretationen zu betrachten. Mansilla entwirft in seiner Dissertation ein stark reflektiertes, aber auch sehr konstruiertes Geschichtsbild. Er beschreibt das in der von ihm untersuchten Dichtung vorherrschende Weltbild als eine schematische Einteilung in pasado und presente. Indem er die Starre dieses Weltbildes an den untersuchten Gedichten aufzeigt, setzt er sich immer auch mit der eigenen Dichtung und der eigenen Geschichte auseinander. Die starke Betonung der Polarität von Vergangenheit und Gegenwart deutet letztlich darauf hin, dass er selbst mit diesem Bruch leben und ringen muss. Die Beschäftigung mit fremder Dichtung wird nach dem eigenen Schreiben zu einem weiteren Versuch, den Riss durch die Geschichte zu bewältigen. Und der Riss, der die Vergangenheit von der Gegenwart trennt, der die Geschichte und das Leben der Menschen durchtrennt, ist der 11. September 1973. 


\section{SChlussbetrachtung}

... escribiremos nuestra historia en las pequeñas hojas donde caben los poemas nada más poemas y canciones...

Mario Contreras Vega

Im Verlauf der Arbeit ist deutlich geworden, dass es für den konkreten Fall der Geschichtsdarstellung in südchilenischer Lyrik bereits verschiedene Untersuchungen chilenischer Herkunft gibt, die eine ähnliche Fragestellung haben und die mir sehr hilfreich waren. Insbesondere finden sich in den Dissertationen von Trujillo und Mansilla zu einzelnen Autoren entsprechende Überlegungen. Weiterhin sind das umfangreiche Nachwort Escritura, historia identidad: Poesía actual del sur de Chile der Anthologie von Galindo/Miralles und die Artikel Descubrimientos y conquistas de intertexto en la poesía chilena actual und Modernos cronistas de Indias von Soledad Bianchi zu nennen. Zu einzelnen Dichtern liegen ebenfalls Untersuchungen vor, die die Behandlung von Geschichte betrachten (insbesondere von Mansilla und Carrasco). Eine derart umfangreiche Analyse von Texten verschiedener Autoren zum Thema der Geschichtsdarstellung, wie ich sie in dieser Arbeit vorgenommen habe und die erst Verallgemeinerungen ermöglichen kann, ist jedoch noch nicht geleistet worden. Außerdem ist auffällig, dass in den bisherigen wissenschaftliche Veröffentlichungen die Gegenwart der Diktatur, die in dieser Arbeit immer wieder Fluchtpunkt der Betrachtungen war, nur vorsichtig und in Andeutungen angesprochen wurde. Eine Ausnahme bilden die kritischen Texte Mansillas.

Zunächst war es notwendig, den zugrundegelegten Begriff der ,Repräsentation` zu klären. Nach einer Annäherung an den Begriff über sprachwissenschaftliche Definitionen wurde insbesondere auf die Verwendung des Terminus' in der neueren Ethnographie hingewiesen und damit auf die zentrale Rolle, die Perspektive und Perspektivierung bei der Betrachtung einer fremden Kultur, also des Anderen spielen. Schon hier wurde die Möglichkeit angesprochen, Methoden und Begrifflichkeit aus der Ethnographie auf die Historiographie zu übertragen, da die zeitliche Distanz ebenfalls kulturelle Differenz schafft.

Um einen Einblick in die Problematik der Darstellung von Geschichte zu geben, wurden anschließend ausgewählte Diskussionen der Historiographie, insbesondere des 20. Jahrhunderts skizziert. Hervorgehoben habe ich die Kontroverse um die Rolle, die die Narration in der Geschichtsschreibung spielt. In Anbetracht der Tatsache, dass es sich bei den zu 
untersuchenden Texten um Lyrik handelt, stellte sich die Frage, inwieweit möglicherweise narrative Elemente unentbehrlich sind, um geschichtliche Ereignisse wiederzugeben und wie dies in lyrischen Texten geschehen kann. Weitere zentrale Begriffe der Geschichtsdarstellung sind wiederum die Perspektive und - eng damit verbunden - die Subjektivität. Ob und inwieweit der Historiograph eine eigene, subjektive Perspektive einnehmen darf oder sogar sollte sowie die Forderung nach der Transparenz dieser Subjektivität, sind Themen einer Debatte der Historiographie, die niemals an Aktualität verloren hat.

Die Annäherung an den konkreten Gegenstand der Untersuchung erfolgte geographisch, indem zunächst Schlaglichter auf zwei prominente Beispiele für die Darstellung von Geschichte in lateinamerikanischer Lyrik geworfen wurden. Pablo Neruda hat mit seinem Geschichtsepos Canto general sicherlich die größte Vorbildfunktion für chilenische Dichterinnen und Dichter. Als Charakteristika für Nerudas Darstellung von Geschichte habe ich vier Punkte hervorgehoben: Die starke Anlehnung an koloniale Geschichtswerke, die Bedeutung des Kollektivs, das den klassischen Helden ersetzt, eine mythische Struktur, die sich manchmal der Chronologie entzieht und die starke Präsenz des Ich, also des subjektiven Erzählers. Alle vier Punkte haben sich in den zu untersuchenden Texten wiedergefunden. Besondere Beachtung hat aber die Intention Nerudas gefunden, der offiziellen Geschichte eine neue Perspektive entgegenzusetzen, die den Menschen Lateinamerikas gerecht werden sollte. Dabei verwendet er häufig einen Blickwinkel, der als visión de los vencidos bereits Tradition hat. Es ist die ,Geschichte von unten', die Geschichte derer, die übergangen werden und nicht zu Wort kommen, die counter-bistory, die geschrieben werden soll.

An der Geschichtsdichtung Ernesto Cardenals habe ich insbesondere die formale Eigenart der Collage- oder Mosaik-Dichtung hervorgehoben, die Cardenal für Lateinamerika etabliert hat. Diese Technik arbeitet mit Zitaten aus verschiedensten Texten und Textsorten: aus der Dichtung anderer, aber auch aus historischen Quellen, Gebrauchstexten, Zeitungsartikeln, Gesetzestexten, wissenschaftlichen Abhandlungen, Briefen usw. Auf diese Weise wird Authentizität geschaffen - oder suggeriert. Besonders bemerkenswert ist, dass Cardenals Geschichtsdarstellung durch die von ihm geprägte Dichtung des exteriorismo zwar fast prosaisch nüchtern wirkt, jedoch eine wirkungsmächtige Transzendenz in sich birgt, die weit über den eigenen geschichtlichen und geographischen Kontext hinausweist wie die internationale Rezeption beweist. 
In einem nächsten Schritt habe ich die politische und gesellschaftliche Situation Chiles während der Militärdiktatur seit 1973 und insbesondere die Auswirkungen auf die Literatur dargelegt. Die Repressionen und die angespannte Situation ließen erwarten, dass Menschen inmitten einer solchen Gegenwart ein spezielles Verhältnis zur Vergangenheit und zur Geschichte im Allgemeinen entwickeln würden.

Schließlich habe ich meine Arbeit mit der Stadt Concepción als nördlichstem Punkt geographisch abgesteckt. Die einzelnen Regionen wurden vorgestellt und stichwortartig geschichtlich und dichterisch charakterisiert, um zu zeigen, dass der Süden einerseits einen dichterisch produktiven und eigenständigen Teil Chiles darstellt und andererseits vielschichtig und heterogen ist.

Fünf von den sechs Textanalysekapiteln behandeln jeweils einen Textband, das sechste vergleicht kritische Texte zweier Dichter miteinander. Ich fasse die wichtigsten Ergebnisse der Analysen in Abschnitten zusammen, um sie darauf vergleichen zu können.

\section{Juan Pablo Riveros: De la tierra sin fuegos}

Bei Riveros verbindet sich das historiographische mit dem ethnographischen Interesse. Das dreibändige Werk des Ethnographen Martin Gusinde über die Feuerlandindianer ist der Hintergrund, auf dem De la tierra sin fuegos entstehen konnte. In seinen einleitenden Texten thematisiert Riveros die Perspektive des Ethnographen. Seinen Erzähler lässt er entführen, um die Unmittelbarkeit und die Authentizität eines Augenzeugenberichtes zu erwecken. Es verbinden sich die Vergangenheit (der indigenen Völker) und die Gegenwart (der Diktatur). Mit Hilfe der Juxtaposition können Parallelen zwischen beiden gezogen werden, die Strukturen erkennbar werden lassen: Es deutet sich ein Vergleich zwischen der Ausrottung der Selk'nam, der Alacalufe und der Yamana einerseits und andererseits der Gewalt der Militärdiktatur an. In den dargestellten historischen Situationen sind die Rollen von Tätern und Opfern klar verteilt. So entsteht die Vorstellung einer inhaltlichen Kontinuität der Geschichte, die zu durchbrechen der Autor auffordert.

Ereignisse der Diktatur werden lediglich sehr verborgen und zT uneindeutig thematisiert, was auf die innenpolitischen Zustände zurückzuführen ist, in denen keine offene Kritik geübt werden konnte. Diese Camouflage-Technik bietet oftmals die einzige Möglichkeit, die Zensur zu umgehen, und auf unüblichen Wegen die Zeitgeschichte betreffende Aufzeichnungen zu veröffentlichen.

Stilistisch finden sich Anklänge an Cardenal, da der Text viele Zitate verwendet und verschiedene Stimmen zu Wort kommen lässt, größtenteils mit Quellenangaben in den Anmerkungen. 


\section{Rosabetty Muñoz: Baile de señonitas}

Die Geschichte in Baile de señoritas ist eine counter-history im dreifachen Sinn: Erstens nimmt sie die Perspektive derer ein, die von den Spaniern, entdeckt ${ }^{\star}$ werden, über die also meistens aus der Sicht der Eroberer berichtet wurde. Zweitens handelt es sich um die Bevölkerung der Insel Chiloé, die kulturell und gesellschaftlich innerhalb Chiles marginalisiert wurde und wird und die bis heute in Chile oftmals als das Personal einer folkloristischen Anekdote behandelt wird. Drittens erzählt Muñoz die Ereignisse aus der Sicht der Frauen.

Ihre Darstellung lebt von der Parallelisierung der kulturellen Differenz und der sexuellen Differenz, was zT anachronistisch anmutende Aspekte offenlegt. Insgesamt lassen sich aber historische Ereignisse wie die unblutige Eroberung Chiloés oder die Angriffe von Piraten erkennen, die mehr sind als nur historischer Hintergrund.

Auch bei Muñoz finden sich Parallelen zur Gegenwart. Die Diktaturerfahrung ist hier kaum merklich, ich habe in drei Texten mögliche Anspielungen aufgezeigt. Wichtiger für Muñoz ist die Entwicklung der Insel als Touristenziel im Zuge der neoliberalistischen Politik der 80er Jahre des zwanzigsten Jahrhunderts. In den Touristen sieht sie die neuen Invasoren, die das Leben auf der Insel verändern. Muñoz will ihre Leserschaft dazu bringen, sich auf die eigenen Wurzeln, die aus der Verbindung zweier Kulturen hervorgegangen sind, zu besinnen. Gleichzeitig will sie aber auch vor dem Verlust der eigenen Identität durch die neuen Eindringlinge warnen. So trägt ihre Geschichtsdarstellung zur Rückbesinnung und Bewahrung der eigenen Identität bei.

Sprachlich ist Baile de señoritas einer der Texte, der von den untersuchten am ehesten der traditionellen Vorstellung von Lyrik entspricht. Muñoz verwendet keine Zitate und keine Prosatexte, dafür eine sehr knappe, dichte und metaphernreiche Sprache.

\section{Clemente Riedemann: Karra Maw'n}

Karra Maw'n ist die Geschichte der Stadt Valdivia und ihrer Bevölkerung. Zunächst leben die Mapuche am ,Ort des Regens', bis die Spanier eindringen und beginnen, das Paradies zu zerstören. Später siedeln sich deutsche Auswanderer im chilenischen Süden an und bringen neue ethnische Konflikte. Riedemann lässt im Text deutlich werden, dass er selbst deutscher Abstammung ist, gleichzeitig ergreift er ausdrücklich Partei für die Mapuche. Da er zwar das Verhalten der Deutschen (insbesondere gegenüber den Mapuche) in Chile nicht gutheißt, aber doch seine eigene Abstammung nicht leugnet, erzählt er die Geschichte nicht nur aus einem subjektiven Blickwinkel, sondern verkörpert beide Seiten eines kulturellen Konfliktes.

Auffällig ist die Gesamtkonstruktion des Textes, die nicht zufällig der in sich geschlos- 
senen, mythischen Struktur des Gedichtes The Waste Land folgt. Das führt dazu, dass auch die dargestellte Geschichte sich dieser Struktur unterwerfen muss, und schicksalhaft und unausweichlich wird. Verstärkt wird dieser Eindruck durch die ständige Präsenz der bösen Macht der Mapuche-Gottheit Wekufe. Er ist für alles Übel verantwortlich, nimmt die Gestalt der spanischen Eroberer an und führt das Erdbeben von 1960 herbei, bei dem Valdivia zu großen Teilen zerstört wurde. Niemand kann sich seinem Wirken entziehen. Die Geschichte wird bestimmt von der naturhaften und unausweichlichen Macht des Bösen. Auch die chronikartige Zusammenstellung von Namen und Ereignissen der 50er und 60er Jahre liest sich als Aneinanderreihung von Krieg und Machtpolitik, durchsetzt von der Erwähung einiger technisch-militärischen Errungenschaften.

Die Sprache Riedemanns ist abwechslungsreich. Es finden sich Zitate, aber auch viele Stilund Tempowechsel (ein Prosatext, eine anektotenhafte Erzählung, direkte Reden, visuelle Poesie, ein Augenzeugenbericht). So subjektiv einige Abschnitte auch sind, so lässt er doch viele verschiedene Stimmen zu Wort kommen, auch darin ähnelt sein Text dem Buch Riveros'.

\section{Elicura Chihuailaf: En el país de la memoria}

Chihuailaf ist einer der bekanntesten Dichter der Mapuche, der sich eingehend mit der Geschichte seines Volkes beschäftigt hat und sich dafür einsetzt, dessen Kultur, Bräuche und mündliche Geschichtserzählungen, soweit dies noch möglich ist, zu bewahren. Die Darstellungen von Geschichte, die ich aus dem Band En el país de la memoria herausgegriffen habe, sind also unbedingt als Beiträge zu einer visión de los vencidos zu verstehen. Wie es schon bei allen bisher besprochenen Texten in unterschiedlichem Maß der Fall war, verbindet auch Chihuailaf die Vergangenheit mit der Gegenwart der Diktatur, jedoch ist hier die Diktatur nicht der Höhepunkt der Gewalt und des Schreckens, sondern nur ein weiteres Kapitel in der leidvollen Geschichte der Mapuche. Es ist eine andere Geschichte, die erzählt wird, wenn sie auch in einer ähnlichen Weise erzählt wird. Erklärtes Ziel Chihuailafs ist es, die Identität der Mapuche zu stärken, also dieselbe Absicht, die Neruda mit seinem Canto general für ganz Lateinamerika oder Rosabetty Muñoz mit Baile de señoritas für Chiloé verfolgt. Genau wie Muñoz erkennt auch Chihuailaf an, dass die Mapuche hinter einen bestimmten Punkt nicht mehr zurück können; dass ein nicht geringes Maß an Akkulturation bereits unwiderruflich stattgefunden hat. Daher akzeptiert er die schriftliche Fixierung von Geschichte nicht nur, sondern sieht sie als eine Chance, durch die Schriftlichkeit vielleicht auch Teile der mündlichen Geschichtsüberlieferung zu bewahren. 


\section{Tomás Hamis: Cipango}

Der Text von Harris ist zunächst eine freie Interpretation von Colóns Diario de a bordo, das teilweise wörtlich zugrundeliegt, zT noch schemenhaft zu erkennen ist, manchmal aber auch völlig überlagert wird von dem anderen Szenario, der Straße Orompello in Concepción. Harris nähert im Text die Vergangenheit und die Gegenwart einander an, bis sie fast nicht mehr zu unterscheiden sind. Dabei wird aber nichts des Erzählten fassbar, alles ist Täuschung - oder könnte zumindest Täuschung sein. Die Geschichte ist nicht nur den unwillkürlichen Verzerrungen durch die Zeit und das Vergessen oder durch persönliche Umstände des Betrachters ausgesetzt, sondern zusätzlich den Manipulationen durch andere, den absichtlichen Fälschungen und Inszenierungen. Ich habe gezeigt, wie Harris bestimmten Motiven auf den historischen Ebenen, aber auch in verschiedenen Kontexten und in Verbindung mit anderen Motiven unterschiedliche Bedeutungen zuweist. Im Text finden sich viele historische Motive und Elemente, insbesondere die Figur des Cristóbal Colón spielt eine wichtige Rolle. Da der Text jedoch jede Wahrnehmung, jedes Wissen und jede Erfahrung in Frage zu stellen scheint, entsteht eher eine Anti-Historie, die Negation von erzählbarer Geschichte. Ich habe eine Metapher des Textes hervorgehoben, die meiner Meinung nach diesen Skeptizismus ausdrückt, der den Text maßgeblich prägt: Wir sitzen am Boden eines Brunnens und alles, was wir sehen, sind gezeichnete Weltkarten oder Fotos, die die Welt von unterschiedlichen Seiten beleuchten.

\section{Carlos Alberto Trujillo und Sergio Mansilla}

Im letzten Kapitel der Textanalysen habe ich einen andere Methode für meine Untersuchung gewählt. Ich habe kritische Texte von zwei Dichtern untersucht, in denen jeder die Lyrik des jeweils anderen behandelt. Bei beiden war das zentrale Anliegen eine Analyse der eigenen Gegenwart. Trujillo versucht, sowohl in seiner Dichtung als auch in der Dissertation, die Geschichte als Thema nicht allzu explizit werden zu lassen. Zwar stößt er immer wieder auf Texte und Textfragmente, um deren offensichtliche Geschichtlichkeit anzuerkennen er nicht umhinkommt, doch hält er sich bei einer Analyse in unmittelbarer Nähe zu den Texten und bemüht sich um möglichst textimmanente Betrachtungen. Mansilla hingegen abstrahiert sehr stark von den Texten und theoretisiert vor politischem und psychologischem Hintergrund einzelne Wesenszüge der Dichtung Trujillos. Jedoch beschwört Mansilla innerhalb seiner literaturwissenschaftlichen Texte die Macht der Dichtung, Wirklichkeit verändern und Wirklichkeit schaffen zu können und weist ihr damit eine wichtige Funktion zu. Beide literaturwissenschaftlichen Arbeiten sind aufschlussreich und spiegeln die Lyrik und den Umgang beider Dichter nicht nur mit der Lyrik, sondern auch mit der Geschichte und mit ihrer eigenen Gegenwart. 
Wichtig war bei allen Texten die Frage nach dem Wie der Repräsentation: Teilweise wurden Methoden der Historiographie herangezogen, etwa die Verwendung dokumentierter Quellen, Zitate oder ein Stil, der an das Verfahren der Oral history erinnert sowie Elemente aus der Mikro- oder der Alltagsgeschichte. Ein anderes wichtiges Merkmal der Repräsentation ist die narrative Darstellung. Bei Riveros, Muñoz und Riedemann sind jeweils ein oder mehrere personale Erzähler auszumachen, aus deren Perspektive wir die Geschehnisse erleben, bei Riedemann sogar ein klar autobiographisch motivierter Erzähler. Chihuailaf verwendet einen Erzähler mit auktorialen Zügen, der - wie es auch in einigen Texten von Riedemann geschieht - von außen auf das Geschehen blickt. Bei Mansilla und Trujillo ist am ehesten das traditionelle lyrische Ich vorhanden, das kleine Szenen und Gedanken aus einer Innensicht beschreibt. Bei beiden sind die wenigsten Elemente von erzählender epischer Dichtung auszumachen. Cipango von Harris ist in dieser Hinsicht der am schwierigsten zugängliche Text. Auch wenn manchmal eine Perspektive eingenommen wird (meist die von Colón), mag man sich mit keinem der personalen Erzähler wirklich identifizieren, zumal etwa Colón an anderer Stelle wieder als dritte Person Singular auftritt. Andererseits scheint es aber auch keine auktoriale Außensicht zu geben, nur viele, betont subjektive ,points of view'.222

Ein anderes wichtiges Merkmal, das wiederum bis auf die Texte von Trujillo und Mansilla alle untersuchten Titel aufweisen, ist die Anordnung der einzelnen Gedichte zu einem in sich geschlossenen Zyklus, der sowohl formal als auch inhaltlich als Einheit strukturiert ist. Alle drei Merkmale, die narrativen Elemente, die Stimme eines Erzählers sowie die zyklische Form der Texte erinnern an die Gattung des epischen Gedichtes. Riveros nennt seinen Text selbst in einem Interview einen ,canto épico‘.

In Kapitel 2 wurde bereits die Frage gestellt, wie sich in der Lyrik die narrativen Elemente und die perspektivische Darstellung verwirklichen lassen könnten, die für die Geschichtsschreibung wichtig sind. Die meisten der hier untersuchten Texte wählen eine lockere Verbindung der Lyrik mit dem epischen Gedicht. Während sich die Sprache zwischen Lyrik und lyrischer Prosa bewegt, ist die Form bei Harris, Riveros, und Riedemann mehr, bei Chihuailaf, Muñoz, Mansilla und Trujillo weniger deutlich der Epik angenähert.

Eine andere eingangs gestellte Frage betraf die Intention, mit der die Dichter und die Dichterin Geschichte thematisieren. Für alle Texte konnte festgestellt werden, dass ihnen 
das Bedürfnis oder die Notwendigkeit zugrunde liegt, der offiziellen Geschichtsschreibung etwas entgegenzusetzen. Eine visión de los vencidos oder auch counter-history steckt in allen vorgestellten Texten. In manchen sehr deutlich, zB wenn Muñoz aus der Position der doppelten Differenz (culture und gender) die Geschichte neu erzählt; oder wenn Riveros für diejenigen spricht, die selbst nicht mehr in der Lage sind, ihre Geschichte zu erzählen.

Eng mit der counter-bistory verbunden, aber doch etwas anders ausgerichtet ist die identitätskonstituierende Funktion der Geschichtsdarstellung. Im Falle von Muñoz ist es die Identität des bedrohten Lebensraums und der Kultur von Chiloé, die bewahrt werden soll. Im Text von Chihuailaf steht die Identität der Mapuche im Mittelpunkt. Bei Riedemann ist in langen Passagen seine individuelle Identität mit ihren verschiedenen Wurzeln der Drehund Angelpunkt.

Woher rührt nun die auffällige Verbindung von Lyrik und Geschichte, bzw. was spricht dafür, Geschichte gerade mit Hilfe von Lyrik zu vermitteln? Wenn wir davon ausgehen, dass in Anbetracht der alles bestimmenden innenpolitischen Situation Geschichte nicht erzählt werden konnte, ohne sich dabei auf die eigene Gegenwart zu beziehen, ist der Hinweis auf die Zensur bereits eine Antwort. Ein Geschichtsbuch ist von vornherein politisch verdächtig, während Lyrik zunächst eher als unpolitisch gilt. Ein weiterer Vorteil der Lyrik ist die Möglichkeit, durch Metaphern, Vergleiche, Chiffren und ähnliche Stilmittel die eigentliche Botschaft zu verstecken. Erst durch genaues Lesen und Interpretieren des Textes erschließt sich der eigentliche Inhalt, und die Autorin oder der Autor kann letztlich nicht auf die verfängliche Bedeutung festgelegt werden. Außerdem sind Gedichte kurz und können leicht und schnell weitergegeben, verbreitet und versteckt werden, was von großem Nutzen ist zu Zeiten der clandestinidad.

Schließlich ist zu bedenken, dass, wer eine counter-history schreiben will, sich vielleicht auch formal von der traditionellen Art der Geschichtsschreibung abheben möchte.

Im synthetisierenden Blick auf die Ergebnisse möchte ich abschließend einige Verallgemeinerungen versuchen. Das wichtigste Strukturprinzip der untersuchten Texte ist die Unterscheidbarkeit von zwei Ebenen. An keiner Stelle ist ausschließlich von der Vergangenheit die Rede, immer verweist die Darstellung von historischen Ereignissen mehr oder weniger deutlich auf die Gegenwart. Riveros, Riedemann, Chihuailaf und Harris stellen die Ebenen der Geschichte und der Gegenwart in ihren Texten explizit dar, Muñoz und Trujillo arbeiten unterschwelliger mit den verschiedenen Zeiten. Bei Mansilla finden sich die beiden 
Ebenen hauptsächlich in seinen literaturwissenschaftlichen Überlegungen, gewissermaßen über den Umweg einer Beschäftigung mit anderen Texten.

Alle untersuchten Texte verwenden Strategien, um die Zensur zu umgehen. In vielen Fällen ist das die vordergründige Darstellung von Vergangenem, die letztlich als Tarnung für Kritik an der Gegenwart fungiert (besonders deutlich bei Riveros und Riedemann). In den Gedichten von Muñoz, Chihuailaf und zT Trujillo und Mansilla erschwert die kunstvoll-lyrische Sprache, bei Harris der idiosynkratische Gebrauch von Chiffren einen Zugang zum Gedicht, die Texte werden uneindeutig und auslegungsbedürftig.

Durchgängig wird Dichtung zur Äußerung tiefer Unsicherheit darüber, was Geschichte ist. Schreibend wird man sich der Unmöglichkeit bewusst, die eigenen (Diktatur-)Erfahrungen in einen geschichtlichen Kontext einzubetten, es kommt zu einem Auseinanderfallen von persönlich Erlebtem und offiziellen Verlautbarungen. Schließlich scheint das Vermögen, zwischen Realität und Fiktion zu unterscheiden, getrübt. Besonders auffällig ist das bei Harris (Wahrnehmung und Täuschung) und Riedemann (Historia vs. historia), aber auch die Wirklichkeit der Señoritas bei Muñoz oder des gefangenen Ich der Feuerlandindianer bei Riveros wird zumindest als nahe der Schwelle zur Unwirklichkeit beschrieben. Hier zeigt sich eine Problematik, die der der geschichtstheoretischen Überlegungen aus Kapitel 2 ähnelt. In den Gedichten kommen verschiedene Stimmen zu Wort, werden verschiedene Perspektiven eingenommen, weil eine objektive Darstellung als so wenig erreichbar wie erstrebenswert angesehen wird (Contreras Vega, Riveros, Riedemann, Harris). Dabei besteht jedoch die Gefahr, das Gefühl für die Wirklichkeit zu verlieren, wie der Taucher bei Riveros Gefahr läuft, mit dem Schlauch die Verbindung zu seinem Lebensraum und zu der ihm lebensnotwendigen Luft zu verlieren. Je nachdem, wie das lyrische Ich, der Erzähler, mit der Situation der fragwürdigen Realität umgeht, ergibt sich ein anderes Geschichtsbild. Besonders bei Riveros und Chihuailaf überwiegt der Eindruck eines Ich, das ein Ziel verfolgt und von der Erreichbarkeit dieses Zieles und somit der Möglichkeit, die Geschichte zu gestalten, überzeugt ist. (Im ersten Fall wird Gedächtnis-Arbeit geleistet, ein Volk soll vor dem Vergessen gerettet werden, im zweiten stehen Erneuerung und Rückbesinnung eines Volkes im Mittelpunkt.) Bei allen anderen Autoren überwiegt ein Geschichts-Fatalismus. Muñoz' Chiloé dreht sich hilflos im Strudel der Geschichte, Riedemann stellt die Geschichte als unausweichliche Naturgewalten dar (Pflanzenwuchs und Erdbeben), bei Harris liefert sich das Ich den Versuchungen und Schrecken ohne Gegenwehr aus. Trujillo und Mansilla sind der eigenen Vergangenheit verhaftet, die noch nicht aufgehört hat, die Gegenwart zu vergiften, wenn auch zumindest Mansilla eine Chance in den gestaltenden Kräften sieht, die er der Sprache zugesteht. 
Alle untersuchten Texte sind entweder Ausdruck des Glaubens an die Gestaltbarkeit von Geschichte, also an die Möglichkeit der eigenen Einflussnahme oder aber Audruck von Geschichtsfatalismus und Schicksalsergebenheit. Die Autoren wollen die erlebte Geschichte, nicht nur als erzählte Geschichten dokumentieren und festhalten, sondern in den größeren Kontext eines allgemeinen Geschichtsverlaufs einbetten. Zum einen versuchen sie auf diese Weise, die Sinnzusammenhänge zu verstehen und zu verarbeiten. Zum anderen konstruieren sie genau diese Zusammenhänge erst durch ihre Texte

Dafür bietet die Lyrik durch Stilmittel, Textstruktur und Tonfall nicht nur die sprachlichen Mittel, sondern sie hilft gleichzeitig durch ihre äußere Form, in der konkreten politischgesellschaftlichen Situation einer Zensur zu entgehen. 


\section{LITERATURVERZEICH NIS}

\section{Primärtexte:}

ARENAS, Reinaldo. 1997. El mundo alucinante. Una novela de aventuras. Barcelona: Tusquets Editores.

CARDEnAL, Ernesto. 1980. El estrecho dudoso. Madrid: Visor.

CArPentier, Alejo. 1983. Obras completas de Alejo Carpentier. 7 Bde. Bd. 4. Mexiko: Siglo veintiuno.

Cervantes, Miguel de. 1992. Don Quijote de la Mancha I. Madrid: Cátedra.

Chinuailaf, Elicura. 1988. En el país de la memoria. Quechurewe-Temuco [ohne Verlagsangabe].

Colón, Cristóbal. 1982. Textos y documentos completos. Madrid: Alianza Editorial.

Contreras Vega, Mario. 1984. Palabras para los días venideros. Ancud: Ediciones del Archipiélago. 1993. La gallina ciega y otros poemas. Valdivia: El Kultrún.

Eliot, T. S. 1998. The W aste Land and Other Poems. New York: Penguin Books.

ERCILLA, Alonso de. 1979. La Araucana. Madrid: Editorial Castalia.

EsPaÑA, Aristóteles. [ohne Jahr, ca. 1987]. Dawson. Santiago: Bruguera.

GALEANO, Eduardo. ${ }^{171989}$ [11982]. Memoria del fuego. 3 Bde. Bd. 1: Los nacimientos. Madrid: Siglo XXI Editores.

HARris, Tomás. 1996. Cipango. Santiago: Fondo de Cultura Económica.

Lessing, Gotthold Ephraim Lessing. 1997. Werke und Briefe. 12 Bde. Bd. 4: Werke 17581759. Frankfurt: Deutscher Klassiker Verlag.

LiENLAF, Leonel. ${ }^{2} 1990$ [11989]. Se ha despertado el ave de mi corazón. Santiago: Editorial Universitaria.

Manns, Patricio. 1985. Actas del alto Bio-Bio. Santiago: Ediciones Michay.

Mansilla, Sergio. 1986. Noche de agua. Santiago: Ediciones Rumbos.

-----. 1991. El soly los acorralados danzantes. Valdivia: Paginadura.

MuÑOZ, Rosabetty. 1994. Baile de Señoritas. Valdivia: El Kultrún. 1986. En lugar de morir. Santiago: Editorial Cambio.

NerudA, Pablo. ${ }^{2} 1975$ [11974]. Poesía. 2 Bde. Bd. 1. Barcelona: Editorial Noguer.

Riedemann, Clemente. 1984. Karra Mawn. Valdivia: Editorial Alborada.

Riedemann, Clemente. 1995. Karra Mawn y Otros Poemas. Valdivia: El Kultrún.

Riveros, Juan Pablo. 1986. De la tierra sin fuegos. Concepción: Ediciones de Maitén.

RoJAS, Gonzalo. ${ }^{2} 1993$ [11964]. Contra la muerte. Santiago: Editorial Universitaria.

SAHAgúN, Bernardino de. 1981. Historia general de las cosas de Nueva España. Mexiko: Editorial Porrúa.

SCHOPF, Federico. 1985. Escenas de peep-show. Santiago: Ediciones Manieristas.

SERrano, Bruno. 1978. El antiguo ha sucumbido. [Ohne Ortsangabe]. Ediciones Quilla de Navío.

TORRES, Nelson. 1993. De Indias. Santiago: San Cristóbal. 1986. Los que no vemos debajo del agua. Santiago: Cambio.

VegA, Garcilaso de la. 1964. Obras Completas. Madrid: Editorial Castalia. 


\section{Sekundärliteratur:}

Aldunate Del Solar, Carlos. 1986. Cultura mapuche. Santiago: Museo Chileno de Arte Precolombino.

Alonso, María Nieves et al. 1989. „La diáspora“. In: Las plumas del colibrí. Quince años de poesía en Concepción (1973-1988). Estudio y antología. Santiago: IMPRODE/CESOC, $9-52$.

Alonso, Gabriel. 1988. „De la tierra sin fuegos, poemas de Juan Pablo Riveros“. In: La Tribuna, 4. August 1988, 12.

ANCÁn JarA, José. 1992. „Los ríos que caen de la luna. Acerca de la poesía de Elicura Chihuailaf". In: Nütram 33, 3-7.

Araya G., Juan Gabriel. 1987. „Escritos de la Patagonia“. In: La Discusión, Chillán vom 5. März 1987, 2.

Assmann, Jan. 1992. Das kulturelle Gedächtnis. Schrift, Erinnerung und politische Identität in frühen Hochkulturen. München: Beck.

BarrazA, Eduardo. 1991. „Clemente Riedemann y Carlos Trujillo: Premios Pablo Neruda para la poesía de la Décima Región“. In: Alpha 7, 9-15.

BARThOld, Bonnie J. 1981. Black Time. Fiction of Africa, the Caribbean, and the United States. Yale: University Press.

BARTSCH, Hans-Werner et al. (Hgg.). 1974. Chile. Ein Schwaræbuch. Köln: Pahl-Rugenstein.

BAssler, Moritz (Hg.). 1995. New Historicism. Literaturgeschichte als Poetik der Kultur. Frankfurt/Main: Fischer.

BAUER, Ralph. 1998. „Imperial History, Captivity, and Creole Identity in Francisco Núñez de Pineda y Bascuñan's Cautiverio feliz". In: Colonial Latin American Review 1, Bd. 7, $59-82$.

BengoA, José. 1991 [11985]. Historia del pueblo Mapuche. Siglo XIX y XX. Santiago: Ediciones Sur.

Berg, Eberhard; Martin Fuchs. ${ }^{2} 1995$ [11993]. Kultur, soziale Praxis, Text: die Krise der ethnographischen Repräsentation. Frankfurt/Main: Suhrkamp.

BERG, Walter Bruno. 1995. Lateinamerika. Literatur - Gechicbte - Kultur. Eine Einfübrung. Darmstadt: Wissenschaftliche Buchgesellschaft.

BergentHAL, Kathrin; Annette Karl. 2000. Intertextualidad nacional e internacional en la lírica chilena entre 1960 y 1990. [Unveröffentlicht.]

BIALE, David. 1999. „Counter-History and Jewish Polemics Against Christianity“. In: Jewish Social Studies 6.1, 130-145. Zitiert nach

< http://www.press.jhu.edu/journals/jewish social studies/v006/6.1biale02.html> (03.12.00).

BiAnCHI, Soledad. 1990a. Poesía chilena. (Miradas. Enfoques. Apuntes). Santiago: Ediciones Documentas/CESOC.

-1990b. „Una suma necesaria. Literatura chilena y cambio: 1973-1990“. In: Revista Chilena de Literatura 36, 49-62.

-1990c. „Modernos cronistas de Indias“. In: La Época, 21. Oktober 1990. Beilage Literatura y Libros 132, 1-2.

-1992. „Descubrimientos y conquistas como intertexto en la poesía chilena actual“. In: Cartas de Don Pedro de Valdivia que tratan del descubrimiento y conquista de la Nueva Extramadura. Barcelona: Lumen, 278-291.

BitTERLI, Urs. ${ }^{4} 1992$ [11991]. Die Entdeckung Amerikas. Von Kolumbus bis Alexander von Humboldt. München: C.H. Beck.

Borrero, José María. 1957. La patagonia trágica. Buenos Aires: Editorial Americana.

BRIESEMEISTER, Dietrich. 1989. „Geschichte und Mythos in der epischen Dichtung Ernesto Cardenals“. In: Harald Wentzlaff-Eggebert (Hg.). Realität und Mythos in der lateinamerikanischen Literatur. Köln: Böhlau Verlag, 291-310.

BrockmeIER, Peter. 1990. „Literatur als erfahrene Geschichte. Überlieferung und 
Erklärung.“ In: Hartmut Eggert et al. (Hgg.). Geschichte als Literatur: Formen und Grenzen der Repräsentation von Vergangenheit. Stuttgart: Metzler, 40-55.

CAMPOS, Javier. 1995. „Tomás Harris y la cultura de la imagen (algunas reflexiones sobre poesía chilena de los 80)“. In: Revista Chilena de Literatura 46, 87-90.

CÁNOVAS, Rodrigo. 1986. Texto y censura: Libn. CENECA 77.

CARrasco MuÑoz, Hugo. 1993. „Poesía mapuche actual: De la apropiación hacia la innovación cultural“. In: Revista Chilena de Literatura 43, 75-87.

Carrasco MuÑoz, Iván. 1986. „Prólogo“. In: Sergio Mansilla Torres. Noche de agua. Santiago: Ediciones Rumbos, 8-13.

. 1989a. „Poesía chilena de la última década (1977-1987)“. In: Revista Chilena de Literatura 33, 31-46.

. 1989b. „Poesía chilena actual: No sólo poetas.“ In: Paginadura 1, 3-10.

. 1989c. „Carlos Trujillo: Poesía de la dificultad de vivir“. In: Revista Chilena de Literatura 34, 49-56.

1991a. „Los textos de doble codificación. Fundamentos para una investigación“. In: Estudios filológicos 26, 5-15.

1991b. „Textos poéticos chilenos de doble registro“. In: Revista Chilena de Literatura 37, 113-122.

. 1992. „Literatura del contacto interétnico“. In: Estudios filológicos 27, 107-112.

1993a. „Literatura etnocultural en Hispanoamérica: concepto y precursores“. In: Revista Chilena de Literatura 42, 65-72.

. 1993b. „Metalenguas de la poesía etnocultural de Chile I“. In: Estudios filológicos 28, 67-73.

. 1994a. „Metalenguas de la poesía etnocultural de Chile (autores sureños) II“. In: Estudios filológicos 29, 91-100.

1994b. „Aportes de la textualidad mapuche a la literatura“. In: Lengua y Literatura Mapuche 6, 83-90.

1995b. „Las voces étnicas en la poesía actual“. In: Revista Chilena de Literatura 47, $57-70$.

1995c. „Karra Maw'n: Las voces de la historia“. In: Estudios Filológicos 30, 145-154.

1995d. „Folklore y etnoliteratura en Chiloé“. In: Revista de Investigaciones Folklóricas 10, 65-68.

-. 1996a. „El invasor en Baile de Senoritas de Rosabetty Munoz“. In: Actas IX Congreso Internacional de Estudios Literarios. Valdivia: SOCHEL, 52-55.

. 1996b. „Tensiones entre la intra y la interculturalidad en la poesía de Elicura

Chihuailaf y Leonel Lienlaf“. In: Lengua y Literatura Mapuche 7, 27-39.

-1998a. „De la tierra sin fuegos: Voz de los que no tienen voz“. In: Revista Chilena de Literatura 52, 69-82.

-1998b. Poesía chilena en el sur: Décima Región. [Unveröffentlicht.]

Castagnino, Raúl H. 1978. „Ernesto Cardenal“. In: Wolfgang Eitel (Hg.). Lateinamerikanische Literatur der Gegenwart in Einzeldarstellungen. Stuttgart: Kröner.

Castellano-Girón, Hernán. 1994. [Ohne Titel, Rezension.] In: INTI 39, 321-323.

CASTILLO SANDOVAL, Roberto. 1996. „Remedios para el ,embrollado laberinto“ de Arauco: Barros Arana y el lugar del Cautiverio Feliz en la historiografía de Chile". In: Mapocho 39, 131-143.

CATRILEO, María. 1999. „Humboldt State University: International Studies“. $<$ http://www.humboldt.edu/ intlst/page11.html > (04.12.00).

CEA, Margarita. 1990. „Cuando la poesía es mapuche“. In: Análisis 344, 38-39.

CERDA, Patricio. 1990. „Equivalencias y Antagonismos en la Cosmovisión Mapuche y Castellana“. In: Nütram 2, 11-35.

CHÁveZ, Guillermo Raúl. 1990. „Leonel Lienlaf, poeta: Traducir el mapuche al castellano pasa a convertirse todo en poesía“. In: La ciudad, 07. Januar 1990, A10.

Chimuailaf N., Arauco. 1998. „Poesia Mapuche“. 


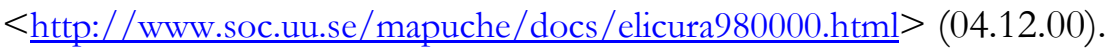

Clark, Stuart. 1999. „The Annales Historians“. In: The Annales School. Critical Assessments. Bd.1. London: Routledge.

Contreras, Marta. 1987. „Poética contemporánea“. In: El Sur, 28. Juni 1987. Beilage Arte y cultura.

COÑA, Pascual. 1973. Memorias de un cacique mapuche, Santiago: Ed. Instituto de Capacitación e Investigación en Reforma Agraria (ICIRA).

Coronel URTEChO, José. 1980 [11966]. „Carta a propósito del Estrecho Dudoso“. In: Ernesto Cardenal. El estrecho dudoso. Madrid: Visor, 1-57.

CORTínEZ, Verónica. 1991. „Crónica, épica y novela: La historia verdadera de la conquista de la Nueva España y ,El Mundo Nuevo“ de Terra Nostra“. In: Revista Chilena de Literatura 38, 59-72.

Cronos, Chillan. 1987. „De la tierra sin fuegos“. In: El Sur, 14. Mai 1987, 2.

DANTO, Arthur C.. 1980. Analytische Philosophie der Geschichte. Frankfurt/Main: Suhrkamp.

Delaborde, Jean; Helmut Loofs. 1962. Am Rande der Welt. Patagonien und Feuerland. Berlin: Safari-Verlag.

DelanOIR, Roger; Christophe d'Argent. 2000. Kolonien der Sonnengötter. Kap.1 „Vom Sauhirt zum Eroberer“. Zitiert nach

$<$ http://home.t-online.de/home/056213298-0001/pizarr 1.htm> (04.12.00).

DiAz GACITÚA, Miguel. 1993. „Cultura e identidad en la región de la Araucanía“. In: Nütram 33, 49-55.

Domínguez, Delia. 1988. „Colonización alemana: Épica y leyenda del paralelo $40^{\circ}$ Sur“. In: Boletín Académica chilena 68, 115-122.

El Degollamiento. 2000. „El degollamiento de Parada, Guerrero y Nattino“. El Siglo 993. 21. Juli 2000. <http://www.elsiglo.cl/993/12.htm> (05.12.00).

EL TERREMOTO. „El terremoto de Valdivia“ $<$ http://www.angelfire.com/nt/terremotoValdivia $>$ (03.12.00).

Elías, Eduardo F. 1991. „El estrecho dudoso: Del discurso histórico a la épica contemporánea“. In: Revista Iberoamericana 157. Sondernummer Literatura de Nicaragua. Bd. LVII, 923-931.

EnCINA, Francisco A. 1983. Historia de Chile. 20 Bde. Bd. 1. Santiago: Editorial Lord Cochrane.

Febel, Gisela; Ludwig Schrader. 1995. Canto cósmico oder Movimiento kloaka?: Wege lateinamerikanischer Gegenwartslyrik. Tübingen: Narr.

FelLmanN, Ferdinand. 1973. „Das Ende des Laplaceschen Dämons“. In: Kosellek (Hg.). Poetik und Hermeneutik: Geschichte - Ereignis und Erzäblung. München: Wilhelm Fink, 115-138.

FITZ-RoY, Robert. 1839. Narrative of the Surveying Voyages of his Majesty's ships „Adventure" and „Beagle", between the years 1826 and 1836, describing their examination of the southern shores of South America and the "Beagle" circumnavigation of the globe. Vol. II. Proceedings of the Second Expedition, 1931-1836, under the command of Captain Robert Fitz-Roy. London 1839.

FOHRMANN, Jürgen. 1993. „Die Allegorese der Wirklichkeit. Zu Hayden Whites rhetoriktheoretischem Ansatz am Beispiel der Schriften Metahistory und The Content of the Form". In: Internationales Archiv für Sozialgeschichte der deutschen Literatur. Bd. 18 (2), 161-168.

FORSTER, Edward M. 1947. Aspects of the Novel. London [ohne Verlagsangabe].

Fuentes, Jordi et al. 51978. Diccionario histórico de Chile. Santiago: Editorial del Pacífico.

Funkenstein, Amos. 1993. Perceptions of Jewish History. Berkeley [ohne Verlagsangabe].

FURET, François. 1987. „Die Methoden der Sozialwissenschaften in der Geschichtsforschung und die ,histoire totale“ “. In: Pietro Rossi (Hg.). Theorie der modernen Geschichtsschreibung. Frankfurt/Main: Suhrkamp, 147-172.

GaCiTúa GonZÁLEZ, Oscar. 1990. „Conversaciones con Clemente Riedemann“. In: El 
Diario Austrál, 25. November 1990, A 14-A 15 und 26. November 1990, A 6.

GALEANO, Eduardo. ${ }^{6} 1985$ [11971]. Las venas abiertas de América Latina. Madrid: Siglo XXI

Editores.

Galindo, Oscar; David Miralles. 1992. Poetas actuales del sur de Chile. Valdivia: Paginadura Ediciones.

GEERTZ, Clifford. 51997 [11987]. Dichte Beschreibung. Beiträge zum Verstehen kultureller Systeme. Frankfurt/Main: Suhrkamp.

GEERTZ, Clifford. 1988. Works and Lives. The Anthropologist as Author. Stanford: University Press.

GEWECKE, Frauke. 1981. „Nachwort“. In: Christoph Kolumbus. Bordbuch. Frankfurt/Main: Insel Verlag, 301-331.

GESELlSCHAFT FÜR BEDROHTE VÖLKER. 13.01.1999. „Chile: Verbrechen gegen die Menschlichkeit an Mapuche-Indianern unter Ex-Diktator Pinochet (1973-1990)“.

$<$ http://www.gfbv.de/dokus/mrmomap.htm $>$ (04.12.00).

GIL-Montero, Marta. 1990. „The Elusive Reign of Orelie-Antoine“. In: Americas Bd. 42/5. Zitiert nach <http://www.geocities.com/Athens/Crete/2954/Kap1.htm> (04.12.00).

Giordano, Jaime. 1987. Dioses, Antidioses... Ensayos críticos sobre poesía bispanoamericana. Concepción: LAR.

1994. „Tomás Harris: Macrorrelato con carrozas“. In: Revista Iberoamericana 60, 885-890.

GOBERNACIÓN PROVINCIAL DE CHILOÉ. 1997. „Plan de desarrollo de Chiloé““. $<\underline{\text { http://www.chiloeweb.com/gobernacion/plan_desarrollo/sectores_productivos.html }>}$ (28.12.00).

GÓMEZ LÓPEZ, Ricardo. 1995. „Elicura Chihuailaf: El Azul en la poesía“. In: Rayentrú 8, 25.

GONZÁlEZ CANGAS, Yanko. 1994. „Ritos de paso. Joven poesía emergente: Sur de Chile y otros horizontes. (Notas para un recuento e interpretación)“. In: Bernardo Colipán; Jorge Velásquez (Hgg.). Zonas de Emergencia. Valdivia: Paginadura, 155-183.

------. 1995. „Nuevas prácticas etnográficas: El surgimiento de la antropología poética“. In: Actas IX Congreso Internacional de Estudios Literarios. Valdivia: SOCHEL, 82-87. - 1996. „Antropología y poesía en Clemente Riedemann.“ In: Alpha 11, 63-81.

- 1999. Héroes civiles y santos laicos. Palabra y perifería: Trece entrevistas a escritores del sur de Chile. Valdivia: Barba de palo.

Greenblatt, Stephen. 1988. Marvellous Possessions. The Wonder of the New World. Oxford: University Press.

1991. Schmutzige Riten. Betrachtungen zwischen Weltbildern. Berlin: Wagenbach.

Guerrero, Pedro Pablo. 1994. „La Poesía Mapuche Hoy“. In: Mercurio, 13. März 1994. Beilage Revista de Libros 254, 1 und 3-5.

1995. „Tomás Harris: Intento buscar lo prenatural“. In: Mercurio, 22. Oktober 1995, Beilage Revista de Libros 337, 3.

1996. „Entrevista a Elicura Chihuailaf: Poeta Azul de la Tierra“. In: Mercurio, 21. September 1996. Beilage Revista de Libros, 3.

Gusinde, Martin. 1931. Die Feuerlandindianer, 3 Bde. Bd. 1: Die Selknam. Mödling bei Wien: Verlag der internationalen Zeitschrift „Anthropos“.

1974. Die Feuerlandindianer, 3 Bde. Bd. 3: Die Halakwulup. Mödling bei Wien: St. Gabriel.

(Hg.). 1966. Nordwind-Südwind. Mythen und Märchen der Feuerlandindianer. Kassel: Erich Röth-Verlag.

Hamburger, Käte. ${ }^{2} 1968$ [zweite, stark veränderte Auflage; ${ }^{1} 1957$ ]. Die Logik der Dichtung. Stuttgart: Klett.

HARTH, Dietrich. 1990. „Historik und Poetik. Plädoyer für ein gespanntes Verhältnis“. In: Hartmut Eggert et al. (Hgg.): Geschichte als Literatur: Formen und Grenzen der 
Repräsentation von Vergangenheit. Stuttgart: Metzler, 12-23.

Haumann, Heiko. 1982. Arbeiteralltag in Stadt und Land. Neue Wege der Geschichtsschreibung. Berlin: Argument-Verlag.

Hegel, G.-W.-F. 1986. Werke. 20 Bde. Bd. 12 Vorlesungen über die Philosophie der Geschichte. Frankfurt/Main: Suhrkamp.

HESS, Rainer; Gustav Siebenmann. 1989. Literaturwissenschaftliches Wörterbuch für Romanisten. Tübingen: Francke.

HumAN RightS WATCH. 1998. „Limits of tolerance: Freedom of Expression and the Public Debate in Chile“. <http://www.igc.org/hrw/reports98/chile/Chilerpt03.htm\#P539 141416> (06.12.00).

Jösch K., Melanie. 2000. „Alfredo Castro debió censurar imagen de Carlos Ibáñez“. La Tercera, 21. Mai 2000, Cultura. Zitiert nach

$<$ http://www.tercera.cl/diario/2000/05/21/t-21.56.3a.CUL.PATAS.html > (06.12.00).

KARL, Annette. 1995. Metapoetische Lyrik in Chile seit 1973. Examensarbeit. Göttingen. [Unveröffentlicht.]

KocH, Gertrud M. 1983. Zum Verbältnis von Dichtung und Geschichtsschreibung. Theorie und Analyse. Frankfurt/Main: Peter Lang.

Koelliker, Oscar. 1908. Die erste Umsegelung der Erde durch Fernando de Magallanes und Juan Sebastian del Cano, 1519-1522. München [ohne Verlagsangabe].

KoselLeK, Reinhart. 1986. „Einführung“. In: Hayden White. Auch Klio dichtet oder Die Fiktion des Faktischen: Studien zur Tropologie des historischen Diskurses. Stuttgart: Klett.

KRATOR, James. 1996. „Thomas Harris, el hijo pródigo. La Desesperanzadora Esperanza“. In: Diario del dia, 20. Februar 1996. Beilage Reseñas Culturales, 2-3.

LA FUnDACIÓN CHOLCHOL. „Los Mapuches“. < http://www.cholchol.org/mapuche-s.htm> (03.04.00).

LA TerCerA. 2000. „Terremoto de Valdivia: un día de furia“. La Tercera, 21. Mai 2000. Zitiert nach <http://www.tercera.cl/diario/2000/05/21/t 21.00.3A.REP.TERREMOTO.html> (22.12.00).

LARA, Omar. 1993. „La difícil cultura de provincia“. In: Pluma y Pincel 161, 37-38.

LARrAín, Ana María. 1995. „El que Entienda, Mariposa, que Entienda“. In: El Mercurio, 22. Oktober 1995. Beilage Revista de Libros, 2.

LIENLAF, Leonel. 1990. „Cuando la poesía es mapuche“. In: Análisis 344, 38-39.

LiEnHARD, Martin. 1990. La vozy su buella. La Habana: Casa de las Américas.

LOS INDIOS HAUSH. 1999. <http://www.multimania.com/jes/sur/elsur-haus.htm> (16.12.00).

LUIGI LeMUS, Juan de. 1985. „América, todavía mundo nuevo“. In: Atenea 451, 49-50.

LÜTZELER, Paul Michael. 1997. Klio oder Kalliope? Literatur und Geschichte: Sondierung, Analyse, Interpretation. Berlin: Erich Schmidt.

1990. „Der postmoderne Neohistorismus in den amerikanischen Humanities“. In: Hartmut Eggert et al. (Hg.). Geschichte als Literatur: Formen und Grenzen der Repräsentation von Vergangenheit. Stuttgart: Metzler, 67-76.

MAACK, Anamaría.1987. „Desde el silencio de los mares del sur. La voz de Juan Pablo Riveros en la Tierra sin Fuegos“. In: Extremos 3-4, 51-59.

-------. 1987. „Versos desde un cautiverio poético“. In: El Sur, 8. März 1987, 4-5.

Madariaga, Salvador de. 1992 [Sonderausgabe]. Kolumbus. Leben, Taten und Zeit des Mannes, der mit seiner Entdeckung die Welt veränderte. Bern, München, Wien: Scherz.

MANSILLA, Sergio. 1994. „Esa manera oblicua y dolida de ver las cosas. (Poesía en el sur de Chile: 1975-1990)“. In: Acta Literaria 19, 87-100. - 1996. Poesía del sur de Chile (1975-1995). El paraíso vedado ó el deseo de un lenguaje y una historia imposible. Dissertation. University of Washington, Dep. of Romance Languages and Literature. [Unveröffentlicht.]

. 1996a. „Poesía chilena en el sur de Chile (1975-1990). Clemente Riedemann y la textualización de la temporalidad histórica“. In: Revista Chilena de Literatura 48, 3963. 
1996b. „Clemente Riedemann: deseo de una historia y de un lenguaje vedados“. In: Estudios filológicos 31, 57-74.

. 1996c. „Carlos Trujillo: El sueño de otra historia“ In: Torres, Jorge (Hg.): Por el territorio de los límites. Aproximaciones a la poesía de Carlos Trujillo. Valdivia: Barba de Palo, 35-55.

-. 1996d. „Sur de Chile: Poesía y memoria histórica“ In: Estudios de literatura chilena e hispanoamericana contemporánea. Osorno: Editorial Universidad de los Lagos, 247-252.

-. 1997. „Neruda y nosotros adolescentes de 1973 (Poesía chilena en las provincias del sur, 1975-1997)“. In: Alpha 13, 67-89.

. 1999. El paraíso vedado. Ensayos sobre poesía chilena del contragolpe (1975-1995). [Unveröffentlicht.]

MARHIKEWUn, R. 1998. „The Mapuche Nation - History“. $<$ http://members.aol.com/mapulink3/mapulink-3e/map-his.html > (04.12.00).

MARHIKEWUN, Huichacurha. 1988. „El Reino de la Araucania y la Patagonia“. Boletin Aukiñ 13. Zitiert nach < http://members.aol.com/mapulink5/mapulink-5e/art17.html> (04.12.00).

MARILEO LefíO, Armando: „Aspectos de la cosmovisión mapuche“. In: Nütram 3, 43-47.

MARIMÁn, José A. 1994. „Transición democrática en Chile. Nuevo ciclo reivindicativo mapuche?" < http://www.soc.uu.se/mapuche/mapuint/jmar5a.htm> (04.12.00).

Martínez E., Pacían. 1981. „Una voz distinta, Juan Pablo Riveros“. In: La Prensa, 23. November 1981, 2 u. 8.

--------. 1987. „Los fuegos que se extinguieron“. In: El Sur, 22. Februar 1987, 3.

MAY, Hilda. 1991. La poesía de Gonzalo Rojas. Madrid: Ediciones Hiperión.

Meissner GreBe, Carlos. 1987. „De la tierra sin fuegos“. In: El Sur, 23. Juni 1987, 2.

MetzdorfF, N. 1995. „Thomás Harris y la Generación del Roneo“. In: La Mañana, 6. Mai $1995,6$.

MitCHeLl, W.J.T. ${ }^{2} 1995$ [11990]. „Representation“. In: F. Lentricchia; T. McLaughlin (Hgg.). Critical Terms for Literary Study. Chicago: University of Chicago Press, 11-22.

MonteCINO, Sonia. 1992. „Literatura mapuche: oralidad y escritura“. In: Simpson Siete, Bd. II., 155-166.

MontiEL, Dante. 10.10.2000. „Chiloé“. < http://chiloe.multimania.com/index.htm> (05.12.00).

Moreno, Verónica. 1993. „Elicura Chihuailaf sueña en azul“. In: El Diario Austral, 18. April 1993, D3.

Moss, William W.; Peter C. Mazikana (Hgg.). 1986. Archives, Oral History and Oral Tradition: A Ramp Study. Paris: UNESCO.

Moulian, Tomás. ${ }^{19} 1998$ [11997]. Chile actual: Anatomía de un mito. Santiago: LOMArcis.

MuÑoz, Rosabetty. 1993a. „Situación de la cultura local“. In: Pluma y Pincel 159, 47.

--------. 1993b. „A propósito de la literatura del sur y de Carlos Trujillo“. In: Pluma y Pincel $163,40$.

MuÑoz G., Luis. 1987. „De la tierra sin fuegos de Juan Pablo Riveros“. In: Acta Literaria 12, 127-129.

MuÑoz Lagos, Marino. 1987. „Nuestros pueblos aborígenes a través de un libro poético“. In: El Magellanes, 22. März 1987, 9.

Norambuena Jipoulou, Julio R. 1998. „Breve Historia de la Isla de Chiloé““. $<$ http:// www.geocities.com/inorambuena/historia.html $>$ (03.12.00).

NovoA, Marcelo: „Palabra por palabra. ¿El poeta en peligro?“. In: El Mercurio, 18. Oktober 1993, 36.

NÜNNING, Ansgar (Hg.). 1998. Metəler-Lexikon Literatur- und Kulturtheorie: Ansätze - Personen - Grundbegriffe. Stuttgart: Metzler.

OexLE, Otto Gerhard. 1992. „Sehnsucht nach Klio. Hayden Whites ,Metahistory ${ }^{\text {— }}$ - und wie man darüber hinwegkommt“. In: Rechtshistorisches Journal 11, 1-18. 
Ogden, C. K.; I. A. Richards. 81953 [11923]. The Meaning of Meaning. A Study of The Influence of Language upon Thought and of the Science of Symbolism. New York: Routledge.

O'Gorman, Edmundo. 1958. La invención de América. El universalismo de la cultura de Occidente, México: Fondo de Cultura Económica.

Olivarez, Carlos. 1993. Conversaciones con Jorge Teillier. Santiago: Editorial Los Andes.

Ostria GonZÁLEZ, Mauricio. 1992. „De la tierra sin fuegos: Los fuegos de la escritura“. In: Acta Literaria 17, 171-184. . 1996. „Tomás Harris y Juan Pablo Riveros: conjuros y revelaciones“. In: Actas IX Congreso Internacional de Estudios Literarios. Valdivia: SOCHEL, 152-157. 1995. „El fin del viaje?“. In: La Mañana, 31. Dezember 1995, 8.

Otazo Hermosilla, Jaime. 1995. „Los siete náufragos del apocalipsis“. In: El Diario Austral, 19. November 1995, A 20.

Oviedo, José Miguel. 1986. „Ernesto Cardenal oder Die Entdeckung der Neuen Welt“. In: Ernesto Cardenal. Die Farbe des Quetzal. Wuppertal: Peter Hammer, 7-16.

Oyarzún, Kemy. 1992. „Trazos de una polifonía encubierta: Del Popol Vub a Elicura Chihuailaf". In: Acta Literaria 17, 25-44.

PFLEIDERER, Elsa. 1998. „La anónima. Su pasado oculto“. In: Lote 10. Zitiert nach: $<$ http://www.revistalote.com.ar/nro010/pfleider.htm > (16.12.00).

Pincheira A., Rodrigo. 1990. „Un viaje musical convertido en libro“. In: El Sur, 9. Dezember 1990, 8.

PiNTO, Rodrigo. 1994. „Historia personal del miedo“. In: Caras 159, 126.

Preminger, Alex; T. V. F. Brogan. 1993. The new Princeton Encyclopedia of poetry and poetics. Princeton: University Press.

Pulido BIOSCA, Javier. [Ohne Jahr]. „Nuevo Ixcatlan“. $<$ http://www.bbslaguna.com.mx/Ixcatlan.htm $>$ (03.12.00).

Quilodrán, Fernando. 1993. [Ohne Titel, Rezension]. In: El Siglo, 25. Juni 1993, 17 und 10. Juli 1993, 15.

Quintana Mansilla, Bernardo. [Ohne Jahr]. Chiloé mitológico. Mitos - Pájaros agoreros Ceremonias mágicas de la provincia de Chiloé. [Ohne Ortsangabe; ohne Verlagsangabe].

RAPHAEL, Lutz. 1994. Die Erben von Bloch und Febvre. Annales-Geschichtsschreibung und nouvelle histoire in Frankreich 1945-1980. Stuttgart: Klett-Cotta.

RENNER, Rolf Günter; Engelbert Habekost. 1995. Lexikon literaturtheoretischer Werke. Stuttgart: Kröner.

Riedemann, Clemente. 1990. „La poesía como ejercicio de libertad“. In: La Época, 16. Dezember 1990. Beilage Literatura y libros, 3.

RiQuelme, Ramón. 1994. „Cipango“. In: La Discusión, 30. Januar 1994, 2.

RILKE, Reiner Maria. 1991. Briefe. 2 Bde. Bd. 2: 1919 bis 1926. Frankfurt/Main: Insel.

Rodríguez PArís, Antonieta. 1995. „Baile de Señoritas“. In: El Llanquibue, 27. Februar 1995, 34.

Rojas PIÑA, Benjamín. 1988. „De las tierras sin fuegos: Un testimonio de vida, dolor y amor“. In: El Sur, 28. Februar 1988. Beilage Arte y Cultura.

Rosales, Diego de. 1877. Historia del Reyno de Chile. Valparaíso. Zitiert nach $<$ http://www.uchile.cl/facultades/csociales/lenguajes/chonos4.htm > (27.05.01).

RÖSSNER, Michael. 1995. Lateinamerikanische Literaturgeschichte. Stuttgart: Metzler.

RossI, Pietro (Hg.). 1987. Theorie der modernen Geschichtsschreibung. Frankfurt/Main: Suhrkamp.

RÜSEN, JÖRN. 04.09.1996. „Historische Sinnbildung. Interdisziplinäre Untersuchungen zur Struktur, Logik und Funktion des Geschichtsbewußtseins im interkulturellen Vergleich“. < http://www.uni-bielefeld.de/ZIF/periplus.htm> (03.12.00).

Salvatori, Massimo L. 1987. „Die vielen Historien“. In: Pietro Rossi (Hg.). Theorie der modernen Geschichtsschreibung. Frankfurt/Main: Suhrkamp, 274-281.

SAussure, Ferdinand de. 31965 [11916]. Cours de linguistique générale. Paris [ohne Verlagsangabe]. 
SCHOPF, Federico. 1991. „Fronteras de la violencia“. In: La Época, 12. Mai 1991. Beilage Literatura y libros, 3-4.

SChulte-SASSE, J.; R. Werner. 51987 [11977]. Einführung in die Literaturwissenschaft. München: Wilhelm Fink Verlag.

SCHUlZE, Winfried. ${ }^{2} 1991$ [11987]. Einführung in die Neuere Geschichte. München: Wilhelm Fink Verlag.

SChuster, Hans. 1993. „Los Malos Pasos o el Testimonio de la Memoria Colectiva“. In: Pluma y Pincel 162, 38-39.

--------. „El sol y los acorralados danzantes o la crítica relación entre arte y vida“. In: Pluma y Pincel 163, 33.

SCHWEIKLE, Günther und Irmgard (Hgg.). ${ }^{21990 . ~ L i t e r a t u r ~ L e x i k o n . ~ S t u t t g a r t: ~ M e t z l e r . ~}$

SEGUEL VORPAHL, Ramón. 1987. „El libro De la tierra sin fuego“ [sic]. In: La Estrella de Arica, 11. September 1987, 4.

SIEGLER, Heinrich von. 1973. Archiv der Gegenwart. Bd. 43. Bonn: Verlag für Zeitarchive.

SIEWEKE, Gabriele. 1994. Der Romancier als Historiker: Untersuchungen zum Verbältnis von Literatur und Geschichte in der englischen Historiographie de 19. Jabrbunderts. Frankfurt/Main: Verlag Peter Lang.

SINGER, Christine. 1998. Zur Sonderstellung der deutschen Minderbeit in Chile. Deutsche Auswanderer zwischen Mythos und Realität. Magisterarbeit, Konstanz. Zitiert nach: $<$ http://www.uni-konstanz.de/ZE/Bib/dipl/s/singer/singer.htm $>$ (11.12.00).

SLAWNER, Karen. Interpreting Victim Testimony: Survivor Discourse and the Narration of History. $<$ http://www.yendor.com/vanished/karenhead.html $>$ (05.12.00).

Solá, María Magdalena. 1980. Poesía y política en Pablo Neruda. (Análisis del "Canto general"). Puerto Rico: Editorial Universitaria.

STANZEL, Franz K. ${ }^{4} 1989$ [11979]. Theorie des Eræählens. Göttingen: Vandenhoeck und Ruprecht.

Strepponi, Blanca. 1998. Cristóbal Colón. Diario de a bordo [Rezension]. In: El Nacional. Literaturbeilage August 1998. Zitiert nach $<$ http://www.el-nacional.com/libros/abordo.html > (20.12.00).

Suau Camus, María. 1990. „Rasgos de una sabiduría olvidada“. In: La Época, 22. April 1990: Beilage Literatura y Libros.

Swinburn, Daniel. 1989. „El Despertar de la Poesía Araucana“. In: Mercurio, 22. Oktober 1989. Beilage Revista de Libros, 1-3.

TAKeTAni, Etsuko. 1995. „The North American Review, 1815-1835: The Invention of the American Past". In: American Periodicals. Bd. 5, 111-127.

Teitelboim, Marina. 1996. „Premio Casa de las Américas. Tomas Harris, poeta de la esperanza“. In: Punto Final 363, 22.

TERREMOTOS. < http://www.angelfire.com/nt/terremotoValdivia $>$. (22.12.00).

THE MAPUCHE PEOPLE. < http://www.cholchol.org/mapuche.htm> (24.05.00)

Todorov, Tzvetan. 1982. La conquête de L'Amérique. La question de l'autre. Paris: Seuil.

TriviÑos, Gilberto. 1985. „Nuevo Mundo, Indias, América“. In: Atenea 451, 51-79.

------. 1989. „El Regreso“. In: Las plumas del colibrí. Quince años de poesía en Concepción (1973-1988). Estudio y antología. Santiago: IMPRODE/CESOC, 55-113.

Troy, Abelardo. 1987. „Tertulia Penquista“. In: La Disención, 14. Mai 1987, 2.

TrujILlo, Carlos Alberto. 1993a. „Entrevista a Clemente Riedemann“. In: El Llanquihue, 21. Februar 1993, A 18; 28. Februar 1993, A 16 und 7. März 1993, A 18.

--------. 1993b. Por la Décima Región. Poesía del sur de Chile (1973-1993). Dissertation. University of Pennsylvania. [Unveröffentlicht.]

VALDÉS, Adriana. 1992. „Un ojo falta, reflexión sobre las culturas y los quinientos años“. In: Acta Literaria 17, 45-57.

VAlente, Ignacio. 1989. „Todo un Joven Poeta Mapuche“. In: El Mercurio, 22. Oktober 1989, Beilage Revista de Libros, 1-2.

VeEser, Aram (Hg.). 1994. The New Historicism Reader. New York: Routledge. 
Vega Letelier, Carlos. 1981. „Nimia: un nombre y un libro“. In: La Prensa Austral, 25. Juni 1981, 3.

VIDAL, Virginia. 1993. „La Machi invoca la palabra“. In: Punto Final 294, 19.

VILLEGAS, Juan. 1976. Estructuras miticas y arquetipos en el CANTO GENERAL de Neruda. Barcelona: Editorial Planeta.

WALTHER, Gerrit. 1992. „Fernes Kampfgetümmel. Zur angeblichen Aktualität Hayden Whites ,Metahistory“ “. In: Rechtshistorisches Journal 11, 19-40.

WeBER, Francisco. 1998. Breves Apuntes Históricos.

$<$ http://www.geocities.com/inorambuena/historia.html > (03.12.00).

WHITE, Hayden. 1987. „Das Problem der Erzählung in der modernen Geschichtstheorie“. In: Pietro Rossi (Hg.). Theorie der modernen Geschichtsschreibung. Frankfurt/Main: Suhrkamp, 57-106.

. ${ }^{81993 ~[11973] . ~ M e t a h i s t o r y . ~ T h e ~ H i s t o r i c a l ~ I m a g i n a t i o n ~ i n ~ N i n e t e e n t h-C e n t u r y-E u r o p e . ~}$ Baltimore, London: Johns Hopkins University Press.

Williams, Tamara. 1994. „Narrative Strategies and Counter-History in El estrecho dudoso“. In: INTI 39, 47-57.

YAMAL, Ricardo. 1988. „La poesía chilena joven en el período 1961-1973“. In: Ricardo Yamal. La poesía chilena actual (1960-1984) y la crítica. Concepción: LAR 19-49.

YANCEY, Philip. 1997. Finding God in Unexpected Places. Michigan: Servant Publications.

ZAPATER., Horacio. 1997. „Huincas y mapuches (1550-1662)“. [Rezension]. In: HISTORLA

30. Zitiert nach: $<$ http://www.udec.cl/historia/rese-re7.htm $>$ (03.12.00).

ZERÁN, Faride. 1990. „Lienlaf, el extranjero“. In: La Época, 02. September 1990. Beilage Literatura y Libros, 4-5.

1993. „Riedemann y la utopía del sur“. In: La Época, 20. Juni 1993. Beilage Literatura y Libros, 4-5.

ZuRITA, Raúl. 1988. Literatura, Lenguaje y Sociedad. 1973-1983. Santiago: CENECA. 